\title{
Factors Affecting the Implementation of Policy 2450, Distance Education and the West Virginia Virtual School, as Perceived by Principals/Assistant Principals, Counselors, and Distance Learning Contacts and/or Course Facilitators
}

Keith R. Burdette

West Virginia University

Follow this and additional works at: https://researchrepository.wvu.edu/etd

\section{Recommended Citation}

Burdette, Keith R., "Factors Affecting the Implementation of Policy 2450, Distance Education and the West Virginia Virtual School, as Perceived by Principals/Assistant Principals, Counselors, and Distance Learning Contacts and/or Course Facilitators" (2013). Graduate Theses, Dissertations, and Problem Reports. 549.

https://researchrepository.wvu.edu/etd/549

This Dissertation is protected by copyright and/or related rights. It has been brought to you by the The Research Repository @ WVU with permission from the rights-holder(s). You are free to use this Dissertation in any way that is permitted by the copyright and related rights legislation that applies to your use. For other uses you must obtain permission from the rights-holder(s) directly, unless additional rights are indicated by a Creative Commons license in the record and/ or on the work itself. This Dissertation has been accepted for inclusion in WVU Graduate Theses, Dissertations, and Problem Reports collection by an authorized administrator of The Research Repository @ WVU.

For more information, please contact researchrepository@mail.wvu.edu. 
Factors Affecting the Implementation of Policy 2450, Distance Education and the West Virginia Virtual School, as Perceived by Principals/Assistant Principals, Counselors, and Distance Learning Contacts and/or Course Facilitators

\author{
Keith R. Burdette \\ Dissertation submitted to the \\ College of Education and Human Services \\ at West Virginia University \\ in partial fulfillment of the requirements for the degree of
}

Doctor of Education

in

Educational Leadership Studies

\author{
Helen M. Hazi, Ph.D., Chair \\ Harry N. Boone, Jr., Ph.D. \\ Stanley E. Hopkins, Ph.D. \\ Pamela Whitehouse, Ed.D. \\ Adriane Williams, Ph.D. \\ Department of Educational Leadership Studies
}

Morgantown, West Virginia

2013

Keywords: Policy Implementation; Virtual School; Distance Learning 


\begin{abstract}
Factors Affecting the Implementation of Policy 2450, Distance Education and the West Virginia Virtual School, as Perceived by Principals/Assistant Principals, Counselors, and Distance Learning Contacts and/or Course Facilitators
\end{abstract}

Keith R. Burdette

This study examined the factors important to the implementation of West Virginia Board of Education Policy 2450, Distance Learning and the West Virginia Virtual School. The purpose of this study was to determine the factors that facilitated and impeded implementation of the policy, as perceived by principals/assistant principals, counselors, and distance learning contacts and/or distance learning course facilitators in 110 West Virginia high schools. The 659 individuals in the target population were invited to complete an online questionnaire rating 35 survey items using a bipolar scale. There were 216 respondents for a return rate of $32.78 \%$. The three public school groups identified 22 factors predominately from four categories that facilitated the policy's implementation. The people category was rated the highest and a fifth category, resources, was rated the lowest. The study found five conclusions: (1) people, structure, communication, and culture facilitated the implementation of WVBE Policy 2450; (2) the people category of factors, which involved the support, knowledge, and willingness of administrators and faculties to learn about distance learning, was the most facilitating; (3) the structure category, including the organizational hierarchy, policies, and procedures of a school, ranked second among the factor categories; (4) there were more differences in perceptions about resources, especially time, than any other category of factors; and (5) all five categories of factors important to policy implementation were rated higher in schools where at least $1 \%$ of the students were enrolled in distance learning courses. The study's findings and conclusions prompted recommendations for policy, practice, and research. 


\section{Acknowledgements}

YES! I have wanted to say "yes" for so long to all of those who have asked me if I had completed my dissertation. I've told a lot of people "no," "not quite," or "it's coming along" but not until the committee's approval of this document could I give the answer I have been longing to provide. From this moment on, the answer is "YES!"

I am indebted to so many people who have helped me reach this personal milestone. I want to express my appreciation to Dr. Helen Hazi, academic advisor and chair, for her expertise, dedication, and patience. I also want to thank my other committee members - Dr. Harry Boone, Dr. Stanley Hopkins, Dr. Pamela Whitehouse, and Dr. Adriane Williams - for their valuable contributions. It was a joy to meet or become better acquainted with the individuals in the EDLS cohort. The camaraderie was superb, and I learned so much from each of them. A special note of thanks goes to Vicki Jenkins, Mary Lynn Westfall, and Janie DeVaul for their participation in conference calls that provided so much valuable encouragement. Thanks also go to Larry White for his assistance in understanding the world of statistics.

I am especially grateful for a wonderful family that has demonstrated exceptional patience and support. My wife Gloria is my biggest fan and never doubted my ability to complete this degree. I wouldn't have started or completed this without her unwavering faith in me. My children - Kayla (husband Andrew), Staci (fiancé Trevor), and Steven - have also expressed their pride in me, but it can never equal the pride I have in them. My parents were always proud of my accomplishments, and I certainly wish my father were alive to experience this with my mother and the rest of our family. Somehow I think he knows. Many unnamed friends and co-workers have also played important roles in the completion of this study and I am appreciative of their well wishes. Above all, I want to thank God for giving me the opportunity to complete this degree and placing all of these people in my life to help make it happen. 


\section{Table of Contents}

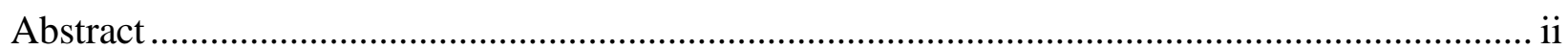

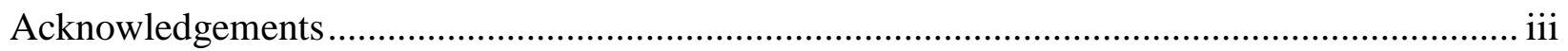

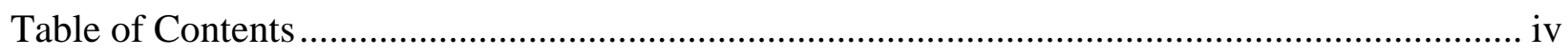

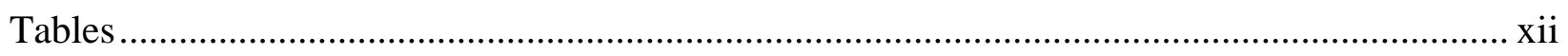

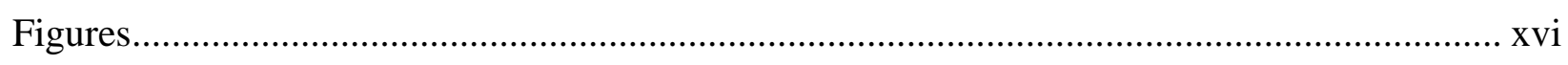

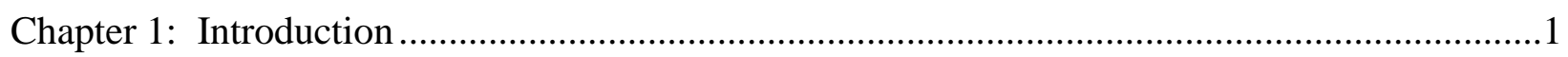

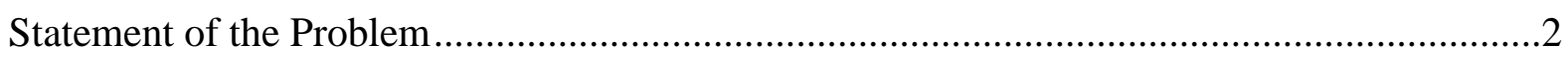

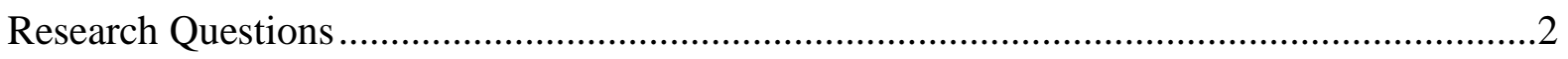

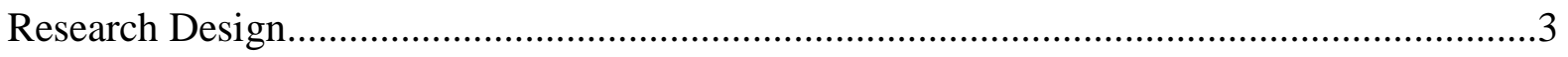

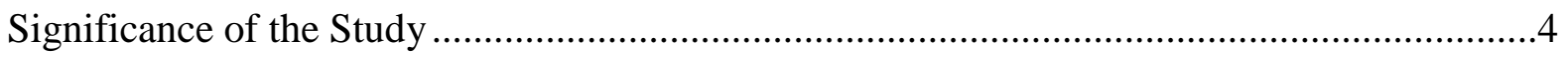

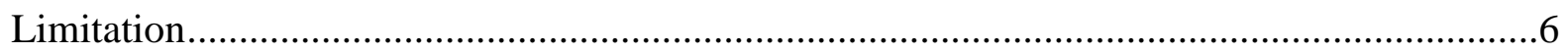

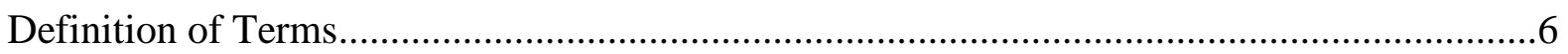

Organization of the Document .....................................................................................

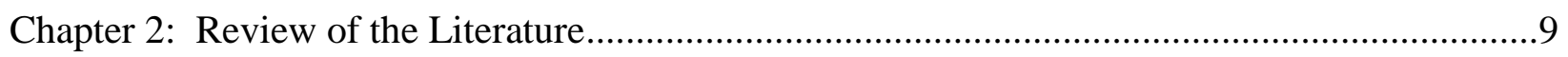

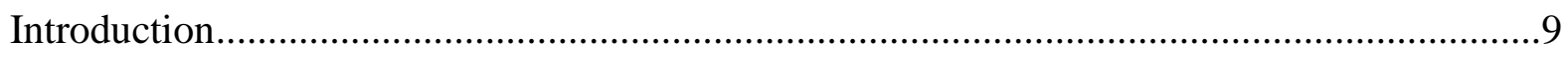

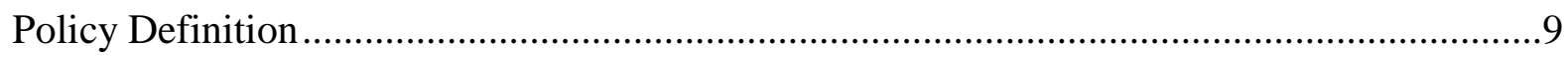

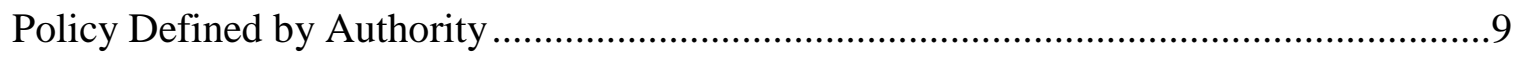




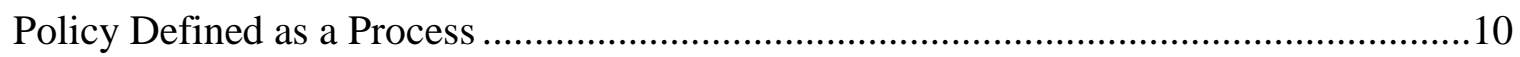

Policy Defined by Outcomes ………………………................................................11

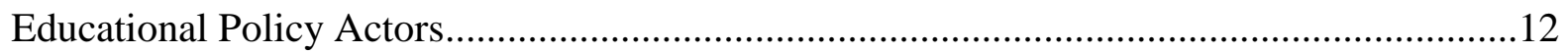

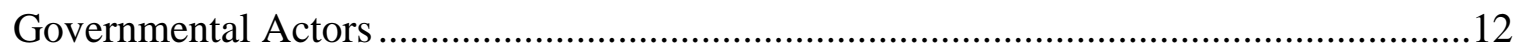

Actors in the Legislative Branch...........................................................................13

Actors in the Executive Branch ..........................................................................14

Actors in the Judicial Branch ..............................................................................17

Actors in Local Government.................................................................................18

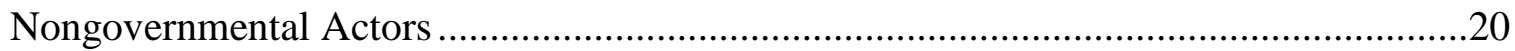

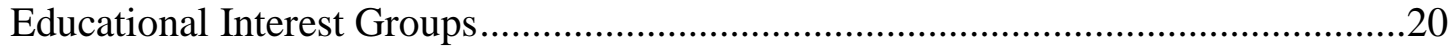

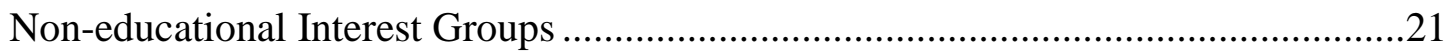

Policy Networks and Policy Planning Organizations ..................................................23

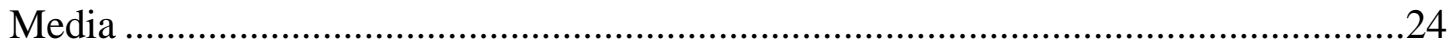

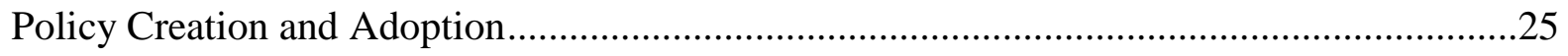

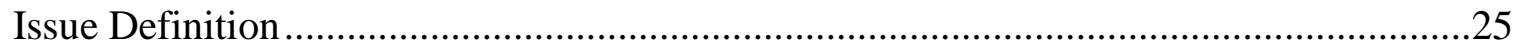

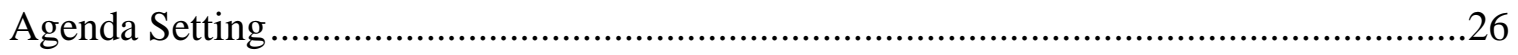

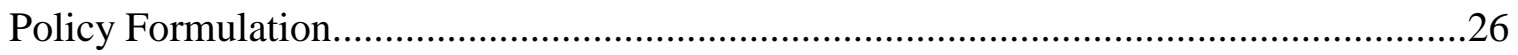




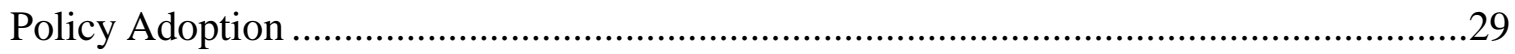

Adoption of WVBE Policies.....................................................................................

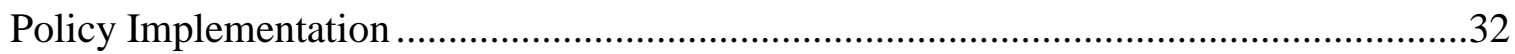

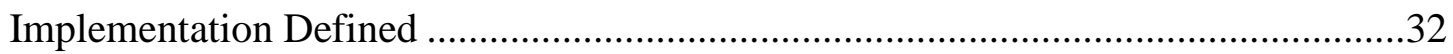

Top-Down versus Bottom-Up Perspectives.............................................................32

Factors Affecting Policy Implementation .................................................................34

People

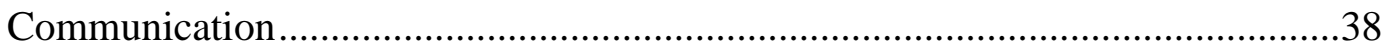

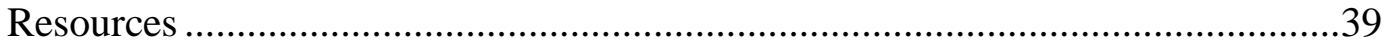

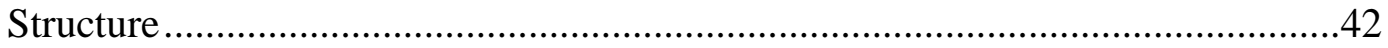

Culture

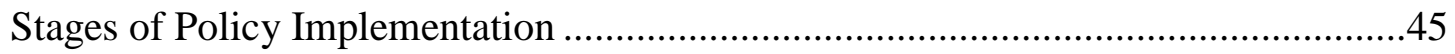

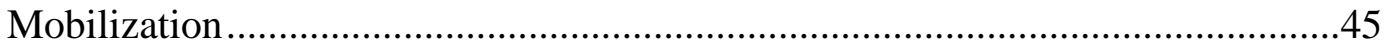

Implementation Proper....................................................................................4

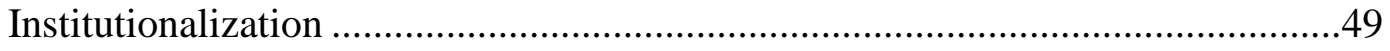

Implementation versus Compliance ...................................................................49

Research on Statewide Educational Policy Implementation ......................................50 
Distance Learning and the West Virginia Virtual School

Definition of Online Learning .55

Definition of Virtual School .55

Classification of Virtual Schools .56

Distance Learning in the United States .57

Teaching in the Age of Distance Learning ..... .60

West Virginia Virtual School. .61

Creation and Purpose .61

Structure and Management .62

Funding and Costs. .66

Classification of Distance Learning Courses. .67

Classification by the Amount of Content Delivered Online .67

Classification by the Type of Interaction between Teachers and Students .68

Specific Studies on Distance Learning in Public High Schools .69

Benefits of Distance Learning .75

Challenges of Distance Learning. .78 
Summary

Chapter 3: Research Design

Introduction. .82

Research Rationale

Research Theoretic

Study Population .85

Research Procedures

Survey Instrumentation.

Survey Development.

Validity and Reliability.

Panel of Experts

Reliability Test

Data Collection .96

Data Analysis

Summary

Chapter 4: Data Analysis and Interpretation. 
Demographic Information.

Reliability of the Survey Instrument

Research Question 1

Research Question 2

Research Question 3

Research Question 4

Factor Category: People

Factor Category: Communication

Factor Category: Resources

Factor Category: Structures

Factor Category: Culture.

Summary of Findings

Related Findings

Chapter 5: Summary, Conclusions, Discussion, and Recommendations

Summary

Conclusions

Discussion 


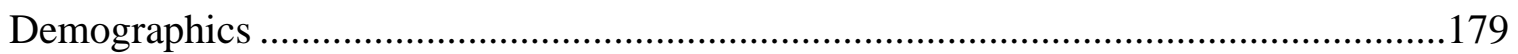

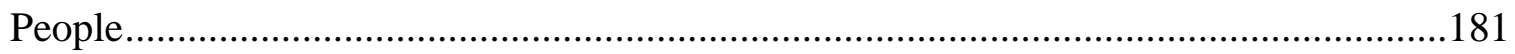

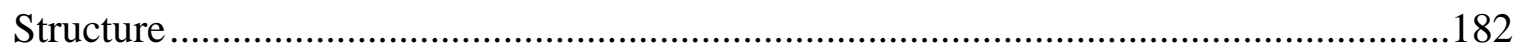

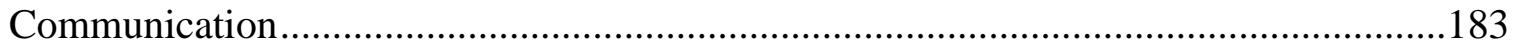

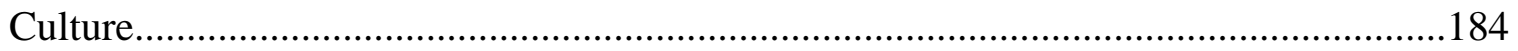

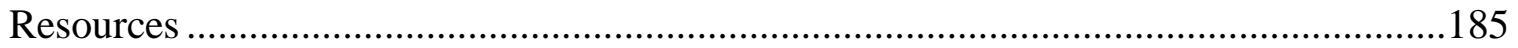

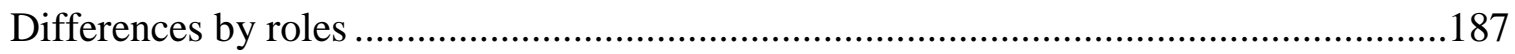

Principals versus Distance Learning Contacts and/or Course Facilitators ................188

Counselors versus Distance Learning Contacts and/or Course Facilitators ..............191

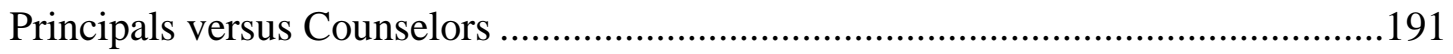

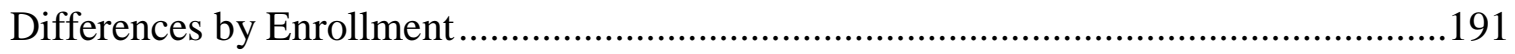

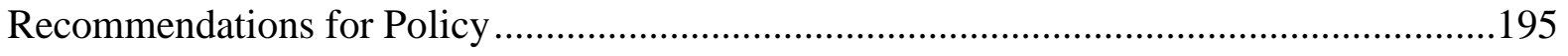

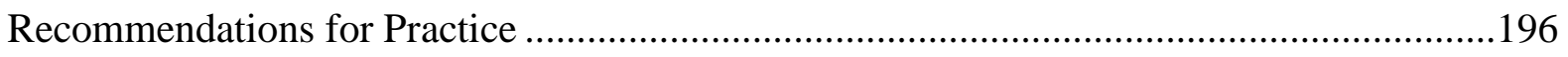

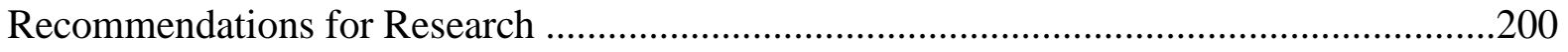

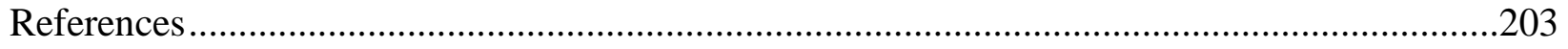

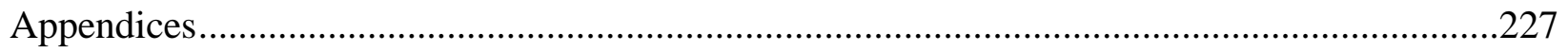

A - WVBE Policy 2450, Distance Learning and the West Virginia Virtual School............227 
B - Rank Order of West Virginia High Schools by Percentage of the Total Students (Grades 9-12) Enrolled in Distance Learning Courses, 2008- 2011

C - Survey Instrument: Factors Affecting Implementation of WVBE Policy 2450, Distance Learning and the West Virginia Virtual School

D - Matrix Displaying the Relationship between the Literature and the Survey Items

E - Draft Survey Sent to Panel of Experts for Review

F - Directions to Panel of Experts Reviewing the Proposed Survey Instrument .261

$\mathrm{G}-$ Superintendent Notification Letter...... .270

$\mathrm{H}$ - Letter of Invitation to Participate in Survey....

I - Comparison of Early Respondents to Late Respondents on Ratings of Survey Items.....274

J - Number of Responses, Mean Score, and Standard Deviation of Responses to Survey Items .275

K - Survey Items Ranked in Descending Order of Mean Scores (All Respondents). .277

L - Principals’ Ranking of Survey Items in Descending Order of Mean Scores

M - Counselors' Ranking of Survey Items in Descending Order of Mean Scores .281

N - Distance Learning Contacts/Course Facilitators' Ranking of Survey Items in Descending Order of Mean Scores.

O - Comparison of Mean Scores and Standard Deviations by Respondents' Primary Positions

$\mathrm{P}$ - Results of One-Way Analysis of Variance (ANOVA)

Q - One-Way Analysis of Variance (ANOVA) Results on Survey Items with Significant Differences among the Means of Principals/Assistant Principals, Counselors, and Distance Learning Contacts and/or Distance Learning Course Facilitators

$\mathrm{R}$ - Independent Samples t-Test Results .295

$\mathrm{S}$ - Comments Provided by Respondents, Grouped by Subject .302 


\section{Tables}

List of Tables xii

1. Individuals to be Surveyed Regarding Implementation of Policy 2450, Distance Learning and the West Virginia Virtual School .88

2. Survey Response Items and Corresponding Implementation Factor Categories

3. Number and Percent of Respondents within the Population

4. Group Composition and Survey Return Rates 106

5. Composition of Respondents in Groups A and B

6. Number and Percent Return Rate of Groups A and B 108

7. Comparison of Demographic Information of Early Respondents and Late Respondents

8. Respondents' Primary Position within the School

9. Number of Years Respondents Have Served in Their Primary Positions

10. Ways Respondents Were Directly Involved in Distance Learning 114

11. Number of Respondents Located in Schools of Different Size 116

12. Number (Percent) of Respondents in Groups A and B by Size of School

13. Survey Items that Facilitate Implementation of WVBE Policy 2450

14. Mean Scores and Standard Deviations of Factors Affecting the Implementation of Policy 2450

15. Survey Items with Mean Scores Below 3.6

16. Survey Items with Significant Differences in Perceptions among the Three Groups of Respondents.

17. Comparison of Perceptions Regarding the Skills of Distance Learning Course Facilitators

18. Comparison of Perceptions Regarding Student Access to Technology and Instructional Support 
19. Comparison of Perceptions Regarding Time Available for School Personnel to Implement Distance Learning Policy 2450

20. Comparison of Perceptions Regarding the Number of Computers

Available for Students in Distance Learning Courses

21. Comparison of Perceptions Regarding Broadband Capacity/Access to the Internet in Schools

22. Comparison of Perceptions Regarding Computer Network Security (Protection from Computer Viruses and Hackers).

23. Comparison of Perceptions Regarding WVBE Policy 2460 and the Implementation of WVBE Policy 2450 .

24. Comparison of Perceptions Regarding Assessment of Student Learning in Distance Learning Courses .

25. Comparison of Perceptions Regarding Support from West Virginia Department of Education Personnel

26. Comparison of Perceptions Regarding the Importance of Teacher Digital Literacy.......137

27. Survey Items having Significant Differences in Mean Scores between Groups and Effect Sizes

28. Comparison of Perceptions Regarding the School Counselor as a Source of Information about Distance Learning Courses.

29. Comparison of Support of Administrators on the Use of Technology in Instruction......146

30. Comparison of Principals' Perceptions of Traits Needed by Students to be Successful in Distance Learning Courses

31. Comparison of Principal's Willingness to Include Distance Learning Courses in the School Curriculum

32. Comparison of Perceptions Regarding School Faculty’s Knowledge of Teaching Methods Used in Distance Learning....

33. Comparison of the Perceptions Regarding Skills of Distance Learning Course Facilitators in the School 148

34. Comparison of the Faculty's Willingness to Learn about Distance Learning Courses ...148 
35. Comparison of Perceptions Regarding Communication among

All School Personnel within a School

36. Comparison of Perceptions Regarding Information about Distance Learning

Courses Being Made Available to Students.

37. Comparison of Perceptions Regarding Communication with External Audiences (e.g., Parents)

38. Comparison of Perceptions Regarding the Clarity of WVBE Policy 2450,

Distance Learning and the West Virginia Virtual School

39. Comparison of Perceptions Regarding the Guidance from the West

Virginia Department of Education....

40. Comparison of Perceptions Regarding the Time Available for School

Personnel to Implement Distance Learning Policy 2450

41. Comparison of Perceptions Regarding the Size of a School (i.e., Number

of Students in Grades 9-12) and the Implementation of Policy 2450

42. Comparison of Perceptions Regarding the Cost of Distance Learning Courses

43. Comparison of Perceptions of Student Access to Technology and Instructional Support

44. Comparison of Perceptions Regarding the Number of Computers Available for Students in Distance Learning Courses.

45. Comparison of Perceptions Regarding Broadband Capacity/Access to the Internet.......155

46. Comparison of Perceptions Regarding Computer Network Security

47. Comparison of Perceptions Regarding Funding for Professional Development about Distance Learning

48. Comparison of Perceptions Regarding Distance Learning Course Facilitators Having the Opportunity to Network with Distance Learning Course Facilitators in Other Schools

49. Comparison of Perceptions Regarding Assessment of Student Learning in Distance Learning Courses

50. Comparison of Perceptions Regarding the Ability for Students to Enroll in Distance Learning Courses without Experiencing Scheduling Conflicts 
51. Comparison Regarding Procedures in the School (e.g., Daily Class Schedules, Attendance, School Calendar, Procedures for Recording Grades) and the Implementation of Policy 2450.

52. Comparison of Perceptions Regarding the Impact of Policy 2460 on the Implementation of Policy 2450.

53. Comparison of Perceptions Regarding the Acceptance of Credits for Distance Learning Courses

54. Comparison Regarding the Recognition of Distance Learning Courses by Colleges and Universities

55. Comparison of Perceptions about the School's Ability to Maintain Academic Integrity (Control Cheating) in Distance Learning Courses....

56. Comparison of Perceptions Regarding Support from West Virginia Department of Education Personnel ....

57. Comparison of Perceptions Regarding the Faculty's Acceptance of State Policy

58. Comparison of Perceptions on the Support of Distance Learning Among the Faculty...164

59. Comparison Regarding the Importance of Student Digital Literacy

60. Comparison of Perceptions Regarding the Importance of Teacher Digital Literacy on the Implementation of Policy 2450

61. Comparison of Perceptions Regarding the Quality of Distance Learning Classes Compared to Face-to-Face Classes. 166

62. Comparison Regarding Parents’ Perception of Distance Learning 166

63. Survey Items Having Significant Differences between Respondents in Group A and Group B. 168

64. Overall Comparison of All Responses from Those in Groups A and B 169 


\section{Figures}

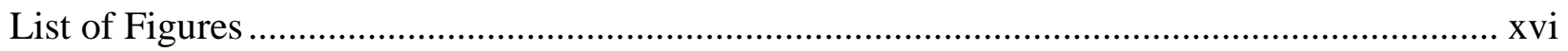

1. Procedure Followed in the Adoption of WVBE Policies ...................................................31

2. Categories of Factors Affecting Policy Implementation ..............................................35

3. Enrollments in the West Virginia Virtual School, 2003-2011 ......................................65 


\section{Chapter 1}

\section{Introduction}

Policy implementation is a course of action through which policy directives are carried out by designated levels of government (Nakamura \& Smallwood, 1980; McLaughlin \& Elmore, 1982). Implementation is a critical phase of the policy process in which policymakers hope their expressed intentions produce desired conditions. Even explicit legislative intent, however, does not guarantee the desires of policymakers will be preserved through the implementation process (Garn, 1999). "Many official policies are never implemented at all, and many others are implemented only partially or incorrectly" (Fowler, 2009, p. 270).

Implementation of policies concerning the use of technology in schools has struggled to keep pace with the rapid advancements in technology (Watson, 2007). These struggles have stymied the use of technology in some schools. Policies which would enable greater use of technology in K-12 education have not been developed or have encountered sufficient implementation problems to have little effect (Chubb, 2012). In 2007-08, two percent of all K-12 students in the United States took an online course (Picciano \& Seaman, 2009). One percent of West Virginia students in grades 9-12 took an online course between 2008 and 2011(WVDE, 2011a) even though the West Virginia Virtual School, intended to make online learning more accessible to students, has been in existence since 2000 (W. Va. Code, 2012).

Prensky (2001) asserted that schools should provide learning opportunities that complement students' learning styles and needs. He labeled today’s students “digital natives" (p. 1), contending their interaction with technology in everyday life has created a generation of students who think and learn differently than previous generations. "Digital immigrants" (Prensky, 2001, pp. 1-2) are those not born into the digital world but who have, at some later point in their lives, become fascinated by and adopted many or most aspects of the new 
technology. In many schools, digital immigrants are responsible for implementing distance learning policies intended to benefit digital natives. Is the implementation of distance learning policies affected by people, resources, or other factors in schools?

This study examined the perceptions of selected personnel at 110 West Virginia high schools regarding the implementation of West Virginia Board of Education (WVBE) Policy 2450, Distance Learning and the West Virginia Virtual School (Appendix A). Principals, assistant principals, counselors, and distance learning contacts and facilitators - individuals who implemented the policy - had the opportunity to indicate if they believed five categories of factors facilitated or impeded the implementation of WVBE Policy 2450. The study also compared the perceptions of these individuals who were located at schools that had $1 \%$ or greater of the students enrolled in distance learning courses between 2008 and 2011 versus those at schools with less than $1 \%$ of the students enrolled in distance learning courses during the same time period.

\section{Statement of the Problem}

This study sought to determine the factors that facilitated and impeded implementation of WVBE Policy 2450, Distance Learning and the West Virginia Virtual School, as perceived by principals/assistant principals, counselors, and distance learning contacts and/or distance learning course facilitators in West Virginia high schools.

\section{Research Questions}

The study sought to answer four research questions:

1. What are the factors that facilitate the implementation of WVBE Policy 2450, Distance Learning and the West Virginia Virtual School, in high schools according to perceptions of three select groups: (a) principals/assistant principals, (b) counselors, and (c) distance learning contacts and/or distance learning course facilitators? 
2. What are the factors that impede the implementation of WVBE Policy 2450, Distance Learning and the West Virginia Virtual School, in high schools according to perceptions of three select groups: (a) principals/assistant principals, (b) counselors, and (c) distance learning contacts and/or distance learning course facilitators?

3. Is there a difference in perceptions of factors important to the implementation of WVBE Policy 2450, Distance Learning and the West Virginia Virtual School, in high schools among three select groups: (a) principals/assistant principals, (b) counselors, and (c) distance learning contacts and/or distance learning course facilitators?

4. Is there a difference in perceptions of factors important to implementation of WVBE Policy 2450, Distance Learning and the West Virginia Virtual School, in schools with 1\% or greater of the high school students enrolled in distance learning courses between 2008 and 2011 versus schools with less than $1 \%$ of the high school students enrolled in distance learning courses during the same time period?

\section{Research Design}

This study was intended to determine what factors affected implementation of WVBE Policy 2450, Distance Learning and the West Virginia Virtual School. The policy contains information about the use of distance learning in West Virginia school systems that choose to use this form of course delivery. Perceptions of the population were collected through the use of an online survey. Survey items addressed five categories of factors that can facilitate or impede policy implementation in local schools: (a) people, (b) communication, (c) resources, (d) structure, and (e) culture.

The principals, assistant principals, counselors, and distance learning contacts and/or distance learning course facilitators at 110 West Virginia high schools constituted the survey 
population. The support of school principals and assistant principals as school administrators "is essential to the success of virtual school implementation at the local level" (WVDE, 2012a, para. 1). A counselor assists students in academic program planning and individual course selection (WVBE Policy 2315, 2012). A distance learning contact is an individual in each school identified by the county superintendent to disseminate information about virtual courses and manage the delivery of virtual courses at the school (WVBE Policy 2450, 2012). A distance learning course facilitator is a person of record who monitors the academic performance of students enrolled in distance learning courses and is designated to receive reports from the course provider concerning individual student progress (G.Burdette, personal communication, Apr. 6, 2012).

The study reported the perceptions of the survey population of factors that facilitated and impeded the implementation of WVBE Policy 2450. Mean scores and standard deviations were calculated for each survey item to determine which factors facilitated and which factors impeded implementation of WVBE Policy 2450. Responses were further analyzed to determine if there were differences in respondents' perceptions based on their role in implementation. The study also reported if there were differences in the perceptions of those in schools where $1 \%$ or more of the students were enrolled in distance learning courses between 2008 and 2011 versus schools with less than $1 \%$ of the students enrolled in the courses during the same time period.

\section{Significance of the Study}

This study contributed to the literature in educational leadership by filling gaps which existed in research pertaining to state education policy implementation, especially in the area of distance learning. A search of the ProQuest Dissertations \& Theses database using the subject "policy implementation" and descriptor "elementary and secondary education" yielded 40 
studies published between 2008 and 2011. Seven of the 40 studies were not relevant to this research as they were outside the United States and another five were not directly related to the implementation of public school policy (e.g., higher education policy studies, studies of infants affected by illegal substances). Of the 28 other dissertations, only nine specifically addressed state education policy implementation. When the descriptor "virtual learning" was added to the search, only two qualitative studies remained. Little attention has been given to the implementation of state-developed policies, and the research which exists tends to have limited the sources of data to interviews with school superintendents and principals.

Additional searches using different descriptors identified literature that was relevant and contributed to this study. Studies that focused on policy implementation barriers and were referenced in this research include the works of Myers (2008), Shepherd (2001), Fowler (2009), and Moser (2005). Research that focused on the implementation of virtual learning in public schools included the national studies of Setzer and Lewis (2005) and Picciano and Seaman (2007). These two studies were among the first national studies of virtual learning in the U.S. and were foundational to other research. Dissertations addressing the implementation of virtual learning in schools and were referenced in this study include those by Morse (2010), Bral (2007), and Reviea (2010).

The results of this study may assist West Virginia high schools seeking to improve the implementation of WVBE Policy 2450.The results may also help state education leaders better understand the factors that affect the implementation of this and other state policies from the perspectives of those at the school level. Improved understanding of the factors that facilitate or impede policy implementation can impact the development of future state policies and/or guidance documents to assist local school systems in the implementation of state policies. 


\section{Limitation}

Data for this study was collected through an online survey and the invitation to complete the survey was sent via email. Email messages sent to multiple recipients do not always reach their intended destinations. In some cases, such messages do not appear in recipients' inboxes and are directed to junk mail folders. Receipt of some messages may have been blocked if individuals established a preference of electronic blocking (Survey Monkey, 2011). The number of responses may have been limited if some members of the study population did not receive their invitations to participate in the study.

\section{Definition of Terms}

Counselor: A professionally trained and certified person employed by a school system who utilizes a variety of techniques and strategies to help students explore academic, career, and personal/social issues (WVBE Policy 2315, 2012). A counselor is the leading source of information for students about academic opportunities (Osumi, 2010) and assists students in academic program planning and individual course selection.

Distance learning: A type of formal study in which teachers and learners are separated by time or space (Keegan, 1996; Cavanaugh et al., 2009).

Distance learning contact: An individual at a local school designated by the county superintendent to ensure virtual course information is provided to students and parents, any necessary affiliation agreements with the course provider are secured, and that a facilitator has been identified for each course offered (WVBE Policy 2450, 2012). The distance learning contact has the authority to contact the West Virginia Virtual School to enroll students in distance learning courses. 


\section{Distance learning course (also known as a virtual course or an online course): A}

series of classes characterized by substantial use of distance learning methods and limited faceto-face interaction with the content teacher.

\section{Distance learning course facilitator (also known as virtual course facilitator): A} person of record who monitors the academic performance of students enrolled in distance learning courses and is designated to receive reports from the course provider concerning individual student progress (G.Burdette, personal communication, Apr. 6, 2012).

Online learning (also known as virtual learning): A form of distance education "in which instruction and content are delivered primarily via the Internet" (Watson, Winograd, \& Kalmon, 2004, p. 95).

Policy: A rule, regulation, law, ordinance, decision, or other action that is the outcome of a political system.

Policy implementation: A multi-stage course of action through which policy directives are carried out by designated levels of government (Nakamura \& Smallwood, 1980; McLaughlin \& Elmore, 1982).

Principal: A person holding appropriate and valid administrative certification who, under the supervision of the superintendent and in accordance with the rules and regulations of the county board of education, assumes administrative and instructional supervisory responsibility for the planning, management, operation and evaluation of the total educational program of the school or schools to which he or she is assigned (W. Va. Code, 2012). A principal's approval and support of virtual learning is essential for successful implementation at the local level (WVDE, 2012a). 
West Virginia Virtual School: A statewide supplemental program described in WV Code $§ 18-2$ E-9 that utilizes distance learning methods to offer individual courses otherwise unavailable to students in their local schools.

\section{Organization of the Document}

This document is organized into five chapters. Chapter One provides an overview of the study with an introduction to the topic, statement of the problem, study purpose, research questions, limitations, and definitions of terms.

Chapter Two is a review of study-related literature about factors affecting policy implementation. The chapter also presents information about distance learning that is helpful in understanding WVBE Policy 2450, Distance Learning and the West Virginia Virtual School. The implementation of WVBE Policy 2450 was the subject of this study.

Chapter Three presents the research design used in this study. The chapter includes the rationale and procedures that were used and provides information about the development of the survey instrument. Chapter Three also contains a description of the data analysis methods that were used.

Chapter Four provides a description and analysis of the data collected. The chapter includes the return rate, demographic statistics, data relevant to the four research questions, and findings.

Chapter Five presents a summary of the study, conclusions, and discussion. The chapter also contains recommendations for policy, practice, and research. 


\section{Chapter 2}

\section{Review of the Literature}

\section{Introduction}

The purpose of this chapter is to review the existing research on policy implementation in public schools. This study sought to determine the factors that facilitated and impeded implementation of WVBE Policy 2450, Distance Learning and the West Virginia Virtual School, in high schools as perceived by three select groups: (a) principals/assistant principals, (b) counselors, and (c) distance learning contacts and/or distance learning course facilitators. Topics included in this chapter are: policy definition, policy actors, policy creation and adoption, and factors that enable or impede policy implementation. The chapter includes a comparison between implementation and compliance. Finally, the chapter provides information about WVBE Policy 2450 , the specific policy whose implementation was the focus of this study.

\section{Policy Definition}

This section contains three definitions of policy. Policy can be defined by its authority, as a process, and as an outcome. This section will disclose the importance of all three elements and identify the definition most appropriate for this study.

Policy defined by authority. One branch of policy research focused on the authority of governing organizations to establish policy. Dunn (1977) described public policy as an "authoritative guide for carrying out governmental actions in national, state, regional and municipal jurisdictions" (p. 22). This definition stressed the presence of an authoritative body - a fundamental element to a policy's existence. Dunn's definition implied public policy was backed by public law (enforceable by the police and courts), had legitimacy through a creating public body, and applied to all citizens within its jurisdiction. Ball (1990) also addressed the authoritative component of public policy but added an observation about the relationship 
between a governing body and its society: "Policy is clearly a matter of the authoritative allocation of values" (p. 3). Since public policy is adopted and administered by a recognized level of government, a fair interpretation of this relationship is that public policy is an expression of a society's values (Ball, 1990).

Other definitions of policy specifically referenced the individuals serving in positions of authority. Bryson and Crosby (1992) described public policy as "substantive decisions, commitments, and actions made by those who hold or affect government positions of authority, as they are interpreted by various stakeholders" (p. 63). Bryson and Crosby's words acknowledged the human factor in policy and clearly emphasized that people, not authorities, administer policy.

The influence of individuals on policy was a topic also examined by Firestone (1989) who contended that the entire policy process from creation to implementation is profoundly affected by individuals with varying levels of interest. "Policy as a chain of decisions stretching from the statehouse to the classroom is a byproduct of games and relationships; no one is responsible for the whole thing" (Firestone, 1989, p. 23). Two major points can be derived from Firestone's words: (a) many individuals are involved in the development and implementation of educational policy, and (b) by referring to policy as a "byproduct" and comparing the policy process to "games," Firestone implied some powerbrokers disingenuously engage in educational policy conversations in exchange for opportunities to advance entirely different political agendas including their own political futures.

Policy defined as a process. Some scholars referred to policy as a process. Knapp (1997) stated policy is a "purposeful course of action by individuals at higher levels of the system, to guide, direct, and support actions at lower levels of the system across settings and across time" 
(p. 233). This "purposeful course of action" implies taking steps toward completion of a task. Knapp relied on the action steps themselves as a means of defining policy.

Fowler (2009) analyzed an assortment of definitions for the term public policy and proposed the following: "Public policy is the dynamic and value-laden process through which a political system handles a public problem. It includes a government's expressed intentions and official enactments as well as its consistent pattern of activity and inactivity" (p. 4). Fowler, like Knapp, acknowledged the presence of a governing entity and mentioned "official enactments" (p. 4); however, she more clearly tied policy to a process by specifically describing policy as a "dynamic and value-laden process" (p. 4) whereby issues are addressed.

Policy defined by outcomes. Third, public policy can be defined as outcomes of decisions and actions (University of Texas at Austin, 2011). It is the "outputs of a political system, usually in the form of rules, regulations, laws, ordinances, court decisions, administrative decisions, and other forms" (Kruschke \& Jackson, 1987, p. 35). "A political system consists of the formal and informal structures which manifest the state's sovereignty over a territory and people" (Rummel, 1976, para. 3). Statutes found in West Virginia Code and educational policies adopted by the WVBE are examples of outcomes of a political system. When properly designed and implemented, public policy should consistently yield similar results whether they be official enactments of government or informal practices (Cibulka, 1995). Stated differently, policy is an outcome intended to consistently produce other outcomes (University of Texas at Austin, 2011; Cibulka, 1995).

Outcomes are the logical means by which state departments of education measure policy success. Policies devised to reduce student absenteeism are likely considered effective if attendance rates improve. Policies enacted to make schools more energy efficient are applauded 
if energy consumption decreases. Bangser (2008) cautioned individuals, however, to consider as much information as possible when determining a policy's effectiveness. He encouraged individuals to distinguish as best as possible between the gross outcomes and the net impacts of a policy. While the gross outcome may provide a glimpse to the overall effect of a policy, the net impact more clearly reveals if intended outcomes were achieved as a direct result of its presence.

A definition which focused on policy as a product of a political process was the one most appropriate for this study. This research was built on the understanding that policy consists of the rules, regulations, laws, ordinances, decisions and other actions which are outcomes of a political system.

\section{Educational Policy Actors}

An extensive cast of characters is often involved in the policy process. Since the Tenth Amendment of the U.S. Constitution gives each state the authority to oversee education in its schools, this review will focus on actors involved in the implementation of state educational policies. The section first describes actors in government positions who play major roles in the creation, adoption, and implementation of state educational policies. The section then examines educational policy actors in nongovernmental organizations. This section concludes with a review of the relationship between the West Virginia Department of Education (WVDE) and local school systems.

Governmental actors. Individuals in all three branches of government - legislative, executive, and judicial - influence the design and adoption of educational policy. This section will identify key positions in each of these branches, examine their roles in the policy process, and briefly review how local government actors influence policy. 
Actors in the legislative branch. The power of legislators to affect policy is well-known; they ranked as the most influential policy actors in research conducted by Marshall, Mitchell, and Wirt (1989). The state legislature is comprised of individuals representing citizens in their home districts whose function is the development and consideration of bills which may become law. A bill is an idea for a new law or an idea to change or do away with an existing law (West Virginia Legislature, 2011). An education bill that becomes law may require the development of an administrative policy that reflects the intent of the law and provides specific information about how it will be implemented.

West Virginia's legislature is a part-time legislature consisting of two chambers: the Senate and the House of Delegates. The 34 members of the Senate are elected to four-year terms and the 100 members of the House are elected to two-year terms. Each chamber is structured with its own set of officers and operating rules and has standing committees whose members are appointed by the Senate President or the Speaker of the House according to the rules of the respective chamber. Standing committees study issues on a variety of topics including education, finance, and health and human resources. The full legislature meets annually in regular session for a sixty-day period from January to March (February through April during years following a General Election). Legislators attend interim meetings between the regular legislative sessions to examine issues and lay the groundwork for future sessions. In addition to the regular legislative session, the governor may convene the legislature by proclamation whenever the public safety or welfare shall require it or when three-fifths of the members of each chamber provide a written request to the governor for a special session (W. Va. Const. art. VI, §19, 2012). West Virginia's legislature is considered a part-time legislature and the time required of legislators is similar to 
the demands of legislators in sixteen other states (National Conference of State Legislatures, 2009).

Some legislators have more influence than other legislators regarding which education bills have genuine chances to become law. The support of officers in the West Virginia Legislature, such as the Speaker of the House or the Senate President, is critical to a bill's prospects. Legislators that chair their respective chambers' Education or Finance Committees also have significant influence, since they have substantial control of the placement of a bill on a committee agenda and can assist or impede its progress.

Actors in the executive branch. A state's governor has substantial influence on the educational policy process and is a powerful policy actor. West Virginia's governor is elected to a four-year term. Throughout the year and especially during the legislative session, the governor meets with senators and delegates to promote his/her agenda and discuss other legislation under consideration. Some governors choose to give educational issues greater priority than those who preceded them in office. The governor may request legislative leaders to introduce bills on his or her behalf. The governor also has the authority to veto bills which pass both chambers of the legislature. A governor's power is affected by a number of factors including the length of term, the margin of victory when elected, previous experience in state government (Fowler, 2009), and his/her personal style and presence (Beyle, 2001).

The influence of West Virginia's governor as an educational policy actor is also illustrated by the authority provided in W. Va. Code $§ 18-2-1$ (2012) to appoint individuals to serve on the WVBE and the board's authority provided in W. Va. Code $§ 18-3-1$ (2012) to select the state superintendent. Although a state board of education exercises both quasi-legislative and quasi-judicial functions, its administrative role and relationship to the governor merits its 
inclusion in a discussion of the executive branch of government (Fowler, 2009). The composition of the twelve-member WVBE is described in W. Va. Code $\$ 18-2-1$ (2012). Three of the members - the State Superintendent of Schools, the Chancellor of the West Virginia Higher Education Policy Commission, and the Chancellor of Community and Technical College Education - are non-voting, ex-officio members. The remaining nine are voting citizen members appointed by the governor to serve overlapping nine-year terms. No more than five may belong to the same political party. The board's mission is to establish policies and rules to assure implementation of education goals and to ensure the general supervision, oversight and monitoring of a thorough and efficient educational system.

The West Virginia State Superintendent of Schools serves as the state's chief state school officer (W.Va. Code §18-3-1, 2012). West Virginia's state superintendent is appointed by the state board of education and works at its will and pleasure to supervise all public schools. He/she is often viewed as the spokesperson for the state's public education system and is in frequent contact with the governor and legislators to provide information on educational issues. State superintendents across the nation rank second to legislators and legislatures as a whole in the ability to influence educational policy (Marshall et al., 1989).

The WVDE, similar to other state departments of education, is also a policy actor. The WVDE is a state agency headed by the State Superintendent of Schools. WVDE staff members are employed at the will and pleasure of the state superintendent to perform tasks associated with supervision of the schools in the state. Staff members provide leadership to local school systems by overseeing implementation of state board policies, providing technical assistance to schools, and performing other tasks as determined by the state superintendent (WVDE, 2008). The department is also contacted by legislators to provide data and project the probable impact of 
education bills under consideration. Most state departments of education are responsible for drafting polices which contain the detailed rules and regulations to implement newly-adopted legislation. "A state department of education may ignore or block legislation, or it may opt to dilute it by the way it writes the rules to accompany it" (Fowler, 2009, p. 149). A state department of education is expected to determine if local districts are meeting the requirements of state law and/or policy and may monitor district compliance aggressively, loosely, or not at all (Madsen, 1994; Pipho, 1990).

The responsibilities of state departments of education including the WVDE have expanded in recent years. Prior to the 1980s, state departments of education were primarily designed to channel money to local school districts. State departments devoted most of their resources to compliance-oriented activities and gave little attention to school reform (Brown, Hess, Lautzenheiser, \& Owen, 2011). The release of the report A Nation at Risk (National Commission on Excellence in Education, 1983), however, prompted a flurry of state reforms during the 1980s and an expanded federal role in education during the 1990s. These actions placed additional responsibilities on state departments of education to provide leadership and/or support to school reform efforts.

A substantial amount of research has been produced about the state's role in the educational policy process but most of it focuses on the state's oversight in the implementation of federally-mandated policies. A query in the ProQuest Dissertations \& Theses database searching for studies conducted between 2000 and 2012 using "policy implementation" and "elementary and secondary education" and "United States" as descriptors in all fields and text yielded over 30,000 results, but a scan of titles and abstracts overwhelmingly confirmed the interest in the state's role as an intermediary in the federal policy process. Little attention has 
been given to the implementation of state-developed policies, and the research which does exist tends to limit the sources of data to superintendents and principals.

The responsibilities of the WVDE and other state departments of education to ensure compliance, facilitate school reform, and administer state policies have occasionally created tensions between state and local boards of education. Local school officials have sometimes wondered aloud if the federal and/or state departments of education have overstepped their authority and excessively limited local control of the schools (Rothman, 2011; Toch, 2012). A high-ranking official in one state education agency summarized the relationship when he described his department as a "very hard place to be, because we are constantly pressured by the feds to do better and more intense monitoring, but at the same time constantly pressured by local education agencies to back off and let them do their work" (Brown et al., 2011, p. 24).

Actors in the judicial branch. Educational policy actors are also present in West Virginia's judicial system. While the system includes municipal, magistrate, and family courts, the two levels most involved in educational policy issues are circuit courts and the Supreme Court of Appeals of West Virginia. Circuit courts are the state's only general jurisdiction trial courts of record. Circuit court judges have jurisdiction over a number of issues including all civil cases in equity, all civil cases at law over $\$ 300$, and all felonies. Circuit judges are elected in partisan elections to eight-year terms. The governor appoints circuit judges to fill vacancies until a new judge is elected.

The Supreme Court of Appeals of West Virginia is the state's highest court and the court of last resort. The court may choose to hear appeals to circuit court decisions. West Virginia is one of only ten states with a single appellate court. The Court has extraordinary power and may grant or refuse to review appeals of decisions from lower courts. The Court is also empowered to 
interpret the laws and Constitutions of West Virginia and the United States. The five Supreme Court justices are elected in partisan elections to twelve-year terms. The governor appoints justices to fill vacancies.

An example of how justices can influence educational policy was found in Circuit Court Judge Arthur Recht's decision in Pauley v. Bailey (1982) that affected the way funds are distributed to West Virginia school districts. The case was originally filed in 1975 by Janet Pauley from Lincoln County who alleged her children and others attending schools in propertypoor counties were not receiving educational opportunities equal to students in richer counties. She also alleged the quality of their education did not meet the "thorough and efficient" standard required by the state constitution. Justice Recht found that the financing of the state's education system was unconstitutional and called for the creation of a comprehensive plan that he described as "no less than a call to the Legislature to completely re-construct the entire system of education in West Virginia” (Pauley v. Bailey, 1982, §X).) “The decision addressed every conceivable aspect of the public schools" (Hazi, 1989, p. 21). Upon learning of Judge Recht's decision, Attorney General Chauncey Browning stated "We have a court deciding how much money our citizens should spend on the school system" (Grimes, 1982, para. 8). The decision led to the redistribution of funds for improvements in school facilities and curriculum, initiated significant changes in the state's school aid formula, and confirmed the role of the judiciary as an educational policy actor.

Actors in local government. Local school officials are important actors in the implementation of state educational policy. Local boards of education are legal agencies of state government (Fowler, 2009), but their composition, selection, and authority are found in state law. Laws regarding county boards of education in West Virginia are found in Chapter 18, 
Article 5 of West Virginia Code (2012). Although states assert authority over local boards on issues such as assessment and accountability, local boards frequently create and adopt appropriate local policies within the framework of broader state policies. In addition, some state policies are not mandated; they are available but optional for district implementation at the discretion of the local board of education.

The local superintendent of schools serves as the chief executive officer of a school district. Local superintendents regularly interact with county boards of education and the public. The first superintendents employed in the mid-1800s were expected to serve as teacher-scholars. Society's changing needs has caused the superintendent's position to evolve so that today's superintendent often fills four additional roles: organizational manager, democratic statesman, applied social scientist, and communicator (Kowalski, 2006).

The challenges of serving as a system's educational leader has caused many superintendents to leave their positions or not have their contracts renewed after relatively short tenures. Many superintendents and board of education members who participated in Zickefoose's (1979) study indicated they were unaware of the impact local situations can have on the success of a superintendent. Many felt the local superintendent alone was completely responsible for his success or lack of success. In 2002, Orr (as cited in Byrd, Drews, \& Johnson, 2006) stated that most superintendents in the United States believed current issues schools faced were similar to those confronted in years past but differed in size or complexity. Today's superintendents are more aware of the effect federal and state policies can have on the success of their districts and tend to become more involved in the early phases of the policy process (Carter \& Cunningham, 1997). West Virginia's county superintendents are appointed by the local school boards and offered employment contracts for terms not less than one nor more than four years (W.V. Code, 
18-4-1, 2012). A local superintendent may have his or her contract renewed at the conclusion of the term specified in the contract.

Nongovernmental actors. Organizations not directly affiliated with government can also play significant roles in the educational policy process. This section will provide information about educational interest groups, non-educational interest groups, policy networks, and the media.

One type of nongovernmental actor which can affect the policy process is an interest group. An interest group is "an association of individuals or organizations...that, on the basis of one or more shared concerns, attempts to influence public policy in its favor" (Thomas \& Hrebenar, 2004, p. 102). Interest groups usually employ representatives called lobbyists to establish relationships that facilitate their access to governmental policy actors and provide relevant information to these decision makers (Fowler, 2009).

Educational interest groups. Some interest groups focus exclusively on educational issues or view topics with regard to how they might impact education. Teacher unions are the most powerful of these education interest groups (Marshall et al., 1989). The National Education Association (NEA) is the largest national teacher union, having a membership of 3.2 million members and affiliates in all fifty states. The West Virginia affiliate has nearly 15,000 members (West Virginia Education Association, 2011). The American Federation of Teachers (AFT) has 1.3 million members nationwide, most of whom are located in larger metropolitan areas. AFT is affiliated with the American Federation of Labor-Congress of Industrial Organizations (AFLCIO). AFT-WV has 15,000 members (American Federation of Teachers - West Virginia, 2011). Other educational interest groups also monitor pertinent issues but lack either the size or organizational structure to carry the influence of the teacher unions. These groups include state 
and local affiliates of the National School Boards Association, the American Association of School Administrators, and the Parent-Teacher Association.

Non-educational interest groups. Another powerful set of policy actors are interest groups not directly tied to education, but whose daily activities can be significantly impacted by educational policy. Thomas and Hrebenar (2004) identified four types of business groups active in state politics that are affected by educational policy. The list includes (a) general business organizations such as chambers of commerce, (b) trade associations representing various sectors in the economy such as banking or health care, (c) manufacturers and their associations, and (d) utility and insurance companies. One commonality shared by the business groups is their desire to keep taxes as low as possible. Since public schools benefit from tax revenues, business groups are sometimes at odds with public school officials on the amount of taxes which should be provided to school districts.

"The West Virginia Chamber of Commerce is the largest, most influential general business organization, representing all business sectors in every region of the state" (West Virginia Chamber of Commerce, 2012a, para. 1). The chamber's structure includes 15 standing committees that explore issues affecting the state's business community. The mission of the Chamber's Education Committee is to provide leadership to affect change in educational policy and practice as desired by its members (West Virginia Chamber of Commerce, 2012b).

Organizations seeking to influence public policy frequently employ lobbyists to contact and provide information to state legislatures or state regulatory agencies. West Virginia Code defines a lobbyist as a person who, through communication with a government officer or employee, promotes, advocates or otherwise attempts to influence legislation, rules or regulations (W.Va. Code, 2012, §6B-3-1(8)(A)). Except for some exemptions, those who are 
employed as lobbyists or spend money on a public servant as a result of lobbying activities in West Virginia must register with the West Virginia Ethics Commission, complete training provided by the commission, and provide reports of expenditures (West Virginia Ethics Commission, 2012). The list of all registered lobbyists is available to the public on the West Virginia Ethics Commission website. In 2010, there were 491 businesses, associations, and special interest groups represented by lobbyists. Those with the largest number of registered lobbyists were Appalachian Power, the West Virginia Chamber of Commerce, the Hospital Association of West Virginia, the Independent Oil and Gas Association of West Virginia, Allegheny Energy, Brickstreet Mutual Insurance Co., the West Virginia Coal Association, Mountain State Blue Cross and Blue Shield, and the Pharmaceutical Research and Manufacturers Association ("What you need," 2010).

Other non-educational interest groups are policy actors by virtue of their interest in race and religion (Fowler, 2009). The National Association for the Advancement of Colored People and the National Council of LaRaza represent the interests of African Americans and Hispanics, respectively, and closely monitor the achievement of minority students. The groups are also concerned about how their respective racial groups are represented in curriculum. Similarly, organizations such as the Christian Coalition and the Anti-Defamation League monitor issues in public education and may become more visible when education policies are inconsistent with their beliefs.

In 1974-75, non-educational interest groups were deeply involved in the controversy surrounding the approval of textbooks by the Kanawha County (West Virginia) Board of Education. The books included the concepts of multiculturalism and egalitarianism and were viewed by some conservative groups as lewd and unpatriotic. The county board of education, 
local parent groups, a coalition of ministers from the West Virginia Council of Churches, and out-of-state influence groups were engaged in a lengthy and heated controversy that led to threats, violence, and an extended closure of schools in the county. The list of approved texts was eventually maintained, those convicted of crimes were imprisoned, and a previously nonexistent group of private schools pledging to honor traditional values emerged (Foerstel, 2002).

Policy networks and policy planning organizations. The policy process can be impacted by organizations which gather, analyze, and exchange information about public education. Some of these organizations are linked to each other to form policy networks that coordinate a wide range of efforts to influence policy. For example, the Education Commission of the States is a nonprofit, nonpartisan policy network created in 1965 to "improve public education by facilitating the exchange of information, ideas and experiences among state policymakers and education leaders" (Education Commission of the States, 2011, para. 1). Other policy networks such as the Children's Defense Fund and Voices for America's Children provide information on a number of children's issues and often become involved in educational policy as well.

Policy-planning organizations are frequently referred to as "think tanks" and can substantially affect which education issues merit public attention. Most of these organizations are not connected with the government; rather, they receive their funding from foundations, corporations, and individuals. The Brookings Institution, the Consortium for Policy Research in Education, and the Bill \& Melinda Gates Foundation are examples of such organizations. Research conducted by these and similar organizations often provides the data from which policy issues emerge. Identification of a specific issue by one of these organizations can push it to the forefront on a number of other policy actors' agendas and increase the likelihood it will be 
addressed in through public law or policy. The West Virginia Center on Budget and Policy is an example of one such organization within the state that "focuses on how policy decisions affect all West Virginians, including low and moderate-income families, other vulnerable populations, and the important community programs that serve them" (West Virginia Center on Budget and Policy, 2012, para. 5).

Media. The media, which includes print and broadcast media, wire services, online services, and the Internet, is another influential policy actor. The power of the media to affect public opinion has long been known, and this power ensures the media's inclusion in the discussion of important policy actors. Those associated with the media "not only report on policy issues and some stages of the policy process, but are also important actors in it" (Fowler, 2009, p. 156). The media is the source of information on educational issues for many citizens, and reporters have the responsibility to "screen, select, and re-contextualize information" (Fowler, 2009, p. 156). Especially important policy actors are editors and those in similar positions of leadership who decide which stories will be featured in the respective media. In addition, the manner in which information is conveyed can sway public opinion to support or reject specific educational policy issues.

The WVDE Office of Communications consistently provides information and news releases to the media. The office also maintains the WVDE website (http://wvde.state.wv.us) as well as its presence in social media such as Twitter and Facebook. The office is frequently contacted by newspapers, television, and radio stations to provide information or offer responses to happenings related to public education. The two West Virginia newspapers with the highest circulation in 2012 were the Charleston Gazette (36,063 circulations) and the Huntington HeraldDispatch (26,909 circulations) (Mondotimes, 2012). The state had 11 television stations with 
four located in the Huntington-Charleston market (USNPL, 2012). In 2000, the WVDE Office of Communications and media outlets reported the state's advancements in distance learning and the creation of the West Virginia Virtual School but were not significant actors in its establishment.

\section{Policy Creation and Adoption}

The policy process typically follows six phases: issue definition, agenda setting, policy formulation, policy adoption, implementation, and evaluation (Fowler, 2009). This section includes a description of each of these phases.

Issue definition. Issue definition is the first phase in the policy process that Fowler (2009) described as "transforming a problem into an issue that the government can address" ( $p$. 168). Not all problems in public schools can be solved through policies. Buses break down and students daydream in class, but no government official is likely to propose a policy against such. Some problems, however, are serious or widespread enough to attract the public's attention and cause individuals to question aloud if anything can be done to remedy a particular situation. Discussions among interested parties can help clearly define a problem - an important development in the progression of a problem to an issue (Fowler, 2009). Problems differ from policy issues in that issues are frequently controversial and "imply an interpretation of the problem, a set of values, and an understanding of the proper role of government" (Fowler, 2009, p. 169) to which some may disagree.

WVBE policies cover a wide assortment of topics including harassment, safe use of the Internet, class sizes, and curriculum. Educational issues appropriate for policy consideration can emerge from a number of sources including policy planning and research communities, policy research organizations (think tanks), consortiums, and foundations. These groups can serve as 
forums in which issues are examined before advancing to the agenda setting phase (Fowler, 2009).

Agenda setting. Agenda setting, the second phase of the policy process, is that period when all the issues related to a specific policy domain are discussed. These conversations typically involve a broader audience than the issue definition phase and may include discussions with members of the profession, media, and general public. If support for the issue grows, it may advance from the professional, media, and public agendas to the governmental agenda. Issues which reach this level are "on the list of subjects or problems to which governmental officials...are paying some serious attention at any given time" (Kingdon, 2003, p. 3). Fowler (2009) described issue definition and agenda setting as the two most important phases in the entire policy process but indicated they "occur so quietly that they are almost invisible to the general public" (p. 195).

Policy formulation. Policy formulation, the third phase in the policy process, is usually quite visible to the public. Policy formulation is the process of putting a group's intent into written language. Lively debates frequently erupt during the policy design phase and often generate a high level of public interest. Those who formulate policy language are keenly aware of the subtle differences in words. It is not unusual for stakeholders to wrangle over seemingly trivial choices of words so a policy more perfectly aligns with their philosophical beliefs. One group of policy actors especially adept at policy formulation has been labeled policy entrepreneurs. These individuals work from outside the formal governmental system to introduce, translate, and implement innovative ideas into public sector practice (Roberts \& King, 1991). Policy entrepreneurs tend to offer more "radical" (p. 155) solutions to problems than the modest, incremental changes offered by traditional reformists. 
The battles of policy formulation are not restricted to wars of words but also involve fiscal matters. "Neither the U.S. Congress nor the fifty state legislatures are required to fund all the policies for which they adopt official funding" (Fowler, 2009, p. 196). School leaders are quite familiar with unfunded mandates which surface when officials create policies absent of the fiscal resources to bring them to life. Policies are more likely to bring about intended change when language and funding are both given adequate attention in the formulation phase.

The political, social, and economic climate at any given time impacts the policy process. Climate is defined as "the prevailing attitudes, standards, or environmental conditions of a group, period, or place" (Climate, 2011). Climate refers to the current feelings and attitudes and “reflects what is happening today" (Gonder \& Hymes, 1994, p. 13).

Upon their initial ascensions to power, political leaders usually review existing education policies in their domain and may propose changes. A new president, governor, or state superintendent may have a different set of priorities than his or her predecessor and may have an opinion on a particular issue that either facilitates or impedes existing policy efforts. The appointment of a new district superintendent or election of different members to the board of education can similarly change the local political climate. In response, stakeholders frequently (and sometimes covertly) research new leaders' positions on policy issues in an attempt to predict how they may impact existing efforts. An understanding of the political climate can help stakeholders determine the most appropriate strategies for continued policy work.

The social climate is a reflection of what is on the public's mind. For example, the nation was rocked by the news of the horrific school shooting at Columbine High School on April 20, 1999, in which two high school seniors killed twelve fellow students and one teacher before taking their own lives. Extensive media coverage of the Columbine shootings invoked a sense of 
urgency for schools to examine security issues, although school shootings only account for one percent of homicides of school-age youth (Calefati, 2009). Numerous calls from parents after the Columbine incident prompted school officials across the nation to quickly adopt and implement local antiviolence policies and crisis management plans (Muschert, 2007). While zero-tolerance policies and other similar measures are intended to increase student safety, some of the actions in the wake of the Columbine shootings were labeled "knee-jerk responses" (Muschert, 2007, p. 72) and determined to be less effective than the threat assessment strategies recommended by the Secret Service (Vossekuil, Fein, Reddy, Borum, \& Modzeleski, 2002). Most school leaders, however, were sensitive to the social climate following the tragedy and realized the need to calm parents' concerns even if some policy decisions were mostly symbolic in nature.

Finally, the economic climate of the nation, state, and/or school district can impact the implementation of a new policy. In times of overall economic prosperity, schools are more likely to receive the resources needed to achieve full implementation. In times of recession, however, school systems may see drastic reductions in revenue because of decreased economic activity or a changing population. In such an economy, portions of a policy may be omitted or the implementation efforts may be dropped altogether unless the policy promises to bring additional funds to the district (Sabatier \& Mazmanian, 1983). A sluggish economy can also cause school systems to seek grants from private organizations though doing so may require them to contemplate policy changes they might not otherwise consider. For example, the Bill and Melinda Gates Foundation website states "We fund work that meets our grant-making priorities and supports our guiding principles" (Bill \& Melinda Gates Foundation, 2011, para. 1). School systems desperate for funds from this organization would likely examine how closely their 
policies align with the foundation's priorities and consider if changes in policy are necessary to become more attractive to a grant selection committee.

Policy adoption. Adoption is the fourth phase in the policy process and occurs when a governing body accepts a proposed policy and provides it with legitimacy (Dunn, 1977). The WVBE is granted its legal authority by The Constitution of West Virginia Article XII, §2 (2012) and W. Va. Code $§ 18-2-5$ (2012). The board acts as an administrative agent to provide direction to the state's schools and can adopt policies consistent with its mission.

An action of the legislature or the courts can provide the stimulus for the State Board of Education to adopt a policy. Legislative proposals are officially introduced as bills and may become laws. These laws can lead to the development of State Board policies. For example, West Virginia Code (2012) §18-2-9(a) states that all schools shall provide one year of instruction in the history of West Virginia prior to the completion of the eighth grade. Accordingly, WVBE Policy 2520.4, $21^{\text {st }}$ Century Social Studies Content Standards and Objectives for West Virginia Schools (2012), lists the eighth grade social studies course West Virginia Studies as a requirement and describes its content.

The judicial system can also cause boards of education to adopt or revise policies. WVBE Policy 2436.10 (2012) describes the requirements for students to be eligible to participate in extracurricular activities. The policy states that students must maintain a 2.0 grade point average and meet all state and local attendance requirements in order to participate in extracurricular activities. WVBE Policy 2436.10 is cited in West Virginia Secondary School Activities Commission Rules Series 2 - Athletics, Provisions Governing Eligibility (2011). School systems use the two documents as the basis for local athletic eligibility policies, but schools now report frequent legal challenges to them. Although many of these cases are dropped, dismissed, or 
settled out of court, legitimate cases can expose flaws necessitating the adoption of revised policies. The attorney for Kanawha County Schools reported the county's athletic eligibility policy had been amended "at least seven times over the past ten years due to misinterpretations and abuse of the rules" (Marra, 2011, para. 17).

Adoption of WVBE policies. It is valuable to understand the procedure by which an authoritative body adopts policies. Since this study will examine the implementation of a policy created by the WVBE, the following section will describe the adoption process for state board policies.

The procedure for the WVBE to establish a procedural, interpretive, or legislative rule is described in W. Va. Code §29A-3B (2012) and in WVBE Policy 1242, State Board of Education Policy Making Process (2012). Proposed board policies must be filed with the West Virginia Secretary of State and the West Virginia Legislative Oversight Commission on Education Accountability. The filing must contain the language of the text as well as "a fiscal note attached itemizing the cost of implementing the rules as they relate to this state and to persons affected by the rules and regulations" (W. Va. Code, 2012, §29A-3B-4(b)). After filing is complete, the proposed policy is distributed to interested parties including local boards of education and Regional Education Service Agencies and made accessible to the public. A public comment period of at least thirty days commences immediately after the proposed policy is filed. The state board has the right to conduct regional public hearings on major education issues or suspend the comment and review period in the event of an emergency as described in W. Va. Code §29A-3B10 (2012). All comments received are reviewed by the state board and the state department of education prior to the proposed policy's final reading. If the state board adopts the policy, the action is filed in the state register and the policy becomes effective on the date stated in the 
policy or thirty days after the filing, whichever is later. If the board does not adopt or withdraw the policy within six months after the close of the comment period, the policy is considered withdrawn (W. Va. Code, 2012). Figure 1 depicts the sequence in events in the adoption of WVBE policies.

Figure 1. Procedure Followed in the Adoption of WVBE Policies

\section{Adoption of WVBE Policies}

W.Va. Code 29A-3B(2012); WVBE Policy 1242, State Board of Education Policy Making Process (2012)

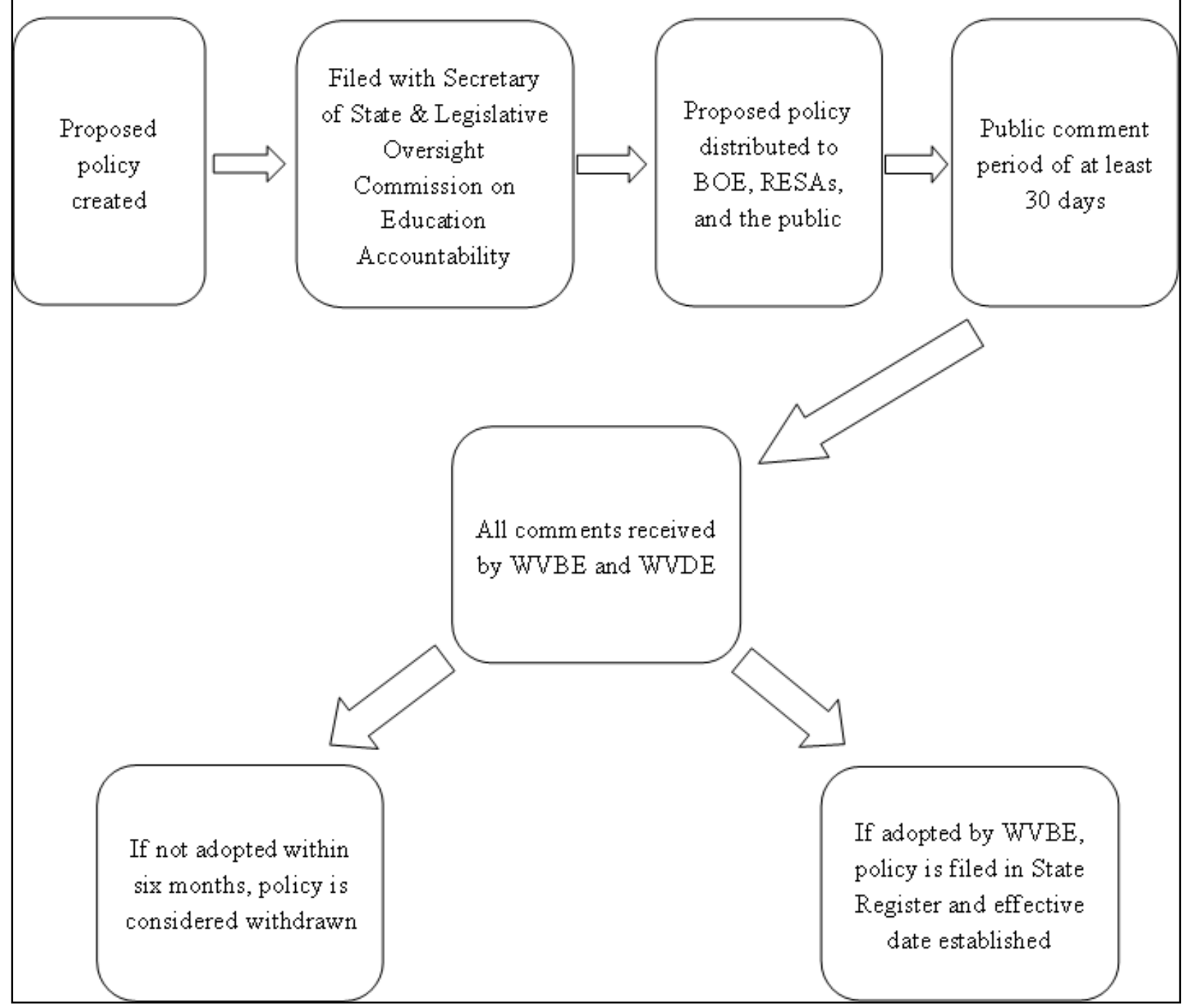


Policy implementation. Policy implementation is the fifth phase in the policy process and has been called "the most difficult of all" (Jerald, 2005, p. 2). This section will define implementation and describe two perspectives of policy implementation. The section will identify five categories of factors that affect policy implementation and describe how each of the factors can either facilitate or impede implementation. The section also includes descriptions of policy implementation stages and overviews of statewide educational policy implementation studies.

Implementation defined. Public policy implementation is defined as the action of carrying out authoritative public policy directives (Nakamura \& Smallwood, 1980). McLaughlin and Elmore (1982) offered a similar but expanded definition of the term after studying the allocation of federal resources intended to affect change in schools. Results of their studies led them to describe implementation as a multi-stage course of action involving federal, state, and local government. The definition used for this study used language provided by both. For this study, public policy implementation was understood to be a multi-stage course of action through which policy directives are carried out by designated levels of government.

Top-down versus bottom-up perspectives. Policy implementation research tends to focus on implementation from either a top-down or bottom-up perspective. "Top-down supporters see policy designers as the central actors and concentrate their attention on factors that can be manipulated at the national level” (Brynard, 2005, p. 9). Top-down scholars define successful implementation as those instances when implementation procedures are consistent with the intentions of the policymakers; any deviation from the intended result is perceived as negative (Williamson, 2009). Sabatier and Mazmanian (1983) conducted top-down research which examined implementation from a policy's origin through its administrative channels. Sabatier 
(1991) applied this research framework to disciplines outside of education to holistically examine the interaction that occurred when policies were developed at one level and administered at another. The research revealed that multiple, small implementation deficits along the way collectively led to the inability to achieve full policy implementation for the target group. Those who have also conducted top-down policy implementation research include VanMeter and VanHorn (1975) and Pressman and Wildavsky (1984).

Others believe implementation should be viewed from the bottom-up perspective that focuses on implementers closest to the target group (Berman, 1978; Elmore, 1979; Weatherly \& Lipsky, 1977). They argue the vantage provided by the front-line implementers - street-level bureaucrats (Weatherly \& Lipsky, 1977) - is more valuable to the understanding of the process. These bottom-up scholars contend that a policy as administered to individuals in the target group is the true policy and that top-down theorists are unrealistic to believe all policies can be uniformly applied in all circumstances. Bottom-up researchers cite situations when practitioners such as teachers and social workers vie for limited resources. Lipsky (1980) contended that "the decisions of street-level bureaucrats, the routines they establish, and the devices that they invent to cope with uncertainties and work pressures, effectively become the public policy they carry out" (p. xii). Similar, more-recent, studies affirm the power street-level workers have as policy implementers. Through a series of interviews with police officers, teachers, and counselors, Maynard-Moody and Musheno (2003) reported street-level work is "rule saturated but not rule bound" and determined "rules and procedures can never universally fit each case and every circumstance" (p. 10). Most of those interviewed in their bottom-up research reported using personal discretion in applying policy and frequently made exceptions based on the perceived character and personal circumstances of their clients. 
Although top-down and bottom-up studies examine implementation from different perspectives and make unique observations along the way, both frequently arrive at similar if not precisely the same conclusions. In fact, synthesis theorists have emerged which incorporate aspects of both approaches (Williamson, 2009). This study acknowledged the presence of the top-down and bottom-up views and incorporated elements of each. This study collected bottomup data from street-level bureaucrats (e.g., principals, counselors, distance learning contacts) as they implemented a top-down policy (WVBE Policy 2450). This study did not seek to determine the success or failure of the policy, only perceptions of factors important to its implementation.

Factors affecting policy implementation. Implementation is a complex phase in the policy process that is affected by five categories of factors: (a) people, (b) communication, (c) resources, (d) structures, and (e) culture. Implementation is impacted by how policy actors regard each. Any of these five categories of factors may facilitate or impede implementation. Just as careful consideration of these factors can lead to implementation success, failure to give them appropriate consideration can lead to undesired results. These five will be examined individually by first considering their importance to implementation and then explaining how they can impede implementation. Figure 2 illustrates the categories of factors that affect policy implementation. 
Figure 2. Categories of Factors Affecting Policy Implementation

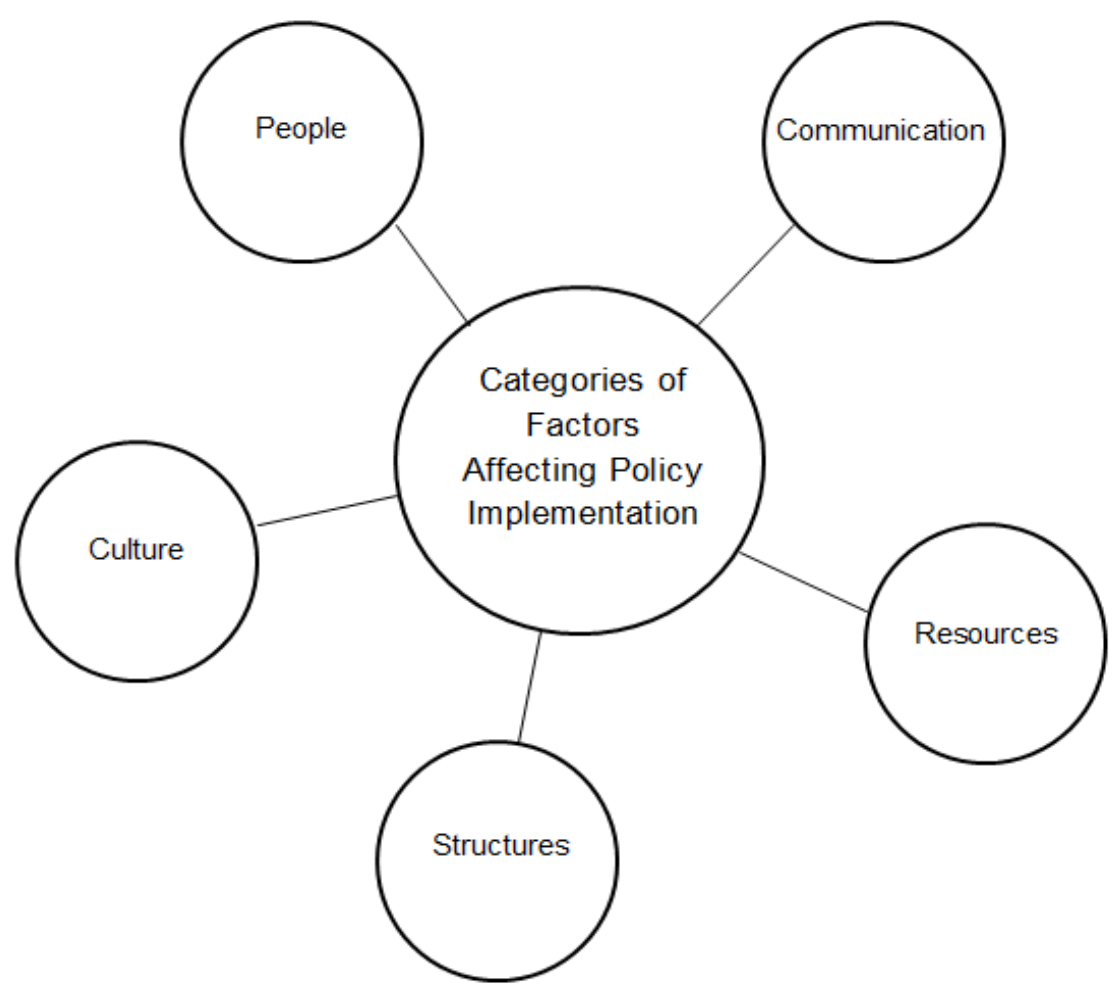

People. In their definitions of policy, Bryson and Crosby (1992) and Firestone (1989) discussed the impact of people on policy implementation. These researchers described policy as the chain of substantive decisions, commitments, and actions of individuals rather than institutions. They also asserted that the true content of a policy is dependent on the people directly involved in its implementation.

Fowler (2009) identified two types of individuals who play crucial roles in the implementation phase: formal implementers and intermediaries. Formal implementers are the "major actors in the implementation arena" (Fowler, 2009, p. 270). They consist of government officials with the legal authority to see that new policies are put into effect. In policies originating at the federal level, the Secretary of Education and other United States Department of Education officials serve as formal implementers. The State Superintendent of Schools is the 
formal implementer of WVBE policies, and the district superintendent or central office administrators serve as formal implementers for policies created at the local level. Intermediaries are individuals delegated by the formal implementers to carry out the policies' activities and are positioned between the formal implementers and the target population. The term target population is defined as "a particular group of people that is identified as the intended recipient of an advertisement, product, or campaign" (Target population, 2011). Students comprise the target population for most educational policies (Fowler, 2009). The number of intermediaries is greater in federally developed policies than in locally-produced policies and depending on a policy's origin may include state department of education officials, local school boards, superintendents, principals and teachers.

People who implement policy in the manner in which it was intended frequently possess two attributes: will and capacity. "Will" refers to the desire of intermediaries to perform tasks necessary for implementation. "The presence of the will...to embrace policy objectives or strategies is essential to generate the effort and energy necessary to a successful project" (McLaughlin, 1991, p. 147). Will must be sustained for policies to be properly enacted (Fowler, 2009), and incentives for teachers, classrooms, and entire schools are helpful in the effort to sustain will (McLaughlin \& Elmore, 1982). Research indicates an implementer's opinions and attitudes, often an indication of will, are crucial to successful policy implementation. "Whether policy enters the classroom and how it is transformed there seems to be determined, at least in part, by teacher beliefs" (Eisenhart, Cuthbert, Shrum, \& Harding, 1988, p. 137).

Implementers, however, need more than the will to enact a policy. Implementers must also possess the personal capacity to do so. An educator's capacity refers to the skills, abilities, and knowledge derived from his or her training and experiences relevant to the classroom 
(Lopez, 1995). In short, it is the "know-how." WVBE Policy 2460, Educational Purpose and Acceptable Use of Electronic Resources, Technologies and the Internet, states that "Teachers should integrate technology resources to personalize learning, enhance instruction, implement multiple technology-based learning strategies, implement high quality digital content and assessments, and utilize digital resources, technologies, and the Internet in the classroom" (WVBE, 2012, §3.8). That responsibility, however, is reliant upon the teachers' personal instructional abilities to meet this obligation. "All the will in the world cannot overcome lack of capacity or inability to do what the policy requires" (Fowler, 2009, p. 271). People who facilitate policy implementation are those who possess the will and capacity to advance this phase of the policy process.

Just as the presence of an implementer's will plays a major role in the success of policy implementation, the absence of will can lead to a policy's demise. Educators are frequently confronted with school leaders who are not supportive of new policies they feel were imposed upon them by those with greater authority. Kotter (1998) identified unsupportive intermediary supervisors as some of the biggest obstacles in policy implementation and stressed the impact they can have when subordinates sense their lack of support. A lack of will can undermine the collective moral purpose needed in order to enact policies for meaningful change in schools (Fullan, Bertani, \& Quinn, 2004).

Those who lack the capacity to implement policy can also become obstacles. A prominent reason for unsuccessful implementation is the lack of specific skills and knowledge needed by intermediaries. In numerous studies examining implementation efforts that failed, intermediaries confessed they did not fully understand the change to be enacted, did not know how to use new pedagogy, or lost the enthusiasm needed for sustained skill development to 
implement the policy (Bodilly, 1998; Gross et al., 1971; Huberman \& Miles, 1984). Motivated, skilled individuals are more likely to implement policy as intended than those with lesser degrees of will and capacity.

Communication. Communication is the second category of factors that can facilitate policy implementation in schools. School leaders have long realized effective communication increases the odds of successful policy enactment. There are two major reasons: (a) it leads to greater understanding of specific implementation procedures, and (b) it builds ownership and support from stakeholders (Fullan, 2001).

Communication associated with policy implementation may be divided into that which occurs within internal groups (such as information exchanges with implementation intermediaries) and external groups (those who are affected by a policy but have limited participation in the implementation process) (Johnson \& Chang, 2000). Information intended for internal groups tends to be more technical and utilizes specific jargon associated with the policy, i.e., the "fine print" implementation details. In educational policy internal communication may consist of research reports and training manuals. Such information, however, is too voluminous for those with limited interest. Although parents and other taxpayers are stakeholders in the public education system, most of these external group members are not interested in this depth of information. The thirst for information from external groups may be satisfied with policy briefs or media releases. The external group's need for less detailed information, however, should not be interpreted to mean its members can have little or no effect on policy implementation.

Poor communication with intermediaries or those with special interest in a policy can create major obstacles in the implementation phase. Failure to provide clear details about each step in implementation, including the responsibilities of each intermediary, can produce 
undesirable results. This attention to detail is especially true when the implementation chain from the originators to the target population contains an inordinate number of intermediaries. Policy is transformed as it moves from one intermediary to another (McLaughlin \& Elmore, 1982), and each individual involved represents an opportunity for the policy to be misunderstood or mishandled. Unclear responsibilities and procedures can doom policy implementation.

Kotter (1998) warned of the dangers of "undercommunicating" (p. 12) new policies and challenged leaders to take every opportunity to promote their vision of reform. He also challenged leaders to align their behavior with their words: "Nothing undermines change more than behavior by important individuals that is inconsistent with their words" (p. 12). This reminder that "actions speak louder than words" is important as leaders communicate with internal and external groups and may help foster support for a policy to which leaders have demonstrated personal commitment.

Resources. Adequate resources such as money, time, personnel, space, equipment and materials are important to successful policy implementation. While all of these factors affect an organization's capacity to carry out implementation objectives (Lipskey, 1980), this section will focus on the two most frequently mentioned as crucial to success: money and time.

Adequate financial resources are crucial to the implementation of new policies because money can be used to obtain other resources (Fowler, 2009). Berman and McLaughlin (1978) discovered that many educational leaders overestimate the importance of abundant fiscal resources. The manner in which money is spent is more critical than the total expenditure. For example, Louis and Miles (1990) reported that the commonly used practice of providing modest salary stipends to many different participants involved in the implementation of a new policy is essentially wasteful. Research suggests that the best use of money is to pay for ongoing 
assistance for the implementers to a facilitator to oversee the implementation phase (Fowler, 2009).

Time is a fixed resource; no one has more than twenty-four hours in a day. It is therefore imperative for educational leaders to identify and utilize the most effective strategies to allocate and manage this finite resource to accomplish intended results. One frequently used practice to provide relevant professional development is giving implementers released time from their regular responsibilities in order to learn about a new policy and, where possible, practice its use. Providing released time may create the need to employ part-time or substitute teachers so implementers may participate in planning or team meetings. Other practices include using regularly-scheduled staff meetings for professional growth rather than administrative or informational purposes, providing common planning time for teachers most affected by new policies, and scheduling early-released days for students so teachers may learn how to best implement new policies (Abdal-Haqq, 1996).

Just as money and time are important resources to facilitate policy implementation, the lack of either can become a significant obstacle. One example of inadequate funds affecting policy implementation can be found in the American Recovery and Reinvestment Act of 2009 (ARRA). One goal of this massive federal stimulus act was to stabilize state and local education budgets and encourage long-range school reforms leading to increased student achievement. The federal government's $\$ 100$ billion investment in schools was intended to initiate reform efforts that would later be sustained through state support. Designers believed such efforts would reduce pending teacher layoffs in financially challenged districts, produce marked improvements in student learning, and have a positive effect on the country's economy. 
The fiscal inability of states to continue support of ARRA-initiated reforms, however, diminished this massive attempt to create meaningful, lasting changes in education and improvements in the nation's economy. Almost three-fourths of all states reported their state funding for K-12 education had decreased by more than 5\% or remained flat in fiscal year 2011 when compared with the previous year. A similar number of states expected declining or stagnant budgets for K-12 education in fiscal year 2012. Since most of the federal stimulus money would be gone by 2012, many state education leaders predicted state dollars alone would be insufficient to sustain the reform efforts initiated by the ARRA legislation (Center on Education Policy, 2011). Insufficient funds can create discouragement among employees and erode their collective will to implement new policies (McLaughlin \& Elmore, 1982).

The control of fiscal resources is arguably as important as the availability of them. Large numbers of school leaders complain that they have insufficient control of budgets to effectively implement new policies. Less than $50 \%$ of principals believe they have adequate control of the school's budget (Archer, 2004). In addition, local leaders often felt they had a better plan than formal implementers of how funds should be spent to maximize their effect but were unable to distribute the money in that manner because of restrictions in federal and/or state law. Jerald (2005) opined "If school leaders are to be held accountable for making improvement work, they need to be able to reallocate resources away from things that are not helping the school improve and toward new strategies for changing instructional practice" (p. 7).

Implementers often struggle to find the time to learn how to properly implement new policy. Changes in policy usually create the need for implementers to learn new behaviors or practices. Learning how to do things differently requires more time than acting in routine ways (Fowler, 2009). One example of a policy placing additional demands of time on implementers 
can be found in WVBE Policy 2510, Assuring Quality of Education: Regulations for Education Programs (2012). The policy requires West Virginia high schools to annually offer a minimum of four College Board Advanced Placement (AP) Courses or the International Baccalaureate (IB) Program. This policy requirement, however, translates into additional commitments of time from teachers. Those who teach AP Courses must initially attend a four-day Advanced Placement Summer Institute (APSI) delivered through the West Virginia Center for Professional Development or other College Board endorsed APSI. Teachers of AP courses must also attend an APSI once every three years after completing the initial APSI and attend an AP fall workshop every two years (WVBE, 2012). Schools that plan to offer AP Courses must consider the substantial commitments of time required from their staff in order to implement this policy component.

While teachers may be willing for a season to dedicate some additional time and effort to implement a new policy, it is unreasonable to expect them to consistently work twelve-hour days or sacrifice weekends and personal vacations to do so. Fowler (2009) described such excessive demands as "a sure recipe for failure" (p. 292). Principals likewise see time as a major constraint in their attempts to guide implementation of new policies. Many express the desire to be active educational leaders in their schools but find themselves relegated to the task of managing rather than leading. More than $80 \%$ of principals report they must spend some time every day managing facilities, resources, and procedures. Only a minority (27\%) find time every day to guide the development and evaluation of curriculum and instruction (Archer, 2004).

Structure. The fourth category of factors affecting policy implementation is the structure of an organization. For this study, structure refers to the established chain of command in an organization as well as existing laws, policies, and procedures employees must follow in order to 
accomplish their work. Organizational structure in school systems can reduce chaos and promote efficiency. Structure can benefit all aspects of school operation, including instruction, finances, transportation, and personnel management, and can increase employee satisfaction and innovation (Hoy \& Sweetland, 2001).

In the past, schools were organized in a variety of ways ranging from very controlled, tightly-run systems to loosely-connected, independent organizations. Most school systems now resemble a hybrid of the two (Boyd \& Crowson, 2002). Today's school districts display benefits of tightly-run organizations such as centralization and coordination of efforts yet still maintain levels of independence associated with loosely-connected organizations. Such is the case with West Virginia's public schools. Local school systems must comply with federal and state policies, but still have flexibility in the specific organizational structure, policies, procedures, and programs they can use to educate students. Barton's (2010) study found that the level of support provided by the district or state to the local school contributes to policy implementation consistency.

Kotter (1996) determined that structures such as laws, policies, and protocol intended to facilitate work often become obstacles when leaders attempt to make meaningful changes in schools. A 2001 survey of over 900 randomly-selected public school principals revealed that only $30 \%$ believed that the procedures of their school system helped them accomplish their goals. About one-half indicated the only way they could get things done was to work around the system's protocol (Farkas, Johnson, Duffett, \& Foleno, 2001). In a similar study, superintendents also cited the requirement to operate within the established structure as a significant obstacle to reform efforts. The frustration experienced while trying to work within these structures is one of the reasons given by superintendents for leaving the field of education (Farkas et al., 2001). 
Specific laws and policies identified as structural obstacles are those affecting personnel. State personnel laws (such as W. Va. Code §18A-2-2) that provide teachers with the rights of tenure and can bring stability to a school's staff are sometimes perceived as obstacles when administrators wish to make staffing changes. Among the chief complaints of principals is the lack of autonomy to reward exceptional teachers and fire ineffective ones (Farkas et al., 2001).

Some policies cannot be enacted without substantial changes in law, other policies, or the organization's chain of command. Structures are sometimes altered without consideration of the wide-reaching effects the changes may have (McLaughlin \& Elmore, 1982). No policy operates in isolation, and the implementation of one policy may interact or even interfere with the implementation of another. Teachers report that the convergence of conflicting policies is a major condition with which they must learn to cope (Knapp, Bamburg, Ferguson, \& Hill, 1998).

Culture. A fifth category of factors affecting policy implementation is an understanding of how a policy fits into the culture of a school. School culture may be defined as the guiding beliefs and expectations evident in the way a school operates (Fullan, 2007) and consists of the traditional beliefs, norms, and habits (Jerald, 2005). Such values may have become imbedded in the school through repeated communication of common beliefs, and the recognition of heroes and heroines whose actions embody the rituals and ceremonies that reinforce the values (University-Community Partnerships, 2004). A new policy that fundamentally aligns with an existing culture is more readily accepted by those who will be affected.

Even the best efforts to communicate the positive aspects of a new policy do not ensure that it will be widely accepted into a school's culture. A new policy may clash with the deeply ingrained perceptions of what a particular school represents and lead to resistance from external 
groups such as parents and community leaders. "Whether or not the community as a whole has 'bought in' to the policy will impact implementation” (Wood, 2008, p. 35).

Resistance to a new policy can also be found within the school itself. McCarthy (2001) examined the slow pace of school reform in the state of Washington by interviewing the principals or lead teachers in fifteen elementary schools. Findings of the study revealed that faculty members were often significant sources of resistance. Some schools had high levels of teacher individualism and housed staff members who displayed little interest to work collectively to implement new policies. One group of teachers expressed distrust and questioned the motives for a new policy, while another group examined the policy, determined "this too shall pass" (p. 23), and presented minimal commitment. New policies have a much greater likelihood of success, if teachers are given the opportunity to provide input when the policy is being developed (Penuel et al., 2008).

Stages of policy implementation. Policy implementation tends to flow through three stages: mobilization, implementation proper, and institutionalization. The precise beginning and ending of each stage may be difficult to identify. This section will address these stages and reveal critical junctures when implementation is threatened.

Mobilization. Mobilization consists of the initial activities associated with putting a policy into effect such as ensuring amply-prepared staff members and other essential resources are in place. Mobilization has been called the most critical stage of policy implementation (Fowler, 2009). Oversights and omissions at this point can cause intermediaries to lack the capacity to implement the policy as intended by its creators. These circumstances may also diminish the will of intermediaries and seriously lessen the potential for effective implementation. The mobilization stage typically lasts fourteen to seventeen months (Huberman 
$\&$ Miles, 1984) and may take a longer period of time depending on the complexity of the policy being implemented.

Some federal and state educational policies are optional to local schools. For example, West Virginia schools are not obligated to include distance learning in the curriculum although information about doing so is contained in WVBE Policy 2450. One of the first steps in mobilization is to determine whether an optional federal or state education policy should be implemented at the local level. Local boards of education are encouraged to consider three factors when making such decisions: (a) reasons for the policy, (b) appropriateness of the policy, and (c) stakeholder support.

Berman and McLaughlin (1978) identified two good reasons to implement a new policy. The first is when a new policy helps solve a bona fide, well-recognized problem. Policy proponents may find it relatively easy to build support when it appears the policy's provisions will address a specific problem. A second reason to implement a new policy is to build the capacity of individuals so they can later implement other reforms.

Appropriateness may refer to the cultural acceptance of the policy as well as the resource levels available for implementation (Mirel, 1994; Prestine \& McGreal, 1997). Policies which are effective in one geographic area may not be well-received in others. A long-standing tradition of the U.S. educational system has been the concept of local control and the opportunity for districts to consider the particular needs of teachers and schools when aligning with state and local initiatives (Penuel et al., 2008).

Policies that do not have the support of key stakeholders are unlikely to be implemented as originally intended. Support should be carefully assessed and monitored and never taken for granted (Fullan, 2001). Numerous education policies are lost by the failure of policymakers to 
engage principals and teachers in the policy process. In such cases, policy designers find themselves encountering resistance from front-line implementers and having to persuade them to buy into an already-adopted policy (Penuel et al., 2008). Others whose level of support is important to successful education policy implementation include parents, social service agencies, unions, and students (Fowler, 2009).

Mobilization is the stage when details affecting future stages must be considered. It is important that each of the previously-mentioned categories of factors (people, communication, resources, structure, and culture) be in place for the next stage of implementation to commence. Missteps in the mobilization stage, including the adoption of policies which lack good reason, are inappropriate, or lack adequate support, jeopardize policy implementation before the second stage of implementation is ever reached. Specific questions must be asked. Are the funds in place? Have the implementers been trained? Have those who will be affected by the policy change been informed? Individuals serving in leadership roles are encouraged to review implementation plans to eliminate oversights and unintended results.

Implementation proper. Implementation proper is the stage of policy implementation when intermediaries assemble the necessary components of a policy and bring it to life. Implementation proper can be difficult even when mobilization is well-planned because the implementers may need to demonstrate new behaviors on a regular basis. These adjustments can contribute to stress and make implementers feel anxious, tired, overloaded, and depressed (Fowler, 2009). Huberman and Mills (1984) discovered that if a successful mobilization stage preceded the second stage, implementers could more frequently cope with their early frustrations. A rough start can actually be an indicator of future accomplishment (Huberman \& Mills, 1984). The presence of complications usually indicates implementers are exerting genuine 
efforts to make the policy work and have not chalked it up as wasted effort. "Three factors stand out as predictors of ultimate success: (1) a rough start, (2) pressure by leaders to continue trying the new approach, and (3) ongoing assistance of various kinds" (Fowler, 2009, p. 295). New policies should be enacted at a logical point in time, such as the beginning of the school year or a semester (Fowler, 2009).

Implementation proper faces other challenges as time progresses. It is during this time intermediaries may need to debug a project or substitute more effective components of a policy for ineffective ones. Implementer burnout and funding issues are two of the most common reasons for implementation failure in this stage (Fowler, 2009). Teachers may have made personal commitments of time and energy to the new policy and eventually feel it is not worth their continued personal sacrifice. A cut in funding or realization that the amount of money budgeted is insufficient can also lead to disastrous results when activities must be omitted. This can lead to anger and cynicism, especially when leaders propose a new policy in the future (Gross et al., 1971; Huberman \& Miles, 1984; Prestine \& McGreal, 1997).

The level of professional support is especially critical during the implementation proper stage. Three points should be made regarding this support. First, implementers benefit from monitoring and feedback from watchful education leaders. Supervisors may become aware of common problems and be able to correct these situations. The mere presence of supervisors can communicate their interest in the policy to subordinates and provide encouragement to those who may be losing their enthusiasm. Second, technical assistance is critical to sustaining the implementation process. Assistance is the most important form of support (Berman \& McLaughlin, 1978; Fullan, 2001). While there is no single best type of assistance, implementers may benefit from additional training, visits to other sites, meetings with other implementers, or 
just a sympathetic ear (Fowler, 2009). Third, leaders should accept the fact that problems will emerge and make provisions to address them as they occur. Louis and Miles (1990) divided implementation problems into three categories: (a) program-related problems, such as delays, conflicts, or weak coordination; (b) people-related problems, such as lack of implementer skills and skepticism; and (c) setting-related problems, such as insufficient resources and powerlessness regarding key decisions. Louis and Miles (1990) characterized implementation as “a problem-rich enterprise" (p. 272) and described program problems as the easiest to solve, people problems as the next most difficult, and setting problems involving bureaucracy, existing policies and procedures, or physical structures as the most challenging of all.

Institutionalization. Institutionalization is the implementation stage during which an innovation is incorporated into the organization (Gross et al., 1971). It may take a period of time before policies become accepted and ingrained into the normal function of a school or district. Full institutionalization is reached when the policy is no longer considered as new or special and "has been seamlessly integrated into the routine practices of the school or district" (Fowler, 2009, p. 299).

The quest for institutionalization may require a leader to give careful attention to policy funding. New policies are frequently funded as special or innovative projects with soft money (Fowler, 2009). If, however, the newly-implemented policy is to have lasting power, it should not be supported with funds that can evaporate during an economic downturn. Leaders who oversee policy implementation are encouraged to seek stable funding sources to increase the chances of policy institutionalization.

Implementation versus compliance. Full implementation of a policy usually exceeds compliance requirements; however, merely meeting compliance requirements does not ensure 
full implementation. The success of a policy is often exaggerated and any level of accomplishment is actually the result of superficial compliance (Fullan, 2001). Easily implemented and often less intrusive portions of policies are frequently implemented, while those portions requiring more substantive change in practice are ignored. The resulting inconsequential effect of a policy is often viewed as a failure of the policy's content and design when the failure was actually the result of improper implementation (Jearl, 2005). Garn (1999) refers to such erosion from intent to implementation as "slippage," while Huberman and Miles (1984) labeled the downsizing of a policy "midgetizing." The difference between implementation and compliance can be illustrated through the remarks of a Title I director from one state education agency who described his state as having "some perfectly legal but perfectly horrible Title I programs" (McLaughlin \& Elmore, 1982, p. 12).

Policymakers may attempt to force organizations to implement policies. Those in positions of authority can increase the likelihood that policies will be implemented by using four discrete methods: (a) setting rules, (b) conditionally transferring money, (c) investing in future capacity, and (d) granting or withdrawing authority to individuals and agencies (McDonnell \& Elmore, 1987). Two additional strategies available to force implementation are less discrete: investigate and publicize. These actions can lead to the embarrassment of an agency and its officials (Baum, 1984). These strategies are rarely used (Garn, 1999) because leaders realize mere legal compliance does not ensure effectiveness (McLaughlin \& Elmore, 1982).

Research on statewide educational policy implementation. Most of the research found on statewide educational policy implementation tends to rely on case study methodology. Principals and district school administrators were the most frequent participants although some studies also collected data from teachers. A query in the ProQuest Dissertations \& Theses 
database searching for studies conducted in any time period using "policy implementation" as the subject and the descriptors "elementary and secondary education," "public education," and "state education policy" and not "foreign countries" in all fields and text yielded 27 results. This section will provide details about four studies that were relevant to this research. The studies addressed the importance of the following categories of factors to policy implementation: (a) people, including the capacity, will, and attitude of policy implementers; (b) communication; (c) resources; (d) structure; and (e) the culture of a school and community.

Myers (2008) researched the factors impacting teacher efficacy in the implementation of the Reading First Initiative in selected schools. Myers interviewed principals, district reading coaches, and teachers in her case study to collect data about factors that enhanced or undermined an individual's capacity to meet policy goals. Myers found that financial resources were often adequate to implement policies but that the individual and organizational will to implement a policy was a frequent barrier. Will is a necessary attribute of those entrusted to implement policies (McLaughlin, 1991; Fowler, 2009). Myers' study also identified the inflexible structure of the school day as a problem that impeded the full implementation of the Reading First Initiative and indicated that the inflexible nature of structures such as daily schedules can contribute to policy implementation problems.

Shepherd (2001) investigated the implementation of state policy reforms in the areas of school curriculum and instruction in North Carolina. Shepherd conducted a qualitative case study at one school spanning a period of three years in which he interviewed teachers, made classroom observations, and collected artifacts associated with the implementation of a new state policy. Shepherd found that teacher isolation was one of the leading barriers to successful policy implementation. His research also identified teacher attitudes and the level of administrative 
support within a school as critical to implementation. Shepherd's research linked the value of networking among implementers to successful policy implementation. The study's findings also indicated the need for flexibility within some policies to allow teachers the opportunity to make minor adjustments as necessary for successful implementation.

Fowler's (2009) research, much like Shepherd's (2001), identified the value of networking to exchange information and personal implementation experiences when policy implementers are located in different settings. Fowler conducted a case study of special education directors in South Carolina in 2008. In her qualitative research of factors influencing the implementation of the Individuals with Disabilities Education Improvement Act of 2004, Fowler described the pressure special education directors experienced because of the need to implement the new federal law. This pressure coupled with ambiguous guidance from federal and state agencies on how to implement the law forced the directors to rely on each other to create a workable implementation plan. Special education directors relied most heavily on the decision making of colleagues whom they trusted and who were faced with the same accountability and compliance demands. Directors stated that they felt there was a sense of safety in all directors making like decisions in light of the unclear implementation strategies and resorted to mimicking implementation strategies perceived to be most effective.

The research of Moser (2005) confirmed that the absence of policy guidance or poor communication of it can lead to inconsistent implementation. Moser surveyed over 300 Tennessee public high school principals about the disciplinary actions they would select in the enforcement of the state's exclusion policy. Those surveyed were presented with 19 different disciplinary scenarios based on actual occurrences and asked what action they would take. While some incidents would have been treated in the same manner by as many as $70 \%$ of the 
respondents, there was great variation in the handling of 11 of the 19 scenarios. Moser's possible explanations for the variations in a policy's implementation were that some policies grant too much flexibility to implementers, are subject to multiple interpretations, are poorly communicated, or are out of touch with the culture in the school or community. Inconsistent communication and application of policies were identified as implementation problems by McLaughlin and Elmore (1982) and the level of policy acceptance within a school or community's culture impacts implementation (Wood, 2008). The findings of Moser's study support the concepts that (a) the inflexible nature of policy can cause some policy components to act as structures that either facilitate or impede actual implementation, (b) the clarity of a policy and its communication to audiences are important to policy implementation, and (c) the culture of a school and community affect policy implementation.

Policy evaluation. Policy evaluation is the final phase of the policy process. Evaluation is "the systematic investigation of the worth or merit of an object" (Joint Commission on Standards for Educational Evaluation, 1994, p. 3). Regardless of the size of an organization, practically all policy evaluations follow the same general procedures. The steps are: (1) determine the goals of the policy, (2) select items, (3) select or develop data collection instruments, (4) collect data, (5) analyze and summarize data, (6) write an evaluation report, and (7) respond to evaluators' recommendations (Fowler, 2009).

There are four types of policy evaluations that all serve different purposes. Two types of evaluations are legitimate and two are unethical. Summative and formative evaluations are legitimate. Summative evaluations assess the quality of a policy that has been in place for some time and may determine whether a policy should be continued. Because summative assessments may be used to hold implementers accountable, the evaluations are often conducted by those 
outside of an organization. Formative policy evaluations are the result of an ongoing process that permits implementers to make necessary changes during the policy's life. Formative evaluations are designed to help implementers make good decisions during the life of the policy and may use internal evaluators (Popham, 1993).

Two types of "pseudoevaluations” (Stufflebeam, 2002, p. 36) also exist.

Pseudoevaluations are unethical assessments that appear to be sound evaluations but fail to produce and report valid indications of merit and worth. One type of pseudoevaluation is a politically controlled study in which the data collection and dissemination of the final report is carefully controlled to create the desired impression of the policy, whether negative or positive. The second type of pseudoevaluation is a public relations evaluation in which those who commission the study indicate before the study begins what the findings must be. Conclusions of such studies are expected to show the positive effects of a policy and "add luster to the public image that has already been created" (Fowler, 2009, p. 317). Those who commission such studies assure the desired findings will be reached by carefully selecting what data are collected in the study.

\section{Distance Learning and the West Virginia Virtual School}

This study sought to determine the factors that facilitated and impeded implementation of WVBE Policy 2450, Distance Learning and the West Virginia Virtual School, as perceived by principals, assistant principals, counselors, and distance learning contacts and course facilitators in West Virginia high schools. This section defines online learning and virtual schools and provides classifications of virtual schools. The section then provides a brief history of distance learning in the United States and information about the emergence of Policy 2450 and the West Virginia Virtual School. The section concludes with a review of how distance learning courses 
are classified and the benefits and challenges of using distance learning courses in secondary schools.

Definition of online learning. Online learning is a form of distance education "in which instruction and content are delivered primarily via the Internet" (Watson, Winograd, \& Kalmon, 2004, p. 95). Distance education is a type of formal study in which teachers and learners are separated by time or space (Keegan, 1996; Cavanaugh et al., 2009).

Distance education for elementary and secondary students is seen as a solution to several educational problems, including crowded schools, a shortage of secondary courses for remedial or accelerated students, a lack of access to qualified teachers in a local school, and the challenge to accommodate students who need to learn at a pace or in a place different from a school classroom. (Cavanaugh et al., 2009, p. 1)

Other terms are also frequently used to describe online learning. For this study, the terms “distance learning," “online learning," "virtual learning," "digital learning," “virtual schooling," and "e-learning" were viewed as synonymous. The terms "distance learning courses," "online courses," and "virtual courses" were synonymous.

Definition of virtual school. A virtual high school is defined as "a state approved and/or regionally accredited school that offers secondary credit courses through distance learning methods that include Internet-based delivery" (Clark, 2000, p. i). State virtual schools are those which are created by legislation or a state-level agency, and/or administered by a state education agency and/or funded by a state appropriation. The West Virginia Virtual School was created by the West Virginia Legislature in 2000 and was one of 31 state virtual schools in 2010 (Watson, Murin, Vashaw, Gemin, \& Rapp, 2010). 
Some states support distance learning initiatives but, unlike West Virginia, do not have state virtual schools. These states typically offer online tools and resources for schools but do not have centralized student enrollment systems to track students in online courses. One example of a state-led online initiative is the Massachusetts Online Network for Education. Eight states had state-led online initiatives in 2010 (Watson et al., 2010).

Most enrollments in distance learning courses are the result of students supplementing their schedules with one or two classes that are not available at their schools (Glass, 2009). In some cases, these are Advanced Placement courses that provide college credit upon demonstration of content mastery. Students may also face the need to take courses not offered at their school but required for eligibility into specific college majors. Remedial students may enroll in distance learning courses as a means of capturing lost credits rather than dropping out of school (Glass, 2009).

Classification of virtual schools. Watson, Winograd, and Kalmon (2004) grouped virtual schools into five categories: statewide-supplemental programs, district-level supplemental programs, single-district cyber schools, multi-district cyber schools, and cyber charters. This classification of virtual schools is based on the geographic reach of the virtual program and the level of student enrollment (i.e., part-time vs. full-time). This virtual school classification system is the more commonly utilized model (Barbour \& Reeves, 2009).

Statewide supplemental programs are the most prevalent of all virtual schools (Watson et al., 2004). Students enrolled in this type of virtual school take individual courses but are enrolled in a physical school or cyber school within the state. Statewide supplemental programs are authorized by the state and overseen by state education governing agencies. 
The West Virginia Virtual School is a statewide supplemental program. The West Virginia Virtual School is classified as a statewide supplemental program and has no full-time students. "In order for a student to receive credit for a technology-delivered course, he/she must be a student enrolled in a West Virginia public school" (WVBE Policy 2450, 2012, §2.1). The title "West Virginia Virtual School" was used in the original legislation that organized the delivery of state-approved distance learning courses and is not meant to imply that the West Virginia Virtual School has full-time students or issues diplomas. Students taking courses through the West Virginia Virtual School must be enrolled in the courses by a WVDE staff member, and their progress in the courses is checked periodically by the state staff member.

One other category of virtual schools found in West Virginia school districts was the district-level supplemental program. These programs are typically operated by autonomous districts and are typically not tracked by state agencies. Two district-level supplemental programs existed in West Virginia. Harrison County Schools and Kanawha County Schools provided a small number of online courses delivered by their own district online teachers. Students participating in these courses were not enrolled in the West Virginia Virtual School and their individual progress was not monitored by the WVDE.

Distance learning in the United States. Distance learning courses that utilized computers were used at a few colleges as early as the 1960s but became more plentiful in higher education after the introduction of the worldwide web in 1991 (Moore \& Anderson, 2003). Distance learning courses in elementary and secondary schools can be traced to 1996 when the Concord (Massachusetts) Consortium and nearby Hudson Public Schools partnered and created Virtual High School. Its goal was to pool teaching resources and increase course offerings to high schools regardless of location (Kozma, Zucker, \& Espinoza, 1998). Florida also became a 
leader in online education when the state legislature created Florida Virtual School, an Internetbased public high school in 1997 (Florida Virtual School, 2012). Enrollments in both schools grew rapidly after their creation. For example, students earned over 10,000 half-credit units from the Florida Virtual School in 2001-02.

The number of virtual schools in the U. S. soared soon after the introduction of Virtual High School and Florida Virtual School. Within two years, three states had established virtual schools and three more were in the planning stages (Clark, 2000). By 2001 total virtual school enrollments were estimated to be between 40,000 and 50,000 students (Clark, 2001).

The decade from 2000 to 2010 showed continued expansion of distance learning opportunities. By 2002-2003 over one-third of the nation's public school districts (36 percent) had students enrolled in virtual courses (Setzer \& Lewis, 2005). Many states created their own virtual schools or developed policies to enable the use of distance learning courses provided by vendors in their schools. Private companies such as APEX Inc. and Class.com Inc. emerged, promising to provide high-quality distance learning courses at competitive costs. Virtual charter schools and online homeschool associations were also established. As the sources of distance learning courses grew, researchers found it increasingly difficult to report the precise number of unique students involved in distance learning. Barbour and Reeves (2009) reported the obvious growth in virtual school enrollments during this time but acknowledged that the rapid expansion revealed the need for better accounting of student participation in virtual schools.

The total number of students participating in distance learning continues to increase. In 2011 Virtual High School had 676 participating schools and over 15,000 student enrollments in 425 course sections. Participating schools included 43 international schools and schools located in 30 U.S. states (Virtual High School, 2012). In terms of student enrollment, Florida Virtual 
School is nearly 10 times larger than any other state-led program (Center for Digital Education, 2008). Florida Virtual School had over 122,000 students in nearly 260,000 half-credit

enrollments in 2010-11. Florida Virtual School currently serves students in all 67 Florida school districts, 49 states, and 57 countries. The school has over 1,400 staff members and offers over 110 courses including core subjects, world languages, electives, honors, and 15 Advanced Placement courses (Florida Virtual School, 2012). The International Association for K-12 Online Learning estimates that 1.5 million students in the U.S. took one or more online courses in 2010 (Wicks, 2010).

The use of distance learning in public schools has been accompanied by the creation or modification of state education policies. These policies address a number of delivery issues but especially focus on funding of and student access to distance learning courses. Most states fund online courses differently than those delivered face-to-face. Policies such as those in Nebraska and New Mexico allow state funds to be used for infrastructure to enable access to virtual courses but leave decisions regarding their use and related additional costs to local officials. Georgia students taking online courses during the traditional school day are not charged a fee; however, students who wish to take additional virtual courses to recover lost credits or further enhance their education are charged a fee. Nine states fund district-run online programs but have policies that restrict access to students located within specific geographic boundaries (Center for Digital Education, 2008).

Recent state educational policy changes are likely to even further increase enrollments in virtual learning. Alabama and Michigan now require one online course in a core subject (science, math, English, or social studies) of each high school graduate (Glass, 2009). West Virginia does not require students to complete a distance learning course prior to graduation; however, a recent 
revision in WVBE Policy 2510, Assuring the Quality of Education: Regulations for Education Programs, recommended "that all students complete an online learning experience during grade 9-12” (2012, §5.6).

Teaching in the age of distance learning. The opportunity for K-12 students to participate in distance learning has created some concern among teachers that their positions may be jeopardized. Hassel and Hassel (2011) responded to these fears by proposing "that digital education needs excellent teachers and that the teaching profession needs digital education" (p. 1). The ability to motivate students, assist with time and task management, and help students dig deeper into material and develop higher-order thinking skills, are teaching skills not readily replaced by technology. The teaching profession, however, can benefit from the digital age by enabling teachers to reach more students, attracting and retaining excellent teachers, and boosting effectiveness and job options for average teachers (Hassel \& Hassel, 2011). "Policies and management systems must change in order to make these new arrangements viable" (Hassel \& Hassel, 2011, pp. 6-7).

The proficiency of teachers to utilize today's technology in education is a reflection of their level of digital literacy.

The term 'digital literacy' ... is most closely related to the factor of 'competence'. However, digital literacy is not limited to knowing the facts about certain technology, or knowing how to use it effectively in a certain context. It is also the ability to build and expand the existing skillset with confidence, to retrieve information and guidelines efficiently from the community, and to evaluate and analyze given technology and its use in a correct and objective manner. (Stockman \& Truyen, 2011, p. 811) 
Ongoing advancements in technology necessitate continuing professional development for teachers seeking to improve their levels of digital literacy. Plair (2010) studied the experiences of middle-aged teachers attempting to become more fluent in the use of educational technology in their classrooms. Through multiple case studies spanning five years, Plair discovered teachers who were intimidated by technology but convinced of the need to obtain professional development to improve their proficiency. The teachers in the study were interviewed prior to their training to determine their level of digital literacy and willingness to change their instructional strategies. Follow-up visits to teachers after adequate implementation time identified some who had utilized the training but others who had reverted to previouslyused strategies. "Teachers stressed the need for ongoing support in the form of a knowledge broker to assure continued efficacy and proficiency while integrating technology into their content and their practice" (Plair, 2010, p. iii).

West Virginia Virtual School. This section provides specific information about the West Virginia Virtual School. Information is group into three segments: creation and purpose, structure and management, and funding and fees.

Creation and purpose. The West Virginia Virtual School was created by the West Virginia Legislature in 2000 and is defined in W. Va. Code $§ 18-2 E-9$ (2012). The legislature created the West Virginia Virtual School after reviewing information indicating virtual learning gives students access to courses that would not be available in their area. The legislature determined that more course offerings could be made available through technology, especially to students who are geographically disadvantaged (W.Va. Code, 2012). The legislature also based its decision to create the West Virginia Virtual School on the finding that distance learning enables students to learn at times other than the normal school day and at a different pace. 
The creation of the West Virginia Virtual School occurred when Cecil H. Underwood was serving in his second term as Governor. Much of the groundwork for the West Virginia Virtual School, however, had occurred when Gaston Caperton served as Governor from 1989 to 1997. Caperton helped develop one of the nation's most comprehensive approaches to include technology in the schools. His long range initiative was to place computers in every elementary classroom in the state and to provide educators with the appropriate training to successfully utilize the computers to enhance student achievement (WVDE, 2012d).

The mission of the West Virginia Virtual School is to "assure consistent, high quality education for West Virginia students through courses delivered via technology, promote efficacy and equity in course offerings, and provide options for implementation across the public school system" (WVDE, 2012e, para. 1). The West Virginia Virtual School helps "bridge the barriers of time, distance and inequities for all West Virginia students by providing access to resources" (WVDE, 2012e, para. 1). The West Virginia Virtual School is a statewide supplemental program (Watson et al., 2004) that offers individual courses otherwise unavailable to students in their local schools. School systems are not obligated to enroll students in the West Virginia Virtual School. A West Virginia Virtual School course is not intended to be used when student interest and the availability of a highly-qualified teacher warrant the delivery of the course in the school through traditional means (WVDE, 2012e).

Structure and management. The structure and management of the West Virginia Virtual School is described in WVBE Policy 2450, Distance Learning and the West Virginia Virtual School (2012). Sections of the policy include course approval, management, evaluation of pupil progress, technology access, and funding. Distance learning courses may be approved by the WVDE when curriculum content cannot be delivered due to a shortage of certified personnel, a 
need to provide low-incidence courses, a need to offer a course while the teacher/facilitator renews course-related skills, or any other validated student need to access technology-delivered courses. Each student receiving credit for completion of distance learning courses must be enrolled in a West Virginia public school. WVBE Policy 2450 also states that each county superintendent shall designate a distance learning contact at the school level to ensure distance learning class information is provided to students and parents, any necessary affiliation agreements with the course provider are secured, and that a facilitator has been identified for each course offered (2012).

WVBE Policy 2450 states "Course facilitators located in West Virginia schools may be required to hold specific certification/qualifications based upon provider guidelines that may vary from course to course" $(2012, \S 4.1)$. WVBE Policy 2450 also states that course facilitators shall receive training or technology-delivered instructions pertaining to course organization, classroom management, assessment, and other related issues. The facilitator is expected to monitor student behavior and assist with the delivery of the course at the local site. The facilitator also serves as the person of record who monitors the academic performance of students and is designated to receive reports from the course provider concerning individual student progress. The requirements for course facilitators vary from state to state but they usually are not content experts in the course's subject matter. In many cases, course facilitators are librarians, technology teachers, or teachers who are available to supervise students.

The state director of the West Virginia Virtual School is empowered by WV Code §182E-9 (2012) to review courses and courseware and make determinations and recommendations relative to the cost and quality of the courses and the alignment with the instructional goals and objectives of the state board. Over 250 courses covering 11 different curricular areas are 
currently approved for use in West Virginia. The list and descriptions of approved distance learning courses are contained in the West Virginia Virtual School Course Catalog available on the WVDE website. The West Virginia Virtual School directly provides two of the courses, Spanish and Cisco Computer Networking, and the instructors are WVDE employees. The other courses are provided by 11 outside vendors such as Aventa Learning, Florida Virtual School, and Lincoln Interactive (WVDE, 2012f).

The director of the West Virginia Virtual School consults with an advisory council for guidance. The council originated in 1989-90 and helped develop the legislation and policy for the virtual school. Original council members advocated that the director of the West Virginia Virtual School be empowered to make decisions about daily operations consistent with their intentions (B. Williams, personal communication, Dec. 7, 2011). The council agreed that the virtual school should meet the needs of individual students without displacing teachers in the process. Although the state legislature was and continues to be a major source of funding for the West Virginia Virtual School, the council supported the concept of assessing fees to school systems if enrollments exceed an established number of students per class per school. The presence of a fee structure encourages school systems to seek qualified personnel to offer courses in a face-to-face method and maintains the intention for the West Virginia Virtual School to fill gaps in curriculum without displacing teachers (B. Williams, personal communication, Dec. 7, 2011). The advisory council meets annually to review the status of the school and consider future action.

The number of students enrolled in the West Virginia Virtual School increased from three students in 2000-2001 (WVDE, 2012e) to nearly 2000 students in 2010-11. Over 11,000 West Virginia students received a portion of their K-12 public education through the West Virginia 
Virtual School by enrolling in nearly 19,000 half-credit units between 2003 and 2011(WVDE, 2011a). Figure 3 depicts enrollments in the West Virginia Virtual School between 2003 and 2011.

Figure 3. Enrollments in the West Virginia Virtual School, 2003-2011

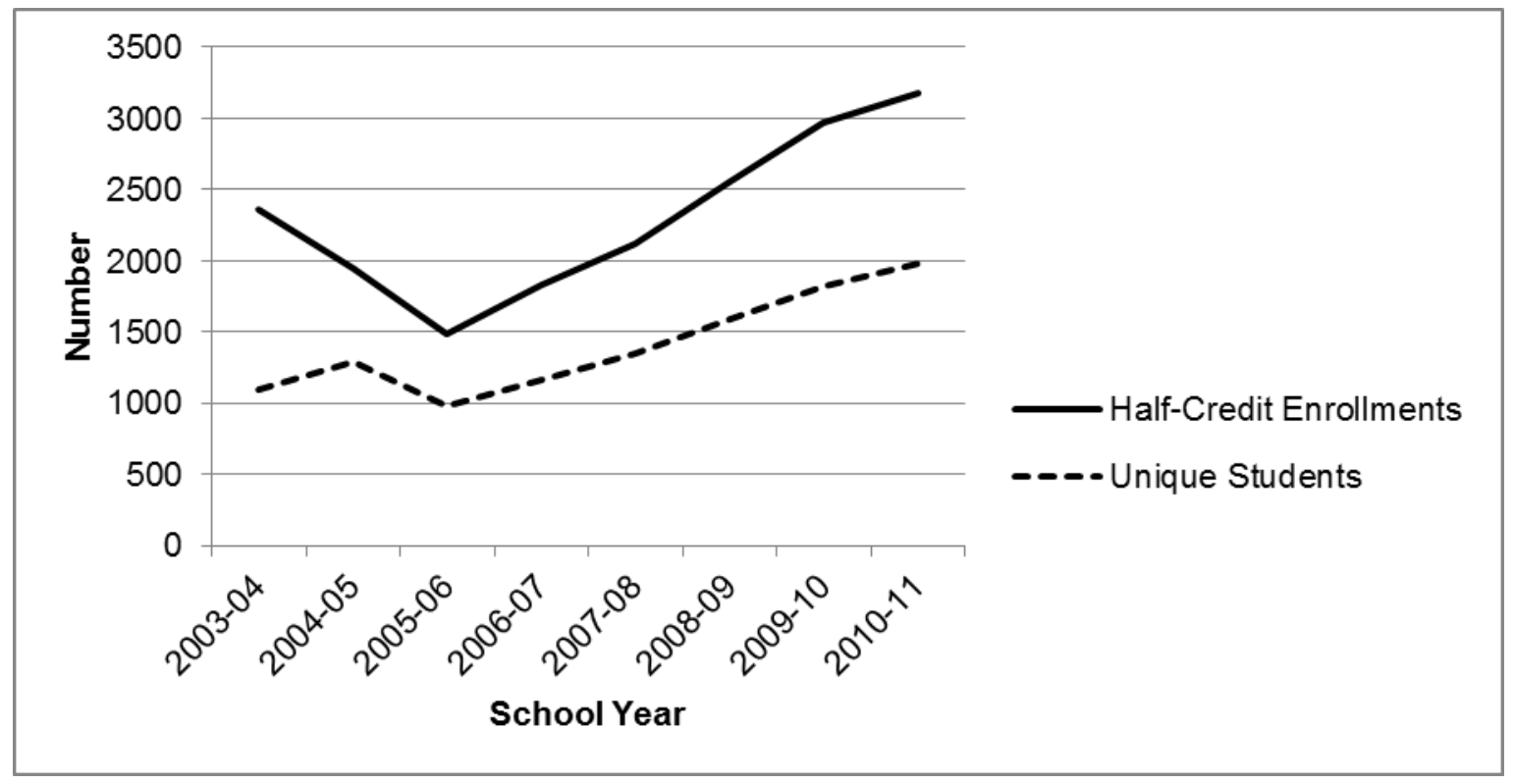

The West Virginia Virtual School performs one additional function by providing 28 online courses through a program called onTargetWV Credit Recovery. "Credit recovery provides students an opportunity to recoup credit from failed courses required for graduation and develop skills and work habits that will contribute to their continued academic success" (WVDE, 2012g, para. 3). The program is intended to reduce the student dropout rate and was piloted in a limited number of schools during the 2010-11 school year. The program became available to all school systems in 2011-12, and over 500 students enrolled in credit recovery courses that year (R. McCoy, personal communication, November 18, 2011). Data associated with onTargetWV Credit Recovery courses were not included in this study since the program was in a pilot phase in 2010-2011. 
Student access to information about available courses and programs is essential if the students are to have the opportunity to enroll in them. Osumi's (2010) survey of high school principals and assistant principals in Hawaii found that the leading source of information for students about academic opportunities was the school counselor. Counselors reported using marketing tools such as school-wide announcements or newsletters to promote programs. When asked what prevented students from participating in a dual credit program, seventy-nine percent of respondents identified "student did not know about the program" as either a very important or important factor (p.108).

Funding and costs. The West Virginia Virtual School receives funding from the West Virginia Legislature to make distance learning courses affordable to school districts. The WVDE serves as the fiscal agent for the West Virginia Virtual School. To affirm the intention of West Virginia Virtual School courses to supplement a school's curriculum rather than replacing courses that could be offered within the school (based on teacher availability and student interest), the West Virginia Virtual School Advisory Council recommended and the WVDE implemented the following fee structure:

Funding for virtual courses and associated materials may be provided through state funding, the school system instructional budgets, or grant awards. Pending the availability of funding, full tuition costs for first 10 students in an individual course per year at a school are paid for through West Virginia Virtual School state funds. Tuition for each student above 10 in the same course, from the same school, is a $\$ 200$ per student cost commitment from the local district. State funds will be used to pay the remaining per student course cost (ranging from $\$ 400$ to $\$ 750$ ). Summer courses may be offered 
through the West Virginia Virtual School but payment for summer enrollment shall be the responsibility of the county or the guardian. (WVDE, 2012h, para. 25)

The fee structure for credit recovery courses is different. School districts must pay $\$ 75$ for each half-credit enrollment to the WVDE to help offset costs. The fees were established after consideration of total costs and projected use of credit recovery courses (S. Gainer, personal communication, December 6, 2011).

Classification of distance learning courses. Distance learning courses can be classified by the amount of content that is delivered online and by the type of interaction between distance learning course teachers and students. This section will provide information about these two methods of classification.

Classification by the amount of content delivered online. The Sloan Consortium studies (Picciano \& Seaman, 2007; Picciano \& Seaman, 2009) defined three categories of virtual courses in K-12 online learning: a) fully online courses, in which at least $80 \%$ of a student's time is spent in online activities and nearly all of the content is delivered online; b) blended (also called hybrid) courses that mix online and face-to face content delivery and 30 to $79 \%$ of the content is delivered online; and c) web-facilitated courses, in which 1 to $29 \%$ of the content is delivered online and technology facilitates what is essentially a face-to-face course.

Blended learning is "likely the fastest-growing segment in online learning" (Watson et al., 2010, p. 8). The two courses provided by the West Virginia Virtual School (Spanish and Cisco Networking) were blended courses (G. Burdette, personal communication, November 29, 2011). Students enrolled in Virtual Spanish courses reported to a classroom each school day and were under the supervision of the designated course facilitator. The online Spanish teachers phoned the class twice per week and usually stayed on the phone for an entire class period to 
monitor student learning and provide time for student practice with the language. The online Spanish teachers visited the class in person once or twice per semester. The online Cisco Networking teacher did not speak to a class as frequently as the Spanish teachers, instead working more directly with the course facilitators to guide instruction. The teacher visited each school approximately every three weeks.

\section{Classification by the type of interaction between teachers and students. Distance} learning courses can be classified into three categories based on the amount and timing of interaction between teachers and students. The three categories using these criteria are (a) independent delivery, (b) synchronous delivery, and (c) asynchronous delivery (Barbour \& Reeves, 2009). Independent delivery is similar to a traditional correspondence course except a computer serves as the medium through which the learning occurs. Although the instruction is under the direction of a teacher, there is little actual involvement between the student and the teacher (Kaseman \& Kaseman, 2000). The course provider usually supplies the materials used by the student and the student essentially teaches the content to himself or herself. Students showing the most success in this delivery method are those who are highly-motivated, self-directed, and/or who like to work independently (Barbour \& Reeves, 2009).

Most courses available through the West Virginia Virtual School used synchronous delivery. Synchronous delivery of distance learning courses requires students to be online simultaneously. Synchronous course classes are usually scheduled during the regular school day with an on-site facilitator physically present with the students. After logging into a course, students are usually able to communicate with the teacher via direct messaging or an online hand raising tool (Murphy \& Coffin, 2003). Online teachers frequently conduct classes as if they were physically present with students by delivering lectures, engaging them in class discussions, or 
assigning them into work groups. The teacher has the ability to conduct public or private conversations with students and assign moderator controls to individual students for presentations.

Students in asynchronous courses are not required to be online simultaneously. They may access the course content at any time desired. Asynchronous delivery of online courses requires "a robust course management system that allows interaction between the teacher and the students and among students themselves" (Barbour \& Reeves, 2009, p. 406). A course management system (also called a learning management system) is a software package that includes communication tools, instructional tools, and assessment features (Watson et al., 2010). Students interact with the curriculum and complete assignments to demonstrate content mastery. The teacher usually then provides feedback in an electronic chat room or by phone or email. This delivery method is more common among schools that serve full-time virtual school students (Barbour \& Reeves, 2009).

Specific studies on distance learning in public high schools. Studies found on the implementation of distance learning in high schools tended to use survey methodology. Some also contained follow-up interviews with respondents. Principals and district school superintendents were the most frequent participants. Very few studies about distance learning collected data from teachers. Most studies indicated a demographic trend that higher enrollments in online courses were found in larger schools but that a greater number of smaller than larger schools utilized distance learning.

This section will provide details about five studies that are relevant to this research. Two of the studies were among the first to collect nationwide data on the reasons public school systems implement distance learning and the obstacles they encounter. The other three are 
doctoral dissertations that identify factors important to implementation of distance learning. Categories of factors addressed include: (a) people, such as the level of support for distance learning from staff members; (b) communication; (c) resources, including equipment, professional development, and technical support for distance learning; (d) structures such as federal, state, or local laws and policies; and (e) culture, including the perceptions of distance learning courses in the school and community.

Setzer and Lewis (2005) conducted the first nationally representative study examining the availability, course offerings, and enrollments in technology-based distance education in the nation's elementary and secondary schools. The absence of data led to a request for the study from the Office of Educational Technology of the U. S. Department of Education. The researchers mailed a survey to 2,035 public school district superintendents who were asked to review the questionnaire and determine the person in the district who was best suited to complete it. Suggested respondents were the director of curriculum, the technology coordinator, or the distance education coordinator. The survey collected data for the 2002-03 school year on the prevalence of technology-based distance education courses across the nation as well as estimated enrollments of public elementary and secondary school students in distance education courses. The survey also requested information on districts' reasons for having distance education courses and factors districts report that prevent their expansion of distance education course offerings. The survey response rate was $94 \%$.

Setzer and Lewis found that about one-third (36\%) of school districts had students enrolled in distance education courses. A greater portion of rural districts (46\%) had students enrolled in distance education courses than did suburban (28\%) or urban areas (23\%). The reason identified as very important for having distance education courses by $80 \%$ of the respondents 
was offering courses not otherwise available at the school. Other reasons frequently cited as very important were meeting the needs of specific groups of students (59\%) and offering Advanced Placement or college-level courses (50\%). Reducing scheduling conflicts for students was mentioned as very important in $23 \%$ of districts. Respondents cited cost of distance learning courses as a major factor that prevented the expanded use of them. Fifty-four percent of respondents said federal, state, or local laws or policies would not prevent them from expanding the use of distance learning courses. Issues regarding technology infrastructure and course quality were identified as factors that would prevent the expanded use of distance learning by less than half of the respondents.

Picciano and Seaman (2007) conducted a national study in the 2005-06 school year of school district administrators to explore the nature of online learning in schools and establish baseline data for more extensive future studies. Issues related to planning, operational difficulties, and online learning providers were examined. A postcard invitation to complete an online survey was mailed to 7,700 school districts. Email invitations and follow-up messages were issued to randomly selected districts, and 1,200 randomly selected school districts were sent a paper copy of a letter of invitation and the survey instrument with a business reply envelope. Responses were received from 366 districts in 44 states. The response rate represented approximately two percent of the public school districts in the U. S. Over $45 \%$ of the responses came from school districts in rural areas. Follow-up telephone discussions were also conducted with selected respondents in an attempt to verify and gain further insights into what was reported on the survey.

Those surveyed in the Picciano and Seaman study were asked to rate a series of factors using a seven-point Likert scale. During data analysis, the seven-point scale was recoded into a 
three-point scale representing levels of importance. Respondents identified five reasons as most important for the use of online learning. The reasons were (a) offering courses not otherwise available at the school, (b) meeting the needs of specific groups of students, (c) offering Advanced Placement or college-level courses, (d) reducing scheduling conflicts for students, and (e) permitting students who failed a course to take it again. The major barriers and issues identified in the study were (a) concerns about course quality, (b) course development and/or purchasing costs, (c) concerns about receiving funding based on student attendance for online and/or blended/hybrid education courses, and (d) the need for teacher training. Issues related to technology infrastructure or government policies were not deemed to be serious by most of the respondents, similar to findings by Setzer and Lewis (2005).

A query in the ProQuest Dissertations \& Theses database searching for dissertations using "virtual learning" as the subject and the descriptors "implementation," "high schools," "public schools," and "barriers" in all fields and text yielded 13 studies. The dates of the studies clustered between 2007 and 2012. Information about three studies relevant to this research will be provided.

Morse (2010) sought to determine school administrators' perceptions of barriers to the implementation of virtual learning in Rhode Island's public schools. Morse utilized a mixedmethods approach in her study and first distributed a survey instrument to 48 district superintendents, acquiring a $60 \%$ response rate. She then conducted personal interviews with five individuals located in two districts: a superintendent, an assistant principal, a technology director, and two virtual learning site coordinators.

Morse's survey instrument contained two demographic questions regarding the district's metropolitan status (urban, urban-ring, suburban, or rural) and enrollment classification (charter 
or non-charter). The remainder of the survey instrument contained Likert-type response items to potential implementation barriers. Categories of factors measured included people (such as the level of support from staff members), resources (such as costs, professional development, time, and technical support), structures (such as federal, state, or local laws and policies), and culture (such as the perception of virtual courses within the community). The interview questions focused on acquisition of resources, opinions about the most important issues related to virtual learning, and obstacles encountered when incorporating online learning.

Morse's findings on what administrators viewed as important about virtual learning differed from earlier research studies in which offering courses not otherwise available and meeting the needs of specific students were primary concerns (Setzer \& Lewis, 2005; Picciano \& Seaman, 2007). Rhode Island school administrators placed the most importance on permitting students who failed a course to take it again. In their interviews, some district administrators reported there had been "pushback" (Morse, 2010, p. 113) and other types of concerns from teacher associations regarding potential replacement of traditional courses with online courses. Those who expressed concerns perceived the implementation of online courses as a move to replace teachers and reduce staff. Other issues highly rated as barriers to implementation of virtual learning were course development and/or purchasing costs, the lack of other sources of funding, and the lack of grants. The technological infrastructure of schools was not viewed as a barrier to the implementation of virtual learning.

Bral (2007) researched the incorporation of online courses in public high school curricula. Two hundred seventy-one principals from Iowa, Missouri, and Nebraska rated survey items to determine which ones were perceived as barriers. The response rate was approximately $25 \%$ and the distribution of responses was fairly even among all three states (Iowa, 35.4\%; 
Nebraska, 33.2\%; and Missouri, 31.3\%). The vast majority of the respondents (86\%) were from small districts of less than 2,500 students. Most of the principals $(63.8 \%)$ indicated they used online classes as part of their curriculum and over half (55.4\%) indicated they wanted to begin using online classes or expand their use in the curriculum. Nearly $12 \%$ indicated they did not want to begin or expand the use of online classes in the high school curriculum.

Respondents in Bral's (2007) study had the opportunity to rate survey items important to the use of virtual courses in the categories of funding, faculty and administration, technology, and implementation. Survey items were indicated in multiple research studies as being potential barriers. A number of the items were drawn from the work of Setzer and Lewis (2005). Possible responses to each item were "not a barrier," "somewhat of a barrier," or "a significant barrier." Of seven potential funding barriers presented, principals rated funding for faculty training as the most significant. Among eight potential barriers associated with faculty and administration, the perception of virtual courses being inferior to face-to-face courses was considered somewhat of a barrier or a significant barrier by over $79 \%$ of respondents. Seven potential technology barriers were presented in the survey but none of them were considered to be barriers by a majority of respondents. As in Morse's (2010) research, issues related to instructional technology were the least reported barriers. Funding for hardware, software, and equipment were not considered a barrier by $46.8 \%$ of respondents, and $79.1 \%$ did not see access to the Internet as a barrier. Fourteen potential barriers related to the implementation of virtual courses were considered. Over $70 \%$ of the respondents indicated they did not believe students have the motivation and/or self-discipline necessary to be successful in online courses. Over $60 \%$ identified conflicts in student schedules as a barrier. Faculty beliefs about the quality of online learning were also reported as barriers to the incorporation of online courses into the curricula. 
Bral's study revealed significant differences in the principals' perceptions of the survey items based on their school's involvement with online courses. Those principals who reported no use of online classes in their schools rated all barrier categories as more severe than did principals who had incorporated virtual courses into the curriculum. Bral recommended that additional studies be conducted to determine the specific reasons why those in schools that currently use online classes have significantly different views of virtual learning than those in schools that do not incorporate online classes in the curricula.

Reviea (2010) conducted an historical analysis of the Virtual VA program, a virtual learning program in Virginia intended to make Advanced Placement and other advanced courses available to students who would otherwise be unable to enroll in these courses in their home school due to budgetary or staffing limitations. Her study consisted of document review and interviews with five administrators of the Virtual VA program. Reviea found that the program had grown quickly through a strong commitment to national and state standards for quality instruction and courses. Strong communication with all stakeholders also contributed to the program's success. Reviea's study led to five recommendations for virtual learning policy: (a) secondary schools should promote the integration of online course work for all students; (b) educational institutions should explore the use of online delivery models for credit recovery, dropout prevention, and other unique student circumstances; (c) schools should explore online learning as a means to better allocate resources in lean economic times; (d) an external research firm should conduct regular and periodic evaluations of the virtual programs; and (e) input about the virtual programs should be collected from parents and staff.

Benefits of distance learning. A review of literature revealed four major benefits of students' participation in distance learning: (a) access to a greater variety of courses, (b) 
exposure to high-quality courses and teachers, (c) greater cost efficiency, and (d) more individualized instruction. This section will provide more detail about these benefits.

One of the most-mentioned benefits of distance learning is students' opportunity to access courses that would not otherwise be available in their schools (Berge \& Clark, 2005; Cavanaugh, 2001; Picciano \& Seaman, 2009; Watson, 2007). Picciano and Seaman (2009) link the limited access of courses to the teacher shortage in the U.S. and the resulting uneven distribution of qualified teachers among subject areas and geographical locations. For example, it has been estimated that high school students in rural areas are less likely to take advanced placement science courses than students in central cities and in suburban fringe areas because of a lack of teachers and resources (United States Department of Education, 2005). The desire to give students expanded access to courses that would not be available in their geographic area was one of the reasons the West Virginia Legislature created the West Virginia Virtual School (W. Va. Code, 2012).

Exposure to high-quality courses and teachers is another benefit of distance learning (Berge \& Clark, 2005; Picciano \& Seaman, 2009; Watson, 2007). "In online instruction, the teacher must combine both instructional and subject-area knowledge with a working knowledge of rapidly evolving online tools for communication and collaboration, content management, and assessment" (Texas Virtual School Network, 2011, para. 2). In 2008 the National Standards for Quality Online Teaching were established to "provide states, districts, online programs, and other organizations with a set of quality guidelines for online teaching and instructional design" (International Association for K-12 Online Learning, 2011, p. 2). Thirteen standards with detailed rubrics were developed after a review of existing standards such as the National Education Association Guide to Teaching Online Courses and the Southern Regional Education 
Board Standards for Quality Online Teaching. The standards are voluntary but some course providers use them as a means to convey to customers their attention to quality instruction (Trotter, 2008). The standards were revised in 2011 and now consist of 11 rather than 13 standards (International Association for K-12 Online Learning, 2011). West Virginia recognizes these standards and utilizes course suppliers who deliver courses according to the standards.

Reduced per pupil cost is another benefit of distance learning (Moe \& Chubb, 2009; Picciano \& Seaman, 2009; Watson, 2009). "Online learning can provide districts with a cost beneficial method of providing courses for students who otherwise would be taught by underqualified teachers or would require the hiring of teachers who would not have enough students to justify their salaries" (Picciano \& Seaman, 2009, p. 6). Moe and Chubb (2009) stated "Schools can be operated at lower cost, relying more on technology (which is relatively cheap) and less on labor (which is relatively expensive)" (p.7). Affordable distance learning courses coupled with financial support from the West Virginia Legislature have provided educational opportunities to students in situations when it would not be economically feasible to offer the courses in a traditional face-to-face manner.

Attention to the individual need of each student is also a benefit of distance learning. Some see virtual learning as an opportunity for schools to provide customized learning opportunities to students based on their interests, abilities, and learning styles (Lips, 2010; Watson \& Gemin, 2009). The notion of giving students the opportunity to work until they master content rather than pushing forward before they are ready has been described as "transformative" (Watson \& Gemin, 2009, p. 5). The WVBE established goals in 2011 that include the desire to provide personalized pathways and guidance for students (WVDE, 2011b). 
Challenges of distance learning. School systems face five challenges in providing distance learning to students: (a) cost, (b) funding, (c) quality of instruction, (d) student assessment, and (e) public perception. This section will provide more detail about these challenges.

The costs associated with virtual courses are frequently cited as a challenge to online learning (Berge \& Clark, 2005; Morris, 2002; Morse, 2010; Picciano \& Seaman, 2009). Facilitating distance learning courses may create significant start-up expenses for schools such as purchasing new hardware, completing necessary infrastructure upgrades, and buying course content from outside vendors. Vendors may require fees to maintain their learning platforms.

Funding is another concern associated with distance learning. Funding differs from costs because costs are expenses to a school system while funding is the system's income. Educational leaders express concern over the lack of state funds, grants, and other sources of funds to support online learning (Morse, 2010). Educational policy development has not kept pace with the advancements in online education (Watson, 2007) and some of the gaps in policy affect funding to schools. Most state funding to schools is based on school enrollments but there is inconsistency among states regarding the inclusion of enrollments in online courses in these calculations. This is especially problematic to school districts that enroll students in virtual courses that originate in other districts or states (Watson \& Germin, 2009). Some fear state support of virtual courses will reduce the amount of funding available to local schools or eliminate teaching positions (Clark \& Berge, 2005). The impact of online courses on school staffs was a concern during the creation of the West Virginia Virtual School (B. Williams, personal communication, Dec. 7, 2011). 
Concern over the quality of the instruction provided in distance learning courses is a long-standing challenge. Many individuals believe virtual courses are less rigorous than traditionally delivered courses (Picciano \& Seaman, 2009). Even the adoption of the National Standards for Quality Online Teaching, intended to improve the quality of instruction and heighten course rigor, did not quiet some critics who believe the standards are well-intentioned but inadequate (Trotter, 2008). In a 2008 Gallup poll (as cited in Barbour \& Reeves, 2009) only $27 \%$ of people were willing to have their child take most of their high school courses online at home without attending a public school. Concerns about rigor are frequently related to the qualifications of those employed to teach online courses for certain vendors. In 2008 a California state court ruled that students whose education is provided by state funding must be taught by a credentialed teacher. The court later vacated its decision when pressured by administrators in schools with substantial enrollments in virtual courses being taught by teachers without credentials (Glass, 2010).

Another challenge to distance learning courses is the issue of student assessment. Black, Ferdig, and DiPietro (2008) concluded that effective means for assessing and evaluating distance learning have not been fully developed. The need for quality assessment led to the creation in 2008 of the National Standards for Quality Online Teaching. The standards were revised in 2011. Five of the eleven standards address the creation, delivery, and proper use of student assessments (International Association for K-12 Online Learning, 2011). A major concern related to assessment involves the quality of the assessments as well as the issue of academic integrity/ cheating. "Those in distance education are faced with a formidable challenge to ensure the identity of test takers and integrity of exam results" (Howell, Sorensen, \& Tippets, 2009, para 1). 
The final challenge to distance learning is the public's perception of it. Online learning is not fully understood by much of the public, and this absence of knowledge leads to misconceptions. Watson (2007) identified common misconceptions about online learning. Some of the misconceptions included: (a) online learning is just a high-tech version of the old correspondence course, (b) online students spend all of their time in front of a computer, (c) online learning is essentially teacher-less, (d) online courses are easy to pass, (e) online learning is only good for highly motivated, highly able students, and (f) online students are isolated from their peers and short-changed on important socialization skills. Distance learning providers and advocates face challenges as they attempt to refute these misconceptions.

\section{Summary}

This chapter began with a review of the literature that describes the meaning of the word "policy" and identified the definition used in this study. This study was built on the understanding that policy consists of the rules, regulations, laws, ordinances, decisions and other actions intended to produce consistent outcomes. The chapter included information about governmental and nongovernmental actors that can affect educational policy. The six phases of the policy process were described with the major portion of the chapter being devoted to policy implementation. Fowler (2009), McLaughlin and Elmore (1982), Fullan (2007), and other researchers described factors that are important to the success or failure of policy implementation. These factors were grouped into five categories: people, communication, resources, structure, and culture.

Four studies specifically related to educational policy implementation were described in this chapter. Categories of factors affecting policy implementation in schools included people (Myers, 2008; Shepherd, 2001), communication (Fowler, 2009; Moser, 2005), resources (Myers, 
2008), structure (Shepherd, 2001), and culture (Moser, 2005). The studies found that these categories of factors have the power to either facilitate or impede the implementation of any policy.

This study investigated the implementation of WVBE Policy 2450, Distance Learning and the West Virginia Virtual School in West Virginia high schools. Distance education is a type of formal study in which teachers and learners are separated by time or space (Keegan, 1996; Cavanaugh et al., 2009). Distance learning (also called online learning or virtual learning) is a form of education which primarily uses the Internet to deliver instruction. The chapter provided an overview of distance learning in the United States and included specific details about the creation, operation, and management of the West Virginia Virtual School.

Five studies specifically related to distance learning were addressed in this chapter. The studies were those conducted by Setzer and Lewis (2005), Picciano and Seaman (2007), Morse (2010), Bral (2007) and Reviea (2010). These studies found that five categories of factors (people, communication, resources, structure, and culture) affect the implementation of distance learning in schools. The studies found that the technology needed by schools for distance learning was usually not a barrier. People's attitudes of distance learning and the acceptance of it as an alternative to face-to-face instruction were frequently identified as barriers. Other specific items affecting the implementation of distance learning were the communication with students, parents, and faculty and existing district policies that affect the acceptance of credits for distance courses. 


\section{Chapter 3}

\section{Research Design}

\section{Introduction}

Chapter Three addresses the methods used to determine the factors that facilitated and impeded implementation of WVBE Policy 2450, Distance Learning and the West Virginia Virtual School, as perceived by principals, counselors, and distance learning contacts and facilitators in West Virginia high schools. This chapter contains the research rationale, the research theoretic, and a description of the study population. The chapter also contains a description of the research procedures used including survey instrumentation and development. Finally, the chapter describes the specific manner in which data were analyzed.

The study sought to answer the following research questions:

1. What are the factors that facilitate the implementation of WVBE Policy 2450, Distance Learning and the West Virginia Virtual School, in high schools according to perceptions of three select groups: (a) principals/assistant principals, (b) counselors, and (c) distance learning contacts and/or distance learning course facilitators?

2. What are the factors that impede the implementation of WVBE Policy 2450, Distance Learning and the West Virginia Virtual School, in high schools according to perceptions of three select groups: (a) principals/assistant principals, (b) counselors, and (c) distance learning contacts and/or distance learning course facilitators?

3. Is there a difference in perceptions of factors important to the implementation of WVBE Policy 2450, Distance Learning and the West Virginia Virtual School, in high schools among three select groups: (a) principals/assistant principals, (b) counselors, and (c) distance learning contacts and/or distance learning course facilitators? 
4. Is there a difference in perceptions of factors important to implementation of WVBE Policy 2450, Distance Learning and the West Virginia Virtual School, in schools with 1\% or greater of the high school students enrolled in distance learning courses between 2008 and 2011 versus schools with less than $1 \%$ of the high school students enrolled in distance learning courses during the same time period?

A survey based on the literature review was developed to gather the perceptions of principals, assistant principals, counselors, and distance learning contacts and/or distance learning course facilitators in 110 West Virginia high schools on how five categories of factors (people, communication, resources, structure, and culture) affected the implementation of WVBE Policy 2450, Distance Learning and the West Virginia Virtual School. The survey asked individuals to respond to items related to the five categories of implementation factors. Data were collected through a five-point bipolar rating scale.

This chapter describes the research design used in this study and is divided into two sections. Section one, Research Rationale, includes (a) an explanation of the research theoretic and (b) criteria and procedures for selecting the study sample. Section two, Research Procedures, examines (a) survey instrumentation, (b) data dissemination and collection, and (c) data analysis.

\section{Research Rationale}

This section addresses two areas of research design. It will first address the characteristics of quantitative research and provide justification why this study was best conducted in this manner. The section will then provide information about the study population including the criteria for selecting these individuals.

Research theoretic. The choice of the research design for a study is affected by factors such as the worldview assumptions of the researcher (e.g., postpositivism, constructivism), the 
inquiry strategies to be used, and the intended methods of data analysis and interpretation (Cresswell, 2009). Two basic types of research design are used in educational studies: quantitative research and qualitative research. Quantitative research gathers data in numerical form that can be grouped in categories or units of measurement. Quantitative data can be acquired through experiments or by other means such as asking participants to complete rating scales or answer closed questions on a questionnaire (McLeod, 2008). Qualitative research differs in that it produces descriptive data collected by the researcher through interviews, observations, or open-ended questions (Miles \& Huberman, 1994). The researcher is the primary instrument for data collection (Merriam, 2002; Patton, 1990) and frequently immerses him or herself into the environment to gain a rich understanding of a problem in its context.

A quantitative descriptive research design was used for this study. Descriptive research is concerned with assessing attitudes and perceptions of respondents (Gay, Mills, \& Airasian, 2009). Quantitative research design is the best method to use if a research problem "calls for (a) the identification of factors that influence an outcome, (b) the utility of an intervention, and (c) understanding the best predictors of outcomes" (Cresswell, 2009, p. 18). This type of research measures information numerically, uses unbiased approaches of data collection, and employs statistical procedures for analysis (Cresswell, 2009).

The researcher approached this study with postpositivist assumptions. "Postpositivists hold a deterministic philosophy in which causes probably determine effects or outcomes" (Cresswell, 2009, p. 7). Data for this study was collected through a survey of principals, assistant principals, counselors, distance learning contacts, and distance learning course facilitators. A postpositivist approach to this data was that the factors associated with the 
implementation of WVBE Policy 2450 likely affected the number of students enrolled in distance learning courses in West Virginia high schools between 2008 and 2011.

Study population. The population of 659 individuals identified for this study consisted of the principals, assistant principals, counselors, and distance learning contacts and/or distance learning course facilitators at 110 West Virginia high schools. These individuals were surveyed because of the roles they played in determining which distance learning courses were made available to students in their schools. It is the responsibility of the local school to approve distance learning courses, facilitate registration of the courses through the West Virginia Virtual School contact, and record the grades for the courses on transcripts (WVDE, 2012h). Principals and assistant principals serve as instructional leaders in schools and their approval and support "is essential to the success of virtual school implementation at the local level. Administrators are responsible for ensuring student access to technology and instructional support" (WVDE, 2012a, para. 1). Counselors assist students in academic program planning and individual course selection (WVBE Policy 2315, 2012). "School counselors are responsible for identifying students who may benefit from virtual courses, helping students identify appropriate courses, and confirming that courses selected align with each student's five year plan" (WVDE, 2012a, para. 2). A distance learning contact is required by Policy 2450 at each school to share information about distance learning courses with students and parents, identify course facilitators, and manage the delivery of the courses at the school. Each school's distance learning contact is to be appointed by the county superintendent (WVBE Policy 2450, 2012). Distance learning course facilitators are expected to monitor student behavior and assist with the delivery of the courses at the local site. A distance learning course facilitator also serves as the person of record who monitors the academic performance of students and is designated to receive reports from the 
distance learning course provider concerning individual student progress (G. Burdette, personal communication, Apr. 6, 2012).

In some schools, individuals served in more than one role as defined in this study. Some principals, assistant principals, and counselors also served as their schools' distance learning contacts and/or distance learning course facilitators. Each individual in the target population was asked on the questionnaire to identify his/her primary role in the school and if he/she also served as a distance learning contact and/or course facilitator. The names, locations, and email addresses of those surveyed were obtained from the WVDE Office of Instructional Technology, WVDE Office of Information Systems, WVDE Office of School Improvement, and WVDE School Directory.

Slightly less than $1 \%$ of all West Virginia high school students (based on unique student count) were enrolled in distance learning courses between 2008 and 2011 (WVDE, 2011a). A school's percentage of students enrolled in distance learning courses was determined by first averaging the school's number of unique students enrolled in distance learning courses in 200809, 2009-10, and 2010-11. The mean number of students enrolled in distance learning courses during those three school years was then divided by the mean second month total school enrollment for 2008-09, 2009-10, and 2010-11 to determine the percentage of students in the school enrolled in distance learning courses. All of West Virginia's public high schools $(\mathrm{N}=116)$ were then placed in rank order based on this calculation and a school code was assigned to maintain anonymity (Appendix B). Sixty-one of the 116 schools had 1\% or more of their students enrolled in distance learning courses (at or above the state average after rounding). Fifty-five out of 116 schools had less than $1 \%$ of the student enrolled in distance learning courses (below the state average after rounding). In order to invite similar numbers of respondents to 
participate in the study, fifty-five schools with $1 \%$ or more of their students enrolled in distance learning courses were placed in one group (Group A) and the 55 schools with less than $1 \%$ of their students enrolled in distance learning courses were placed in a comparison group (Group B). The six schools eliminated from inclusion in Group A in order to have groups of similar size were the overall top two schools in the ranking (School Codes 001 and 002) and the four schools appearing at the bottom of the group of 61(School Codes 058-061). The percentage of the student participating in distance learning courses in the top two schools was so high in these schools (50\% and 30\% participation, respectively) that they were considered statistical outliers. An outlier is an observation in a sample lying outside of the bulk of the sample data (Lee, 2008). The other four schools eliminated had participation rates ranging from $0.53 \%$ to $0.57 \%$. A summary of those surveyed in this study is provided in Table 1. 
Table 1

Individuals Surveyed Regarding Implementation of Policy 2450, Distance Learning and the West Virginia Virtual School

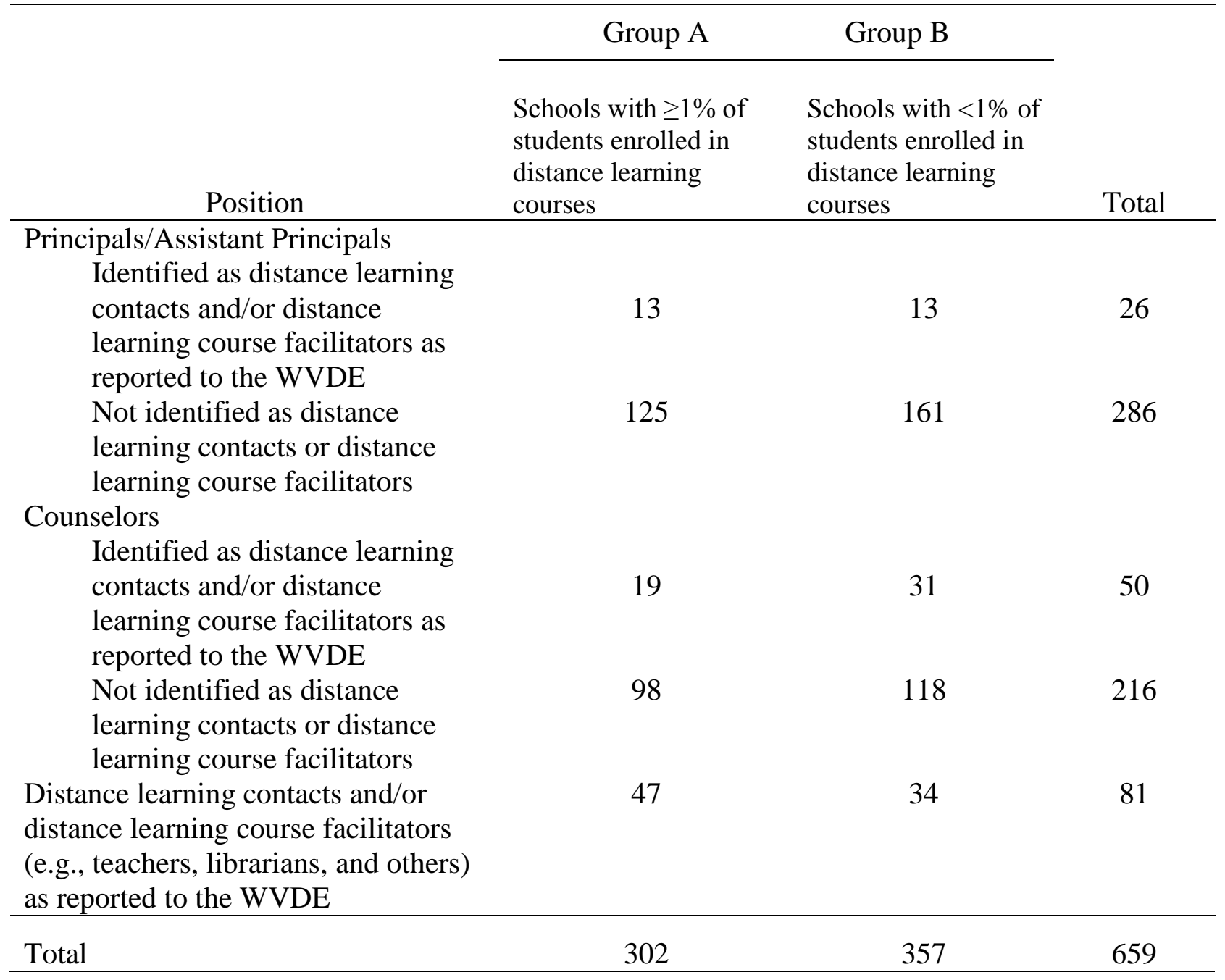

The target population was identified in the following manner:

1. The WVDE Office of Instructional Technology supplied a list of distance learning contacts and distance learning course facilitators in all West Virginia public high schools.

2. The list was compared to the list of principals and assistant principals that had been provided by the WVDE Office of Information Systems. Twenty-six principals/assistant principals were identified as distance learning contacts and/or distance learning course 
facilitators in their schools. A total of 286 principals/assistant principals were not identified as distance learning contacts or course facilitators.

3. The list of distance learning contacts and course facilitators was then compared to the list of guidance counselors provided by the WVDE Office of School Improvement. The WVDE School Directory and individual school websites were consulted when information for specific schools had been omitted from the Office of School Improvement's list. Fifty counselors were identified as distance learning contacts and/or distance learning course facilitators. A total of 216 counselors were not identified as distance learning contacts or course facilitators.

4. The remaining 81 distance learning contacts and/or course facilitators were teachers, librarians, or other position titles (e.g., technology integration specialist).

All individuals invited to participate in the study were sent an email describing the purpose of the research and explaining that participation was voluntary and included the right to omit items an individual did not want to answer. The email ensured anonymity and confidentiality of information; no data reflecting responses from specific schools was to be released. Finally, the email contained the researcher's contact information and informed participants of the opportunity to voluntarily provide contact information if they wished to participate in a drawing for gasoline cards given in appreciation for completing the surveys. Respondents could also provide contact information if they wished to receive a copy of the study's results upon completion.

\section{Research Procedures}

Survey instrumentation. The research population was sent a link to a self-reporting, web-based survey developed utilizing Qualtrics, a widely-used commercial grade surveying 
software product. The online survey contained items representing the five categories of policy implementation factors identified in the literature and a rating scale to indicate to what degree respondents believed each specific item facilitated or impeded the implementation of WVBE Policy 2450. The survey method is useful for investigating a variety of educational problems and issues. It is effective in collecting data related to attitudes, preferences, demographics, and practices (Gay, Mills, \& Airasian, 2009). There are three advantages to using surveys rather than telephone or personal interviews: (a) surveys provide an efficient way to collect data, (b) surveys are useful for collecting information on sensitive matters, and (c) survey research is economical (Patten, 2011).

The survey used for this study contained a bipolar rating scale. A bipolar scale is characterized by a continuum between two opposite end points. "A central property of the bipolar scale is that it measures both the direction (side of the scale) and intensity (distance from the center) of the respondent's position on the concept of interest" (Kennedy, 2008, p. 64). Five and seven-point scales are the most commonly used bipolar scales (Kennedy, 2008). Bipolar scales have similar qualities to Likert scales by using bipolar and balanced response sets. Like Likert scales, they are subject to response distortion and central tendency bias resulting from responder reluctance to select extreme response categories (Brill, 2008). It is common for researchers using five or seven-point rating scales to combine groups of data into one or two corresponding categories for data analysis.

Survey development. An extensive review of literature did not reveal a pre-existing survey that was applicable for this study, and it became necessary for the researcher to develop a survey to address the research questions. Survey development should be based on the principles of accuracy and relevancy (Iarossi, 2006). Biemer and Lyberg (2003) provided three goals to 
consider when designing surveys: (a) write items that convey the meaning of the inquiry exactly as the research is intended, (b) provide the correct manner to retrieve the most accurate information possible from respondents, and (c) minimize the time burden on respondents in proportion to the analytical requirements of the survey.

"The kinds of questions a survey author should create are based on two things: the objectives of the survey and the information to be collected" (Survey Monkey, 2011, p. 4). Survey authors use their skills to turn the objectives of a study into a set of information requirements and from there develop items-that accurately provide the desired information (Brace, 2008). Iarossi (2006) established four criteria to guide the construction of survey items: (a) be brief, (b) be objective, (c) be simple, and (d) be specific. Other recommendations for survey item construction include using words and expressions familiar to all respondents, avoiding the use of words such as "always," "never," "only" or "just," and avoiding leading questions (Iarossi, 2006).

The review of literature about policy implementation and distance learning provided information that was used in the development of survey items. The review of literature identified five categories of factors that influence policy implementation: people, communication, resources, structure, and culture. A survey consisting of 35 items was developed from specific references cited in the review of literature addressing the five categories. Each item was related to an implementation factor category. Each group of items was followed by a text box in which respondents could write comments. The comment section provided an opportunity for respondents to clarify any of the ratings they had made in that section. The survey items and their corresponding implementation factor categories are shown in Table 2. The survey instrument is 
found in Appendix C. A matrix displaying the relationship between the literature and the survey items is found in Appendix D.

Table 2

Survey Response Items and Corresponding Implementation Factor Categories

\begin{tabular}{cc} 
Survey Response Item & $\begin{array}{c}\text { Implementation Factor } \\
\text { Category }\end{array}$ \\
\hline Items 1-7 & People \\
Items $8-12$ & Communication \\
Items 22-29 & Resources \\
Items 30-35 & Structure \\
\end{tabular}

Four additional items in the survey were demographic questions. Item 36 was a question that asked respondents to indicate the primary role in which they served in their high schools (principal, assistant principal, counselor, librarian, teacher, or other). This item was needed to appropriately disaggregate data to answer Research Question 3. Item 37 was a question that asked how long the individual had served in the role identified in Item 36 . The length of time individuals are in the same position in a school can impact the level of resistance to new policies. Item 38 was a question that asked individuals to indicate if they were directly involved in virtual learning in their school by serving as the distance learning contact, a distance learning course facilitator, or both. Individuals could also write other ways they were involved in virtual learning. Item 39 was a question that asked respondents to indicate their school's total enrollment in grades 9-12 (less than 450 students, 450 to 800 students, or over 800 students). The enrollment figures used in these possible responses represented near equal distribution of West 
Virginia high schools based on grade 9-12 enrollments. Information about school and/or district enrollments was collected in a number of studies including those of Setzer and Lewis (2005), Bral (2007) and Morse (2010). School and/or district size provided basic descriptive information about respondents' locations in most studies and was used in some as a way to establish comparison groups for data analysis. Frequently-asked demographic questions regarding age and gender were not included in the survey because Hauge's (2008) study found that age and gender did not influence respondents' perceptions of distance learning. Demographic questions are sometimes perceived as unrelated to the topic of a survey and are generally placed last (Patten, 2011).

The survey instrument was posted at two Internet sites using two different web addresses. In order to create the comparison groups needed to answer Research Question \#4, it was necessary to know if responses were being provided by those from a school at or above the $1 \%$ distance learning course enrollment level (Group A) or below the 1\% enrollment level (Group B). Assigning those in Group A to one URL and those in Group B to another eliminated the need for respondents to know the precise percentage of students enrolled in distance learning courses in their schools.

Validity and reliability. Validity is defined as the extent to which an instrument measures what it is supposed to measure (Anderson, 1998). "Validity is the most important characteristic a test or measure can have. Without validity, the interpretations of the data have inappropriate (or no) meaning” (Gay, Mills, \& Airasian, 2009, p. 158).

Reliability is defined as the ability of a survey instrument to consistently measure what it proposes to measure (Black \& Champion, 1976). Reliability is related to the level of confidence a researcher can place in a study. Highly reliable data collection instruments are those that 
collect essentially the same data if the instruments were used with the same respondents at another time or by different individuals (Gay, Mills, \& Airasian, 2009).

Validity in this study was established by inviting a panel of experts to review the survey instrument before it was administered (Suskie, 1996). Cronbach's alpha, a coefficient of the internal consistency of a test, was calculated to measure the reliability of the research. The next section of the chapter describes these procedures.

Panel of experts. A review by a panel of experts is an effective means of providing validity to a survey instrument. Asking experts to review a survey before it is administered reveals if items are clear and easily understood and have a relationship with the study's topic and goals (Suskie, 1996). Individuals selected to evaluate a survey should include those familiar with the field of study and those who are experts in survey design (Ramirez, 2002).

A panel of four individuals was selected to review and provided feedback on the survey. Two of the individuals were nationally renowned experts in virtual learning. One was an associate professor at a major university who had authored numerous articles and papers about virtual learning, and the other was vice-president of an international online learning association that provided services to state departments of education. The third content expert directed instructional technology initiatives in West Virginia public schools. The fourth individual who served on the panel of experts worked in the WVDE Office of Research and was an expert in survey design.

Panel members reviewing the survey were Dr. Catherine Cavanaugh, Associate Professor of Educational Technology in the College of Education, University of Florida; Dr. Allison Powell, Vice President of State and District Services, International Association for K12 Online Learning (iNACOL); Brenda Williams, Executive Director, Office of Instructional Technology, 
WVDE; and Dr. Steven Whisman, Coordinator, Office of Research, WVDE. The alternate expert was Dr. Anduamlak Meharie, Coordinator, Office of Research, WVDE.

Panel members were invited to participate via an electronic email that briefly described the nature of the study. Upon acceptance of the invitation, a second email was sent containing a draft copy of the survey (Appendix E) and reviewer instructions and response form (Appendix F). Suggestions from the panel of experts were incorporated into the survey prior to its distribution to the sample group.

The panel was asked to review the survey and provide feedback to the following questions (Ramirez, 2002):

- $\quad$ Is each survey item clear and easily understood?

- Is each survey item related to the study's topic and goals?

- Is each survey item important to the research aims?

- $\quad$ Are there survey items that should be deleted? If so, which one(s)?

- $\quad$ Are there survey items that should be modified? If so, which one(s)?

- $\quad$ Are there additional survey items you would recommend? If so, please describe the item(s) and provide a rationale.

- $\quad$ Are the instructions to respondents clear and easily understood?

- Do respondents have adequate assurance of confidentiality and anonymity?

- Is there an unreasonable cost or burden to the respondent population?

Reliability test. Cronbach's alpha is a widely-used measure of internal consistency and was used in this research to measure reliability. Cronbach's alpha is calculated following the collection of data. The formula for Cronbach's alpha is: 


$$
\alpha=\frac{N \cdot \bar{c}}{\bar{v}+(N-1) \cdot \bar{c}}
$$

In the formula, $\mathrm{N}$ is equal to the number of survey items, c-bar is the average inter-item covariance among the items, and v-bar equals the average variance. Reliability values of .70 or higher are recognized standards sought by researchers (Nunnally \& Bernstein, 1994).

Data collection. The population for this survey consisted of 659 principals, assistant principals, counselors, and distance learning contacts and/or distance learning course facilitators located at 110 West Virginia high schools. Emails were sent to county superintendents to inform them of the research before invitations were extended to the survey sample group. The notification to superintendents was sent as a professional courtesy and is found in Appendix G. The names and email addresses of all identified individuals were obtained from the WVDE.

The survey was available online and hosted by Qualtrics. Those invited to complete the survey were provided a website address of the online survey form and an IRB approved statement ensuring confidentiality and anonymity. The text of the email inviting individuals to participate in the study is found in Appendix H.

The survey was made available online at two URLs. Group A was directed to access the survey at one site and Group B accessed the identical survey at a different site. Group assignments were based on the percentage of students in the school enrolled in distance learning courses. Some respondents may not have readily known the level of school enrollment in distance learning courses and may have opted out of the survey if asked to provide that percentage or indicate into which group their school falls. Directing the presorted groups of schools to different web addresses eliminated the need for respondents to indicate into which 
group their school belonged. This strategy should have helped increase response rates. Results were available to the researcher daily on a password-protected website.

Gay, Mills, and Airasian (2009) recommended providing two to three weeks for data completion. For this study, survey dissemination and the data collection process were initiated two days following the superintendents' notice. In an effort to maximize the response rate, the 659 individuals were invited up to a maximum of three times to participate in the study using the automatic email feature of Qualtrics. First, individuals received an invitational email directing them to the web-based survey via the URL. A reminder email was sent two days later to those who had not responded. Those invited to participate received a final email reminder at the end of the first week if they had not yet provided their responses.

Providing incentives is an effective way to increase response rates and the number of early responses (Boulianne, 2008). The invitation to participate in the survey informed individuals of the opportunity to win one of three $\$ 50$ gasoline cards that were given in appreciation for completing the survey. Two cards were awarded to individuals responding within the first week. Those not receiving prizes at the end of the first week were included in a second-chance drawing including all respondents at the survey's closing. Participants were also be given the opportunity to receive survey results at the completion of the study.

The sequence of disseminating and collecting data included the following steps:

Step 1: The survey was sent to the panel of experts for review. Any needed modifications were based upon the panel's feedback.

Step 2: Following the review of the survey instrument, approval to conduct the study was solicited from the West Virginia University Institutional Review Board. 
Step 3: During the Spring Semester 2012, a courtesy email was sent to county superintendents informing them of the study.

Step 4: The population was sent an email message inviting them to participate in the survey.

Step 5: A reminder email was sent out two days after the first message.

Step 6: After two weeks the survey was to be closed and data analysis was to begin.

The target population received e-mail invitations on May 14, 2012, the same day the survey was opened on the Qualtrics website. A reminder was sent to those who had not responded by May 18,2012, and a second reminder was sent on May 25, 2012. The survey was originally intended to close after a two-week time period but the closing date was extended until June 8, 2012. The need for this extension was based on three factors: 1) the entire email system used by West Virginia teachers statewide suffered a catastrophic error and was completely shut down during a portion of the survey period (May 23-24 and May 27-29, 2012); 2) the date the survey was distributed coincided with the first day of the statewide assessment, an event that demanded substantial attention from school personnel; and 3) because of a mild winter, most school systems did not need to adjust their school calendars to extend instruction later into the month of June to make-up days lost to bad weather. The last day of employment for teachers varied among school districts and ranged from May 18 to June 8, 2012 This situation caused many end-of-the-year school activities to occur during the original survey window that may have prevented some individuals from completing the survey within the original time period.

The standard probability level (also called level of significance) used by educational researchers is usually 5 out of 100 chances $(p=.05)$ that an observed difference occurred by chance (Gay, Mills, \& Airasian, 2009). This may also be expressed as a $95 \%$ confidence level 
and confidence interval of 5. Lower levels of significance (e.g., $p=.01$ ) are used in some studies to indicate a lesser likelihood of results occurring by mere chance and provide a higher level of confidence in the results. The survey response rate required to determine if results are statistically significant varies with the established level of significance. Lower levels of significance require higher response rates for results to be viewed as statistically significant. The level of significance for this study followed the standard recognized by educational researchers of a $95 \%$ confidence level and confidence interval of 5.

Response rates to surveys vary greatly and are affected by the interest of the population in the topic, incentives offered, and survey delivery method selected. Response rates for surveys administered by email average $40 \%$ and an email survey response rate of $50 \%$ is considered good. Online surveys average a 30\% response rate (Survey Monkey, 2011). Since this survey was initiated by an email and offers incentives, a response rate of $50 \%$ was anticipated.

Data analysis. Mean scores and standard deviations were calculated for each of the survey items to determine which factors facilitated and which ones impeded implementation of WVBE Policy 2450. The survey instrument utilized a balanced bipolar rating scale that enabled respondents to indicate their responses on a continuum ranging from "significantly impedes implementation" to "significantly facilitates implementation." Scores ranged between 1 (significantly impedes implementation) and 5 (significantly facilitates implementation). Individuals also had the opportunity to select "don't know" as a response to all survey items. Those items scoring 3.6 or higher were viewed as factors that facilitated implementation and those items scoring 2.5 or lower were viewed as factors that impeded implementation.

Tests measuring analysis of variance between perceptions of individuals by position in the school (principal/assistant principal, counselor, or distance learning contact and/or distance 
course facilitator) were performed. Tests of significance (t-independent tests) were administered to determine if there were differences in the perception of implementation factors between respondents at schools with distance learning course enrollments involving $1 \%$ or more of the students and those with less than $1 \%$ of the students. Other post-hoc tests that were performed included Scheffe's test, Levene's Test for Equality of Variances, and the calculation of Cohen's $d$ to determine the magnitude of the differences where they existed. Statistical analysis was performed using Statistical Package for Social Sciences (SPSS).

The specific method of data analysis for each research question was as follows:

Question 1: What are the factors that facilitate the implementation of WVBE Policy 2450, Distance Learning and the West Virginia Virtual School, in high schools according to perceptions of three select groups: (a) principals/assistant principals, (b) counselors, and (c) distance learning contacts and/or distance learning course facilitators?

Responses from all three groups surveyed (principals/assistant principals, counselors, and distance learning contacts and/or distance learning course facilitators) were used to calculate the mean score and standard deviation for each item on the survey. The mean scores for the items were grouped according to the specific categories of factors they measured. These scores were used to determine which (if any) of the five categories of factors were perceived as facilitating the implementation of Policy 2450. Those items scoring 3.6 or higher were viewed as implementation facilitators. Values were reported by item and category. Items were also reported by rank order of values.

Question 2: What are the factors that impede the implementation of WVBE Policy 2450, Distance Learning and the West Virginia Virtual School, in high schools according to 
perceptions of three select groups: (a) principals/assistant principals, (b) counselors, and (c) distance learning contacts and/or distance learning course facilitators?

Responses from all three groups surveyed (principals/assistant principals, counselors, and distance learning contacts and/or distance learning course facilitators) were used to calculate the mean score and standard deviation for each item on the survey. The mean scores for the items were grouped according to the specific categories of factors they measured. These scores were used to determine which (if any) of the five categories of factors were perceived as impeding the implementation of Policy 2450. Those items scoring 2.5 or lower were viewed as factors that impeded implementation. Values were reported by item and category. Items were also reported by rank order of values.

Question 3: Is there a difference in perceptions of factors important to the implementation of WVBE Policy 2450, Distance Learning and the West Virginia Virtual School, in high schools among three select groups: (a) principals/assistant principals, (b) counselors, and (c) distance learning contacts and/or distance learning course facilitators?

The null hypothesis for this question was:

$H_{0}$ : There are no significant differences in the perceptions of principals/assistant principals, counselors, and distance learning contacts and/or distance learning course facilitators regarding the categories of factors affecting the implementation of WVBE Policy 2450 in West Virginia high schools.

The alternative hypothesis for this question was:

$H_{a}$ : There are significant differences in the perceptions of principals/assistant principals, counselors, and distance learning contacts and/or distance learning course facilitators regarding 
the categories of factors affecting the implementation of WVBE Policy 2450 in West Virginia high schools.

An analysis of variance (ANOVA) test was used to determine if there were significant differences in the perceptions among principals/assistant principals, counselors, and distance learning contacts and/or distance learning course facilitators of categories of factors important to the implementation of WVBE Policy 2450. An ANOVA is a statistical technique used to compare groups on possible differences in the mean of a quantitative study (Klugkist, 2008). Results from ANOVA tests either reject or fail to reject the null hypothesis. The ANOVA is limited in its results as a rejection of a null hypothesis does not inform the researcher about which pairs of means differ from each other. If there were significance differences revealed by the ANOVA used in this study, two different post-hoc tests were used. Scheffe's method was used to determine between which groups the differences were found. It was the appropriate posthoc test to use due to variations in size of the comparison groups. Cohen's $d$ was then calculated to give an indication of the magnitude of the differences.

Question 4: Is there a difference in perceptions of factors important to implementation of WVBE Policy 2450, Distance Learning and the West Virginia Virtual School, in schools with $1 \%$ or greater of the high school students enrolled in distance learning courses versus schools with less than $1 \%$ of the high school students enrolled in distance learning courses?

The null hypothesis for this question was:

$H_{0}$ : There are no significant differences in the perceptions of factors important to implementation of WVBE Policy 2450 between respondents in schools with $1 \%$ or greater of the high school students enrolled in distance learning courses and respondents in schools with less than $1 \%$ of the high school students enrolled in distance learning courses. 
The alternative hypothesis for this question was:

$H_{a}$ : There are significant differences in the perceptions of factors important to implementation of Policy 2450 between respondents in schools with $1 \%$ or greater of the high school students enrolled in distance learning courses and respondents in schools with less than $1 \%$ of the high school students enrolled in distance learning courses.

A t-test is a statistical process to assess the probability that a particular characteristic (the mean) of two groups is different (Shapiro, 2008). Levene's Test measures variance homogeneity, which is a precondition for accurate t-test results. If Levene's Test confirmed the assumption of homogeneity, then the corresponding $t$ value and significance value for "equal variances assumed" were reported. If Levene's test indicated that the samples may not have been homogeneous, then that condition was noted and the $t$ value and significance value for "equal variances not assumed" were used. Calculated t-scores resulting from the data collected in this study were compared to established t-values to determine if significant differences between the two comparison groups existed.

\section{Summary}

Chapter Three addressed the methods used in this study to answer questions regarding factors that facilitated and impeded the implementation of WVBE Policy 2450, Distance Learning and the West Virginia Virtual School. This chapter included the research rationale and contained information regarding the research theoretic and selection of the study population. The chapter contained a description of the research procedures including survey instrumentation and development. Finally, the chapter described the specific manner in which data were analyzed. 


\section{Chapter 4}

\section{Data Analysis and Interpretation}

The purpose of this study was to determine the factors that facilitated and impeded implementation of WVBE Policy 2450, Distance Learning and the West Virginia Virtual School, as perceived by principals, counselors, and distance learning contacts and distance learning course facilitators in West Virginia high schools. Responses were collected from selected personnel in West Virginia high schools (e.g., principals/assistant principals, counselors). The perceptions of respondents located at schools that had $1 \%$ or greater of the students enrolled in distance learning courses between 2008 and 2011 (Group A) were compared with those at schools with less than $1 \%$ of the students enrolled in distance learning courses (Group B) during the same time period.

Chapter 4 provides a description and analysis of the data collected utilizing the survey instrument, Factors Affecting Implementation of WVBE Policy 2450, Distance Learning and the West Virginia Virtual School (Appendix C). This chapter includes the return rate and demographic statistics, provides data which address each of the study's four research questions, and concludes with a summary of findings.

\section{Return Rate}

The population for this study consisted of 659 individuals who served as principals/assistant principals, counselors, and distance learning contacts and/or distance learning course facilitators. Table 3 displays survey return data from individuals who served in these types of roles. 
Table 3

Number and Percent of Respondents within the Population

Type of Respondents No. (\%) of Respondents No. (\%) in Population

\begin{tabular}{lcc}
\hline Principals & $37(17.13)$ & $108(16.39)$ \\
Assistant Principals & $52(24.07)$ & $204(30.95)$ \\
Counselors & $82(37.97)$ & $266(40.36)$ \\
Librarians & $13(6.02)$ & $20(3.04)$ \\
Teachers & $21(9.72)$ & $41(6.22)$ \\
Other & $11(5.09)$ & $20(3.04)$ \\
\hline
\end{tabular}

There were 216 respondents to the survey. The greatest number of responses came from counselors $(n=82)$ which also represented the largest number $(n=266)$ in the total population. The remainder of the respondents consisted of 37 principals (17.13\%), 52 assistant principals (24.07\%), 13 librarians (6.02\%), 21 teachers $(9.72 \%)$, and 11 others (5.09\%). Those who marked "Other" identified their primary positions as technology integration specialist, instructional technology support person, director, media specialist, virtual learning mentor and county office employee.

Research Questions $1-3$ asked about the perceptions of three groups: (a) principals/assistant principals, (b) counselors, and (c) distance learning contacts and/or distance learning course facilitators. The individual types of respondents listed in Table 3 were combined to form these groups. The composition and survey return rates of these groups are shown in Table 4. 
Table 4

Group Composition and Survey Return Rates

\begin{tabular}{|c|c|c|c|}
\hline Group & $\begin{array}{l}\text { No. and Type } \\
\text { Respondents }\end{array}$ & $\begin{array}{l}\text { Combined No. (\%) } \\
\text { Respondents }\end{array}$ & No. in Population \\
\hline Principals/Assistant & 37 Principals & & \\
\hline Principals & 52 Assistant Principals & $89(28.53)$ & 312 \\
\hline Counselors & 82 Counselors & $82(30.83)$ & 266 \\
\hline \multicolumn{4}{|l|}{ Distance Learning } \\
\hline Contacts and/or & 13 Librarians & & \\
\hline Distance Learning & 21 Teachers & & \\
\hline Course Facilitators ${ }^{a}$ & 11 Others & $45(55.56)$ & 81 \\
\hline Total & & $216(32.78)$ & 659 \\
\hline
\end{tabular}

${ }^{a}$ Responses were from distance learning contacts and/or distance learning course facilitators who were not principals, assistant principals, or counselors.

The responses from the 37 principals and 52 assistant principals were combined to form a group of 89 Principals/Assistant Principals. The 82 counselors were not combined with any other types of respondents. The 45 distance learning contacts and/or distance learning course facilitators were combined from 13 librarians, 21 teachers, and 11 others who had not been previously identified as principals, assistant principals, or counselors.

Of the 659 individuals invited to complete the questionnaire, 216 responded for a total return rate of $32.78 \%$. Return rates for online surveys average $30 \%$ and those administered by email average 40\% (Survey Monkey, 2011). The survey used for this study was an online questionnaire that was announced by email. The return rate fell within the stated $30 \%$ to $40 \%$ range for this type of survey administration but failed to meet the anticipated return rate of $50 \%$. Principals/assistant principals completed the survey at the lowest rate $(28.53 \%)$ and distance 
learning contacts and/or distance learning course facilitators completed the survey at the highest rate $(55.56 \%)$. The counselor return rate was $30.83 \%$.

Research Question 4 required data from two groups based on student enrollment in distance learning courses. Group A consisted of respondents located in schools that had $1 \%$ or greater of the students enrolled in distance learning courses between 2008 and 2011, and Group $\mathrm{B}$ had less than $1 \%$ of the students enrolled in distance learning courses during the same time period. The composition of the groups is shown in Table 5.

Table 5

Composition of Respondents in Groups A and B

\begin{tabular}{lccc}
\hline & $\begin{array}{c}\text { Group A } \\
\text { Positions of Respondents }\end{array}$ & $\begin{array}{c}\text { Group B } \\
\text { No. (\%) } \\
\text { Respondents }\end{array}$ & Total No. (\%) \\
\hline $\begin{array}{l}\text { Principals / Assistant } \\
\begin{array}{l}\text { Principals } \\
\text { Counselors }\end{array}\end{array}$ & $50(23.15)$ & $39(18.06)$ & $89(41.21)$ \\
$\begin{array}{l}\text { Distance Learning Contacts } \\
\text { and/or Distance Learning }\end{array}$ & $39(18.05)$ & $43(19.91)$ & $82(37.96)$ \\
$\begin{array}{l}\text { Course Facilitators } \\
\text { Total }\end{array}$ & $30(13.89)$ & $15(6.94)$ & $45(20.83)$ \\
\hline
\end{tabular}

${ }^{a}$ Responses were from distance learning contacts and/or distance learning course facilitators who were not principals, assistant principals, or counselors.

As shown in Table 5, 50 (23.15\%) principals/assistant principals were in Group A and 39 $(18.06 \%)$ were in Group B. There were $39(18.05 \%)$ counselors in Group A and $43(19.91 \%)$ in Group B. Twice as many distance learning contacts and/or distance learning course facilitators were in Group A ( $n=30)$ than Group B ( $n=15)$. Group A had a total of $119(55.09 \%)$ respondents and Group B had a total of 97 (44.91\%) respondents. 
The return rates of the two groups were calculated. These return rates are shown in Table

6.

Table 6

Number and Percent Return Rate of Groups A and B

\begin{tabular}{lcc}
\hline \multicolumn{1}{c}{ Positions of Respondents } & $\begin{array}{c}\text { Group A } \\
\text { No. }(\%) \text { Return }\end{array}$ & $\begin{array}{c}\text { Group B } \\
\text { No. (\%) Return }\end{array}$ \\
\hline Principals / Assistant Principals & $50(36.23)$ & $39(22.41)$ \\
Counselors & $39(33.33)$ & $43(28.86)$ \\
Distance Learning Contacts and/or & & \\
Distance Learning Course & $30(63.83)$ & $15(44.12)$ \\
Facilitators & & \\
Total & $119(39.40)$ & $97(27.17)$ \\
\hline
\end{tabular}

${ }^{\mathrm{a}}$ Responses were from distance learning contacts and/or distance learning course facilitators who were not principals, assistant principals, or counselors.

As shown in Table 6, Group A had a total higher response rate (39.40\%) than Group B (27.17\%). Each category of respondents in Group A had a higher response rate than the same category in Group B. The greatest number of responses in Group A was from principals/assistant principals $(n=50)$, and the highest percentage return was from distance learning contacts and/or distance learning course facilitators $(63.83 \%)$. The greatest number of responses in Group B was from counselors $(n=43)$, and the highest percentage return was from distance learning contacts and/or distance learning course facilitators (44.12\%).

A sample size calculator used in statistical analysis was utilized to determine if the return rates were sufficient for results to be viewed at the desired $95 \%$ confidence level and confidence interval of 5. The calculator indicated that a population of 659 requires a sample size of 243 to reach the desired confidence level and interval for this study (Creative Research Systems, 2011). 
The study's 216 responses were insufficient to acquire this standard, calculating to a $95 \%$ confidence level with a confidence interval of 5.47 instead of the desired 5.00.

It is possible to generalize study results to a population even when there are a large number of non-respondents. Late respondents are often similar to non-respondents (Miller \& Smith, 1983). Comparing data from early respondents to late respondents is one method to determine if results represent the entire population. If replies from early respondents are similar to those of late respondents, it can be assumed that the results can be generalized to the population.

The first 40 respondents to the questionnaire were compared to the last 40 respondents to see if similarities existed. The first person to complete the questionnaire began at 6:29 a.m. on May 14,2012 , and the $40^{\text {th }}$ person began the survey at 9:45 a.m. on the same date. The $177^{\text {th }}$ person to complete the survey (the first of the last 40 respondents) began at 8:12 a.m. on May 29, 2012, and the last person to complete the survey began at 11:58 a.m. on June 14, 2012. Demographic data comparing these two groups are shown in Table 7. 
Table 7

Comparison of Demographic Information of Early Respondents and Late Respondents

\begin{tabular}{|c|c|c|c|}
\hline Descriptor & $\begin{array}{l}\text { Early Respondents } \\
\qquad(n=40)\end{array}$ & $\begin{array}{l}\text { Late Respondents } \\
\qquad(n=40)\end{array}$ & $\begin{array}{l}\text { No. Differences } \\
\text { between Early and } \\
\text { Late Respondents }\end{array}$ \\
\hline \multicolumn{4}{|l|}{ Position } \\
\hline Principals & 7 & 7 & 0 \\
\hline Assistant Principals & 10 & 15 & 5 \\
\hline Counselors & 15 & 14 & 1 \\
\hline Librarians & 2 & 2 & 0 \\
\hline Teachers & 6 & 2 & 4 \\
\hline Other & 0 & 0 & 0 \\
\hline \multicolumn{4}{|l|}{ Years in Primary Position } \\
\hline Less than 2 years & 7 & 6 & 1 \\
\hline $2-5$ years & 7 & 14 & 7 \\
\hline $6-10$ years & 6 & 12 & 6 \\
\hline $11-15$ years & 5 & 3 & 2 \\
\hline $16-20$ years & 5 & 0 & 5 \\
\hline Over 20 years & 7 & 4 & 3 \\
\hline No response & 3 & 1 & 2 \\
\hline \multicolumn{4}{|c|}{ Directly Involved in Distance } \\
\hline \multicolumn{4}{|c|}{ Learning? } \\
\hline Yes & 20 & 24 & 4 \\
\hline No & 16 & 15 & 1 \\
\hline No response & 4 & 1 & 3 \\
\hline \multicolumn{4}{|l|}{ How Involved? } \\
\hline Distance learning contact & 12 & 14 & 2 \\
\hline Course facilitator & 10 & 9 & 1 \\
\hline Other & 6 & 8 & 2 \\
\hline \multicolumn{4}{|l|}{ Total Enrollment in School? } \\
\hline Less than 450 & 16 & 12 & 4 \\
\hline $450-800$ & 9 & 17 & 8 \\
\hline Over 800 & 12 & 11 & 1 \\
\hline No response & 3 & 0 & 3 \\
\hline
\end{tabular}

As shown in Table 7, there were five or fewer differences out of the combined 80 early and late respondents in 18 of the 23 possible responses. The only responses exceeding this level 
involved position (more assistant principals were among the late respondents), years in the position (a greater number with 2 to 10 years of experience were late respondents and a greater number of those with 16 to 20 years of experience were early respondents), and size of the school (a greater number of those in schools with 450 to 800 students were late respondents).

The responses to the survey items were analyzed to determine if early respondents were statistically similar to late respondents. The comparisons are displayed in Appendix I. As shown in Appendix I, only one survey item (Survey Item \#28) showed a significant difference between

early respondents and late respondents. Because of the similarities in the demographics of early and late respondents (Table 7) and data in Appendix I that indicate no significant differences in their perceptions on 34 of 35 survey items, the data were assumed to be representative of the entire population. Results were generalized to the entire population.

\section{Demographic Information}

The 659 individuals in the population were located in 110 West Virginia high schools. The schools were divided into two groups. Group A consisted of individuals located in 55 schools that had $1 \%$ or greater of the students enrolled in distance learning courses between 2008 and 2011 and Group B consisted of individuals in 55 schools that had less than 1\% of the students enrolled in distance learning courses during the same time period. Demographic data for the population surveyed included the respondents' primary position in their school, the number of years in that position, whether they were directly involved in distance learning in their school and if so, how they were involved, and their schools' enrollments in grades 9-12. These data were collected via Survey Items 36-39.

In some schools, individuals served in only one role as defined in this study (e.g., principal, counselor, distance learning contact). In other schools, principals, assistant principals, 
and counselors also served as their schools' distance learning contacts and/or distance learning course facilitators. Survey Item \#36 asked "What is your primary position in the school?" The item was answered by 202 individuals. Since this information was especially important to Research Question \#3, follow-up of the responses identified the positions of the 14 who had omitted the question. The positions for all 216 respondents by group are displayed in Table 8 . Table 8

Respondents' Primary Position within the School

\begin{tabular}{|c|c|c|}
\hline Position & No. in Group A & No. in Group B \\
\hline Principal & 22 & 15 \\
\hline Assistant Principal & 28 & 24 \\
\hline Counselor & 39 & 43 \\
\hline Librarian & 10 & 3 \\
\hline Teacher & 15 & 6 \\
\hline Other & 5 & 6 \\
\hline Total & 119 & 97 \\
\hline
\end{tabular}

There were 119 in Group A (i.e., those at schools that had 1\% or greater of the students enrolled in distance learning courses between 2008 and 2011) that participated in the study and 97 in Group B (i.e., those in schools with less than $1 \%$ of the students enrolled in distance learning courses during the same time period). There were more principals $(n=22)$, assistant principals $(n=28)$, librarians $(n=10)$, and teachers $(n=15)$ among Group A's respondents than Group B's. There were more respondents who were counselors $(n=43)$ and others $(n=6)$ in Group B than Group A. Those who marked "Other” identified their primary positions as technology integration specialist, instructional technology support person, director, media specialist, virtual learning mentor and county office employee. 
Individuals were asked how long they had served in their primary positions (Survey Item \#37). There were 201 responses to this item. A summary of the data is shown in Table 9. Table 9

Number of Years Respondents Have Served in Their Primary Positions

\begin{tabular}{lcccc}
\hline $\begin{array}{c}\text { No. of Years in } \\
\text { Primary Position }\end{array}$ & $\begin{array}{c}\text { No. of Principals / } \\
\text { Assistant Principals }\end{array}$ & $\begin{array}{c}\text { No. of } \\
\text { Counselors }\end{array}$ & $\begin{array}{c}\text { No. of Distance } \\
\text { Learning Contacts / } \\
\text { Course Facilitators }\end{array}$ & Total \\
\hline Less than 2 years & 17 & 11 & 2 & 30 \\
$2-5$ years & 31 & 16 & 12 & 59 \\
$6-10$ years & 23 & 18 & 4 & 45 \\
$11-15$ years & 6 & 7 & 6 & 19 \\
$16-20$ years & 2 & 12 & 2 & 16 \\
Over 20 years & 0 & 15 & 17 & 32 \\
\hline
\end{tabular}

${ }^{\mathrm{a}}$ Responses were from distance learning contacts and/or distance learning course facilitators who were not principals, assistant principals, or counselors.

The largest number of principals and assistant principals $(n=31)$ were those who had been in their current positions between two and five years. Among counselors, the largest group $(n=18)$ consisted of those who had been in their current positions between six and ten years. Among other distance learning contacts and/or distance learning course facilitators $(n=17)$, the largest group consisted of those with over 20 years of experience. Collectively, the largest group of respondents $(n=59)$ consisted of those who had been in their current positions for two to five years.

Survey Item \#38 was a multiple part item. Individuals were asked if they were directly involved in distance learning at their schools and, if so, how they were involved. Two hundred individuals responded to the item asking if they were directly involved in distance learning. There were 126 individuals who indicated they were directly involved in distance learning, 
which represents $63 \%(126 \div 200)$ of the respondents to the item. There were 74 individuals who were not directly involved in distance learning, which represents $37 \%(74 \div 200)$ of the respondents to the item.

The 126 who were directly involved were asked to indicate how they are involved. Respondents could select multiple answers. Table 10 contains these data.

Table 10

Ways Respondents Were Directly Involved in Distance Learning ${ }^{a}$

\begin{tabular}{lccc}
\hline \multicolumn{1}{c}{ Position } & $\begin{array}{c}\text { No. Distance } \\
\text { Learning Contacts }\end{array}$ & $\begin{array}{c}\text { No. Distance } \\
\text { Learning Course } \\
\text { Facilitators }\end{array}$ & $\begin{array}{c}\text { No. Not Distance } \\
\text { Learning Contacts } \\
\text { or Course } \\
\text { Facilitators }\end{array}$ \\
\hline $\begin{array}{l}\text { Principals / Assistant } \\
\text { Principals }(n=45)\end{array}$ & 22 & 8 & 21 \\
$\begin{array}{l}\text { Counselors }(n=42) \\
\text { Distance learning }\end{array}$ & 27 & 15 & 14 \\
contacts / course \\
facilitators ${ }^{\mathrm{b}}(n=39)$
\end{tabular}

${ }^{a}$ Respondents could select multiple answers.

${ }^{b}$ Responses were from distance learning contacts and/or distance learning course facilitators who were not principals, assistant principals, or counselors.

Of the 126 respondents who were directly involved in distance learning, a total of 77 indicated they served as the distance learning contact. This was the most frequently selected response of how individuals were directly involved in distance learning. A distance learning contact is a person in the school responsible for distributing information to students and parents, securing agreements, and is authorized to enroll students in distance learning courses offered through the West Virginia Virtual School. Of the three public school groups in this study, 22 of 
the principals/assistant principals, 27 of the counselors, and 28 of the other distance learning contacts/distance learning course facilitators served as distance learning contacts.

Of the 126 respondents who were directly involved in distance learning, a total of 58 indicated they served as distance learning course facilitators. A distance learning course facilitator is the person of record in the school who monitors the academic performance of students enrolled in distance learning courses and is designated to receive reports from the course provider concerning individual student progress. Of the three public school groups in this study, the 58 distance learning course facilitators consisted of eight principals/assistant principals, 15 counselors, and 35 other distance learning contacts/distance learning course facilitators.

Of the 126 respondents who were directly involved in distance learning, 21 principals/assistant principals, 14 counselors, and one distance learning contact/course facilitator indicated they were involved in other ways. Those who were involved in other ways were asked to list how they were involved. Some principals responded that they were the administrator, administrator in charge, or a person who passed along information to the guidance counselor. Counselors indicated they were involved by helping build the master schedule, enrolling students in distance learning courses, or responding to parents' questions.

There were 201 respondents who indicated the size of the school in which they work (Survey Item \#39). Possible response choices were based on the school's total student enrollment in Grades 9-12. Data are summarized in Table 11. 
Table 11

Number of Respondents Located in Schools of Different Size ( $n=201)$

\begin{tabular}{|c|c|c|c|c|}
\hline $\begin{array}{c}\text { Student } \\
\text { Enrollment } \\
\text { (Grades 9-12) }\end{array}$ & $\begin{array}{l}\text { No. of Principals / } \\
\text { Assistant Principals }\end{array}$ & $\begin{array}{c}\text { No. of } \\
\text { Counselors }\end{array}$ & $\begin{array}{l}\text { No. of Distance } \\
\text { Learning Contacts } \\
\text { and/or Course } \\
\text { Facilitators }^{\mathrm{a}}\end{array}$ & Total \\
\hline $\begin{array}{l}\text { Less than } 450 \\
\text { students }\end{array}$ & 23 & 29 & 16 & 68 \\
\hline $\begin{array}{l}450-800 \\
\text { students }\end{array}$ & 31 & 26 & 14 & 71 \\
\hline $\begin{array}{l}\text { Over } 800 \\
\text { students }\end{array}$ & 26 & 23 & 13 & 62 \\
\hline
\end{tabular}

Most respondents $(n=71)$ were in schools of 450 to 800 students. The greatest number of principals/assistant principals $(n=31)$ were located in schools having between 450 and 800 students. The largest groups of counselors ( $n=29)$ and distance learning contacts/course facilitators $(n=16)$ were in schools with less than 450 students.

The data collected about the size of the school was also analyzed to determine the representation of different-sized schools in Group A (schools that had 1\% or greater of the students enrolled in distance learning courses between 2008 and 2011) and Group B (schools with less than $1 \%$ of the students enrolled in distance learning courses between 2008 and 2011). Data are summarized in Table 12. 
Table 12

Number (Percent) of Respondents in Groups A and B by Size of School ( $n=201)$

\begin{tabular}{lcc}
\hline $\begin{array}{c}\text { Student Enrollment } \\
(\text { Grades 9-12) }\end{array}$ & $\begin{array}{c}\text { No. (\%) Respondents in } \\
\text { Group A }\end{array}$ & $\begin{array}{c}\text { No. (\%) Respondents in } \\
\text { Group B }\end{array}$ \\
\hline Less than 450 students & $46(42.20)$ & $22(23.91)$ \\
$450-800$ students & $39(35.78)$ & $32(34.78)$ \\
Over 800 students & $24(22.02)$ & $38(41.31)$ \\
\hline
\end{tabular}

The greatest number of respondents $(n=46)$ in Group A were those located in schools having less than 450 students. The least number of respondents $(n=24)$ in Group A were those located in schools with over 800 students. The greatest number of respondents $(n=38)$ in Group B were those located in schools with over 800 students. The least number of respondents $(n=22)$ in Group B were those located in schools of less than 450 students. Over $40 \%$ of the respondents in Group A were in schools of less than 450 students and over $40 \%$ of the respondents in Group B were in schools of over 800 students.

\section{Reliability of the Survey Instrument}

Reliability of the survey instrument was determined by using Cronbach's alpha, a measure of inter-item reliability. SPSS software was used to calculate the Cronbach alpha value for this study. A reliability value of .70 is considered high for the social sciences. The Cronbach alpha value for the survey was 0.969 , indicating the survey instrument used to gather data for this study was highly reliable.

\section{Research Question 1}

Research Question 1: What are the factors that facilitate the implementation of WVBE Policy 2450, Distance Learning and the West Virginia Virtual School, in high schools according 
to perceptions of three select groups: (a) principals/assistant principals, (b) counselors, and (c) distance learning contacts and/or distance learning course facilitators?

Respondents rated survey items indicating to what degree they believed the items influenced the implementation of Policy 2450. The total number of responses, mean, and standard deviation for each item in the order the items appeared in the survey are displayed in Appendix J.

The complete list of survey items with results from all respondents is displayed in descending order of mean scores in Appendix K. Items having mean scores of 3.6 or higher were identified as those that facilitate the policy's implementation. Twenty-two survey items had a mean score of 3.6 or higher. Of the 22 items identified as facilitating implementation, eight were associated with structures, five were associated with people, four were associated with communication, three were associated with culture, and two were associated with resources. The 22 items identified as facilitating the implementation of Policy 2450 are displayed in descending order of mean scores in Table 13. 
Table 13

Survey Items that Facilitate Implementation of WVBE Policy 2450

\begin{tabular}{|c|c|c|c|c|c|}
\hline $\begin{array}{l}\text { Survey } \\
\text { Item } \\
\text { No. }\end{array}$ & Factor Category & Survey Item & $n$ & $M$ & $S D$ \\
\hline 1 & People & $\begin{array}{l}\text { Support of administrators in local school (e.g., } \\
\text { encouragement to teachers to utilize } \\
\text { technology in instruction, provision of } \\
\text { resources) }\end{array}$ & 210 & 4.33 & .904 \\
\hline 3 & People & $\begin{array}{l}\text { Principal's willingness to include distance } \\
\text { learning courses in the school curriculum }\end{array}$ & 209 & 4.33 & .904 \\
\hline 7 & People & $\begin{array}{l}\text { School counselor as a source of information } \\
\text { about distance learning courses }\end{array}$ & 211 & 4.22 & .992 \\
\hline 2 & People & $\begin{array}{l}\text { Principal's perception of traits needed by } \\
\text { students to be successful in distance learning } \\
\text { courses }\end{array}$ & 208 & 4.18 & .914 \\
\hline 24 & Structures & $\begin{array}{l}\text { Acceptance of credits for distance learning } \\
\text { courses by the county board of education or } \\
\text { diploma-granting authority }\end{array}$ & 196 & 4.02 & .961 \\
\hline 29 & Structures & $\begin{array}{l}\text { Support from West Virginia Department of } \\
\text { Education personnel }\end{array}$ & 189 & 3.93 & 1.021 \\
\hline 9 & Communication & $\begin{array}{l}\text { Information about distance learning courses } \\
\text { made available to students }\end{array}$ & 207 & 3.92 & 1.138 \\
\hline 12 & Communication & $\begin{array}{l}\text { Guidance from the West Virginia Department } \\
\text { of Education }\end{array}$ & 200 & 3.89 & 1.093 \\
\hline 25 & Structures & $\begin{array}{l}\text { Recognition of distance learning courses by } \\
\text { colleges and universities }\end{array}$ & 164 & 3.85 & 1.054 \\
\hline 5 & People & $\begin{array}{l}\text { Skills of distance learning course facilitators in } \\
\text { the school }\end{array}$ & 199 & 3.82 & 1.187 \\
\hline 32 & Culture & $\begin{array}{l}\text { Importance of teacher digital literacy (i.e., } \\
\text { abilities to locate, organize, understand, } \\
\text { evaluate, analyze and create information using } \\
\text { technology) }\end{array}$ & 195 & 3.81 & 1.055 \\
\hline 31 & Culture & $\begin{array}{l}\text { Importance of student digital literacy (i.e., } \\
\text { abilities to locate, organize, understand, } \\
\text { evaluate, analyze and create information using } \\
\text { technology) }\end{array}$ & 197 & 3.79 & 1.075 \\
\hline
\end{tabular}


Table 13. (continued)

\begin{tabular}{|c|c|c|c|c|c|}
\hline $\begin{array}{l}\text { Survey } \\
\text { Item } \\
\text { No. }\end{array}$ & Factor Category & Survey Item & $n$ & $M$ & $S D$ \\
\hline 14 & Resources & $\begin{array}{l}\text { Student access to technology and instructional } \\
\text { support }\end{array}$ & 206 & 3.77 & 1.274 \\
\hline 23 & Structures & $\begin{array}{l}\text { WVBE Policy 2460, Educational Purpose and } \\
\text { Acceptable Use of Electronic Resources, } \\
\text { Technologies, and the Internet (pertaining to } \\
\text { acceptable use of the Internet) }\end{array}$ & 193 & 3.70 & .896 \\
\hline 27 & Structures & $\begin{array}{l}\text { School's ability to maintain academic integrity } \\
\text { (control cheating) in distance learning courses }\end{array}$ & 189 & 3.70 & 1.114 \\
\hline 19 & Resources & $\begin{array}{l}\text { Computer network security (protection from } \\
\text { computer viruses and hackers) }\end{array}$ & 207 & 3.70 & 1.144 \\
\hline 26 & Structures & $\begin{array}{l}\text { Assessment of student learning in distance } \\
\text { learning courses }\end{array}$ & 189 & 3.70 & 1.046 \\
\hline 10 & Communication & $\begin{array}{l}\text { Communication about distance learning } \\
\text { courses with external audiences (e.g., parents) }\end{array}$ & 197 & 3.69 & 1.125 \\
\hline 28 & Structures & $\begin{array}{l}\text { Ability for students to enroll in distance } \\
\text { learning courses without experiencing } \\
\text { scheduling conflicts }\end{array}$ & 195 & 3.68 & 1.181 \\
\hline 22 & Structures & $\begin{array}{l}\text { Established operating procedures in the school } \\
\text { (e.g., daily class schedules, attendance, school } \\
\text { calendar, procedures for recording grades) }\end{array}$ & 197 & 3.66 & 1.020 \\
\hline 11 & Communication & $\begin{array}{l}\text { Clarity of WVBE Policy 2450, Distance } \\
\text { Learning and the West Virginia Virtual School }\end{array}$ & 196 & 3.65 & 1.014 \\
\hline 30 & Culture & Faculty's acceptance of state policy & 185 & 3.63 & .919 \\
\hline
\end{tabular}

Note. Items are displayed in descending order of mean score.

The two survey items receiving the highest overall mean score $(M=4.33)$ were associated with people. These two items were Survey Item \#1, "Support of administrators in local school (e.g., encouragement to teachers to utilize technology in instruction, provision of resources)" and Survey Item \#3, "Principal's willingness to include distance learning courses in the school curriculum.” 
As shown in Appendix L, the survey item rated highest $(M=4.34)$ by principals/assistant principals was Item \#3, "Principal's willingness to include distance learning courses in the school curriculum." As shown in Appendix M, the survey item rated highest $(M=4.40)$ by counselors was Item \#7, "School counselor as a source of information about distance learning courses." As shown in Appendix N, the survey item rated highest $(M=4.37)$ by distance learning contacts and/or distance learning course facilitators was Item $\# 2$, "Principal's perception of traits needed by students to be successful in distance learning courses."

The individual survey items were analyzed by factor category to determine if any facilitate the implementation of Policy 2450. Table 14 presents the means and standard deviations of perceptions of all respondents $(N=216)$.

Table 14

Mean Scores and Standard Deviations of Factors Affecting the Implementation of Policy 2450 $(N=216)$

\begin{tabular}{lcc}
\hline \multicolumn{1}{c}{ Factor Category } & $M$ & $S D$ \\
\hline People & 4.00 & 1.06 \\
Structures & 3.78 & 1.04 \\
Communication & 3.74 & 1.10 \\
Culture & 3.61 & 1.09 \\
Resources & 3.39 & 1.24 \\
& & \\
Overall & 3.69 & 1.14 \\
\hline
\end{tabular}

Note. Items are displayed in descending order of mean score.

The people category had the highest overall mean score $(M=4.00, S D=1.06)$, followed by structures $(M=3.78, S D=1.04)$, communication $(M=3.74, S D=1.10)$, culture $(M=3.61, S D=1.09)$, and resources $(M=3.39, S D=1.24)$.Categories of factors with a mean score of 3.6 or higher are those that facilitate policy implementation. Based on the mean score for each category of factors in Table 14, people, communication, structures, and culture facilitate the implementation of Policy 2450. 


\section{Research Question 2}

Research Question 2: What are the factors that impede the implementation of WVBE Policy 2450, Distance Learning and the West Virginia Virtual School, in high schools according to perceptions of three select groups: (a) principals/assistant principals, (b) counselors, and (c) distance learning contacts and/or distance learning course facilitators?

Respondents rated survey items indicating to what degree they believed the items influenced the implementation of Policy 2450. Items having a mean score of 2.5 or lower were identified as those that impede the policy's implementation. Thirteen survey items had a mean score lower than 3.6. Those items are displayed in descending order of mean scores in Table 15. 
Table 15

Survey Items with Mean Scores Below 3.6

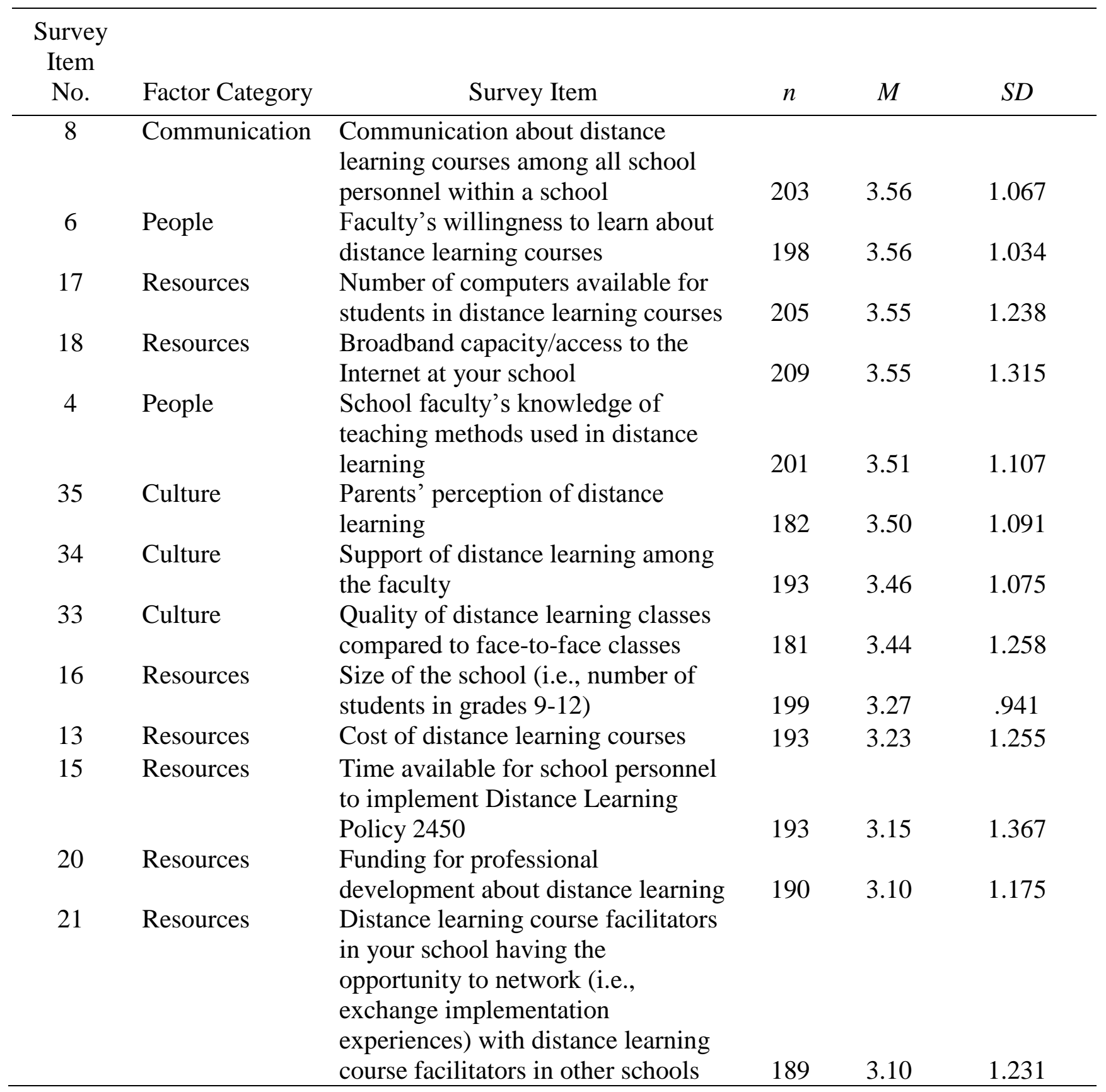

No survey items had an overall mean score of 2.5 or lower; therefore, no items were perceived to impede implementation of Policy 2450. The lowest overall mean score for any item was 3.10 and was calculated for Survey Item \#20 (Funding for professional development about 
distance learning) and Survey Item \#21(Distance learning course facilitators in your school having the opportunity to network (i.e., exchange implementation experiences) with distance learning course facilitators in other schools on the survey). As shown in Table 14, the resources category of factors collectively scored the lowest $(M=3.39, S D=1.24)$ but did not meet the criteria $(M \leq 2.5)$ to be considered as impeding implementation of WVBE Policy 2450.

As shown in Appendix L, the survey item rated lowest $(M=3.02)$ by principals/assistant principals was Item \#13, Cost of distance learning courses. As shown in Appendix M, the survey item rated lowest $(M=2.90)$ by counselors was Item \#15, Time available for school personnel to implement Distance Learning Policy 2450. As shown in Appendix N, the survey item rated lowest $(M=3.18)$ by distance learning contacts and/or distance learning course facilitators was Item \#20, Funding for professional development about distance learning.

\section{Research Question 3}

Research Question 3: Is there a difference in perceptions of factors important to the implementation of WVBE Policy 2450, Distance Learning and the West Virginia Virtual School, in high schools among three select groups: (a) principals/assistant principals, (b) counselors, and (c) distance learning contacts and/or distance learning course facilitators?

The null hypothesis for this question was:

$H_{0}$ : There are no significant differences in the perceptions of principals/assistant principals, counselors, and distance learning contacts and/or distance learning course facilitators regarding the categories of factors affecting the implementation of Policy 2450 in West Virginia high schools.

The alternative hypothesis for this question was: 
$H_{a}$ : There are significant differences in the perceptions of principals/assistant principals, counselors, and distance learning contacts and/or distance learning course facilitators regarding the categories of factors affecting the implementation of Policy 2450 in West Virginia high schools.

The mean scores and standard deviations for each survey item according to each respondent's primary position are shown in Appendix O. These data were used in calculations to determine if there were significant differences between groups. A One-Way Analysis of Variance (ANOVA) was used to test the null and alternate hypotheses. An ANOVA is a statistical technique used to compare groups on possible differences in the mean of a quantitative study (Klugkist, 2008). The complete results of the ANOVA are shown in Appendix P. Significant differences were noted for those survey items with mean scores at the $p<0.05$ level. The ANOVA identified 10 survey items in which there were significant differences in the perceptions of the three groups of respondents. Table 16 lists those 10 items. 
Table 16

Survey Items with Significant Differences in Perceptions among the Three Groups of Respondents $^{a}$

\begin{tabular}{cl}
\hline Survey Item No. & \multicolumn{1}{c}{ Survey Item } \\
\hline 5 & Skills of distance learning course facilitators in the school \\
14 & $\begin{array}{l}\text { Student access to technology and instructional support } \\
\text { Time available for school personnel to implement Distance Learning } \\
\text { Policy 2450 } \\
\text { Number of computers available for students in distance learning courses }\end{array}$ \\
17 & $\begin{array}{l}\text { Broadband capacity/access to the Internet at your school } \\
18\end{array}$ \\
19 & $\begin{array}{l}\text { Computer network security (protection from computer viruses and hackers) } \\
\text { Electronic Resources, Technologies, and the Internet (pertaining to } \\
\text { acceptable use of the Internet) }\end{array}$ \\
23 & $\begin{array}{l}\text { Assessment of student learning in distance learning courses } \\
\text { Support from West Virginia Department of Education personnel }\end{array}$ \\
32 & $\begin{array}{l}\text { Importance of teacher digital literacy (i.e., abilities to locate, organize, } \\
\text { understand, evaluate, analyze, and create information using technology) }\end{array}$ \\
\hline
\end{tabular}

${ }^{a}$ Principals/Assistant Principals, Counselors, and Distance Learning Contacts and/or Distance Learning Course Facilitators

The data from these survey items reject the null hypothesis (that there are no differences in the perceptions of the groups) and support the alternate hypothesis (that there are differences in the perceptions of the groups). The data fail to reject the null hypothesis on the other 25 survey items. ANOVA results for the 10 survey items with significant differences $(p<0.05)$ are shown in Appendix Q.

The results of an ANOVA are limited. Although the data rejected the null hypothesis for the 10 items listed in Table 16, the ANOVA did not inform the researcher about which pairs of mean scores differed from each other (i.e., principals/assistant principals vs. counselors, counselors vs. distance learning contacts/course facilitators, principals/assistant principals vs. 
distance learning contacts/course facilitators). The ANOVA only indicated that at least one of the group's means is significantly different from the others.

A post hoc test on each of the 10 items showing significance was used to specifically determine where group differences were found. Scheffe's test (also called Scheffe's method) is recommended as an appropriate post-hoc test for this purpose when there are unequal group sizes (Cramer \& Howitt, 2004). Scheffe's test was applied to the data from each of the 10 survey items with significant differences to identify whether the differences were between (a) principals/assistant principals and counselors, (b) principals/assistant principals and distance learning contacts and/or distance learning course facilitators, and/or (c) counselors and distance learning contacts and/or distance learning course facilitators.

Cohen's $d$, a measurement of effect size, is another post hoc statistic that was calculated for each survey item in which there was a significant difference. Cohen's $d$ is defined as the difference between two means divided by a standard deviation for the data. Cohen's $d$ is used to show the magnitude of the difference between two sets of values. Cohen's guidelines state that a value of 0.2 is a small effect size, 0.5 is a medium effect size, and 0.8 is a large effect size.

The ANOVA revealed a significant difference among the groups at the $p<.05$ level for Survey Item \#5, Skills of distance learning course facilitators in the school $[F(2,196)=3.95$, $p=.021]$. Scheffe's test was applied to determine where the differences are present. The results are displayed in Table 17. 
Table 17

Comparison of Perceptions Regarding the Skills of Distance Learning Course Facilitators

\begin{tabular}{|c|c|c|c|c|c|c|}
\hline & \multirow[t]{2}{*}{ Primary Positions } & \multirow[t]{2}{*}{$\begin{array}{c}\text { Mean } \\
\text { Difference } \\
(\mathrm{I}-\mathrm{J})\end{array}$} & \multirow[t]{2}{*}{$\begin{array}{l}\text { Std. } \\
\text { Error }\end{array}$} & \multirow[t]{2}{*}{ Sig.* } & \multicolumn{2}{|c|}{$\begin{array}{c}95 \% \\
\text { Confidence } \\
\text { Interval } \\
\end{array}$} \\
\hline & & & & & $\begin{array}{l}\text { Lower } \\
\text { Bound }\end{array}$ & $\begin{array}{l}\text { Upper } \\
\text { Bound }\end{array}$ \\
\hline \multirow{2}{*}{$\begin{array}{l}\text { Principals/ } \\
\text { Assistant } \\
\text { Principals }\end{array}$} & Counselors & .207 & .187 & .544 & -.25 & .67 \\
\hline & $\begin{array}{l}\text { Distance Learning Contacts/ } \\
\text { Course Facilitators }\end{array}$ & -.429 & .221 & .155 & -.97 & .12 \\
\hline \multirow[t]{2}{*}{ Counselors } & Principals/ Assistant Principals & -.207 & .187 & .544 & -.67 & .25 \\
\hline & $\begin{array}{l}\text { Distance Learning Contacts/ } \\
\text { Course Facilitators }\end{array}$ & -.635 & .226 & $.021 *$ & -1.19 & -.08 \\
\hline Distance & Principals/ Assistant Principals & .429 & .221 & .155 & -.12 & .97 \\
\hline $\begin{array}{l}\text { Learning } \\
\text { Contacts/ } \\
\text { Course } \\
\text { Facilitators } \\
\end{array}$ & Counselors & .635 & .226 & $.021 *$ & .08 & 1.19 \\
\hline
\end{tabular}

Post hoc comparisons using Scheffe's test indicated that the mean score for the distance learning contacts and/or distance learning course facilitators $(\mathrm{M}=4.24, \mathrm{SD}=0.958)$ was significantly different than that of the counselors $(\mathrm{M}=3.60, \mathrm{SD}=1.255)$. Cohen's $d$ was calculated to be 0.573 (a medium to large effect size). The mean score for the principals/assistant principals $(\mathrm{M}=3.81, \mathrm{SD}=1.187)$ did not significantly differ from the other two groups.

The ANOVA revealed a significant difference among the groups at the $p<.05$ level for Survey Item \#14, Student access to technology and instructional support, $[F(2,203)=3.92$, $p=.021]$. Scheffe's method was applied to determine where the differences are present. The results are displayed in Table 18. 
Table 18

Comparison of Perceptions Regarding Student Access to Technology and Instructional Support

\begin{tabular}{|c|c|c|c|c|c|c|}
\hline & \multirow[t]{2}{*}{ Primary Positions } & \multirow[t]{2}{*}{$\begin{array}{c}\text { Mean } \\
\text { Difference } \\
(\mathrm{I}-\mathrm{J})\end{array}$} & \multirow[t]{2}{*}{$\begin{array}{l}\text { Std. } \\
\text { Error }\end{array}$} & \multirow[t]{2}{*}{ Sig.* } & \multicolumn{2}{|c|}{$\begin{array}{c}95 \% \\
\text { Confidence } \\
\text { Interval } \\
\end{array}$} \\
\hline & & & & & $\begin{array}{l}\text { Lower } \\
\text { Bound }\end{array}$ & $\begin{array}{l}\text { Upper } \\
\text { Bound }\end{array}$ \\
\hline \multirow{2}{*}{$\begin{array}{l}\text { Principals/ } \\
\text { Assistant } \\
\text { Principals }\end{array}$} & Counselors & -.140 & .202 & .787 & -.64 & .36 \\
\hline & $\begin{array}{l}\text { Distance Learning Contacts/ } \\
\text { Course Facilitators }\end{array}$ & -.699 & .239 & $.015 *$ & -1.29 & -.11 \\
\hline \multirow[t]{2}{*}{ Counselors } & Principals/ Assistant Principals & .140 & .202 & .787 & -.36 & .64 \\
\hline & $\begin{array}{l}\text { Distance Learning Contacts/ } \\
\text { Course Facilitators }\end{array}$ & -.558 & .240 & .070 & -1.15 & .03 \\
\hline Distance & Principals/ Assistant Principals & .699 & .239 & $.015^{*}$ & .11 & 1.29 \\
\hline $\begin{array}{l}\text { Learning } \\
\text { Contacts/ } \\
\text { Course } \\
\text { Facilitators }\end{array}$ & Counselors & .558 & .240 & .070 & -.03 & 1.15 \\
\hline
\end{tabular}

Post hoc comparisons using Scheffe's test indicated that the mean score for the distance learning contacts and/or distance learning course facilitators $(\mathrm{M}=4.23, \mathrm{SD}=1.031)$ was significantly different than that of the principals/assistant principals ( $\mathrm{M}=3.59, \mathrm{SD}=1.284)$. Cohen's $d$ was calculated to be 0.550 (a medium to large effect size). The mean score for the counselors $(\mathrm{M}=3.70, \mathrm{SD}=1.338)$ did not significantly differ from the other two groups.

The ANOVA revealed a significant difference among the groups at the $p<.05$ level for Survey Item \#15, Time available for school personnel to implement Distance Learning Policy 2450, $[\mathrm{F}(2,190)=5.40, p=.005]$. Scheffe's method was applied to determine where the differences are present. The results are displayed in Table 19. 
Table 19

Comparison of Perceptions Regarding Time Available for School Personnel to Implement Distance Learning Policy 2450

\begin{tabular}{|c|c|c|c|c|c|c|}
\hline & \multirow[t]{2}{*}{ Primary Positions } & \multirow[t]{2}{*}{$\begin{array}{c}\text { Mean } \\
\text { Difference } \\
(\mathrm{I}-\mathrm{J})\end{array}$} & \multirow[t]{2}{*}{$\begin{array}{l}\text { Std. } \\
\text { Error }\end{array}$} & \multirow[t]{2}{*}{ Sig.* } & \multicolumn{2}{|c|}{$\begin{array}{c}95 \% \\
\text { Confidence } \\
\text { Interval } \\
\end{array}$} \\
\hline & & & & & $\begin{array}{l}\text { Lower } \\
\text { Bound }\end{array}$ & $\begin{array}{l}\text { Upper } \\
\text { Bound } \\
\end{array}$ \\
\hline \multirow{2}{*}{$\begin{array}{l}\text { Principals/ } \\
\text { Assistant } \\
\text { Principals }\end{array}$} & Counselors & .140 & .220 & .816 & -.40 & .68 \\
\hline & $\begin{array}{l}\text { Distance Learning Contacts/ } \\
\text { Course Facilitators }\end{array}$ & -.756 & 261 & $.017^{*}$ & -1.40 & -.11 \\
\hline \multirow[t]{2}{*}{ Counselors } & Principals/ Assistant Principals & -.140 & .220 & .816 & -.68 & .40 \\
\hline & $\begin{array}{l}\text { Distance Learning Contacts/ } \\
\text { Course Facilitators }\end{array}$ & -.896 & .266 & $.004 *$ & -1.55 & -.24 \\
\hline Distance & Principals/ Assistant Principals & .756 & .261 & $.017 *$ & .11 & 1.40 \\
\hline $\begin{array}{l}\text { Learning } \\
\text { Contacts/ } \\
\text { Course } \\
\text { Facilitators }\end{array}$ & Counselors & .896 & .266 & $.004 *$ & .24 & 1.55 \\
\hline
\end{tabular}

Post hoc comparisons using Scheffe's test indicated that the mean score for the distance learning contacts and/or distance learning course facilitators $(\mathrm{M}=3.75, \mathrm{SD}=1.193)$ was significantly different than that of the principals/assistant principals $(\mathrm{M}=3.07, \mathrm{SD}=1.404)$ and counselors $(\mathrm{M}=2.90, \mathrm{SD}=1.331)$. Cohen's $d$ for the difference between distance learning contacts and/or distance learning course facilitators and principals/assistant principals was calculated to be 0.522 (a medium to large effect size). Cohen's $d$ for the difference between distance learning contacts and/or distance learning course facilitators and counselors was calculated to be 0.673 (a medium to large effect size). There was no significant difference between the scores of principals/assistant principals and counselors.

The ANOVA revealed a significant difference among the groups at the $p<.05$ level for Survey Item \#17, Number of computers available for students in distance learning courses, 
$[\mathrm{F}(2,202)=4.12, p=.018]$. Scheffe's method was applied to determine where the differences are present. The results are displayed in Table 20 .

Table 20

Comparison of Perceptions Regarding the Number of Computers Available for Students in Distance Learning Courses

\begin{tabular}{|c|c|c|c|c|c|c|}
\hline & \multirow[t]{2}{*}{ Primary Positions } & \multirow[t]{2}{*}{$\begin{array}{c}\text { Mean } \\
\text { Difference } \\
(\mathrm{I}-\mathrm{J})\end{array}$} & \multirow[t]{2}{*}{$\begin{array}{l}\text { Std. } \\
\text { Error }\end{array}$} & \multirow[t]{2}{*}{ Sig.* } & \multicolumn{2}{|c|}{$\begin{array}{c}95 \% \\
\text { Confidence } \\
\text { Interval }\end{array}$} \\
\hline & & & & & $\begin{array}{l}\text { Lower } \\
\text { Bound }\end{array}$ & $\begin{array}{l}\text { Upper } \\
\text { Bound }\end{array}$ \\
\hline \multirow{3}{*}{$\begin{array}{l}\text { Principals/ } \\
\text { Assistant } \\
\text { Principals }\end{array}$} & Counselors & .204 & .199 & .592 & -.29 & .69 \\
\hline & Distance Learning Contacts/ & & & & & \\
\hline & Course Facilitators & -.481 & .234 & .124 & -1.06 & .10 \\
\hline \multirow[t]{2}{*}{ Counselors } & Principals/ Assistant Principals & -.204 & .199 & .592 & -.69 & .29 \\
\hline & $\begin{array}{l}\text { Distance Learning Contacts/ } \\
\text { Course Fac2ilitators }\end{array}$ & -.684 & .235 & $.016^{*}$ & -1.26 & -.11 \\
\hline Distance & Principals/ Assistant Principals & .481 & .234 & .124 & -.10 & 1.06 \\
\hline $\begin{array}{l}\text { Learning } \\
\text { Contacts/ } \\
\text { Course } \\
\text { Facilitators }\end{array}$ & Counselors & .684 & .235 & $.016^{*}$ & .11 & 1.26 \\
\hline
\end{tabular}

Post hoc comparisons using Scheffe's test indicated that the mean score for the distance learning contacts and/or distance learning course facilitators $(\mathrm{M}=3.96, \mathrm{SD}=1.107)$ was significantly different than that of the counselors $(\mathrm{M}=3.30, \mathrm{SD}=1.319)$. Cohen's $d$ for the difference between distance learning contacts and/or distance learning course facilitators and principals/assistant principals was calculated to be 0.542 (a medium to large effect size). The mean score for the principals/assistant principals $(\mathrm{M}=3.55, \mathrm{SD}=1.182)$ did not significantly differ from the other two groups.

The ANOVA revealed a significant difference among the groups at the $p<.05$ level for Survey Item \#18, Broadband capacity/access to the Internet at your school, $[F(2,206)=4.22$, 
$p=.016]$. Scheffe's method was applied to determine where the differences are present. The results are displayed in Table 21.

Table 21

Comparison of Perceptions Regarding Broadband Capacity/Access to the Internet in Schools

\begin{tabular}{|c|c|c|c|c|c|c|}
\hline & \multirow[t]{2}{*}{ Primary Positions } & \multirow[t]{2}{*}{$\begin{array}{c}\text { Mean } \\
\text { Difference } \\
(\mathrm{I}-\mathrm{J})\end{array}$} & \multirow[t]{2}{*}{$\begin{array}{l}\text { Std. } \\
\text { Error }\end{array}$} & \multirow[t]{2}{*}{ Sig.* } & \multicolumn{2}{|c|}{$\begin{array}{c}95 \% \\
\text { Confidence } \\
\text { Interval }\end{array}$} \\
\hline & & & & & Lower & $\begin{array}{l}\text { Upper } \\
\text { Bound }\end{array}$ \\
\hline \multirow{3}{*}{$\begin{array}{l}\text { Principals/ } \\
\text { Assistant } \\
\text { Principals }\end{array}$} & Counselors & 110 & 206 & .868 & -.40 & .62 \\
\hline & Distance Learning Contacts/ & & & & & \\
\hline & Course Facilitators & -.544 & .244 & .086 & -1.15 & .06 \\
\hline \multirow[t]{2}{*}{ Counselors } & Principals/ Assistant Principals & -.110 & .206 & .868 & -.62 & .40 \\
\hline & $\begin{array}{l}\text { Distance Learning Contacts/ } \\
\text { Course Facilitators }\end{array}$ & -.654 & 245 & $.030 *$ & -1.26 & -.05 \\
\hline Distance & Principals/ Assistant Principals & .544 & 244 & .086 & -.06 & 1.15 \\
\hline $\begin{array}{l}\text { Learning } \\
\text { Contacts/ } \\
\text { Course } \\
\text { Facilitators }\end{array}$ & Counselors & .654 & .245 & $.030 *$ & .05 & 1.26 \\
\hline
\end{tabular}

Post hoc comparisons using Scheffe's test indicated that the mean score for the distance learning contacts and/or distance learning course facilitators $(\mathrm{M}=4.02, \mathrm{SD}=1.097)$ was significantly different than that of the counselors $(\mathrm{M}=3.33, \mathrm{SD}=1.393)$. Cohen's $d$ for the difference between distance learning contacts and/or distance learning course facilitators and principals/assistant principals was calculated to be 0.550 (a medium to large effect size). The mean score for the principals/assistant principals $(\mathrm{M}=3.49, \mathrm{SD}=1.297)$ did not significantly differ from the other two groups.

The ANOVA revealed a significant difference among the groups at the $p<.05$ level for Survey Item \#19, Computer network security (protection from computer viruses and hackers), 
$[\mathrm{F}(2,204)=3.13, p=.046]$. Scheffe's method was applied to determine where the differences are present. The results are displayed in Table 22 .

Table 22

Comparison of Perceptions Regarding Computer Network Security (Protection from Computer Viruses and Hackers)

\begin{tabular}{|c|c|c|c|c|c|c|}
\hline & \multirow[t]{2}{*}{ Primary Positions } & \multirow[t]{2}{*}{$\begin{array}{c}\text { Mean } \\
\text { Difference } \\
(\mathrm{I}-\mathrm{J})\end{array}$} & \multirow[t]{2}{*}{$\begin{array}{l}\text { Std. } \\
\text { Error }\end{array}$} & \multirow[t]{2}{*}{ Sig.* } & \multicolumn{2}{|c|}{$\begin{array}{c}95 \% \\
\text { Confidence } \\
\text { Interval }\end{array}$} \\
\hline & & & & & $\begin{array}{l}\text { Lower } \\
\text { Bound }\end{array}$ & $\begin{array}{l}\text { Upper } \\
\text { Bound }\end{array}$ \\
\hline \multirow{3}{*}{$\begin{array}{l}\text { Principals/ } \\
\text { Assistant } \\
\text { Principals }\end{array}$} & Counselors & -.170 & .179 & .636 & -.61 & .27 \\
\hline & Distance Learning Contacts/ & & & & & \\
\hline & Course Facilitators & -.560 & .213 & $.033^{*}$ & -1.08 & -.04 \\
\hline \multirow[t]{2}{*}{ Counselors } & Principals/ Assistant Principals & .170 & .179 & .636 & -.27 & .61 \\
\hline & $\begin{array}{l}\text { Distance Learning Contacts/ } \\
\text { Course Facilitators }\end{array}$ & -.390 & .215 & 195 & -.92 & .14 \\
\hline Distance & Principals/ Assistant Principals & .560 & .213 & $.033 *$ & .04 & 1.08 \\
\hline $\begin{array}{l}\text { Learning } \\
\text { Contacts/ } \\
\text { Course } \\
\text { Facilitators }\end{array}$ & Counselors & .390 & .215 & .195 & -.14 & .92 \\
\hline
\end{tabular}

Post hoc comparisons using Scheffe's test indicated that the mean score for the distance learning contacts and/or distance learning course facilitators $(\mathrm{M}=4.07, \mathrm{SD}=0.925)$ was significantly different than that of the principals/assistant principals $(\mathrm{M}=3.55, \mathrm{SD}=1.149)$. Cohen's $d$ for the difference between distance learning contacts and/or distance learning course facilitators and principals/assistant principals was calculated to be 0.499 (a small to medium effect size). The mean score for the counselors $(\mathrm{M}=3.66, \mathrm{SD}=1.217)$ did not significantly differ from the other two groups.

The ANOVA revealed a significant difference among the groups at the $p<.05$ level for Survey Item \#23, WVBE Policy 2460, Educational Purpose and Acceptable Use of Electronic Resources, Technologies, and the Internet (pertaining to acceptable use of the Internet), 
$[\mathrm{F}(2,190)=3.04, p=.050]$. Scheffe's method was applied to determine where the differences are present. The results are displayed in Table 23.

Table 23

Comparison of Perceptions Regarding WVBE Policy 2460 and the Implementation of WVBE Policy 2450

\begin{tabular}{|c|c|c|c|c|c|c|}
\hline & \multirow[t]{2}{*}{ Primary Positions } & \multirow[t]{2}{*}{$\begin{array}{c}\text { Mean } \\
\text { Difference } \\
(\mathrm{I}-\mathrm{J})\end{array}$} & \multirow[t]{2}{*}{$\begin{array}{l}\text { Std. } \\
\text { Error }\end{array}$} & \multirow[t]{2}{*}{ Sig.* } & \multicolumn{2}{|c|}{$\begin{array}{c}95 \% \\
\text { Confidence } \\
\text { Interval }\end{array}$} \\
\hline & & & & & $\begin{array}{l}\text { Lower } \\
\text { Bound }\end{array}$ & $\begin{array}{l}\text { Upper } \\
\text { Bound }\end{array}$ \\
\hline \multirow{2}{*}{$\begin{array}{l}\text { Principals/ } \\
\text { Assistant } \\
\text { Principals }\end{array}$} & Counselors & -.121 & .144 & .704 & -.48 & .24 \\
\hline & $\begin{array}{l}\text { Distance Learning Contacts/ } \\
\text { Course Facilitators }\end{array}$ & -.455 & .170 & $.030 *$ & -.87 & -.03 \\
\hline \multirow[t]{2}{*}{ Counselors } & Principals/ Assistant Principals & .121 & .144 & .704 & -.24 & .48 \\
\hline & $\begin{array}{l}\text { Distance Learning Contacts/ } \\
\text { Course Facilitators }\end{array}$ & -.333 & .172 & .157 & -.76 & .09 \\
\hline Distance & Principals/ Assistant Principals & .455 & .170 & $.030 *$ & .03 & .87 \\
\hline $\begin{array}{l}\text { Learning } \\
\text { Contacts/ } \\
\text { Course } \\
\text { Facilitators }\end{array}$ & Counselors & .333 & .172 & .157 & -.09 & .76 \\
\hline
\end{tabular}

Post hoc comparisons using Scheffe's test indicated that the mean score for the distance learning contacts and/or distance learning course facilitators $(\mathrm{M}=4.00, \mathrm{SD}=0.837)$ was significantly different than that of the principals/assistant principals ( $\mathrm{M}=3.59, \mathrm{SD}=0.896)$.

Cohen's $d$ for the difference between distance learning contacts and/or distance learning course facilitators and principals/assistant principals was calculated to be 0.473 (a small to medium effect size $)$. The mean score for the counselors $(M=3.67, S D=0.904)$ did not significantly differ from the other two groups.

The ANOVA revealed a significant difference among the groups at the $p<.05$ level for Survey Item \#26, Assessment of student learning in distance learning courses, $[F(2,186)=3.71$, 
$p=.026]$. Scheffe's method was applied to determine where the differences are present. The results are displayed in Table 24 .

Table 24

Comparison of Perceptions Regarding Assessment of Student Learning in Distance Learning Courses

\begin{tabular}{|c|c|c|c|c|c|c|}
\hline & \multirow[t]{2}{*}{ Primary Positions } & \multirow[t]{2}{*}{$\begin{array}{c}\text { Mean } \\
\text { Difference } \\
(\mathrm{I}-\mathrm{J})\end{array}$} & \multirow[t]{2}{*}{$\begin{array}{l}\text { Std. } \\
\text { Error }\end{array}$} & \multirow[t]{2}{*}{ Sig.* } & \multicolumn{2}{|c|}{$\begin{array}{c}95 \% \\
\text { Confidence } \\
\text { Interval }\end{array}$} \\
\hline & & & & & $\begin{array}{l}\text { Lower } \\
\text { Bound }\end{array}$ & $\begin{array}{l}\text { Upper } \\
\text { Bound }\end{array}$ \\
\hline Principals/ & Counselors & -.121 & .173 & .785 & -.55 & .31 \\
\hline $\begin{array}{l}\text { Assistant } \\
\text { Principals }\end{array}$ & $\begin{array}{l}\text { Distance Learning Contacts/ } \\
\text { Course Facilitators }\end{array}$ & -.545 & .200 & $.026 *$ & -1.04 & -.05 \\
\hline Counselors & Principals/ Assistant Principals & .121 & .173 & .785 & -.31 & .55 \\
\hline & $\begin{array}{l}\text { Distance Learning Contacts/ } \\
\text { Course Facilitators }\end{array}$ & -.424 & .204 & .117 & -.93 & .08 \\
\hline Distance & Principals/ Assistant Principals & .545 & .200 & $.026^{*}$ & .05 & 1.04 \\
\hline $\begin{array}{l}\text { Learning } \\
\text { Contacts/ } \\
\text { Course } \\
\text { Facilitators }\end{array}$ & Counselors & .424 & .204 & .117 & -.08 & .93 \\
\hline
\end{tabular}

Post hoc comparisons using Scheffe's test indicated that the mean score for the distance learning contacts and/or distance learning course facilitators $(\mathrm{M}=4.07, \mathrm{SD}=0.973)$ was significantly different than that of the principals/assistant principals $(\mathrm{M}=3.54, \mathrm{SD}=1.084)$. Cohen's $d$ for the difference between distance learning contacts and/or distance learning course facilitators and principals/assistant principals was calculated to be 0.515 (a medium to large effect size). The mean score for the counselors $(\mathrm{M}=3.65, \mathrm{SD}=1.004)$ did not significantly differ from the other two groups.

The ANOVA revealed a significant difference among the groups at the $p<.05$ level for Survey Item \#29, Support from West Virginia Department of Education personnel, 
$[\mathrm{F}(2,186)=4.28, p=.015]$. Scheffe's method was applied to determine where the differences are present. The results are displayed in Table 25 .

Table 25

Comparison of Perceptions Regarding Support from West Virginia Department of Education Personnel

\begin{tabular}{|c|c|c|c|c|c|c|}
\hline & \multirow[t]{2}{*}{ Primary Positions } & \multirow[t]{2}{*}{$\begin{array}{c}\text { Mean } \\
\text { Difference } \\
(\mathrm{I}-\mathrm{J})\end{array}$} & \multirow[t]{2}{*}{$\begin{array}{l}\text { Std. } \\
\text { Error }\end{array}$} & \multirow[t]{2}{*}{ Sig.* } & \multicolumn{2}{|c|}{$\begin{array}{c}95 \% \\
\text { Confidence } \\
\text { Interval }\end{array}$} \\
\hline & & & & & $\begin{array}{l}\text { Lower } \\
\text { Bound }\end{array}$ & $\begin{array}{l}\text { Upper } \\
\text { Bound }\end{array}$ \\
\hline \multirow{3}{*}{$\begin{array}{l}\text { Principals/ } \\
\text { Assistant } \\
\text { Principals }\end{array}$} & Counselors & -.334 & .167 & .137 & -.75 & .08 \\
\hline & Distance Learning Contacts/ & & & & & \\
\hline & Course Facilitators & -.537 & 199 & $.028 *$ & -1.03 & -.05 \\
\hline \multirow[t]{2}{*}{ Counselors } & Principals/ Assistant Principals & .334 & .167 & .137 & -.08 & .75 \\
\hline & $\begin{array}{l}\text { Distance Learning Contacts/ } \\
\text { Course Facilitators }\end{array}$ & -.203 & .201 & 601 & -.70 & .29 \\
\hline Distance & Principals/ Assistant Principals & .537 & .199 & $.028 *$ & .05 & 1.03 \\
\hline $\begin{array}{l}\text { Learning } \\
\text { Contacts/ } \\
\text { Course } \\
\text { Facilitators }\end{array}$ & Counselors & .203 & .201 & .601 & -29 & .70 \\
\hline
\end{tabular}

Post hoc comparisons using Scheffe's test indicated that the mean score for the distance learning contacts and/or distance learning course facilitators $(\mathrm{M}=4.23, \mathrm{SD}=1.038)$ was significantly different than that of the principals/assistant principals $(\mathrm{M}=3.69, \mathrm{SD}=1.023)$. Cohen's $d$ for the difference between distance learning contacts and/or distance learning course facilitators and principals/assistant principals was calculated to be 0.524 (a medium to large effect size $)$. The mean score for the counselors $(M=4.03, S D=0.964)$ did not significantly differ from the other two groups.

The ANOVA revealed a significant difference among the groups at the $p<.05$ level for Survey Item \#32, Importance of teacher digital literacy (i.e., abilities to locate, organize, understand, evaluate, analyze, and create information using technology), $[F(2,192)=3.70$, 
$p=.027]$. Scheffe's method was applied to determine where the differences are present. The results are displayed in Table 26.

Table 26

Comparison of Perceptions Regarding the Importance of Teacher Digital Literacy

\begin{tabular}{|c|c|c|c|c|c|c|}
\hline & \multirow[t]{2}{*}{ Primary Positions } & \multirow[t]{2}{*}{$\begin{array}{c}\text { Mean } \\
\text { Difference } \\
(\mathrm{I}-\mathrm{J})\end{array}$} & \multirow[t]{2}{*}{$\begin{array}{l}\text { Std. } \\
\text { Error }\end{array}$} & \multirow[t]{2}{*}{ Sig.* } & \multicolumn{2}{|c|}{$\begin{array}{c}95 \% \\
\text { Confidence } \\
\text { Interval }\end{array}$} \\
\hline & & & & & Lower & $\begin{array}{l}\text { Upper } \\
\text { Bound }\end{array}$ \\
\hline \multirow{3}{*}{$\begin{array}{l}\text { Principals/ } \\
\text { Assistant } \\
\text { Principals }\end{array}$} & Counselors & 229 & .170 & .405 & -.19 & .65 \\
\hline & Distance Learning Contacts/ & & & & & \\
\hline & Course Facilitators & -.311 & 199 & 299 & -.80 & .18 \\
\hline \multirow[t]{2}{*}{ Counselors } & Principals/ Assistant Principals & -.229 & .170 & .405 & -.65 & .19 \\
\hline & $\begin{array}{l}\text { Distance Learning Contacts/ } \\
\text { Course Facilitators }\end{array}$ & -.540 & .200 & $.028 *$ & -1.03 & -.05 \\
\hline Distance & Principals/ Assistant Principals & .311 & .199 & .299 & -.18 & .80 \\
\hline $\begin{array}{l}\text { Learning } \\
\text { Contacts/ } \\
\text { Course } \\
\text { Facilitators }\end{array}$ & Counselors & .540 & .200 & $.028 *$ & .05 & 1.03 \\
\hline
\end{tabular}

Post hoc comparisons using Scheffe's test indicated that the mean score for the distance learning contacts and/or distance learning course facilitators $(\mathrm{M}=4.14, \mathrm{SD}=0.990)$ was significantly different than that of the counselors $(\mathrm{M}=3.60, \mathrm{SD}=1.127)$. Cohen's $d$ for the difference between distance learning contacts and/or distance learning course facilitators and principals/assistant principals was calculated to be 0.509 (a medium to large effect size). The mean score for the principals/assistant principals $(\mathrm{M}=3.83, \mathrm{SD}=0.979)$ did not significantly differ from the other two groups.

Table 27 displays a summary of the 10 survey items in which there were significant differences $(p<0.05)$ among principals/assistant principals, counselors, and distance learning contacts and/or distance learning course facilitators. The table shows between which groups the 
significant differences were found (as revealed by Scheffe's test) and the effect size of those differences (as determined by Cohen's $d$ values). 
Table 27

Survey Items having Significant Differences in Mean Scores between Groups and Effect Sizes

\begin{tabular}{|c|c|c|c|c|c|}
\hline $\begin{array}{l}\text { Survey } \\
\text { Item } \\
\text { No. }\end{array}$ & $\begin{array}{c}\text { Factor } \\
\text { Category }\end{array}$ & Survey Item & $\begin{array}{c}\text { Effect Size Between } \\
\text { Principals/ Assistant } \\
\text { Principals and } \\
\text { Counselors }\end{array}$ & $\begin{array}{c}\text { Effect Size Between } \\
\text { Principals/ Assistant } \\
\text { Principals and Distance } \\
\text { Learning Contacts/ } \\
\text { Course Facilitators }\end{array}$ & $\begin{array}{c}\text { Effect Size Between } \\
\text { Counselors and } \\
\text { Distance Learning } \\
\text { Contacts/Course } \\
\text { Facilitators }\end{array}$ \\
\hline 5 & People & $\begin{array}{l}\text { Skills of distance learning } \\
\text { course facilitators in the school }\end{array}$ & No difference & No difference & Medium - Large \\
\hline 14 & Resources & $\begin{array}{l}\text { Student access to technology } \\
\text { and instructional support }\end{array}$ & No difference & Medium - Large & No difference \\
\hline 15 & Resources & $\begin{array}{l}\text { Time available for school } \\
\text { personnel to implement } \\
\text { Distance Learning Policy } 2450\end{array}$ & No difference & Medium - Large & Medium - Large \\
\hline 17 & Resources & $\begin{array}{l}\text { Number of computers } \\
\text { available for students in } \\
\text { distance learning courses }\end{array}$ & No difference & No difference & Medium - Large \\
\hline 18 & Resources & $\begin{array}{l}\text { Broadband capacity/access to } \\
\text { the Internet at your school }\end{array}$ & No difference & No difference & Medium - Large \\
\hline 19 & Resources & $\begin{array}{l}\text { Computer network security } \\
\text { (protection from computer } \\
\text { viruses and hackers) }\end{array}$ & No difference & Small - Medium & No difference \\
\hline
\end{tabular}


Table 27 (continued).

\begin{tabular}{|c|c|c|c|c|c|}
\hline $\begin{array}{l}\text { Survey } \\
\text { Item } \\
\text { No. }\end{array}$ & $\begin{array}{l}\text { Factor } \\
\text { Category }\end{array}$ & Survey Item & $\begin{array}{c}\text { Effect Size Between } \\
\text { Principals/ Assistant } \\
\text { Principals and } \\
\text { Counselors }\end{array}$ & $\begin{array}{l}\text { Effect Size Between } \\
\text { Principals/ Assistant } \\
\text { Principals and Distance } \\
\text { Learning Contacts/ } \\
\text { Course Facilitators }\end{array}$ & $\begin{array}{l}\text { Effect Size Between } \\
\text { Counselors and } \\
\text { Distance Learning } \\
\text { Contacts/Course } \\
\text { Facilitators }\end{array}$ \\
\hline 23 & Structures & $\begin{array}{l}\text { WVBE Policy } 2460 \text {, } \\
\text { Educational Purpose and } \\
\text { Acceptable Use of Electronic } \\
\text { Resources, Technologies, and } \\
\text { the Internet (pertaining to } \\
\text { acceptable use of the Internet) }\end{array}$ & No difference & Small - Medium & No difference \\
\hline 26 & Structures & $\begin{array}{l}\text { Assessment of student learning } \\
\text { in distance learning courses }\end{array}$ & No difference & Medium - Large & No difference \\
\hline 29 & Structures & $\begin{array}{l}\text { Support from West Virginia } \\
\text { Department of Education } \\
\text { personnel }\end{array}$ & No difference & Medium - Large & No difference \\
\hline 32 & Culture & $\begin{array}{l}\text { Importance of teacher digital } \\
\text { literacy (i.e., abilities to locate, } \\
\text { organize, understand, evaluate, } \\
\text { analyze and create information } \\
\text { using technology) }\end{array}$ & No difference & No difference & Medium - Large \\
\hline
\end{tabular}


As shown in Table 27, there were no significant differences between the perceptions of principals/assistant principals and counselors on any survey items. On only one item (Survey Item 15, Time available for school personnel to implement Distance Learning Policy 2450) did distance learning contacts and/or distance learning course facilitators significantly differ from both principals/assistant principals and counselors, and both of these effect sizes were medium to large. There were significant differences between principals/assistant principals and distance learning contacts and/or distance learning course facilitators on five other items (Survey Items 14, 19, 23, 26, and 29). Three of these (Survey Items 14, 26, and 29) were medium to large in effect size and the other two (Survey Items 19 and 23) were small to medium in effect size. There were significant differences between counselors and distance learning course contacts and/or distance learning course facilitators on four items (Survey Items 5, 17, 18, and 32) in addition to the one previously mentioned (Survey Item 15). All of these differences were medium to large in effect size.

An overall Cohen's $d$ value was calculated using the collective mean scores for all three groups (principals/assistant principals, counselors, and distance learning contacts and/or distance learning course facilitators) on all 35 survey items. Cohen (1969) suggested convenient guidelines of small, medium, and large to help researchers interpret the size of the differences between sets of data. The composite effect size between principals/assistant principals $(\mathrm{M}=3.63$, $\mathrm{SD}=1.13)$ and counselors $(\mathrm{M}=3.58, \mathrm{SD}=1.15)$ was none to small $(d=.044)$, meaning these two groups of respondents had similar perceptions of the survey items and that overall differences in their perceptions were trivial. The composite effect size between principals/assistant principals $(\mathrm{M}=3.63, \mathrm{SD}=1.13)$ and distance learning contacts and/or distance learning course facilitators $(\mathrm{M}=3.93, \mathrm{SD}=1.08)$ was small to medium $(d=.271)$. Cohen (1969) described a medium effect 
size as "visible to the naked eye" (p. 23) and likened it to comparing the heights of 14 year old and 18 year old girls. The small to medium effect size between principals/assistant principals and distance learning contacts and/or course facilitators indicated that the groups had noticeable but not overwhelming differences in their overall perceptions of the survey items. The composite effect size between counselors $(\mathrm{M}=3.58, \mathrm{SD}=1.15)$ and distance learning contacts and/or distance learning course facilitators $(\mathrm{M}=3.93, \mathrm{SD}=1.08)$ was small to medium $(d=.314)$, again suggesting noticeable but not overwhelming differences in the perceptions of counselors and distance learning contacts and/or distance learning course facilitators.

\section{Research Question 4}

Research Question 4: Is there a difference in perceptions of factors important to implementation of WVBE Policy 2450, Distance Learning and the West Virginia Virtual School, in schools with $1 \%$ or greater of the high school students enrolled in distance learning courses between 2008 and 2011 versus schools with less than $1 \%$ of the high school students enrolled in distance learning courses during the same time period?

The responses to Research Question \#4 are displayed in Tables 28 through 64. One table was prepared for each of the 35 rated survey items. The tables are grouped in the order in which the five factor categories appeared in the survey: (a) People, (b) Communication, (c) Resources, (d) Structures, and (e) Culture. Two additional tables display survey items having significant differences between Groups A and B and an overall comparison of responses from those in Groups A and B.

Independent samples t- tests were computed on the response data to determine if respondents located in schools that had $1 \%$ or greater of the students enrolled in distance learning courses (Group A, $n=119$ ) rated the items differently than those in schools with less than 
$1 \%$ of the students enrolled in distance learning courses (Group B, $n=97$ ). Independent samples ttests compare the mean scores of two groups on a given variable to assess the probability that a particular characteristic of the two groups is different (Shapiro, 2008). SSPS calculations derived from the data are provided in Appendix R.

The calculations in Appendix R include a Levene's Test for Equality of Variances. Levene's Test is used to examine the deviations of scores around a median and indicate if differences in results are due to variations in the samples. Variance homogeneity is a precondition for accurate t-test results. The underlying assumption is that the variances in the samples are equal, i.e., not significantly different. Levene's Test measures the degree of variance and generates two sets of calculations (including $t$ values) per item: one set of calculations is referenced when calculations indicate equal variances can be assumed and the other set of calculations is referenced when equal variances are not assumed. In most cases for this study, Levene's test confirmed the assumption of equal variances (homogeneity of variances) and the corresponding $t$ value and significance value for "equal variances assumed" were reported. If Levene's test showed significant differences $(p<.05)$ indicating that the samples may not have been homogeneous, then that condition was noted and the $t$ value and significance value for "equal variances not assumed" were used.

Cohen's $d$, a measurement of effect size, was a post hoc statistic calculated for each survey item in which there was a significant difference $(p<.05)$ between Groups A and B. Cohen's $d$ is defined as the difference between two means divided by a standard deviation for the data. Cohen's $d$ is used to show the magnitude of the difference between two sets of values. Cohen's guidelines state that a value of 0.2 is a small effect size, 0.5 is a medium effect size, and 0.8 is a large effect size. 
The first seven survey items were associated with the factor category People and response data by group are shown in Tables 28 through 34. Survey Items 8-12 were associated with the factor category Communication and response data by group are shown in Tables 35 through 39. Survey Items 13-21 were associated with the factor category Resources and response data by group are shown in Tables 40 through 48. Survey Items 22-29 were associated with the factor category Structures and response data by group are shown in Tables 49 through 56. Survey Items 30-35 were associated with the factor category Culture and response data by group are shown in Tables 57 through 62. Two additional tables display survey items having significant differences between Groups A and B and an overall comparison of responses from those in Groups A and B.

Each table identifies the group of respondents (A or B), the number of respondents in each group, the mean score of each group's responses, the difference between the mean scores (a single value displayed on the top line only), the standard deviations for each group's scores, the calculated $t$ value (a single value displayed on the top line only), and the corresponding level of significance (a single value displayed on the top line only). A negative $t$ value indicates the mean score of Group B was higher than Group A. All tables use the $t$ value associated with Levene's “equal variances assumed" unless otherwise noted. Significance values less than 0.05 were indications that significant differences existed between the two groups. In such cases, Cohen's $d$ values were reported to indicate the effect size (magnitude of the differences).

Factor category: People. To assess potential differences in the perceptions of the two groups of participants, a t-test was computed for each of the seven items related to the factor People. Statistical significance was defined at the $p<.05$ level. These statistical test results are presented in Table 28 through Table 34. 
Only one item (Survey Item \#7, School counselor as a source of information about distance learning courses) within the category of people yielded a significant difference between the two groups. Table 28 displays the results of a t-test for that item.

Table 28

Comparison of Perceptions Regarding the School Counselor as a Source of Information about Distance Learning Courses

\begin{tabular}{ccccccc}
\hline Group & $n$ & $M$ & Difference & $S D$ & $t$ & Significance $^{*}$ \\
\hline A & 117 & 4.37 & .33 & .934 & 2.392 & .018 \\
B & 94 & 4.04 & & 1.036 & & \\
\hline$* p<.05$ & & & & &
\end{tabular}

As indicated by Table 28, respondents located in schools that had $1 \%$ or greater of the students enrolled in distance learning courses (Group A) rated the item higher than those in schools with less than $1 \%$ of the students enrolled in distance learning courses (Group B), $t$ $=2.392, p=.018$. Cohen's $d$ was calculated to determine the effect size (i.e., magnitude of difference) between the two groups. The effect size was 0.335 which indicates a small to medium difference between the groups' responses on this survey item.

Results of t-tests performed on the other six survey items in the people category are displayed in Tables 29 through 34. Table 29 contains data on differences between the groups regarding the "support of administrators in local school (e.g., encouragement to teachers to utilize technology in instruction, provision of resources).” 
Table 29

Comparison of Support of Administrators on the Use of Technology in Instruction

\begin{tabular}{ccccccc}
\hline Group & $n$ & $M$ & Difference & $S D$ & $t$ & Significance * \\
\hline A & 116 & 4.33 & -.01 & .882 & -.102 & .919 \\
B & 94 & 4.34 & & .934 & & \\
\hline$* p<.05$ & & & & & &
\end{tabular}

As indicated by Table 29, the data in Item 1, "support of administrators in local school (e.g., encouragement to teachers to utilize technology in instruction, provision of resources)," did not yield a significant finding ( $p=.919)$. The non-significant statistic means that the two groups are equal and any difference is due to error/chance.

Table 30 contains data on differences between the groups regarding the "principal's perception of traits needed by students to be successful in distance learning courses."

Table 30

Comparison of Principals' Perceptions of Traits Needed by Students to be Successful in Distance Learning Courses

\begin{tabular}{ccccccc}
\hline Group & $n$ & $M$ & Difference & $S D$ & $t$ & Significance * \\
\hline A & 115 & 4.21 & .06 & .932 & .455 & .649 \\
B & 93 & 4.15 & & .896 & & \\
\hline
\end{tabular}

$* p<.05$

As indicated by Table 30, the data in Item 2, "principal's perception of traits needed by students to be successful in distance learning courses," did not yield a significant finding $(p=.649)$. The non-significant statistic means that the two groups are equal and any difference is due to error/chance.

Table 31 contains data on the differences between the groups regarding the "principal's willingness to include distance learning courses in the school curriculum." 
Table 31

Comparison of Principal's Willingness to Include Distance Learning Courses in the School Curriculum

\begin{tabular}{ccccccc}
\hline Group & $n$ & $M$ & Difference & $S D$ & $t$ & Significance * \\
\hline A & 113 & 4.41 & .18 & .841 & 1.422 & .157 \\
B & 96 & 4.23 & & .968 & & \\
\hline${ }^{*} p<.05$ & & & & & &
\end{tabular}

As indicated by Table 31, the data in Item 3, “principal's willingness to include distance learning courses in the school curriculum," did not yield a significant finding $(p=.157)$. The nonsignificant statistic means that the two groups are equal and any difference is due to error/chance.

Table 32 contains data on the differences between the groups regarding the "school faculty's knowledge of teaching methods used in distance learning."

Table 32

Comparison of Perceptions Regarding School Faculty's Knowledge of Teaching Methods Used in Distance Learning

\begin{tabular}{ccccccc}
\hline Group & $n$ & $M$ & Difference & $S D$ & $t$ & Significance * \\
\hline A & 111 & 3.62 & .24 & 1.079 & 1.555 & .122 \\
B & 90 & 3.38 & & 1.137 & & \\
\hline$* p<.05$ & & & & & &
\end{tabular}

As indicated by Table 32, the data in Item 4, "school faculty's knowledge of teaching methods used in distance learning," did not yield a significant finding ( $p=.122)$. The nonsignificant statistic means that the two groups are equal and any difference is due to error/chance.

Table 33 contains data on the differences between the groups regarding the "skills of distance learning course facilitators in the school." 
Table 33

Comparison of the Perceptions Regarding Skills of Distance Learning Course Facilitators in the School

\begin{tabular}{ccccccc}
\hline Group & $n$ & $M$ & Difference & $S D$ & $t$ & Significance * \\
\hline A & 113 & 3.91 & .20 & 1.162 & 1.192 & .235 \\
B & 86 & 3.71 & & 1.216 & & \\
\hline$* p<.05$ & & & & & &
\end{tabular}

As indicated by Table 33, the data in Item 5, "skills of distance learning course facilitators in the school," did not yield a significant finding $(p=.235)$. The non-significant statistic means that the two groups are equal and any difference is due to error/chance.

Table 34 contains data on the differences between the groups regarding the "faculty's willingness to learn about distance learning courses."

Table 34

Comparison of the Faculty's Willingness to Learn about Distance Learning Courses

\begin{tabular}{ccccccc}
\hline Group & $n$ & $M$ & Difference & $S D$ & $t$ & Significance * \\
\hline A & 111 & 3.67 & .24 & 1.012 & 1.637 & .103 \\
B & 87 & 3.43 & & 1.052 & & \\
\hline
\end{tabular}

$* p<.05$

As indicated by Table 34, the data in Item 6, “faculty's willingness to learn about distance learning courses," did not yield a significant finding $(p=.103)$. The non-significant statistic means that the two groups are equal and any difference is due to error/chance.

Respondents had the opportunity to make comments on the survey items associated with this factor category. Ten people provided comments but not all addressed people. Their comments were sorted into appropriate categories by the researcher and are found in Appendix S. 
Factor category: Communication. To assess potential differences in the perceptions of the two groups of respondents (Group A and Group B), a t-test was computed for each of the five items related to the factor, Communication. Statistical significance was defined at the $p<.05$ level. These test results are presented in Table 35 through Table __. No survey items within the category of communication yielded a significant difference between the two groups. The items are presented in the sequence in which they appeared in the survey.

Table 35 contains data on differences between the groups regarding the "communication about distance learning courses among all school personnel within a school."

Table 35

Comparison of Perceptions Regarding Communication among All School Personnel within a School

\begin{tabular}{ccccccc}
\hline Group & $n$ & $M$ & Difference & $S D$ & $t$ & Significance $^{*}$ \\
\hline A & 114 & 3.68 & .26 & 1.043 & 1.729 & .085 \\
B & 89 & 3.42 & & 1.085 & & \\
$* *^{*}<.05$ & & & & &
\end{tabular}

As indicated by Table 35, the data in Item 8, “communication about distance learning courses among all school personnel within a school," did not yield a significant finding $(p=.085)$. The non-significant statistic means that the two groups are equal and any difference is due to error/chance.

Table 36 contains data on differences between the groups regarding "information about distance learning courses made available to students." 
Table 36

Comparison of Perceptions Regarding Information about Distance Learning Courses Being Made Available to Students

\begin{tabular}{ccccccc}
\hline Group & $n$ & $M$ & Difference & $S D$ & $t$ & Significance * \\
\hline A & 117 & 4.04 & .27 & 1.070 & 1.711 & .089 \\
B & 90 & 3.77 & & 1.209 & & \\
\hline${ }^{*} p<.05$ & & & & & &
\end{tabular}

Levene's test did not support the underlying assumption of independence (homogeneity of variances) for this item and it was necessary to use the $t$ value and significance value for "equal variances not assumed." As indicated by Table 36, the data in Item 9, "information about distance learning courses made available to students," did not yield a significant finding ( $p=.089)$. The non-significant statistic means that the two groups are equal and any difference is due to error/chance.

Table 37 contains data on differences between the groups regarding "communication about distance learning courses with external audiences (e.g., parents)."

Table 37

Comparison of Perceptions Regarding Communication with External Audiences (e.g., Parents)

\begin{tabular}{ccccccc}
\hline Group & $n$ & $M$ & Difference & $S D$ & $t$ & Significance * \\
\hline A & 112 & 3.74 & .12 & 1.105 & .725 & .469 \\
B & 85 & 3.62 & & 1.154 & & \\
\hline$* p<.05$ & & & & & &
\end{tabular}

As indicated by Table 37, the data in Item 10, "communication about distance learning courses with external audiences (e.g., parents)," did not yield a significant finding ( $p=.469)$. The non-significant statistic means that the two groups are equal and any difference is due to error/chance. 
Table 38 contains data on differences between the groups regarding the "clarity of WVBE Policy 2450, Distance Learning and the West Virginia Virtual School.”

Table 38

Comparison of Perceptions Regarding the Clarity of WVBE Policy 2450, Distance Learning and the West Virginia Virtual School

\begin{tabular}{ccccccc}
\hline Group & $n$ & $M$ & Difference & $S D$ & $t$ & Significance * \\
\hline A & 112 & 3.72 & .16 & .951 & 1.119 & .264 \\
B & 84 & 3.56 & & 1.090 & & \\
\hline$*_{p}<.05$ & & & & & &
\end{tabular}

As indicated by Table 38, the data in Item 11, "clarity of WVBE Policy 2450, Distance Learning and the West Virginia Virtual School," did not yield a significant finding $(p=.264)$. The non-significant statistic means that the two groups are equal and any difference is due to error/chance.

Table 39 contains data on differences between the groups regarding "guidance from the West Virginia Department of Education.”

Table 39

Comparison of Perceptions Regarding the Guidance from the West Virginia Department of Education

\begin{tabular}{ccccccc}
\hline Group & $n$ & $M$ & Difference & $S D$ & $t$ & Significance * \\
\hline A & 113 & 3.96 & .17 & 1.068 & 1.101 & .272 \\
B & 87 & 3.79 & & 1.122 & & \\
\hline
\end{tabular}

${ }^{*} p<.05$

As indicated by Table 39, the data in Item 12, "guidance from the West Virginia Department of Education," did not yield a significant finding ( $p=.272)$. The non-significant statistic means that the two groups are equal and any difference is due to error/chance. 
Respondents had the opportunity to make comments on the survey items associated with this factor category. Nine people provided comments but not all addressed communication. Their comments were sorted into appropriate categories by the researcher and are found in Appendix S.

Factor category: Resources. To assess potential differences in the perceptions of the two groups of participants, a t-test was computed for each of the nine items related to the factor, Resources. Statistical significance was defined at the $p<.05$ level. These statistical test results are presented in Table 40 through Table 48. Two survey items within the category of resources yielded a significant difference between the two groups. The two items were Item 15, "Time available for school personnel to implement Distance Learning Policy 2450," and Item 16, “Size of the school (i.e., number of students in grades 9-12)." Table 40 displays the results of a t-test for Item 15.

Table 40

Comparison of Perceptions Regarding the Time Available for School Personnel to Implement Distance Learning Policy 2450

\begin{tabular}{ccccccc}
\hline Group & $n$ & $M$ & Difference & $S D$ & $t$ & Significance * \\
\hline A & 108 & 3.33 & .41 & 1.311 & 2.117 & .036 \\
B & 85 & 2.92 & & 1.408 & & \\
\hline$* p<.05$ & & & & &
\end{tabular}

As indicated by Table 40, the data in Item 15, "time available for school personnel to implement Distance Learning Policy 2450,” yielded a significant difference. Respondents located in schools that had $1 \%$ or greater of the students enrolled in distance learning courses (Group A) rated the item higher than those in schools with less than $1 \%$ of the students enrolled in distance learning courses (Group B), $t=2.117, p=.036$. Cohen's $d$ was calculated to determine 
the effect size (i.e., magnitude of difference) between the two groups. The effect size was 0.301 which indicates a small to medium difference between the groups' responses on this survey item. Table 41 displays t-test results on differences between the groups regarding the "size of the school (i.e., number of students in grades 9-12)."

Table 41

Comparison of Perceptions Regarding the Size of a School (i.e., Number of Students in Grades 9-12) and the Implementation of Policy 2450

\begin{tabular}{ccccccc}
\hline Group & $n$ & $M$ & Difference & $S D$ & $t$ & Significance $*$ \\
\hline A & 109 & 3.39 & .27 & .872 & 2.048 & .042 \\
B & 90 & 3.12 & & 1.004 & & \\
\hline
\end{tabular}

${ }^{*} p<.05$

As indicated by Table 41, the data in Item 16, "size of the school (i.e., number of students in grades 9-12)," yielded a significant difference. Respondents located in schools that had 1\% or greater of the students enrolled in distance learning courses (Group A) rated the item significantly higher than those in schools with less than $1 \%$ of the students enrolled in distance learning courses (Group B), $t=2.048, p=.042$. Cohen's $d$ was calculated to determine the effect size (i.e., magnitude of difference) between the two groups. The effect size was 0.287 which indicates a small to medium difference between the groups' responses on this survey item.

Results of t-tests performed on the other seven survey items in the resources category are displayed in Tables 42 through 48 and are provided in the sequence in which the items appeared in the survey. Table 42 contains data on differences between the groups regarding the "cost of distance learning courses." 
Table 42

Comparison of Perceptions Regarding the Cost of Distance Learning Courses

\begin{tabular}{ccccccc}
\hline Group & $n$ & $M$ & Difference & $S D$ & $t$ & Significance * \\
\hline A & 106 & 3.32 & .19 & 1.184 & 1.071 & .286 \\
B & 87 & 3.13 & & 1.336 & & \\
\hline$* p<.05$ & & & & &
\end{tabular}

As indicated by Table 42, the data in Item 13, "cost of distance learning courses," did not yield a significant finding $(p=.286)$. The non-significant statistic means that the two groups are equal and any difference is due to error/chance.

Table 43 contains data on differences between the groups regarding "student access to technology and instructional support."

Table 43

Comparison of Perceptions of Student Access to Technology and Instructional Support

\begin{tabular}{ccccccc}
\hline Group & $n$ & $M$ & Difference & $S D$ & $t$ & Significance * \\
\hline A & 113 & 3.81 & .10 & 1.272 & .585 & .559 \\
B & 93 & 3.71 & & 1.282 & & \\
\hline$* p<05$ & & & & &
\end{tabular}

As indicated by Table 43, the data in Item 14, "student access to technology and instructional support," did not yield a significant finding ( $p=.559)$. The non-significant statistic means that the two groups are equal and any difference is due to error/chance.

Table 44 contains data on differences between the groups regarding the "number of computers available for students in distance learning courses." 
Table 44

Comparison of Perceptions Regarding the Number of Computers Available for Students in Distance Learning Courses

\begin{tabular}{ccccccc}
\hline Group & $n$ & $M$ & Difference & $S D$ & $t$ & Significance $^{*}$ \\
\hline A & 113 & 3.60 & .12 & 1.292 & .709 & .479 \\
B & 92 & 3.48 & & 1.172 & & \\
\hline$* p<.05$ & & & & &
\end{tabular}

As indicated by Table 44, the data in Item 17, "number of computers available for students in distance learning courses," did not yield a significant finding $(p=.479)$. The nonsignificant statistic means that the two groups are equal and any difference is due to error/chance.

Table 45 contains data on differences between the groups regarding "broadband capacity/access to the Internet at your school."

Table 45

Comparison of Perceptions Regarding Broadband Capacity/Access to the Internet

\begin{tabular}{ccccccc}
\hline Group & $n$ & $M$ & Difference & $S D$ & $t$ & Significance * \\
\hline A & 114 & 3.54 & -.01 & 1.390 & -.019 & .985 \\
B & 95 & 3.55 & & 1.227 & & \\
\hline
\end{tabular}

${ }^{*} p<.05$

As indicated by Table 45, the data in Item 18, "broadband capacity/access to the Internet at your school," did not yield a significant finding ( $p=.985)$. The non-significant statistic means that the two groups are equal and any difference is due to error/chance.

Table 46 contains data on differences between the groups regarding "computer network security (protection from computer viruses and hackers).” 
Table 46

Comparison of Perceptions Regarding Computer Network Security

\begin{tabular}{ccccccc}
\hline Group & $n$ & $M$ & Difference & $S D$ & $t$ & Significance * \\
\hline A & 114 & 3.76 & .14 & 1.147 & .872 & .384 \\
B & 93 & 3.62 & & 1.141 & & \\
\hline$* p<.05$ & & & & & &
\end{tabular}

As indicated by Table 46, the data in Item 19, “computer network security (protection from computer viruses and hackers)," did not yield a significant finding ( $p=.384)$. The nonsignificant statistic means that the two groups are equal and any difference is due to error/chance.

Table 47 contains data on differences between the groups regarding "funding for professional development about distance learning."

Table 47

Comparison of Perceptions Regarding Funding for Professional Development about Distance Learning

\begin{tabular}{ccccccc}
\hline Group & $n$ & $M$ & Difference & $S D$ & $t$ & Significance * \\
\hline A & 106 & 3.14 & .09 & 1.099 & .537 & .592 \\
B & 84 & 3.05 & & 1.270 & & \\
\hline
\end{tabular}

$* p<.05$

Levene's test did not support the underlying assumption of independence (homogeneity of variances) and it was necessary to use the $t$ value and significance value for "equal variances not assumed" for this item. As indicated by Table 47 the data in Item 20, "funding for professional development about distance learning," did not yield a significant finding $(p=.592)$. The non-significant statistic means that the two groups are equal and any difference is due to error/chance. 
Table 48 contains data on the differences between the groups regarding "distance learning course facilitators in your school having the opportunity to network (i.e., exchange implementation experiences) with distance learning course facilitators in other schools." Table 48

Comparison of Perceptions Regarding Distance Learning Course Facilitators Having the Opportunity to Network with Distance Learning Course Facilitators in Other Schools

\begin{tabular}{ccccccc}
\hline Group & $n$ & $M$ & Difference & $S D$ & $t$ & Significance $*$ \\
\hline A & 103 & 3.20 & .22 & 1.232 & 1.265 & .208 \\
B & 86 & 2.98 & & 1.227 & & \\
\hline$* p<.05$ & & & & & &
\end{tabular}

As indicated by Table 48, the data in Item 21, "distance learning course facilitators in your school having the opportunity to network (i.e., exchange implementation experiences) with distance learning course facilitators in other schools," did not yield a significant finding $(p=.208)$. The non-significant statistic means that the two groups are equal and any difference is due to error/chance.

Respondents had the opportunity to make comments on the survey items associated with this factor category. Eleven people provided comments but not all addressed resources. Their comments were sorted into appropriate categories by the researcher and are found in Appendix S.

Factor category: Structures. To assess potential differences in the perceptions of the two groups of participants, a t-test was computed for each of the eight items related to the factor, Structures. Statistical significance was defined at the $p<.05$ level. These statistical test results are presented in Table 49 through Table 56. Two survey items within the category of resources yielded a significant difference between the two groups. The two items were Item 26, “Assessment of student learning in distance learning courses," and Item 28, "Ability for students 
to enroll in distance learning courses without experiencing scheduling conflicts.” Table 49 displays the results of a t-test for Item 26.

Table 49

Comparison of Perceptions Regarding Assessment of Student Learning in Distance Learning Courses

\begin{tabular}{ccccccc}
\hline Group & $N$ & $M$ & Difference & $S D$ & $t$ & Significance * \\
\hline A & 104 & 3.85 & .33 & .872 & 2.140 & .034 \\
B & 85 & 3.52 & & 1.004 & & \\
\hline$* p<.05$ & & & & & &
\end{tabular}

Levene's test did not support the underlying assumption of independence (homogeneity of variances) and it was necessary to use the $t$ value and significance value for "equal variances not assumed" for this item. As indicated by Table 49, the data in Item 26, "assessment of student learning in distance learning courses," yielded a significant difference. Respondents located in schools that had $1 \%$ or greater of the students enrolled in distance learning courses (Group A) rated the item higher than those in schools with less than $1 \%$ of the students enrolled in distance learning courses (Group B), $t=2.140, p=.034$. Cohen's $d$ was calculated to determine the effect size (i.e., magnitude of difference) between the two groups. The effect size was 0.351 which indicates a small to medium difference between the groups' responses on this survey item.

Table 50 displays t-test results on differences between the groups regarding the "ability for students to enroll in distance learning courses without experiencing scheduling conflicts." 
Table 50

Comparison of Perceptions Regarding the Ability for Students to Enroll in Distance Learning Courses without Experiencing Scheduling Conflicts

\begin{tabular}{ccccccc}
\hline Group & $n$ & $M$ & Difference & $S D$ & $t$ & Significance $^{*}$ \\
\hline A & 109 & 3.85 & .40 & 1.153 & 2.374 & .019 \\
B & 86 & 3.45 & & 1.185 & & \\
\hline$* p<.05$ & & & & &
\end{tabular}

As indicated by Table 50, the data in Item 28, "ability for students to enroll in distance learning courses without experiencing scheduling conflicts," yielded a significant difference. Respondents located in schools that had $1 \%$ or greater of the students enrolled in distance learning courses (Group A) rated the item higher than those in schools with less than $1 \%$ of the students enrolled in distance learning courses (Group B), $t=2.374, p=.019$. Cohen's $d$ was calculated to determine the effect size (i.e., magnitude of difference) between the two groups. The effect size was 0.342 which indicates a small to medium difference between the groups' responses on this survey item.

Results of t-tests performed on the other six survey items in the resources category are displayed in Tables 51 through 56 and are provided in the sequence in which the items appeared in the survey. Table 51 contains data on differences between the groups regarding "established operating procedures in the school (e.g., daily class schedules, attendance, school calendar, procedures for recording grades)" and the implementation of Policy 2450. 
Table 51

Comparison Regarding Procedures in the School (e.g., Daily Class Schedules, Attendance, School Calendar, Procedures for Recording Grades) and the Implementation of Policy 2450

\begin{tabular}{ccccccc}
\hline Group & $n$ & $M$ & Difference & $S D$ & $t$ & Significance * \\
\hline A & 109 & 3.72 & .13 & 1.044 & .915 & .361 \\
B & 88 & 3.59 & & .990 & & \\
\hline$* p<.05$ & & & & & &
\end{tabular}

As indicated by Table 51, the data in Item 22, "established operating procedures in the school (e.g., daily class schedules, attendance, school calendar, procedures for recording grades)," did not yield a significant finding ( $p=.361)$. The non-significant statistic means that the two groups are equal and any difference is due to error/chance.

Table 52 contains data on differences between the groups regarding "WVBE Policy 2460, Educational Purpose and Acceptable Use of Electronic Resources, Technologies, and the Internet (pertaining to acceptable use of the Internet)" and the implementation of Policy 2450. Table 52

Comparison of Perceptions Regarding the Impact of Policy 2460 on the Implementation of Policy 2450

\begin{tabular}{ccccccc}
\hline Group & $n$ & $M$ & Difference & $S D$ & $t$ & Significance * \\
\hline A & 106 & 3.78 & .17 & .817 & 1.320 & .189 \\
B & 87 & 3.61 & & .981 & & \\
\hline
\end{tabular}

$* p<.05$

Levene's test did not support the underlying assumption of independence (homogeneity of variances) and it was necessary to use the $t$ value and significance value for "equal variances not assumed" for this item. As indicated by Table 52, the data in Item 23, "WVBE Policy 2460, Educational Purpose and Acceptable Use of Electronic Resources, Technologies, and the Internet (pertaining to acceptable use of the Internet)," did not yield a significant finding ( $p=.189)$. The 
non-significant statistic means that the two groups are equal and any difference is due to error/chance.

Table 53 contains data on differences between the groups regarding "acceptance of credits for distance learning courses by the county board of education or diploma-granting authority."

Table 53

Comparison of Perceptions Regarding the Acceptance of Credits for Distance Learning Courses

\begin{tabular}{ccccccc}
\hline Group & $n$ & $M$ & Difference & $S D$ & $t$ & Significance * \\
\hline A & 106 & 4.08 & .14 & .917 & 1.020 & .309 \\
B & 90 & 3.94 & & 1.010 & & \\
\hline$* p<.05$ & & & & & &
\end{tabular}

As indicated by Table 53, the data in Item 24, "acceptance of credits for distance learning courses by the county board of education or diploma-granting authority," did not yield a significant finding $(p=.309)$. The non-significant statistic means that the two groups are equal and any difference is due to error/chance.

Table 54 contains data on differences between the groups regarding the "recognition of distance learning courses by colleges and universities."

Table 54

Comparison Regarding the Recognition of Distance Learning Courses by Colleges and Universities

\begin{tabular}{ccccccc}
\hline Group & $n$ & $M$ & Difference & $S D$ & $t$ & Significance $^{*}$ \\
\hline A & 92 & 3.93 & .19 & .992 & 1.199 & .232 \\
B & 72 & 3.74 & & 1.126 & & \\
\hline$* p<.05$ & & & & &
\end{tabular}


As indicated by Table 54, the data in Item 25, "recognition of distance learning courses by colleges and universities," did not yield a significant finding ( $p=.232)$. The non-significant statistic means that the two groups are equal and any difference is due to error/chance.

Table 55 contains data on differences between the groups regarding a "school's ability to maintain academic integrity (control cheating) in distance learning courses."

Table 55

Comparison of Perceptions about the School's Ability to Maintain Academic Integrity (Control Cheating) in Distance Learning Courses

\begin{tabular}{ccccccc}
\hline Group & $n$ & $M$ & Difference & $S D$ & $t$ & Significance * \\
\hline A & 105 & 3.83 & .28 & 1.078 & 1.732 & .085 \\
B & 84 & 3.55 & & 1.145 & & \\
\hline
\end{tabular}

$* p<.05$

As indicated by Table 55, the data in Item 27, "school's ability to maintain academic integrity (control cheating) in distance learning courses," did not yield a significant finding $(p=.085)$. The non-significant statistic means that the two groups are equal and any difference is due to error/chance.

Table 56 contains data on differences between the groups regarding "support from West Virginia Department of Education personnel."

Table 56

Comparison of Perceptions Regarding Support from West Virginia Department of Education Personnel

\begin{tabular}{ccccccc}
\hline Group & $n$ & $M$ & Difference & $S D$ & $t$ & Significance $^{*}$ \\
\hline A & 108 & 3.99 & .14 & .952 & .905 & .367 \\
B & 81 & 3.85 & & 1.108 & & \\
\hline$* p<.05$ & & & & &
\end{tabular}


Levene's test did not support the underlying assumption of independence (homogeneity of variances) and it was necessary to use the $t$ value and significance value for "equal variances not assumed" for this item. As indicated by Table 56, the data in Item 29, "support from West Virginia Department of Education personnel," did not yield a significant finding ( $p=.367)$. The non-significant statistic means that the two groups are equal and any difference is due to error/chance.

Respondents had the opportunity to make comments on the survey items associated with this factor category. Seven people provided comments and all related to structure. All comments were sorted into appropriate categories by the researcher, and three originally recorded in the communication category were included with these seven in the structure category. The list of all comments is found in Appendix S.

Factor category: Culture. To assess potential differences in the perceptions of the two groups of participants, a t-test was computed for each of the six items related to the factor, Culture. Statistical significance was defined at the $p<.05$ level. These statistical test results are presented in Table 57 through Table . Two survey items within the category of culture yielded a significant difference between the two groups. The two items were Item 30, "Faculty's acceptance of state policy," and Item 34, "Support of distance learning among the faculty." Table 57 displays the results of a t-test for Item 30 .

Table 57

Comparison of Perceptions Regarding the Faculty's Acceptance of State Policy

\begin{tabular}{ccccccc}
\hline Group & $n$ & $M$ & Difference & $S D$ & $t$ & Significance * \\
\hline A & 100 & 3.76 & .19 & .900 & 2.157 & .032 \\
B & 85 & 3.47 & & .921 & & \\
\hline${ }^{*} p<.05$ & & & & & &
\end{tabular}


As indicated by Table 57, the data in Item 30, "faculty's acceptance of state policy," yielded a significant difference. Respondents located in schools that had $1 \%$ or greater of the students enrolled in distance learning courses (Group A) rated the item higher than those in schools with less than $1 \%$ of the students enrolled in distance learning courses (Group B), $t$ $=2.157, p=.032$. Cohen's d was calculated to determine the effect size (i.e., magnitude of difference) between the two groups. The effect size was 0.318 which indicates a small to medium difference between the groups' responses on this survey item.

Table 58 displays t-test results on differences between the groups regarding the "support of distance learning among the faculty."

Table 58

Comparison of Perceptions on the Support of Distance Learning Among the Faculty

\begin{tabular}{ccccccc}
\hline Group & $n$ & $M$ & Difference & $S D$ & $t$ & Significance * \\
\hline A & 106 & 3.61 & .40 & 1.010 & 2.190 & .030 \\
B & 87 & 3.28 & & 1.128 & & \\
\hline$* p<.05$ & & & & &
\end{tabular}

As indicated by Table 58, the data in Item 34, "support of distance learning among the faculty," yielded a significant difference. Respondents located in schools that had $1 \%$ or greater of the students enrolled in distance learning courses (Group A) rated the item higher than those in schools with less than $1 \%$ of the students enrolled in distance learning courses (Group B), $t$ $=2.190, p=.030$. Cohen's $d$ was calculated to determine the effect size (i.e., magnitude of difference) between the two groups. The effect size was 0.308 which indicates a small to medium difference between the groups' responses on this survey item.

Results of t-tests performed on the other four survey items in the culture category are displayed in Tables 59 through _ _ and are provided in the sequence in which the items appeared 
in the survey. Table 59 contains data on differences between the groups regarding the "importance of student digital literacy (i.e., abilities to locate, organize, understand, evaluate, analyze and create information using technology)."

Table 59

Comparison Regarding the Importance of Student Digital Literacy

\begin{tabular}{ccccccc}
\hline Group & $n$ & $M$ & Difference & $S D$ & $t$ & Significance * \\
\hline A & 109 & 3.83 & .08 & 1.087 & .490 & .624 \\
B & 88 & 3.75 & & 1.064 & & \\
\hline$* p<.05$ & & & & & &
\end{tabular}

As indicated by Table 59, the data in Item 31, "importance of student digital literacy (i.e., abilities to locate, organize, understand, evaluate, analyze and create information using technology)," did not yield a significant finding ( $p=.624)$. The non-significant statistic means that the two groups are equal and any difference is due to error/chance.

Table 60 contains data on differences between the groups regarding the "importance of teacher digital literacy (i.e., abilities to locate, organize, understand, evaluate, analyze and create information using technology).”

Table 60

Comparison of Perceptions Regarding the Importance of Teacher Digital Literacy on the Implementation of Policy 2450

\begin{tabular}{ccccccc}
\hline Group & $n$ & $M$ & Difference & $S D$ & $t$ & Significance * \\
\hline A & 109 & 3.85 & .09 & 1.053 & .639 & .524 \\
B & 86 & 3.76 & & 1.062 & & \\
\hline
\end{tabular}

$* p<.05$

As indicated by Table 60, the data in Item 32, "importance of teacher digital literacy (i.e., abilities to locate, organize, understand, evaluate, analyze and create information using 
technology)," did not yield a significant finding ( $p=.524)$. The non-significant statistic means that the two groups are equal and any difference is due to error/chance.

Table 61 contains data on differences between the groups regarding the "quality of distance learning classes compared to face-to-face classes."

Table 61

Comparison of Perceptions Regarding the Quality of Distance Learning Classes Compared to Face-to-Face Classes

\begin{tabular}{ccccccc}
\hline Group & $n$ & $M$ & Difference & $S D$ & $t$ & Significance * \\
\hline A & 103 & 3.58 & .32 & 1.233 & 1.737 & .084 \\
B & 78 & 3.26 & & 1.273 & & \\
\hline
\end{tabular}

${ }^{*} p<.05$

As indicated by Table 61, the data in Item 33, "quality of distance learning classes compared to face-to-face classes," did not yield a significant finding ( $p=.084)$. The nonsignificant statistic means that the two groups are equal and any difference is due to error/chance. Table 62 contains data on differences between the groups regarding "parents' perception of distance learning."

Table 62

Comparison Regarding Parents' Perception of Distance Learning

\begin{tabular}{ccccccc}
\hline Group & $n$ & $M$ & Difference & $S D$ & $t$ & Significance * \\
\hline A & 103 & 3.62 & .28 & 1.011 & 1.723 & .087 \\
B & 79 & 3.34 & & 1.175 & & \\
\hline$*_{p}<.05$ & & & & & &
\end{tabular}

As indicated by Table 62, the data in Item 35, "parents' perception of distance learning," did not yield a significant finding ( $p=.087)$. The non-significant statistic means that the two groups are equal and any difference is due to error/chance. 
Respondents had the opportunity to make comments on the survey items associated with this factor category. Four people provided comments but not all addressed culture. Their comments were sorted into appropriate categories by the researcher and are found in Appendix S.

Significant differences in the perceptions of seven survey items were found between respondents located in schools that had $1 \%$ or greater of the students enrolled in distance learning courses (Group A, $n=119$ ) and those in schools with less than $1 \%$ of the students enrolled in distance learning courses (Group B, $n=97$ ). These survey items and their levels of significance and effect sizes are summarized in Table 63. 
Table 63

Survey Items Having Significant Differences between Respondents in Group A and Group B

\begin{tabular}{|c|c|c|c|c|}
\hline $\begin{array}{l}\text { Survey } \\
\text { Item No. }\end{array}$ & $\begin{array}{c}\text { Factor } \\
\text { Category }\end{array}$ & Survey Item & Significance* & Effect Size \\
\hline 7 & People & $\begin{array}{l}\text { School counselor as a source of } \\
\text { information about distance } \\
\text { learning courses }\end{array}$ & .018 & $\begin{array}{l}.335 \\
\text { (Small to } \\
\text { Medium) }\end{array}$ \\
\hline 15 & Resources & $\begin{array}{l}\text { Time available for school } \\
\text { personnel to implement Distance } \\
\text { Learning Policy } 2450\end{array}$ & .036 & $\begin{array}{l}.301 \\
\text { (Small to } \\
\text { Medium) }\end{array}$ \\
\hline 16 & Resources & $\begin{array}{l}\text { Size of the school (i.e., number of } \\
\text { students in grades 9-12) }\end{array}$ & .042 & $\begin{array}{l}.287 \\
\text { (Small to } \\
\text { Medium) }\end{array}$ \\
\hline 26 & Structures & $\begin{array}{l}\text { Assessment of student learning in } \\
\text { distance learning courses }\end{array}$ & .034 & $\begin{array}{l}.351 \\
\text { (Small to } \\
\text { Medium) }\end{array}$ \\
\hline 28 & Structures & $\begin{array}{l}\text { Ability for students to enroll in } \\
\text { distance learning courses without } \\
\text { experiencing scheduling conflicts }\end{array}$ & .019 & $\begin{array}{l}.342 \\
\text { (Small to } \\
\text { Medium) }\end{array}$ \\
\hline 30 & Culture & $\begin{array}{l}\text { Faculty's acceptance of state } \\
\text { policy }\end{array}$ & .032 & $\begin{array}{l}.318 \\
\text { (Small to } \\
\text { Medium) }\end{array}$ \\
\hline 34 & Culture & $\begin{array}{l}\text { Support of distance learning } \\
\text { among the faculty }\end{array}$ & .030 & $\begin{array}{l}.308 \\
\text { (Small to } \\
\text { Medium) }\end{array}$ \\
\hline
\end{tabular}

$* p<.05$

The responses from those in Group A were significantly different than those in Group B on seven survey items. One item (Item 7) was regarding the factor People, two survey items (Items 15 and 16) were regarding the factor Resources, two survey items (Items 26 and 28) were regarding the factor Structures, and two survey items (Items 30 and 34) were regarding the factor Culture. Effect sizes for these seven items were small to medium. There were no significant differences between Groups A and B regarding the factor Communication. 
A t-test was conducted to determine if there was an overall significant difference in the responses from those in Groups A and B. The t-test results are displayed in Table 64. Table 64

Overall Comparison of All Responses from Those in Groups A and B

\begin{tabular}{ccccccc}
\hline Group & $n$ & $M$ & Difference & $S D$ & $t$ & Significance $*$ \\
\hline A & 119 & 3.78 & .21 & .301 & 4.847 & $<.001$ \\
B & 97 & 3.57 & & .335 & & \\
\hline
\end{tabular}

$* p<.05$

As indicated in Table 64, the overall comparison of responses from those in Groups A and B yielded a significant difference. Respondents located in schools that had $1 \%$ or greater of the students enrolled in distance learning courses (Group A) rated the survey items higher than those in schools with less than $1 \%$ of the students enrolled in distance learning courses (Group B), $t=4.847, p<.001$. Cohen's $d$ was calculated to determine the effect size (i.e., magnitude of difference) between the two groups. The effect size was 0.659 which indicates a medium to large difference between the groups' responses.

These data fail to support the null hypothesis:

$H_{0}$ : There are no significant differences in the perceptions of factors important to implementation of Policy 2450 between respondents in schools with $1 \%$ or greater of the high school students enrolled in distance learning courses and respondents in schools with less than $1 \%$ of the high school students enrolled in distance learning courses.

\section{Summary of Findings}

From an analysis of the questionnaire data, findings are presented regarding the demographics of the respondents and for each research question. The demographic information about the respondents is presented first. 
- The largest group of respondents in the survey were counselors $(n=82)$, followed by assistant principals $(n=52)$.

- Most respondents $(n=119)$ were from schools that had $1 \%$ or greater of the students enrolled in distance learning courses between 2008 and 2011 (Group A). There were 97 respondents from schools with less than $1 \%$ of the students enrolled in distance learning courses during the same time period (Group B).

- The largest group of respondents $(n=59)$ consisted of those who had been in their current positions for two to five years.

- The majority of those directly involved in distance learning served as distance learning contacts. More counselors served as distance learning contacts than did principals/assistant principals.

- Over $40 \%$ of the respondents in Group A were from schools with less than 450 students in Grades 9-12. Over 40\% of the respondents in Group B were from schools with more than 800 students.

1. What are the factors that facilitate the implementation of WVBE Policy 2450, Distance Learning and the West Virginia Virtual School, in high schools according to perceptions of three select groups: (a) principals/assistant principals, (b) counselors, and (c) distance learning contacts and/or distance learning course facilitators?

- People, structures, communication, and culture were the categories of factors that facilitated the implementation of WVBE Policy 2450 in high schools.

- According to all three groups, the category of factors that rated the highest in implementing WVBE Policy 2450 was people, followed by structures. 
- Twenty-two items were identified as factors that facilitate the implementation of WVBE Policy 2450.

- The support of local administrators was overall the most highly rated factor to facilitate the implementation of WVBE Policy 2450 in schools.

- According to principals/assistant principals, the highest-rated factor in the implementation of WVBE Policy 2450 was the principal's willingness to include distance learning courses in the school curriculum.

- According to counselors, the highest-rated factor in the implementation of WVBE Policy 2450 was the school counselor as a source of information about distance learning courses.

- According to distance learning contacts and/or distance learning course facilitators, the highest-rated factor in the implementation of WVBE Policy 2450 was the principal's perception of traits needed by students to be successful in distance learning courses.

2. What are the factors that impede the implementation of WVBE Policy 2450, Distance Learning and the West Virginia Virtual School, in high schools according to perceptions of three select groups: (a) principals/assistant principals, (b) counselors, and (c) distance learning contacts and/or distance learning course facilitators?

- No categories of factors or individual factors were identified as impeding the implementation of WVBE Policy 2450.

- According to all three groups, the category of factors that rated the lowest in implementing WVBE Policy 2450 was resources.

- The five factors that ranked the lowest in the survey were all in the resources category. 
- The two items that tied as the lowest-rated factors important to the implementation of WVBE Policy 2450 were both related to professional development.

- According to principals/assistant principals, the lowest-rated factor in the implementation of WVBE Policy 2450 was the cost of distance learning courses.

- According to counselors, the lowest-rated factor in the implementation of WVBE Policy 2450 was the time available for school personnel to implement the policy.

- According to distance learning contacts and/or distance learning course facilitators, the lowest-rated factor in the implementation of WVBE Policy 2450 was the funding for professional development about distance learning.

- It is the perception in some schools that staff members and parents have received little if any information about distance learning opportunities.

3. Is there a difference in perceptions of factors important to the implementation of WVBE Policy 2450, Distance Learning and the West Virginia Virtual School, in high schools among three select groups: (a) principals/assistant principals, (b) counselors, and (c) distance learning contacts and/or distance learning course facilitators?

- Significant differences existed between the perceptions of principals/assistant principals and distance learning contacts and/or distance learning course facilitators of factors important to the implementation of WVBE Policy 2450. These differences were in the resources and structure categories. Distance learning contacts and/or course facilitators ranked the factors in the resources and structure categories as more important to the policy's implementation than did principals/assistant principals.

- Significant differences existed between the perceptions of counselors and distance learning contacts and/or distance learning course facilitators on factors important to 
the implementation of WVBE Policy 2450. These differences involved resources, people, and culture. Distance learning contacts and/or course facilitators ranked the factors in these categories as more important to the policy's implementation than did counselors.

- There were no significant differences in the perception of principals/assistant principals and counselors on any of the survey items.

4. Is there a difference in perceptions of factors important to implementation of WVBE Policy 2450, Distance Learning and the West Virginia Virtual School, in schools with $1 \%$ or greater of the high school students enrolled in distance learning courses between 2008 and 2011 versus schools with less than $1 \%$ of the high school students enrolled in distance learning courses during the same time period?

- Significant differences in perceptions existed between those in schools that had $1 \%$ or greater of the students enrolled in distance learning courses and those in schools with enrollments in distance learning courses below that amount. These differences involved four factor categories: people, resources, structures, and culture.

- There were significant differences in the perceptions of seven survey items between respondents located in schools that had $1 \%$ or greater of the students enrolled in distance learning courses and those in schools with less than $1 \%$ of the students enrolled in distance learning courses. Those seven items pertained to the following: school counselors, time, assessment, school size, scheduling conflicts, and faculty acceptance of state policy and support of distance learning.

- Those in schools at or above $1 \%$ student enrollment in distance learning courses rated almost every survey item higher (i.e., more important to facilitating policy 
implementation) than did those in schools with enrollments in distance learning courses that were below that amount.

- The largest number of respondents in schools with enrollment in distance learning courses at or above $1 \%$ between 2008 and 2011 were in schools with less than 450 students. The largest number of respondents in schools with enrollment in distance learning courses below $1 \%$ student enrollment in distance learning courses during that time were in schools with over 800 students.

Related Finding. Respondents provided comments containing information supplemental to that collected by the bipolar rating scale. This information is summarized below.

- Respondents provided 41 comments about distance learning in their schools. These comments provided additional details about the implementation of WVBE Policy 2450. The comments pertained to the following categories: People (five comments); Communication (seven comments); Resources (10 comments); Structure (10 comments); Culture (three comments); and Miscellaneous (six comments). 


\section{Chapter 5}

\section{Summary, Conclusions, Discussion, and Recommendations}

This chapter includes a summary, study conclusions, discussion, and recommendations for policy, practice, and research.

\section{Summary}

The West Virginia Virtual School was created by the West Virginia Legislature in 2000 (W. Va. Code, 2012). The structure and management of the West Virginia Virtual School is described in West Virginia Board of Education (WVBE) Policy 2450, Distance Learning and the West Virginia Virtual School, which was adopted in 2000 and revised in 2002. The school's mission is "to assure consistent, high quality education for the students of West Virginia through courses delivered via technology, promote efficacy and equity in course offerings, and provide options for implementation across the public school system" (WVDE, 2012e, para. 1). One percent of West Virginia students in grades 9-12 took an online course between 2008 and 2011 (WVDE, 2011a).

This study examined the perceptions of selected personnel at 110 West Virginia high schools regarding the implementation of WVBE Policy 2450. This study sought to identify factors that facilitated and impeded implementation. Principals/assistant principals, counselors, and distance learning contacts and/or course facilitators provided their perceptions of five categories of factors important to the policy's implementation: (a) people, (b) communication, (c) resources, (d) structures, and (e) culture. Participants were invited to complete an online questionnaire using a bipolar rating scale to indicate their perceptions of 35 survey items related to the five categories of factors. Respondents also had the opportunity to write comments about each factor category and provide demographic information. 
The questionnaire was provided to 659 individuals in the study population. Responses were received from 216 individuals for a $32.78 \%$ return rate. Data were analyzed to determine if any factors were perceived as facilitating or impeding policy implementation and if there were significant differences in the perceptions based on the position or location of the respondents. Survey items with a mean score of 3.6 or higher were considered factors that facilitated policy implementation. Survey items with a mean score of 2.5 or lower were considered factors that impeded policy implementation.

The study contained four research questions. Selected findings follow each:

Research Question 1: What are the factors that facilitate the implementation of WVBE Policy 2450, Distance Learning and the West Virginia Virtual School, in high schools according to perceptions of three select groups: (a) principals/assistant principals, (b) counselors, and (c) distance learning contacts and/or distance learning course facilitators?

Four of the five categories of factors were perceived as facilitating the implementation of Policy 2450. These four categories, listed in order from the highest rated to the lowest rated, were people, structures, communication, and culture. There were 22 individual survey items that were perceived as facilitating implementation.

Research Question 2: What are the factors that impede the implementation of WVBE Policy 2450, Distance Learning and the West Virginia Virtual School, in high schools according to perceptions of three select groups: (a) principals/assistant principals, (b) counselors, and (c) distance learning contacts and/or distance learning course facilitators?

No factors were perceived to impede the implementation of Policy 2450. This may have resulted from the low number of teachers who responded to the survey. The 216 respondents 
were predominately principals/assistant principals $(n=89)$ and counselors $(n=82)$. Only 21 teachers who served as distance learning contacts and/or course facilitators provided responses.

The lowest-rated category of factors was resources and the five lowest-rated items in the entire survey were in the resources category. Opportunities for professional development, funding for professional development, time for implementation, cost of distance learning courses, and size of the school were the topics of the five lowest-rated items..

Research Question 3: Is there a difference in perceptions of factors important to the implementation of WVBE Policy 2450, Distance Learning and the West Virginia Virtual School, in high schools among three select groups: (a) principals/assistant principals, (b) counselors, and (c) distance learning contacts and/or distance learning course facilitators?

There were no significant differences in the perceptions of principals/assistant principals and counselors, but there were between principals/ assistant principals and distance learning contacts and/or distance learning course facilitators. Of the six differences identified, three were related to resources and three were related to structures. There were significant differences in the perceptions of counselors and distance learning contacts and/or distance learning course facilitators on five survey items. Three were related to resources, one was related to people, and one was related to culture. The only survey item with a significant difference in the perceptions of principals/assistant principals and counselors versus distance learning contacts and/or distance learning course facilitators was related to the time available for school personnel to implement WVBE Policy 2450.

Research Question 4: Is there a difference in perceptions of factors important to implementation of WVBE Policy 2450, Distance Learning and the West Virginia Virtual School, in schools with $1 \%$ or greater of the high school students enrolled in distance learning courses 
between 2008 and 2011 versus schools with less than $1 \%$ of the high school students enrolled in distance learning courses during the same time period?

There were significant differences between the perceptions of those in schools with $1 \%$ or greater of the high school students enrolled in distance learning courses between 2008 and 2011 and those in schools with less than $1 \%$ enrollment in distance learning course. Those in schools at or above $1 \%$ enrollment in distance learning courses perceived all five categories of factors as more important to the implementation of WVBE Policy 2450 than those in schools with a lower percentage of students enrolled in distance learning courses. The effect size was medium to large.

\section{Conclusions}

This study found five conclusions about factors that influence the implementation of WVBE Policy 2450, Distance Learning and the West Virginia Virtual School. They are as follows:

1. According to all three public school groups, four of the five categories of factors were perceived to facilitate the implementation of WVBE Policy 2450: people, structures, communication, and culture. The resources category was the least to facilitate.

2. According to all three public school groups, people, including the support, knowledge, and willingness of administrators and faculties to learn about distance learning, was perceived as the most facilitating category of factors to the implementation of WVBE Policy 2450.

3. According to all three public school groups, the organizational structure of a school, including its hierarchy, policies, and procedures, was perceived as the next most important category of factors to the implementation of WVBE Policy 2450. 
4. While no factors impeded the implementation of WVBE Policy 2450, there were more significant differences in perceptions about the importance of resources, especially time, among the three public school groups than with any other factor category.

5. Those who were located in schools where at least $1 \%$ of the students were enrolled in distance learning courses between 2008 and 2011 perceived all five categories of factors to be more facilitating to the implementation WVBE Policy 2450 than those in schools with fewer enrollments in distance learning courses during the same time period.

\section{Discussion}

This section provides information relevant to the study's conclusions. It begins with a review of the demographic information of the respondents. This section contains a discussion of findings related to the factor categories and includes citations of relevant literature. This section also provides the researcher the opportunity to speculate about the implications of the data. The categories of factors are presented in rank order of overall mean scores.

Demographics. Those in the study population were asked to indicate their primary positions in the school. The counselors' group was the largest in number $(n=82)$ and percentage of respondents (37.97) to complete the survey. Assistant principals provided the second-most responses $(n=52)$ and second-highest percentage of respondents (24.07). Individuals in these two positions totaled over $62 \%$ of all respondents.

The questionnaire had a survey item in which individuals could indicate if they were directly involved in distance learning in their schools. Responses showed that $63 \%$ were directly involved in distance learning and that the majority of those directly involved in distance learning served as distance learning contacts. The responsibilities of distance learning contacts were to distribute information to students and parents, secure agreements, and enroll students in distance 
learning courses. It seems logical that counselors and assistant principals (the two largest categories of respondents) might also be asked to serve as distance learning contacts since counselors and assistant principals typically enroll students in courses and/or perform some managerial duties in schools.

Individuals were asked to indicate how long they had been in their primary positions. The largest group of respondents $(n=59)$ consisted of those who had been in their current positions for two to five years. The enrollment data used in this study's design were from the years 2008 to 2011. Since responses for this study were collected in 2012, many of the individuals who had been in their current positions for two to five years would likely have had a connection to the distance learning courses during that time period. This connection may have contributed to the high inter-item reliability ( $\alpha=0.969)$ of the survey instrument. The second largest group $(n=45)$ consisted of those who had been in their current positions for six to ten years. Since WVBE Policy 2450 was created in 2000 and revised in 2002, some of these individuals may have been involved with distance learning since it was first introduced in their schools in that time period. Their perspectives may have also contributed to the reliability of the study.

Most respondents $(n=119)$ were from schools that had $1 \%$ or greater of the students enrolled in distance learning courses between 2008 and 2011 (Group A). Over 40\% of the respondents in Group A were from schools with less than 450 students in Grades 9-12. There were 97 respondents from schools with less than $1 \%$ of the students enrolled in distance learning courses during the same time period (Group B). Over 40\% of the respondents in Group B were from schools with more than 800 students. One may speculate that there could be a connection between the size of the school and enrollment in distance learning courses since more responses from Group A (at or above 1\% enrollment) came from small schools. One of the most-mentioned 
benefits of virtual learning is students' opportunity to access courses that would not otherwise be available in their schools (Berge \& Clark, 2005; Cavanaugh, 2001; Picciano \& Seaman, 2009; Watson, 2007). When creating the West Virginia Virtual School, the West Virginia Legislature determined that more course offerings could be made available through technology, especially to students who are geographically disadvantaged (W.Va. Code, 2012). Was distance learning more successful in smaller schools or were the data the result of mere coincidence? This study was not designed to see if such a relationship existed.

People. The category of factors that was perceived as most facilitating to the implementation of WVBE Policy 2450 was people. Bryson and Crosby (1992) and Firestone (1989) related the importance of the people involved in a policy's implementation to its success. In this study the factor category people had the highest mean score $(M=4.0)$ among the five categories of factors. The four highest-rated survey items were all related to people. When the responses from principals/assistant principals, counselors, and distance learning contacts and/or course facilitators were combined, the three public school groups perceived the support of administrators in the local school and the willingness of principals to include distance learning courses as the top two items that facilitate the policy's implementation in schools.

Evidence suggests that the perspective an individual has in the policy process seems to affect his/her perception of it, including his/her own role in the process. All three groups in this study (principals/assistant principals, counselors, and distance learning contacts and/or distance learning course facilitators) rated the factor category people as the most important to facilitating the policy. The groups, however, did not agree on the highest-rated factor. The survey item rated highest $(M=4.34)$ by principals/assistant principals was Item \#3, Principal's willingness to include distance learning courses in the school curriculum. The survey item rated highest 
$(M=4.40)$ by counselors was Item \#7, School counselor as a source of information about distance learning courses. The survey item rated highest $(M=4.37)$ by distance learning contacts and/or distance learning course facilitators was Item \#2, Principal's perception of traits needed by students to be successful in distance learning courses. One is left to wonder if principals and counselors had specific reasons for rating their own individual roles above all other factors important to the implementation of WVBE Policy 2450.

While this study affirmed that people facilitate policy implementation, one wonders if implementation at some locations has actually been hindered by people. Kotter (1998) identified unsupportive intermediary supervisors as some of the biggest obstacles in policy implementation. Comments from respondents suggest that may also be the case in a few schools represented in this study. Some respondents wrote of principals who would not include distance learning courses into master schedules and counselors who would not recommend the courses to students. One respondent wrote that he/she worked with counselors who were nearing retirement and unwilling to learn new technology. Also, the only survey items associated with the people category of factors that was not identified as facilitating implementation concerned the faculty's knowledge of and willingness to learn about distance learning. While not identified as impeding implementation, these survey items' failure to be included as facilitators suggests there may be faculty members who are not receptive to the policy.

Some schools have very high percentages of students enrolled in distance learning courses while other schools hardly have any students enrolled. Is it unreasonable to believe that people may be a factor in this disparity?

Structure. The organizational structure of a school was found to facilitate the implementation of Policy 2450. For this study, structure referred to the established chain of 
command in the organization as well as existing laws, policies, and procedures employees must follow in order to accomplish their work. The structure factor had the second highest mean score of all factors and all survey items related to it were found to facilitate distance learning in schools. Since all items related to this category were viewed as facilitating implementation, it appears that the implementation of WVBE Policy 2450 may be facilitated by the efficiency and order that is characteristic of sound organizational structure.

The highest rated survey items in the structure category were with regard to diplomagranting authorities and colleges recognizing distance learning courses for credit. One respondent wrote that it was wise for county boards of education to have policies that confirm the acceptance of distance learning courses for credit.

Structure can impede policy implementation when a policy clashes with other policies. The convergence of conflicting policies is a major condition with which teachers must contend (Knapp, Bamburg, Ferguson, \& Hill, 1998). However, responses to the survey items in this study did not suggest that WVBE Policy 2450 significantly conflicted with other policies in schools.

Communication. The communication category of factors was found to facilitate distance learning Policy 2450. The mean score for the category $(M=3.74)$ ranked third among the five categories. All three public school groups perceived four of the five factors in this category as facilitating the implementation of WVBE Policy 2450. Student access to information about distance learning courses was the item in this factor category rated the highest by respondents. The public school groups rated guidance from the WVDE as the second highest item in this category, and some provided written comments that were complimentary of WVDE staff members who work with the West Virginia Virtual School. 
Communication was determined to be a facilitator of Policy 2450 but one may speculate that some school systems are guilty of "undercommunicating" (Kotter, 1998, p.12) information about distance learning. One respondent wrote "There doesn't seem to be much communication about distance learning courses, either within the school or the community" (Appendix S). Similar comments were made by three others. The only survey item in the communication category that was not considered a facilitator involved communication among all personnel within a school.

Culture. Principals/assistant principals, counselors, and distance learning contacts and/or course facilitators perceived culture as another factor category that facilitated the implementation of WVBE Policy 2450. School culture may be defined as the guiding beliefs and expectations evident in the way a school operates (Fullan, 2007) and consists of the traditional beliefs, norms, and habits (Jerald, 2005). This category ranked fourth out of the five categories of factors. The overall mean score for culture $(M=3.61)$ was .01 greater than the score needed to qualify it as a facilitating factor category. Only three of the six survey items were perceived as facilitating distance learning. Study respondents perceived digital literacy (i.e., the abilities to locate, organize, understand, evaluate, analyze and create information using technology) of students, digital literacy of teachers, and the faculty's acceptance of state policy as facilitating policy implementation. The remaining three survey items in this category were among the lowest rated in the entire survey. The public school groups believed comparisons of the quality of distance learning courses to face-to-face courses did not facilitate implementation. The respondents also believed the level of support for distance learning among faculty members and perceptions of parents regarding distance learning courses did not facilitate the implementation of WVBE Policy 2450. Comments provided by respondents suggest that parents may have misconceptions 
of distance learning in general. Some respondents believe that parents sometimes pushed their children into distance learning courses without realizing the rigor of the courses and the commitment required for student success.

Resources. The resources category of factors was not perceived as facilitating the implementation of WVBE Policy 2450. The category was ranked last of the five categories $(M=3.39)$ and the collective responses of all study participants identified only two of the nine survey items as facilitating policy implementation. Those two items were (a) perceptions of student access to technology and instructional support and (b) perceptions of the school's computer network security system. Principals/assistant principals did not perceive even these two as facilitating implementation. While none of the survey items had mean scores low enough to be considered as impeding the policy $(M \leq 2.5)$, the five lowest scoring items in the entire survey were all related to resources. The five items, in order from the lowest rated, were regarding professional development opportunities, funds for professional development, time for implementation, cost of distance learning courses, and size of the school.

As the topic of the two lowest scoring items in this survey, professional development may assist the implementation of distance learning and the West Virginia Virtual School. Bral (2007) identified funding for professional development as the most significant funding barrier to the use of virtual courses in schools. Professional development could provide distance learning contacts and/or distance learning course facilitators the opportunity to improve their skills and learn of best practices to apply in their schools. Professional development about distance learning may also be valuable to faculties. The three public school groups that participated in this study did not perceive faculties' support of distance learning or knowledge of teaching methods used in distance learning as facilitators to the implementation of WVBE Policy 2450. Before 
professional development on this topic is provided, organizers may want to consider the findings of Plair (2010) who determined that professional development in technology can be best served through the ongoing support of a "knowledge broker" (p. iii).

Another survey item in the resource category that was low in the ratings was time to implement WVBE Policy 2450. The item had a mean score of 3.15 and was the third lowest scoring item in the survey. It was the lowest-rated item by counselors. One respondent provided comments to enlighten the researcher on his/her situation. The respondent wrote that he/she acted as the distance learning contact /course facilitator in addition to his/her regular position in the school and did not receive any additional compensation in time or pay for work with distance learning. The respondent described himself/herself as overwhelmed with the number of students in distance learning courses and wrote "(G)iven the lack of time or pay to attend to this job, I am going to have to limit the number of students who can enroll in virtual school courses"

(Appendix S). While this may be an isolated situation, it may also represent the opinions of others especially since the item about time to implement the policy scored so low. Individuals may be willing to make personal sacrifices of time and effort for a short while in order to help in the initial stages of policy implementation. It is unreasonable, however, to expect such sacrifices to continue for an extended period of time, especially without additional compensation. Fowler (2009) described such excessive demands as "a sure recipe for failure" (p. 292).

The cost of distance learning courses was the fourth of the five-lowest rated items in the questionnaire, all related to resources. The three public school groups surveyed in this study did not perceive cost to be a facilitating factor $(M=3.23)$. This researcher expected that cost might be a facilitating factor since the West Virginia Legislature allocates money to the West Virginia Virtual School to keep the costs low to school systems. Full tuition costs for the first 10 students 
in an individual course per year at a school are paid through West Virginia Virtual School state funds. Tuition for each student above 10 in the same course from the same school is $\$ 200$ per student from the local district. State funds are used to pay the remaining per student course cost that ranges from $\$ 400$ to $\$ 750$ (WVDE, 2012h, para. 25). Were respondents aware of the fee structure? Are there many situations where there are more than 10 students per course in the same school? Did those surveyed include other costs associated with distance learning (e.g., computers, Internet access) when responding to this item in the questionnaire? Such questions cannot be answered from this study.

The three public school groups in this study rated a survey item about the size of the school (i.e., number of students in Grades 9-12) as the fifth-lowest in the entire questionnaire. No respondents made comments about school size, and one can only speculate the reasoning behind the item's low score. The largest group of respondents $(n=71)$ consisted of those in schools of 450 to 800 students. The second largest group $(n=68)$ consisted of those in schools with less than 450 students, and the smallest group of respondents $(n=62)$ consisted of those in schools with over 800 students. Does student accessibility to technology vary with school size? Is distance learning more applicable in smaller schools where certified teachers may be unavailable for specific classes or is it more appropriate in larger schools because of greater flexibility in scheduling students? The relationship between size of a school and the implementation of distance learning in West Virginia high schools is unclear.

Differences by roles. This study collected perceptions of factors that may have facilitated and impeded the implementation of WVBE Policy 2450. The study compared the perceptions of individuals who serve in different roles in schools. The comparisons were made on an item-by-item basis using a One-Way Analysis of Variance (ANOVA). 
Principals versus distance learning contacts and/or course facilitators. There were significant differences between principals/assistant principals and distance learning contacts and/or distance learning course facilitators on six survey items. The six involved the resources (three items) and structure (three items) categories. In each case in which there were significant differences, distance learning contacts and/or course facilitators rated the survey items higher (more important to implementation) than the principals/assistant principals. All six items will be presented here and discussion included for those that have not been previously addressed in this chapter.

The three items in the resources category in which there were significant differences between principals/assistant principals and distance learning contacts and/or distance learning course facilitators were (a) student access to technology and instructional support, (b) time available for school personnel to implement WVBE Policy 2450, and (c) computer network security. Distance learning contacts and/or distance learning course facilitators perceived student access to technology and instructional support as a factor that facilitated the implementation of WVBE Policy 2450. Principals/assistant principals did not. This type of support is common in blended (also called hybrid) courses that mix online and face-to face content delivery (Picciano, 2009; Picciano \& Seaman, 2007; Picciano \& Seaman, 2009). One respondent in this study stated that "technology is available whether at the school, in the community at the public library or in the student's home. However, there is a lack of instructional support from trained personnel" (Appendix S). Principals in Iowa believed that students must have certain traits such as selfdiscipline and motivation to be successful in online courses (Prescott, 2004). Since West Virginia principals rated a survey item about technology and instructional support low, one 
wonders if they also believe students should also be self-disciplined, motivated, and perhaps less dependent on the technology and instructional support provided by others.

Distance learning contacts and/or distance learning course facilitators perceived time as an important factor to facilitate the implementation of WVBE 2450. Principals/assistant principals and counselors rated a survey item about time significantly lower than did the others. The topic of time for implementation was previously discussed in this chapter.

Distance learning contacts and/or distance learning course facilitators perceived computer network security (protection from computer viruses and hackers) as a factor that facilitated the implementation of WVBE Policy $2450(M=4.07)$. Principals did not $(M=3.55)$. The difference in these perceptions may be related to familiarity with the technology used in distance learning. Principals/assistant principals may not be aware of firewalls and other safeguards provided by course providers to ensure network security. Online class security issues were not considered a barrier by $56.8 \%$ of respondents in research completed by Bral (2007).

The three items in the structure category in which there were significant differences between principals/assistant principals and distance learning contacts and/or distance learning course facilitators were (a) WVBE Policy 2460, (b) assessment of student learning in distance learning courses, and (c) support from the WVDE. Distance learning contacts and/or distance learning course facilitators perceived WVBE Policy 2460, Educational Purpose and Acceptable Use of Electronic Resources, Technologies, and the Internet, as a factor that facilitated the implementation of WVBE Policy 2450. Principals did not. The mean score required for a factor to be considered as a facilitator was 3.60. The mean score from principals/assistant principals for this item was 3.59, and the effect size was small to medium. WVBE Policy 2460 outlines regulations to help schools meet local, state, and federal statutes pertaining to safe and acceptable 
use of the Internet and various digital resources and technologies. Distance learning contacts and/or course facilitators may have felt WVBE Policy 2460 was essential to the implementation of WVBE Policy 2450 while some principals may have felt the WVBE Policy 2460 conflicted with WVBE Policy 2450. Further research would be needed to determine the reasons behind these perceptions.

Principals/assistant principals rated a survey item about assessment significantly lower $(M=3.54)$ than did distance learning contacts and/or course facilitators $(M=4.07)$. One may speculate that principals/assistant principals may share concerns similar to those found in the research of Black, Ferdig, and DiPietro (2008) that effective means for assessing and evaluating distance learning have not been fully developed. The difference in perceptions may also result from principals being uninformed of the type and rigor of the assessments currently used in distance learning courses. However, this difference could also result from distance learning contacts and/or course facilitators being unfamiliar with the components of high-quality assessments and/or expectations of the principal.

The third item in the structure category having a significant difference in perceptions between principals/assistant principals and distance learning contacts and/or course facilitators was regarding the level of support from the WVDE. Principals did not perceive the support from the WVDE to be as facilitating as did distance learning contacts and/or course facilitators. The difference had a medium to large effect size. It is unclear why this difference exists but could be because distance learning contacts are responsible for some of the managerial duties associated with distance learning including the authority to contact the West Virginia Virtual School to enroll students. As a result, principals/assistant principals may have less contact with WVDE staff than the distance learning contacts, causing them to rate the support lower. 


\section{Counselors versus distance learning contacts and/or course facilitators. The}

perceptions of counselors and distance learning contacts and/or course facilitators significantly differed on five survey items, and three of them were related to resources. Counselors comprised the largest single category of respondents in this study $(n=82)$ and over half of them were directly involved in distance learning. These results suggest counselors may be important to the implementation of distance learning in schools. Like principals/assistant principals, counselors did not perceive the time required for policy implementation to be as facilitating to the implementation of Policy 2450 as did the distance learning contacts and/or course facilitators. This was the only survey item in which there was a significant difference between distance learning contacts and/or course facilitators and the other two groups. These differences cause one to wonder if distances learning contacts and/or course facilitators have conveyed to principals and counselors the amount of time needed to perform their distance learning duties. Other survey items with significant differences between these counselors and distance learning contacts and/or course facilitators related to the factor resources and were regarding the number of computers for students and Internet access.

Principals versus counselors. There were no significant differences in the perceptions of principals/assistant principals and counselors on any of the 35 survey items. One might speculate that counselors are in frequent contact with principals/assistant principals and that these interactions contribute to agreement in their perceptions of distance learning in the school.

Differences by enrollment. Data from respondents in schools having $1 \%$ or more of the students enrolled in distance learning courses between 2008 and 2011 (Group A) were compared with those in schools having less than $1 \%$ of the students enrolled in distance learning courses in the same time (Group B). Over 40\% of the respondents in Group A were from schools with less 
than 450 students in Grades 9-12 and over 40\% of the respondents in Group B were from schools with over 800 students in Grades 9-12. The comparisons were made using Independent t-Tests. Significant differences were found in the perceptions of seven survey items. In each case where there were significant differences between these groups, respondents in Group A rated the survey items higher than those in Group B. One of the seven survey items dealt with the people category of factors, and two survey items were in each of three other categories: resources, structure, and culture. All seven items will be presented here and discussion included for those that have not been previously addressed in this chapter.

The counselor as a source of information was the survey item in the people category that yielded a significant difference in the perceptions of Group A and Group B. While those in both Groups A and B perceived this as a facilitating factor, the perception of the counselor as a source of information was rated significantly higher by those in schools in Group A than in Group B. Counselors assist students in academic program planning and individual course selection (WVBE Policy 2315, 2012). "School counselors are responsible for identifying students who may benefit from virtual courses, helping students identify appropriate courses, and confirming that courses selected align with each student's five year plan" (WVDE, 2012a, para. 2). The higher rating of this survey item by those in Group A is especially interesting because of the demographics of the two groups. There were 39 counselors among the 119 total respondents in Group A. This means 32.77\% of the respondents in Group A were counselors. Group B had 43 counselors among the 97 respondents for a $44.33 \%$ portion. In other words, the group with the smaller portion of counselors (Group A) rated the item about counselors significantly higher than the group with a larger portion of counselors (Group B). Responses from all counselors rated this item the highest of all survey items. One may speculate that the differences in perceptions 
between Group A and Group B on this item may be attributed to the perceptions of those other than counselors.

The two survey items in the resources category with significant differences between Groups A and B were about (a) available time for distance learning contacts and/or course facilitators and (b) size of the school. Neither group perceived either of the factors as facilitators to the implementation of WVBE Policy 2450. Both topics were previously discussed in this chapter

The two survey items in the structures category with significant differences between Groups A and B were about (a) assessment of student learning in distance learning courses and (b) the ability of students to enroll in distance learning courses without experiencing scheduling conflicts. Those in Group A perceived both of these items as facilitating the implementation of WVBE Policy 2450 in schools but those in Group B did not perceive either of these items as facilitating the policy's implementation. Assessment has been previously discussed in this chapter, but student scheduling has not. Setzer and Lewis (2005) found that reducing scheduling conflicts was a listed by $23 \%$ of the districts as a very important reason to utilize distance learning courses. Reducing scheduling conflicts for students is one of the most important reasons for schools to use distance learning (Picciano \& Seaman, 2007). Schools in Group A may have policies or established practices that interfere with scheduling students into distance learning courses.

The two survey items in the culture category with significant differences between Groups A and B were about (a) faculty acceptance of state policy and (b) faculty support of distance learning. Those in Group A perceived both of these items as facilitating the implementation of WVBE Policy 2450 in schools but those in Group B rated them lower. 
Respondents in Group B did not perceive the faculty's acceptance of state policy as a factor that facilitated the implementation of WVBE Policy 2450. The level of policy acceptance within a school or community's culture impacts implementation (Wood, 2008). The West Virginia Virtual School was created by the West Virginia Legislature and is the subject of WVBE Policy 2450. However, schools are not forced to enroll students in courses offered through the West Virginia Virtual School. It may be that some of those located in Group B schools are resistant to state policy and unwilling to make genuine efforts to promote distance learning as described in WVBE Policy 2450.

Respondents in Group B did not perceive faculty support of distance learning as a factor that facilitated the implementation of WVBE Policy 2450. This seems consistent with results from survey items in the people category of factors. Only two items in the people category were not perceived by those in Group B as facilitating the implementation of WVBE Policy 2450. Those items were Item \#4, School faculty's knowledge of teaching methods used in distance learning and Item \#6, Faculty’s willingness to learn about distance learning courses. While neither of these two yielded a significant difference in comparison with results from Group A, they do seem to indicate a culture not conducive to distance learning. The ever-changing world of distance learning may be difficult for some faculty members to accept. Faculty resistance to change was identified as a barrier by $57.5 \%$ of respondents in Bral's (2007) study.

None of the seven questionnaire items having significant differences between Groups A and B individually had an effect size other than small to medium. However, the collective effect size of these items was medium to large. One might speculate that each individual item by itself had little or no effect on the implementation of Policy 2450 but that the coexistence of these factors created a situation that did not facilitate distance learning. 


\section{Recommendations for Policy}

The following policy recommendations are derived from the researcher's review of WVBE Policy 2450 and experiences in the data collection process used for this study.

1. The West Virginia Board of Education should revise Policy 2450 to include definitions of terms used in the policy. Although most respondents in this study believed the policy to be clear, closer examination by this researcher left a different impression. Policy 2450 uses the terms distance learning courses, online learning courses, virtual courses, and technologydelivered courses. In some portions of the policy, the terms appear to mean different things and in other portions of the policy the terms seem to be synonymous. The addition of definitions and consistent use of terms would improve the policy's clarity.

2. The West Virginia Board of Education should revise Policy 2450 to more clearly define the responsibilities of and relationship between a distance learning contact and distance learning course facilitators. A distance learning contact is an individual at a local school designated by the county superintendent to ensure virtual course information is provided to students and parents, secure any necessary affiliation agreements with the course provider, and ensure that a facilitator has been identified for each course offered (WVBE Policy 2450, 2012). The distance learning contact also has the authority to contact the West Virginia Virtual School to enroll students in distance learning courses. The specific definition and responsibilities of distance learning course facilitators are not found in the policy although the policy does outline the training they are to receive. In practice, a distance learning course facilitator is a person of record who monitors the academic performance of students enrolled in distance learning courses and is designated to receive reports from the course provider concerning individual student progress (G. Burdette, personal communication, Apr. 6, 2012). Clarifying the responsibilities of 
and differences between a distance learning contact and distance learning course facilitator in policy may assist its implementation at the local level and be especially helpful to school districts with low enrollments in distance learning courses.

3. The West Virginia Department of Education should create a policy guidance document to assist schools in the implementation of WVBE Policy 2450. Requests for such a document revealed that no such document exists. While schools can access information from the WVDE website and by attending professional development when provided, the development and distribution of a guidance document as a companion to WVBE Policy 2450 may be beneficial to policy implementers at the school level. The document could include information such as: the responsibilities of distance learning contacts and course facilitators; the role of principals and counselors in distance learning; available distance learning courses, course descriptions, providers, and costs and where to find updated information regarding such; typical technology and infrastructure requirements; procedures for enrolling students, monitoring progress, reporting grades, and completing other managerial duties; sources of professional development; and recommended items for inclusion in district and/or school distance learning policies.

\section{Recommendations for Practice}

1. Professional development opportunities specific to distance learning should be made available to distance learning course contacts and/or course facilitators. The two survey items that were the lowest rated in the questionnaire were about the time and money for professional development for distance learning contacts and /or course facilitators. One respondent commented that he/she was unaware of any professional development opportunities about distance learning and another asked if there was still an annual meeting of course facilitators. Professional development opportunities could allow implementers to interact with those in 
similar positions in other schools to share successes experienced and challenges encountered. Representatives from schools with student enrollments in distance learning classes above the state average could share effective strategies with schools having enrollments below the state average. Easing class schedules to provide staff members with more opportunities to exchange materials and tips is a valuable way for school leaders to provide ongoing, targeted assistance (Fowler, 2009).

2. School principals and counselors should be provided with a better understanding of the time required of distance learning contacts and/or distance learning course facilitators to fulfill their responsibilities. Administrators who utilize distance learning courses in their schools apparently do not always consider the additional duties placed on staff members who work with the program. Distance learning contacts and/or course facilitators need to communicate with West Virginia Department of Education and/or distance learning course providers on a regular basis. They must also perform related tasks such as seeking solutions to problems with computers and Internet connectivity to ensure smooth delivery of the courses at the school level. These obligations require time, and it may be difficult for distance learning contacts and/or course facilitators who also serve as counselors, librarians, or teachers of traditional courses to complete their distance learning responsibilities without the provision of additional time in their schedules.

3. More information about the assessments used in distance learning courses should be provided to schools and reviewed at each school in a meeting of principals and distance learning contacts and/or course facilitators. The perceptions of principals/assistant principals about the assessment of student learning in distance learning courses scored significantly lower than those of distance learning contacts and/or distance learning course facilitators. These differences in 
perceptions may have been due to a lack of understanding by either one or both of the groups as a result of lack of knowledge, inadequate communication, different expectations, or other reasons. Conversations between principals and distance learning contacts and/or course facilitators about this topic may result in a better understanding of student assessment in distance learning courses.

4. The West Virginia Department of Education should establish more regular, timely communications with principals about current events in the West Virginia Virtual School. There were six survey items in which there were significant differences between the perceptions of principals/assistant principals and distance learning contacts and/or distance learning course facilitators. One of those items with a medium to large effect size was regarding the level of support provided by the WVDE. Principals/assistant principals did not perceive the support from the WVDE to be as facilitating as did distance learning contacts and/or course facilitators. Updates about available new courses, opportunities for professional development, or effective practices in schools should be shared with administrators on a regular basis.

5. Faculties should be provided with information about distance learning to ensure a more uniform understanding of it. The three public school groups providing responses in this study perceived that faculty members have various levels of understanding about distance learning including the quality of the courses, instructional methods used, and skills needed by course facilitators. Even some respondents indicated by their written comments that they did not know about the costs of these courses and recognition of credit by colleges. One also wonders if some faculty members may actually discourage students from enrolling in distance learning courses out of fear their jobs as teachers of traditional courses would be in jeopardy if enrollment in distance learning increased. 
6. Principals should work with counselors, distance learning contacts, distance learning course facilitators, and/or the WVDE to ensure parents have access to friendly and accurate information about distance learning in schools. Although parents were not surveyed in this study, the public school groups ranked the survey item about parents' perceptions of distance learning $28^{\text {th }}$ out of the 35 items and did not identify it as a factor that facilitates implementation.

Respondents indicated through their comments that providing such information might reduce parents' misconceptions of distance learning and may help them give better advice to their children about including distance learning courses into their schedules.

7. Individuals in a school who are directly involved in distance learning should frequently communicate with the principal, assistant principal(s), counselor(s), and each other about the program's status in the school. Sixty-three percent of respondents identified themselves as directly involved with distance learning in their schools. Since over one-third of those identified for this study were not directly involved with distance learning, regular communication may be beneficial to implementation. The support of administrators in the local school was perceived as one of the factors most facilitating to the implementation of WVBE Policy 2450. Frequent interaction between school leaders and policy implementers, keeping all informed, is valuable to the success of an initiative (Fowler, 2009).

Since administrators and counselors have numerous responsibilities other than those associated with distance learning, it can become easy for them to lose track of the distance learning initiative unless distance learning contacts and/or distance learning course facilitators initiate the communication. It may be necessary for distance learning implementers to request regular meetings with their principal, assistant principal(s), and counselor(s) to provide updates of the program's status and resource needs (including time and professional development). 
8. Based on the researcher's experiences in collecting data for this study, the WVDE should improve its ability to access and report data about distance learning. While the WVDE was accommodating to every request for information in this study, the requests usually required an employee to assemble data found in various files. It appears the accuracy of the data has vastly improved over the last 10 years. The WVDE should now invest the human resources necessary to enable easier access and reporting of data to help the organization and local schools make data-based decisions affecting distance learning.

\section{Recommendations for Research}

1. A study should be conducted researching high school students' perceptions of distance learning courses. Only $1 \%$ of West Virginia high school students enrolled in a distance learning course between 2008 and 2011. Research should be conducted to determine the cause(s) of this. One possible study might compare perceptions of students who enrolled distance learning courses versus those who did not take distance learning courses. Another could compare student perceptions of distance learning from those with varying levels of success in it.

2. A follow-up qualitative study should be conducted involving interviews with a sample of those who participated in this study. This research identified factors important to the implementation of WVBE Policy 2450. No factors scored low enough in the analysis of data to be considered as impeding the policy's implementation. However, comments left by respondents suggest there are obstacles in schools that merit attention. Some respondents described principals and counselors who do not encourage students to take distance learning courses. Others mentioned the lack of information about distance learning being provided to faculty, students, and parents. Reasons for differences in perceptions about the cost of distance learning were 
unclear. A follow-up qualitative study may give a deeper understanding of the data collected in this study.

3. A study should be conducted to determine if there are differences in perceptions of distance learning from those within the same school. This study identified significant differences in perceptions of distance learning between respondents based on (a) their roles in the school (e.g., principals, counselors) and (b) the percentage of students enrolled in distance learning courses in their schools. However, only selected individuals in each school were surveyed. Research conducted within individual schools involving all faculty members may provide more information about factors that facilitate and impede implementation of WVBE Policy 2450.

4. Research should be conducted to examine the relationship between school size (i.e., student enrollment in Grades 9-12) and distance learning. Size of the school was one of only 13 factors that did not facilitate policy implementation. Responses also revealed a significant difference in perceptions between those in Group A and Group B. Further research may be warranted to determine if there are identifiable reasons for these differences.

5. This study should be replicated at some future time to determine if perceptions have changed from those collected in this study. Potential changes in high school graduation requirements, college entrance requirements, public school funding, and/or difficulties in meeting staffing needs may impact the ability of local schools to meet the needs of students through traditional instructional methods. School systems may find the need to more earnestly explore alternative means of course delivery including the use of distance learning classes. Such changes could impact how individuals perceive the factors important to the implementation of Policy 2450. 
6. This study could serve as a model to collect perceptions of the implementation of other state education policies. Policy implementation is affected by five factors: (a) people, (b) communication, (c) resources, (d) structures, and (e) culture. The format of this study's questionnaire could be used to gather perceptions of the implementation of other policies. Survey items could be replaced with those pertinent to other policies. 


\section{References}

Abdal-Haqq, I. (1996). Making time for teacher professional development. ERIC Digest (Report No. EDO-SP-95-4). Retrieved from ERIC database. (ED400259)

American Federation of Teachers - West Virginia. (2011). Frequently asked questions about AFT-WV. Retrieved September 7, 2011, from http://wv.aft.org/index.cfm?action=article\&articleID=21b0f5ed-af49-4791-886bf3587eea7ac0

Anderson, G. (1998). Fundamentals of educational research. Philadelphia: RoutledgeFalmer

Archer, J. (2004, September). Instructional leadership. Education Week, 24(3), S7. Retrieved from http://www.edweek.org/media/wallace04.pdf

Ball, S. J. (1990). Politics and policy making in education: Explorations in policy sociology. London: Routledge.

Bangser, M. (2008). Evaluating the impact of interventions that promote successful transitions from high school. Retrieved from National High School Center website: http://www.betterhighschools.org/docs/ResearchBrief_ImpactofInterventions_073108.pdf

Barbour, M. \& Reeves, T. (2009). The reality of virtual schools: A review of the literature. Computers \& Education, 52(2), 402-416.

Barton, C. (2010). Hawaii Board of Education's Middle Grade Promotion Policy: A policy implementation study (Doctoral dissertation). Retrieved from ProQuest Dissertations and Theses database. (UMI No. 3403522) 
Baum, L. (1984). Legislatures, courts, and the dispositions of policy implementors. In G.C. Edwards III (Ed.), Public policy implementation (pp. 29-57). Greenwich, CN: JAI Press.

Berge, Z. L., \& Clark, T. (2005). Virtual schools: Planning for success. New York, NY: Teachers College Press.

Berman P. (1978). The study of macro and micro implementation. Public Policy 27,157-184.

Berman, P., \& McLaughlin, M. W. (1978). Federal programs supporting educational change, Vol. VIII: Implementing and sustaining innovations. Santa Monica, CA: RAND Education.

Beyle, T. L. (2001). State and local government, 2001-2002. Washington, D.C.: Congressional Quarterly Press.

Biemer, P., and Lyberg, L. (2003). Introduction to survey quality. Hoboken, NJ: John Wiley \& Sons, Inc.

Bill \& Melinda Gates Foundation. (2011). Grants. Retrieved September 6, 2011, from http://www.gatesfoundation.org/grantseeker/Pages/default.aspx

Black, E., Ferdig, R., \& DiPietro, M. (2008). An overview of evaluative instrumentation for virtual high schools. The American Journal of Distance Education, 22. 24-45. doi: $10.1080 / 08923640701713422$

Black, J. A., \& Champion, D. J. (1976). Methods and issues in social research. New York: Wiley. 
Bodilly, S. J. (1998). Lessons from New American Schools'scale-up phase. Santa Monica, CA: RAND Education.

Boulianne, S. (2008). Incentives. In P. Lavrakas (Ed.), Encyclopedia of survey research methods (pp. 329-332). Thousand Oaks, CA: SAGE Publications.

Boyd, W., \& Crowson, R. (2002). The quest for a new hierarchy in education: From loose coupling back to tight? Journal of Education Administration, 40(6), 521-533.

Brace, I. (2008). Questionnaire design: How to plan, structure and write survey material for effective market research (2nd ed.). London: Kogan Page.

Bral, C. (2007). An investigation of incorporating online courses in public high school curricula (Doctoral dissertation). Retrieved from ProQuest Dissertations and Theses database. (UMI No. 3293928)

Brill, J. (2008). Likert scale. In P. Lavrakas (Ed.), Encyclopedia of survey research methods (pp. 428-430). Thousand Oaks, CA: SAGE Publications.

Brown, C., Hess, F., Lautzenheiser, D., \& Owen, I. (2011). State education agencies as agents of change: What it will take for the states to step up on education reform. Washington, DC: Center for American Progress.

Brynard, P. (2005, December). Policy implementation: Lessons for service delivery. Paper presented at the Twenty-seventh AAPAM Annual Roundtable Conference, Livingstone, Zambia. Retrieved from http://unpan1.un.org/intradoc/groups/public/documents/AAPAM/UNPAN025756.pdf 
Bryson, J. M., \& Crosby, B. C. (1992). Leadership for the common good: Tackling public problems in a shared power world. San Francisco: Jossey-Bass.

Byrd, J., Drews, C., \& Johnson, J. (2006). Factors impacting superintendent turnover: Lessons from the field. National Council of Professors of Educational Administration Education Leadership Review 7(2). Retrieved from http://cnx.org/content/m14507/latest/

Calefati, J. (2009, April). School safety, 10 years after Columbine. U. S. News and World Report, 146(4). Retrieved from http://www.usnews.com/education/articles/2009/04/17/schoolsafety-10-years-after-columbine?PageNr=1

Carter, G. R., \& Cunningham, W. G. (1997). The American school superintendent. San Francisco: Jossey-Bass.

Cavanaugh, C. (2001). The effectiveness of interactive distance education technologies in K-12 learning: A meta-analysis. International Journal of Educational Telecommunications, 7(1), 73-78.

Cavanaugh, C. S., Barbour, M. K., \& Clark, T. (2009). Research and practice in K-12 online learning: A review of open access literature. The International Review of Research in Open and Distance Learning, 10(1), 1-22. Retrieved from http://www.irrodl.org/index.php/irrodl/article/view/607/1183

Center for Digital Education (2008). Online learning policy and practice survey: A survey of the states. Retrieved from ERIC database. (ED503110)

Center on Education Policy. (2011). More to do, but less capacity to do it: States' progress in implementing the recovery act education reforms. Washington, DC: Author. 
Chubb, J. (2012, February). Overcoming the governance challenge in K-12 online learning (Working Paper No. 5). Retrieved from the Thomas B. Fordham Institute website: http://www.edexcellence.net/publications/overcoming-the-governance-challenge-in-k-12online-learning.html

Cibulka, J. G. (1995). Policy analysis and the study of the politics of education. In J. D. Scribner \& D. Layton (Eds.), The study of educational politics (pp. 105-125). London: Falmer Press.

Clark, T. (2000). Virtual high schools: State of the states. A study of virtual high school planning and operation in the United States. Macomb, IL: Center for the Application of Information Technologies.

Clark, T. (2001). Virtual schools: trends and issues. A study of virtual schools in the United States. Macomb, IL: Center for the Application of Information Technologies.

Climate. (2011). In Dictionary.com unabridged. Retrieved from http://dictionary.reference.com/browse/climate

Cohen, J. (1969). Statistical power analysis for the behavioral sciences. NY: Academic Press.

Constitution of West Virginia. art. I-XII. (2012). Retrieved on March 15, 2012, from http://www.legis.state.wv.us/WVCODE/WV_CON.cfm

Creative Research Systems. (2011). Sample size calculator. Retrieved January 7, 2012, from http://www.surveysystem.com/sscalc.htm

Cresswell, J. (2009). Research design: Qualitative, quantitative, and mixed methods approaches (3rd ed.). Thousand Oaks, CA: SAGE Publications. 
Dunn, W. (1977). Public administration: Public policy. Chapters 1-6, Package X. Retrieved from ERIC database. (ED194666)

Education Commission of the States. (2011). About ECS. Retrieved July 2, 2011, from http://www.ecs.org/html/aboutECS/home_aboutECS.htm

Eisenhart, M., Cuthbert, A., Shrum, J., \& Harding, J. (1988). Teacher beliefs about their work activities: Policy implications. Theory into Practice, 27(2), 137-144.

Elmore, R. F. (1979). Backward mapping: Implementation research and policy decisions. Political Science Quarterly, 94(4), 601-616.

Farkas, S., Johnson, J., Duffett, A., \& Foleno, T. (2001). Trying to stay ahead of the game: Superintendents and principals talk about school leadership. New York: Public Agenda.

Firestone, W. A. (1989). Educational policy as an ecology of games. Educational Researcher, $18,18-23$.

Florida Virtual School. (2012). Florida Virtual School quick facts. Retrieved January 22, 2012, from Florida Virtual School website: http://flvs.net/areas/aboutus/Pages/QuickFactsaboutFLVS.aspx

Foerstel, H. N. (2002). Banned in the U.S.A.: A reference guide to book censorship in schools and public libraries (Revised and expanded ed.). Westport, CT: Greenwood Press.

Fowler, F. C. (2009). Policy studies for educational leaders: An introduction (3rd ed.). Boston: Allyn \& Bacon. 
Fowler, J. (2009). An investigation of the factors influencing special education directors in South Carolina in the implementation of policy (Doctoral dissertation). Retrieved from ProQuest Dissertations and Theses database. (UMI No. 3355115)

Fullan, M. (2001). Leading in a culture of change. San Francisco: Jossey-Bass.

Fullan, M. (2007). The new meaning of educational change (4th ed.). New York: Teachers College Press.

Fullan, M., Bertani, A., \& Quinn, J. (2004). New lessons for districtwide reform. Educational Leadership, 61(7), 42-46.

Garn, G. (1999). Solving the implementation problem: The case of Arizona charter schools. Education Policy Analysis Archives, 7(26), 1-18. Retrieved from http://epaa.asu.edu.www.libproxy.wvu.edu/ojs/article/view/561/684

Gay, L., Mills, G., and Airasian, P. (2009). Educational research: Competencies for analysis and applications (9th ed.). Upper Saddle River, NJ: Pearson.

Glass, G. (2009). The realities of $K-12$ virtual education. Boulder, CO, \& Tempe, AZ: Education and the Public Interest Center \& Education Policy Research Unit. Retrieved from http://epicpolicy.org/publication/realities-K-12-virtual-education

Glass, G. (2010). Potholes in the road to virtual schooling. School Administrator, 67(4), 32-35.

Gonder, P., \& Hymes, D. (1994). Improving school climate and culture (Critical Issues Report No. 27). Arlington, VA: American Association of School Administrators. 
Gray, L., \& Lewis, L. (2009). Educational technology in public school districts: Fall 2008 (NCES 2010-003). Retrieved from National Center for Education Statistics website: http://nces.ed.gov/pubs2010/2010003.pdf

Grimes, R. (1982, May 14). School funds ruling outrages state officials. The Charleston Daily Mail. Retrieved from http://www.wvculture.org/history/education/recht02.html

Gross, N., Giacquinta, J. B., \& Bernstein, M. (1971). Implementing organizational innovations. New York: Basic Books.

Harris, A. J. (2012, March 15). Broadband installation grant: State schools' high-speed going slo-mo. The Charleston Gazette, pp. C1, C6.

Hassel, B.C, \& Hassel, E. A. (2011, November). Teachers in the age of digital instruction (Working Paper No. 2). Retrieved from the Thomas B. Fordham Institute website: http://www.edexcellence.net/publications/teachers-in-the-age-of-digital-instruction.html

Hauge, J. (2008). High school principal and counselor perceptions concerning distance education and the South Dakota Virtual High School (Doctoral dissertation). Retrieved from ProQuest Dissertations and Theses database. (UMI No. 3318819)

Hazi, H. (1989). Teachers and the Recht decision: A West Virginia case study of school reform. Retrieved from ERIC database. (ED318597)

Honig, M. (2006). Complexity and policy implementation: Challenges and opportunities for the field. In M. Honig (Ed.), New directions in education policy implementation: Confronting complexity (pp. 1-23). Albany, NY: State University of New York Press. 
Howell, S., Sorenson, D., \& Tippets, H. R. (2009). The new (and old) news about cheating for distance educators. Online Journal of Distance Learning Administration 12(3). Retrieved from http://www.westga.edu/ distance/ojdla/fall123/howell123.html

Hoy, W. K., \& Sweetland, S. R. (2001). Designing better schools: The meaning and measure of enabling school structures. Educational Administration Quarterly, 37(3), 296-321.

Huberman, A. M., \& Miles, M. B. (1984). Innovation up close. New York: Plenum Press.

Iarossi, G. (2006). The power of survey design: A user's guide for managing surveys, interpreting results, and influencing respondents. Washington, DC: The World Bank.

International Association for K-12 Online Learning (2011). National standards for quality online teaching. Retrieved from http://www.inacol.org/research/nationalstandards/iNACOL_TeachingStandardsv2.pdf

Jerald, C. (2005). The implementation trap: Helping schools overcome barriers to change. Washington, D.C.: The Center for Comprehensive School Reform and Improvement.

Johnson, J. D., \& Chang, H. (2000). Internal and external communication, boundary spanning, and innovation adoption: An over-time comparison of three explanations of internal and external innovation communication in a new organizational form. The Journal of Business Communication, 37(3), 238-263.

Joint Commission on Standards for Educational Evaluation. (1994). The program evaluation standards (2nd ed.). Thousand Oaks, CA: SAGE Publications.

Kaseman, L., \& Kaseman, S. (2000). How will virtual schools effect homeschooling? Home Education Magazine (November-December), 16-19. 
Keegan, D. (1996). Foundations of distance education. London: Routledge.

Kennedy, C. (2008). Bipolar scale. In P. Lavrakas (Ed.), Encyclopedia of survey research methods (pp. 64-65). Thousand Oaks, CA: SAGE Publications.

Kingdon, J. W. (2003). Agendas, alternatives, and public policies (3rd ed.). New York: Longman.

Klugkist, I. (2008). Analysis of variance (ANOVA). In P. Lavrakas (Ed.), Encyclopedia of survey research methods (pp. 27-28). Thousand Oaks, CA: SAGE Publications.

Knapp, M. S. (1997). Between systemic reforms and the mathematics and science classroom: The dynamics of innovation, implementation, and professional learning. Review of Educational Research, 67(2), 227-266.

Knapp, M. S., Bamburg, J. D., Ferguson, M. C., \& Hill, P. T. (1998). Converging reforms and the working lives of frontline professionals in schools. Educational Policy, 12(4), 397418.

Kotter, J. P. (1996). Leading change. Boston: Harvard Business School Press.

Kotter, J. P. (1998). Leading change: Why transformation efforts fail. In Harvard business review on change (pp. 1-20). Boston: President and Fellows of Harvard College.

Kowalski, T. (2006). The school superintendent: Theory, practice, and cases (2nd ed.). Thousand Oaks, CA: SAGE Publications.

Kozma, R., Zucker, A., \& Espinoza, C. (1998). An evaluation of the Virtual High School after one year of operation. Arlington, VA: SRI International. 
Kruschke, E. R., \& Jackson, B. M. (1987). The public policy dictionary. Santa Barbara, CA:ABC-CLIO.

Lee, H. (2008). Outliers. In P. Lavrakas (Ed.), Encyclopedia of survey research methods (pp. 558-559). Thousand Oaks, CA: SAGE Publications.

Lips, D. (2010). How online learning is revolutionizing $K-12$ education and benefiting students. (Backgrounder No. 2356). Washington, DC: Heritage Foundation.

Lipsky, M. (1980). Street level bureaucracy: Dilemmas of the individual in public services. New York: Russell Sage Foundation.

Lopez, O. (1995). The effect of the relationship between classroom student diversity and teacher capacity on student performance. Retrieved from ERIC database. (ED386423)

Louis, K. S., \& Miles, M. B. (1990). Improving the urban high school. New York: Teachers College Press.

Madsen, J. (1994). Educational reform at the state level. Bristol, PA: Falmer Press.

Marra, A. (2011, August 22). School transfer policy sidelines St. Albans running back. Charleston Daily Mail. Retrieved from http://charlestondailymail.com/News/Kanawha/201108211548

Marshall, C., Mitchell, D., \& Wirt, F. (1989). Culture and education policy in the American states. New York: Falmer Press.

Maynard-Moody, S., \& Musheno, M. (2003). Cops, teachers, counselors: Stories from the front lines of public service. Ann Arbor, MI: University of Michigan Press. 
McCarthy, M. (2001). Washington elementary schools on the slow track under standards-based reform. Seattle, WA: Center on Reinventing Public Education, Daniel J. Evans School of Public Affairs, University of Washington. Retrieved from http://www.crpe.org/cs/crpe/download/csr_files/pub_crpe_wastel_oct01.pdf

McDonnell, L.M., \& Elmore, R.F. (1987). Getting the job done: Alternative policy instruments. Educational Evaluation and Policy Analysis, 9(2), 133-152.

McLaughlin, M. (1991). The Rand Change Agent Study: Ten years later. In A. Odden (Ed.), Education policy implementation (pp. 143-156). Albany, NY: State University of New York Press.

McLaughlin, M., \& Elmore, R. (1982). Implementation of federal education programs: Implications for future federal policy. Peabody Journal of Education, 60 (1), 8-19.

McLeod, S. A. (2008). Simply psychology; Qualitative quantitative. Retrieved January 15, 2012, from http://www.simplypsychology.org/qualitative-quantitative.html

Merriam, S. (2002). Qualitative research in practice: Examples for discussion and analysis. San Francisco, CA: John Wiley \& Sons, Inc.

Miles, M., \& Huberman, A.M. (1994). Qualitative data analysis: An expanded sourcebook (2nd ed.). Thousand Oaks, CA: SAGE Publications.

Miller, L., \& Smith, K.. (1983). Handling nonresponse issues. Journal of Extension, 21(5), 4550. Retrieved from http://www.joe.org/joe/1983september/83-5-a7.pdf

Mirel, J. (1994). The evolution of the New American Schools: From revolution to mainstream. New York: Fordham Foundation. 
Moe, T., \& Chubb, J. (2009). Liberating learning: Technology, politics, and the future of American education. San Francisco: Jossey-Bass.

Mondotimes. (2012). Highest circulation West Virginia newspapers. Retrieved February 5, 2012, from Mondotimes website: http://www.mondotimes.com/newspapers/usa/westvirginianewspaper-circulation.html

Moore, M. G., \& Anderson, W. G. (2003). Handbook of distance education. Mahwah, NJ: Lawrence Erlbaum Associates.

Morris, S. (2002). Teaching and learning online: A step-by-step guide for designing an online $K$ 12 school program. Lanham, MD: Scarecrow Press Inc.

Morse, B. C. (2010). Virtual education in Rhode Island's K-12 public schools: Current status and perceptions of administrators (Doctoral dissertation). Retrieved from ProQuest Dissertations and Theses database. (UMI No. 3397945)

Moser, C. (2005). Principals' implementation of exclusion policy in Tennessee public high schools (Doctoral dissertation). Retrieved from ProQuest Dissertations and Theses database. (UMI No. 3205791)

Murphy, E., \& Coffin, G. (2003). Synchronous communication in a web-based senior high school course: Maximizing affordances and minimizing the constraints of the tool. The American Journal of Distance Education, 17(4), 235-246.

Muschert, G. (2007). Research in school shootings. Sociology Compass, 1(1), 60-80. doi: 10.1111/j.1751-9020.2007.00008.x 
Myers, V. (2008). Factors impacting teacher efficacy in policy implementation: The case of the Reading First initiative (Doctoral dissertation). Retrieved from ProQuest Dissertations and Theses database. (UMI No. 3483994)

Nakamura, R.T., \& Smallwood, F. (1980). The politics of policy implementation. New York: St. Martin's Press.

National Commission on Excellence in Education. (1983). A nation at risk: The imperative for educational reform: A report to the Nation and the Secretary of Education. Washington, DC: U.S. Government Printing Office.

National Conference of State Legislatures. (2009). Full and part-time legislatures. Retrieved September 23, 2011, from http://www.ncsl.org/?tabid=16701\#side_by_side

Nunnally, J. C., \& Bernstein, I. H. (1994). Psychometric theory. New York: McGraw-Hill.

Osumi, J. (2010). The influence of counselors and high school organization on the selection of participants for a dual credit program (Doctoral dissertation). Retrieved from ProQuest Dissertations and Theses database. (UMI No. 3434485)

Patten, M. (2011). Questionnaire research: A practical guide (3rd ed.). Glendale, CA: Pyrczak Publishing.

Patton, M. (1990). Qualitative evaluation and research methods (2nd ed.) Newbury Park, CA: SAGE Publications.

Pauley, et al v. Bailey, et al, Civil Action No. 75-1268. (Kanawha Circuit Court May 11, 1982).

Penuel, W., Fishman, B. J., Gallagher, L. P., Korbak, C., \& Lopez-Prado, B. (2008). Is alignment enough? Investigating the effects of state policies and professional development on 
science curriculum implementation. Science Education, 93, 656-677.

doi:10.1002/sce20321.

Picciano, A. (2009). Blending with purpose: The multimodal model. Journal of Asynchronous Learning Networks, 13(1), 7-18. Retrieved from http://sloanconsortium.org/publications/jaln_main

Picciano, A., \& Seaman, J. (2007). K-12 online learning: A survey of U.S. school district administrators. Journal of Asynchronous Learning Networks, 11(3), 11-37. Retrieved from http://sloanconsortium.org/publications/jaln_main

Picciano, A., \& Seaman, J. (2009). K-12 online learning: A 2008 follow-up of the survey of U.S. school district administrators. Retrieved from the Sloan Consortium website: http://sloanconsortium.org/publications/survey/pdf/k-12_online_learning_2008.pdf

Pipho, C. (1990). State departments: Change on the way. Phi Delta Kappan, 72, 262-263.

Plair, S. K. (2010). On becoming technology fluent: Digital classrooms and middle aged teachers (Doctoral dissertation). Retrieved from ProQuest Dissertations and Theses database. (UMI No. 3435097)

Popham, W. J. (1993). Educational evaluation (3rd ed.). Boston: Allyn \& Bacon.

Prensky, M. (2001). Digital natives, digital immigrants. On the Horizon, 9(5). Retrieved from http://www.marcprensky.com/writing/Prensky\%20\%20Digital\%20Natives,\%20Digital\%20Immigrants\%20-\%20Part1.pdf 
Prescott, J. (2004). A study of Web-based distance learning perceptions and concerns of superintendents and high school principals in Iowa (Doctoral dissertation). Retrieved from ProQuest Dissertations and Theses database. (UMI No. 3143396)

Pressman, J., \& Wildavsky, A. (1984). Implementation: How great expectations in Washington are dashed in Oakland ( $3^{\text {rd }}$ ed.). Berkeley, CA: University of California Press.

Prestine, N., \& McGreal, T. L. (1997). Fragile changes, sturdy lives: Implementing authentic assessment in schools. Educational Administration Quarterly, 33, 371-400.

Ramirez, C. (2002). Strategies for subject matter expert review in questionnaire design. Paper presented at the Questionnaire Design, Evaluation and Testing Conference, Charleston, SC. Retrieved from http://www.jpsm.umd.edu/qdet/final_pdf_papers/ramirez.pdf

Reviea, L. G. (2010). An historical analysis of the Virtual VA program (Doctoral dissertation). Retrieved from ProQuest Dissertations and Theses database. (UMI No. 3415835)

Roberts, N., \& King, P. (1991). Policy entrepreneurs: Their activity structure and function in the policy process. Journal of Public Administration Research and Theory, 1(2), 147-175.

Rothgeb, J. (2008). Pilot test. In P. Lavrakas (Ed.), Encyclopedia of survey research methods (pp. 584-586). Thousand Oaks, CA: SAGE Publications.

Rothman, R. (2011). Something in common: The common core standards and the next chapter in American education. Cambridge, MA: Harvard Education Press.

Rummel, R. J. (1976). Understanding conflict and war, volume 2: The conflict helix [Adobe Digital Editions version]. Retrieved from http://www.hawaii.edu/powerkills/TCH.CHAP31.HTM 
Sabatier, P. (1991). Toward better theories of the policy process. PS: Political science and Politics, 24 (2), 147-156.

Sabatier, P., \& Mazmanian, D. (1983). Policy implementation. In S. Nagel (Ed.), Encyclopedia of policy studies (pp. 143-169). New York: Marcel Dekker, Inc.

Setzer, J. C., \& Lewis, L. (2005). Distance education courses for public elementary and secondary school students: 2002-03. (NCES 2005-010). Washington, DC: U. S. Department of Education, National Center for Education Statistics.

Shapiro, J. (2008). t-Test. In P. Lavrakas (Ed.), Encyclopedia of survey research methods (pp. 912-913). Thousand Oaks, CA: SAGE Publications.

Shepherd, B. (2001). Changing from the inside out: A case study of one school's response to a state reform mandate (Doctoral dissertation). Retrieved from ProQuest Dissertations and Theses database. (UMI No. 3014809)

Stockman, C., \& Truyen, F. (2011). The danger of the downward spiral: Teachers and digital literacy. Proceedings of the European Conference on e-Learning, 10, 811-819.

Stufflebeam, D. (2002). Foundational models for 21st Century program evaluation. In D. Stufflebeam, G. Madaus, \& T. Kellaghan (Eds.), Evaluation models: Viewpoints on educational and human services evaluation (2nd ed., pp. 33-84). Boston: Kluwer Academic Publishers.

Survey Monkey. (2011). Smart survey design. Retrieved from http://s3.amazonaws.com/SurveyMonkeyFiles/SmartSurvey.pdf 
Suskie, L. (1996). Survey research: What works for the institutional researcher? Ithaca, NY: Northeast Association for Institutional Research.

Target population. (2011). In Business online dictionary. Retrieved from http://www.businessdictionary.com/definition/target-population.html

Texas Virtual School Network (2011). Texas Virtual School Network online teaching eligibility and requirements. Retrieved November 15, 2011, from the Texas Virtual School Network website: http://www.txvsn.org/portal/Providers/ProfessionalDevelopment/OnlineTeachingEligibili tyandRequirements.aspx

Thomas, C. S., \& Hrebenar, R. J. (2004). Interest groups in the states. In V. Gray \& R. Hanson (Eds.), Politics in the American states (8th ed., pp. 100-128). Washington, DC: CQ Press.

Toch, T. (2012). The fallacy of 'local control.' Phi Delta Kappan, 93, 66-67.

Trotter, A. (2008). Voluntary online-teaching standards come amid concerns over quality. Education Week, 27(26), 1-15.

Tushman, M. (1977). Special boundary roles in the innovation process. Administrative Science Quarterly, 22(4), 587-605.

United States Department of Education, National Center for Education Statistics. (2005). The condition of education, 2005 (NCES 2005-094). Washington, DC: U.S. Government Printing Office. 
University of Texas at Austin. (2011). American politics: Political economy and public policy glossary. Document posted in University of Texas at Austin Liberal Arts ITS AGOV 310 website. Retrieved April 10, 2011, from http://www.laits.utexas.edu/gov310/PEP/glossary.html

University-Community Partnerships at Michigan State University. (2004, December). Best practice briefs: School climate and learning (Issue Brief No. 31). East Lansing, MI: Author.

USNPL. (2012). West Virginia TV stations. Retrieved February 5, 2012, at USNPL website: http://www.usnpl.com/tv/wvtv.php

VanMeter, D., \& VanHorn, C. (1975). The policy implementation process: A conceptual framework. Administration and Society, 6 (4), 445-488.

Virtual High School (2012). Virtual High School member profile. Retrieved January 22, 2012, from Virtual High School website: http://www.govhs.org/Pages/AboutUs-Home

Vossekuil, B., Fein, R., Reddy, M., Borum, R., \& Modzeleski, W. (2002). The final report and findings of the safe school initiative: Implications for the prevention of school attacks in the United States. Retrieved from U.S. Secret Service website: http://www.secretservice.gov/ntac/ssi_final_report.pdf

Watson, J. F. (2007). A national primer on K-12 online learning. Retrieved from International Association for K-12 Online Learning website: http://www.inacol.org/research/docs/national_report.pdf 
Watson, J. F., \& Gemin, B. (2009). Promising practices in online learning: Policy and funding frameworks for online learning. Retrieved from International Association for K-12 Online Learning website: http://www.inacol.org/research/promisingpractices/NACOL_PP-FundPolicy-lr.pdf

Watson, J. F., Murin, A., Vashaw, L., Gemin, B., \& Rapp, C. (2010). Keeping pace with K-12 online learning: An annual review of policy and practice - 2010. Retrieved from International Association for K-12 Online Learning website: http://www.kpk12.com/cms/wp-content/uploads/KeepingPaceK12_2010.pdf

Watson, J. F., Winograd, K., \& Kalmon, S. (2004). Keeping pace with K-12 online learning: A snapshot of state-level policy and practice. Naperville, IL: Learning Point Associates.

Weatherly, R., \& Lipsky, M. (1977). Street level bureaucrats and institutional innovation: Implementing special education reform. Harvard Educational Review, 47(2), 171- 197.

West Virginia Board of Education (WVBE). (2012). State board policies. Retrieved on March 10, 2012, from http://wvde.state.wv.us/policies/

West Virginia Center on Budget and Policy. (2012). About us. Retrieved February 16, 2012, from West Virginia Center on Budget and Policy website: http://www.wvpolicy.org/about_us.html

West Virginia Chamber of Commerce. (2012a). Meet the chamber. Retrieved February 16, 2012, from West Virginia Chamber of Commerce website: http://www.wvchamber.com/chamber 
West Virginia Chamber of Commerce. (2012b). Committees. Retrieved February 16, 2012, from West Virginia Chamber of Commerce website: http://www.wvchamber.com/chamber/committees.aspx

West Virginia Department of Education (WVDE). (2008). WVDE Employee Handbook. Charleston, WV: Author.

West Virginia Department of Education (WVDE). (2011a). [Student enrollments in the West Virginia Virtual School, 2008-2011]. Unpublished raw data.

West Virginia Department of Education (WVDE). (2011b). WVBE mission and goals. Retrieved November 15, 2011, from WVDE website: http://wvde.state.wv.us/boardgoals/

West Virginia Department of Education (WVDE). (2012a). West Virginia Virtual School welcome school personnel. Retrieved January 22, 2012, from WVDE website: http://virtualschool.k12.wv.us/vschool/personnel/index.html

West Virginia Department of Education (WVDE). (2012b). West Virginia Virtual School system requirements. Retrieved April 21, 2012, from WVDE website: http://virtualschool.k12.wv.us/vschool/courses/systemrequirements.htm

West Virginia Department of Education (WVDE). (2012c). Technology infrastructure summary. Retrieved April 21, 2012, from WVDE website: http://wveis.k12.wv.us/tech/index.cfm?fuseaction=myCircuit.bandwidth\&CFTREEITEM $\mathrm{KEY}=$ Bandwidth\%20Implementation 
West Virginia Department of Education (WVDE). (2012d). First annual Caperton educational technology winners announced. Retrieved March 15, 2012, from WVDE website: https://wvde.state.wv.us/news/481/

West Virginia Department of Education (WVDE). (2012e). West Virginia Virtual School. Retrieved January 22, 2012, from WVDE website: http://virtualschool.k12.wv.us/vschool/index.html

West Virginia Department of Education (WVDE). (2012f). West Virginia Virtual School course catalog. Retrieved January 22, 2012, from WVDE website: http://virtualschool.k12.wv.us/vschool/courses/coursecatalog.cfm

West Virginia Department of Education (WVDE). (2012g). West Virginia Virtual School onTargetWV credit recovery. Retrieved January 22, 2012, from WVDE website: http://virtualschool.k12.wv.us/vschool/courses/CreditRecovery.htm

West Virginia Department of Education (WVDE). (2012h). West Virginia Virtual School FAQs. Retrieved January 22, 2012, from WVDE website: http://virtualschool.k12.wv.us/vschool/faqs/index.html

West Virginia Education Association. (2011). WVEA Fact Sheet. Retrieved September 7, 2011, from http://wvea.org/News---Events/WVEA-Fact-Sheet.aspx

West Virginia Ethics Commission (2012). Lobbyist information. Retrieved February 16, 2012, from West Virginia Ethics Commission website: http://www.ethics.wv.gov/lobbyist/Pages/default.aspx 
West Virginia Legislature Office of Reference and Information. (2011). How a bill becomes a law. Retrieved June 20, 2011, from http://www.legis.state.wv.us/Educational/Bill_Becomes_Law/Bill_Becomes_Law.cfm

West Virginia Secondary Schools Activities Commission. (2011). Athletics, provisions governing eligibility (Series 2). Parkersburg, WV.

What you need to know about lobbyists in West Virginia. (2010, February 19). Herald-Dispatch. Retrieved from http://www.herald-dispatch.com/

Wicks, M. (2010). A national primer on K-12 online learning version 2. Retrieved from International Association for K-12 Online Learning website: http://www.inacol.org/research/docs/iNCL_NationalPrimerv22010-web.pdf

Williamson, C. (2009, February 19). Policy implementation: Can it be analyzed separately and does the field have a future? [Online forum comment]. Retrieved from http://www.associatedcontent.com/article/1478014/policy_implementation_can_it_be_an alyzed.html?cat=9

W. Va. Code. (2012). Retrieved from http://www.legis.state.wv.us/WVCODE/Code.cfm

Wood, J. (2008). Zero tolerance: A policy implementation study (Doctoral dissertation, Vanderbilt University). Retrieved from http://etd.library.vanderbilt.edu/available/etd04112008-180258/unrestricted/JWoodDissertation.pdf

Yin, R. (1984). Case study research: Design and methods. Beverly Hills, CA: SAGE Publications. 
Zickefoose, S. (1979). Successful and unsuccessful school superintendents (Doctoral dissertation). Retrieved from ProQuest Dissertations and Theses database. (UMI No. 8012909) 


\section{Appendix A \\ 126CSR48 \\ TITLE 126 \\ LEGISLATIVE RULE \\ BOARD OF EDUCATION \\ SERIES 48}

\section{Distance Learning and the West Virginia Virtual School (2450)}

\section{\$126-48-1. General.}

1.1. Scope--Establishes requirements for distance, online, and technology delivered learning programs, including student needs, course content, teacher/facilitator guidelines, virtual classes, funding, and management at the state, county and school levels.

1.2. Authority--West Virginia Constitution, Article XII,§2; West Virginia Code $\S 18-2-5$ and $\S 18-2 \mathrm{E}-9$.

1.3. Filing Date-- August 12, 2002

1.4. Effective Date-September 11, 2002

1.5. This is a revision of 126CSR48, West Virginia Board of Education Policy 2450, filed September 18, 2000 and effective October 18, 2000.

\section{\$126-48-2. Purpose.}

2.1. The purpose of this policy is to assure consistent high quality education for the students of West Virginia while utilizing technology-delivered courses. In order for a student to receive credit for a technology-delivered course, he/she must be a student enrolled in a West Virginia public school.

\section{\$126-48-3. Course Approval.}

3.1. Distance, online or virtual learning courses offered for public school credit shall be approved by the West Virginia Department of Education (WVDE). In order to register the technology-delivered learning courses for credit, providers shall submit an online registration form to WVDE for approval. In order for students to receive distance learning courses for credit, a county superintendent or designee shall verify that courses and providers are WVDE approved.

3.2. Distance learning courses may be approved when curriculum content cannot be delivered because there is a shortage of certified personnel, a need to provide low-incidence courses, a need to offer a course while the teacher/facilitator renews course-related skills, or any other validated student need to access technology delivered courses.

3.3. Distance learning course content will be reviewed for correlation with the West Virginia Board of Education content standards and objectives (CSOs). Copies of the CSOs and instructional policies may be found on the WVDE web page at http://wvde.state.wv.us.

3.4. The quality courses approved by the West Virginia Virtual School will be aligned with the CSOs and include appropriate course materials. These materials are 
exempt from the mandatory primary source materials listed on the state multiple list. 3.5. Providers will adhere to the state and federal privacy regulations regarding students.

3.6. In an alternative education setting, distance learning shall in no case be a student's only source of instruction. Provisions of 126CSR20, West Virginia Board of Education Policy 2418: Regulations for Alternative Education Programs for Disruptive Students shall be adhered to including, but not limited to, the provision of behavioral components in addition to academic course work.

\section{\$126-48-4. Management.}

4.1. Course facilitators located in West Virginia schools may be required to hold specific certification/qualifications based upon provider guidelines that may vary from course to course.

4.2. The distance learning course facilitator shall receive inservice training or technology-delivered instructions pertaining to the course organization, classroom management, technical aspects, monitoring of student testing, and securing other student services as needed.

4.3. The county superintendent shall designate a distance learning contact at the school level to ensure virtual class information is provided to students and parents, any necessary affiliation agreements with the course provider are secured, the course facilitator has been identified, and complete other duties as necessary to provide student access.

4.4. If a course is to be produced and delivered from within West Virginia, the West Virginia Virtual Course Production guidelines and procedures must be followed as outlined.

\section{\$126-48-5. Evaluation of Pupil Progress.}

5.1. The local education agency is responsible for establishing specific uniform procedures for evaluating pupil progress and administering a final grade based upon provider guidelines and county policy.

5.2. Evaluations of the success of the virtual program must be documented to provide any continued funding requests.

\section{\$126-48-6. Technology Access.}

6.1. With the statewide technology installations in public schools, students should have access to virtual courses at school.

6.2. When available, student access may be authorized at other equipped locations such as public libraries, community learning centers and homes. 6.3. The school distance learning coordinator will be responsible for assisting students in finding solutions for access. 


\section{\$126-48-7. Funding.}

7.1. Funding for distance learning courses and associated materials may be provided through the school system instructional budgets or grant awards.

7.2. Parents will be responsible for distance learning costs if the selected course is currently being offered at the school and there is no justifiable reason to duplicate the school course.

\section{\$126-48-8. Guidelines and Procedures.}

8.1. To accommodate rapidly changing options for virtual classes and distance learning, guidelines and procedures will be developed to review operational issues in a timely manner and will include legislation components.

8.2. Whenever necessary to provide appropriate virtual classes and distance learning, the waiver process will be utilized.

\section{\$126-48-9. Severability.}

9.1. If any provision of this rule or the application thereof to any person or circumstance is held invalid, such invalidity shall not affect other provisions or applications of this rule. 


\section{Appendix B}

Rank Order of West Virginia High Schools by Percentage of the Total Students (Grades 9-12) Enrolled in Virtual Courses, 20082011

\begin{tabular}{|c|c|c|c|c|c|c|c|c|c|c|}
\hline \multirow{2}{*}{$\begin{array}{l}\text { School } \\
\text { Code }\end{array}$} & \multicolumn{4}{|c|}{$\begin{array}{c}\text { Number of Students Enrolled in } \\
\text { Virtual Courses } \\
\text { (Unique Student Count) }\end{array}$} & \multicolumn{4}{|c|}{$\begin{array}{l}\text { Total School Enrollment } \\
\text { (Unique Student Count, } \\
\text { Second Month Enrollment) }\end{array}$} & \multirow{2}{*}{$\begin{array}{c}\text { Virtual Course } \\
\text { Enrollment } \\
\text { Divided by Total } \\
\text { School } \\
\text { Enrollment } \\
\text { (Three-Year Ave.) }\end{array}$} & \multirow{2}{*}{$\begin{array}{c}\text { Virtual Course } \\
\text { Enrollment } \\
\text { Divided by Total } \\
\text { School } \\
\text { Enrollment } \\
\text { (Rounded) }\end{array}$} \\
\hline & $\begin{array}{c}2008- \\
2009\end{array}$ & $\begin{array}{c}2009- \\
2010\end{array}$ & $\begin{array}{l}2010- \\
2011\end{array}$ & $\begin{array}{l}\text { Three- } \\
\text { Year } \\
\text { Average }\end{array}$ & $\begin{array}{l}2008- \\
2009\end{array}$ & $\begin{array}{c}2009- \\
2010\end{array}$ & $\begin{array}{l}2010- \\
2011\end{array}$ & $\begin{array}{l}\text { Three- } \\
\text { Year } \\
\text { Average }\end{array}$ & & \\
\hline 001 & 26 & 37 & 26 & 29.67 & 65 & 51 & 62 & 59.33 & $50.00 \%$ & $50 \%$ \\
\hline 002 & 32 & 35 & 38 & 35.00 & 127 & 113 & 115 & 118.33 & $29.58 \%$ & $30 \%$ \\
\hline 003 & 5 & 10 & 24 & 13.00 & 73 & 72 & 76 & 73.67 & $17.65 \%$ & $18 \%$ \\
\hline 004 & 13 & 0 & 6 & 6.33 & 57 & 57 & 58 & 57.33 & $11.05 \%$ & $11 \%$ \\
\hline 005 & 1 & 68 & 74 & 47.67 & 616 & 599 & 586 & 600.33 & $7.94 \%$ & $8 \%$ \\
\hline 006 & 13 & 10 & 7 & 10.00 & 153 & 151 & 159 & 154.33 & $6.48 \%$ & $6 \%$ \\
\hline 007 & 74 & 1 & 3 & 26.00 & 478 & 463 & 437 & 459.33 & $5.66 \%$ & $6 \%$ \\
\hline 008 & 8 & 9 & 46 & 21.00 & 391 & 385 & 374 & 383.33 & $5.48 \%$ & $5 \%$ \\
\hline 009 & 2 & 0 & 0 & 0.67 & 14 & 14 & 12 & 13.33 & $5.00 \%$ & $5 \%$ \\
\hline 010 & 48 & 4 & 6 & 19.33 & 421 & 422 & 425 & 422.67 & $4.57 \%$ & $5 \%$ \\
\hline 011 & 13 & 15 & 16 & 14.67 & 323 & 322 & 335 & 326.67 & $4.49 \%$ & $4 \%$ \\
\hline 012 & 19 & 17 & 4 & 13.33 & 327 & 306 & 279 & 304.00 & $4.39 \%$ & $4 \%$ \\
\hline 013 & 32 & 44 & 26 & 34.00 & 820 & 786 & 722 & 776.00 & $4.38 \%$ & $4 \%$ \\
\hline 014 & 49 & 3 & 3 & 18.33 & 436 & 422 & 407 & 421.67 & $4.35 \%$ & $4 \%$ \\
\hline 015 & 12 & 25 & 14 & 17.00 & 432 & 420 & 425 & 425.67 & $3.99 \%$ & $4 \%$ \\
\hline 016 & 3 & 16 & 0 & 6.33 & 177 & 159 & 148 & 161.33 & $3.93 \%$ & $4 \%$ \\
\hline
\end{tabular}




\begin{tabular}{|c|c|c|c|c|c|c|c|c|c|c|}
\hline \multirow{2}{*}{$\begin{array}{c}\text { School } \\
\text { Code }\end{array}$} & \multicolumn{4}{|c|}{$\begin{array}{c}\text { Number of Students Enrolled in } \\
\text { Virtual Courses } \\
\text { (Unique Student Count) }\end{array}$} & \multicolumn{4}{|c|}{$\begin{array}{l}\text { Total School Enrollment } \\
\text { (Unique Student Count, } \\
\text { Second Month Enrollment) }\end{array}$} & \multirow{2}{*}{$\begin{array}{c}\text { Virtual Course } \\
\text { Enrollment } \\
\text { Divided by Total } \\
\text { School } \\
\text { Enrollment } \\
\text { (Three-Year Ave.) }\end{array}$} & \multirow{2}{*}{$\begin{array}{c}\text { Virtual Course } \\
\text { Enrollment } \\
\text { Divided by Total } \\
\text { School } \\
\text { Enrollment } \\
\text { (Rounded) }\end{array}$} \\
\hline & $\begin{array}{c}2008- \\
2009\end{array}$ & $\begin{array}{l}2009- \\
2010\end{array}$ & $\begin{array}{l}2010- \\
2011\end{array}$ & $\begin{array}{l}\text { Three- } \\
\text { Year } \\
\text { Average }\end{array}$ & $\begin{array}{l}2008- \\
2009\end{array}$ & $\begin{array}{c}2009- \\
2010\end{array}$ & $\begin{array}{l}2010- \\
2011\end{array}$ & $\begin{array}{l}\text { Three- } \\
\text { Year } \\
\text { Average }\end{array}$ & & \\
\hline 017 & 5 & 53 & 0 & 19.33 & 492 & 508 & 483 & 494.33 & $3.91 \%$ & $4 \%$ \\
\hline 018 & 20 & 6 & 9 & 11.67 & 374 & 351 & 318 & 347.67 & $3.36 \%$ & $3 \%$ \\
\hline 019 & 25 & 36 & 41 & 34.00 & 1078 & 1146 & 1142 & 1122.00 & $3.03 \%$ & $3 \%$ \\
\hline 020 & 17 & 30 & 19 & 22.00 & 738 & 701 & 771 & 736.67 & $2.99 \%$ & $3 \%$ \\
\hline 021 & 55 & 9 & 3 & 22.33 & 838 & 806 & 792 & 812.00 & $2.75 \%$ & $3 \%$ \\
\hline 022 & 57 & 0 & 13 & 23.33 & 871 & 854 & 854 & 859.67 & $2.71 \%$ & $3 \%$ \\
\hline 023 & 22 & 22 & 18 & 20.67 & 854 & 847 & 818 & 839.67 & $2.46 \%$ & $2 \%$ \\
\hline 024 & 1 & 48 & 0 & 16.33 & 654 & 675 & 708 & 679.00 & $2.41 \%$ & $2 \%$ \\
\hline 025 & 0 & 0 & 11 & 3.67 & 165 & 148 & 149 & 154.00 & $2.38 \%$ & $2 \%$ \\
\hline 026 & 8 & 30 & 17 & 18.33 & 778 & 783 & 813 & 791.33 & $2.32 \%$ & $2 \%$ \\
\hline 027 & 2 & 1 & 15 & 6.00 & 276 & 259 & 274 & 269.67 & $2.22 \%$ & $2 \%$ \\
\hline 028 & 0 & 14 & 4 & 6.00 & 277 & 272 & 270 & 273.00 & $2.20 \%$ & $2 \%$ \\
\hline 029 & 6 & 8 & 6 & 6.67 & 319 & 314 & 306 & 313.00 & $2.13 \%$ & $2 \%$ \\
\hline 030 & 1 & 0 & 12 & 4.33 & 228 & 209 & 202 & 213.00 & $2.03 \%$ & $2 \%$ \\
\hline 031 & 0 & 18 & 10 & 9.33 & 472 & 486 & 449 & 469.00 & $1.99 \%$ & $2 \%$ \\
\hline 032 & 2 & 3 & 15 & 6.67 & 355 & 339 & 331 & 341.67 & $1.95 \%$ & $2 \%$ \\
\hline 033 & 22 & 12 & 13 & 15.67 & 803 & 798 & 823 & 808.00 & $1.94 \%$ & $2 \%$ \\
\hline 034 & 3 & 7 & 1 & 3.67 & 245 & 227 & 207 & 226.33 & $1.62 \%$ & $2 \%$ \\
\hline 035 & 30 & 11 & 12 & 17.67 & 1138 & 1097 & 1115 & 1116.67 & $1.58 \%$ & $2 \%$ \\
\hline 036 & 0 & 8 & 19 & 9.00 & 605 & 583 & 558 & 582.00 & $1.55 \%$ & $2 \%$ \\
\hline 037 & 6 & 5 & 21 & 10.67 & 723 & 691 & 694 & 702.67 & $1.52 \%$ & $2 \%$ \\
\hline 038 & 0 & 2 & 11 & 4.33 & 296 & 303 & 288 & 295.67 & $1.47 \%$ & $1 \%$ \\
\hline
\end{tabular}




\begin{tabular}{|c|c|c|c|c|c|c|c|c|c|c|}
\hline \multirow{2}{*}{$\begin{array}{l}\text { School } \\
\text { Code }\end{array}$} & \multicolumn{4}{|c|}{$\begin{array}{c}\text { Number of Students Enrolled in } \\
\text { Virtual Courses } \\
\text { (Unique Student Count) }\end{array}$} & \multicolumn{4}{|c|}{$\begin{array}{l}\text { Total School Enrollment } \\
\text { (Unique Student Count, } \\
\text { Second Month Enrollment) }\end{array}$} & \multirow{2}{*}{$\begin{array}{c}\text { Virtual Course } \\
\text { Enrollment } \\
\text { Divided by Total } \\
\text { School } \\
\text { Enrollment } \\
\text { (Three-Year Ave.) }\end{array}$} & \multirow{2}{*}{$\begin{array}{c}\text { Virtual Course } \\
\text { Enrollment } \\
\text { Divided by Total } \\
\text { School } \\
\text { Enrollment } \\
\text { (Rounded) }\end{array}$} \\
\hline & $\begin{array}{c}2008- \\
2009\end{array}$ & $\begin{array}{l}2009- \\
2010\end{array}$ & $\begin{array}{l}2010- \\
2011\end{array}$ & $\begin{array}{l}\text { Three- } \\
\text { Year } \\
\text { Average }\end{array}$ & $\begin{array}{l}2008- \\
2009\end{array}$ & $\begin{array}{l}2009- \\
2010\end{array}$ & $\begin{array}{l}2010- \\
2011\end{array}$ & $\begin{array}{l}\text { Three- } \\
\text { Year } \\
\text { Average }\end{array}$ & & \\
\hline 039 & 8 & 5 & 11 & 8.00 & 531 & 572 & 544 & 549.00 & $1.46 \%$ & $1 \%$ \\
\hline 040 & 2 & 3 & 30 & 11.67 & 812 & 838 & 775 & 808.33 & $1.44 \%$ & $1 \%$ \\
\hline 041 & 4 & 2 & 11 & 5.67 & 424 & 444 & 422 & 430.00 & $1.32 \%$ & $1 \%$ \\
\hline 042 & 4 & 5 & 3 & 4.00 & 312 & 314 & 318 & 314.67 & $1.27 \%$ & $1 \%$ \\
\hline 043 & 9 & 9 & 7 & 8.33 & 729 & 747 & 746 & 740.67 & $1.13 \%$ & $1 \%$ \\
\hline 044 & 2 & 0 & 13 & 5.00 & 480 & 458 & 449 & 462.33 & $1.08 \%$ & $1 \%$ \\
\hline 045 & 7 & 14 & 19 & 13.33 & 1296 & 1252 & 1281 & 1276.33 & $1.04 \%$ & $1 \%$ \\
\hline 046 & 4 & 15 & 10 & 9.67 & 997 & 1001 & 962 & 986.67 & $0.98 \%$ & $1 \%$ \\
\hline 047 & 1 & 5 & 3 & 3.00 & 315 & 308 & 314 & 312.33 & $0.96 \%$ & $1 \%$ \\
\hline 048 & 0 & 0 & 17 & 5.67 & 616 & 600 & 616 & 610.67 & $0.93 \%$ & $1 \%$ \\
\hline 049 & 10 & 12 & 21 & 14.33 & 1662 & 1639 & 1580 & 1627.00 & $0.88 \%$ & $1 \%$ \\
\hline 050 & 0 & 7 & 0 & 2.33 & 284 & 276 & 280 & 280.00 & $0.83 \%$ & $1 \%$ \\
\hline 051 & 0 & 6 & 1 & 2.33 & 298 & 318 & 291 & 302.33 & $0.77 \%$ & $1 \%$ \\
\hline 052 & 5 & 7 & 6 & 6.00 & 841 & 834 & 794 & 823.00 & $0.73 \%$ & $1 \%$ \\
\hline 053 & 11 & 1 & 0 & 4.00 & 610 & 561 & 535 & 568.67 & $0.70 \%$ & $1 \%$ \\
\hline 054 & 8 & 3 & 12 & 7.67 & 1105 & 1116 & 1110 & 1110.33 & $0.69 \%$ & $1 \%$ \\
\hline 055 & 5 & 4 & 24 & 11.00 & 1688 & 1630 & 1690 & 1669.33 & $0.66 \%$ & $1 \%$ \\
\hline 056 & 5 & 5 & 3 & 4.33 & 685 & 695 & 652 & 677.33 & $0.64 \%$ & $1 \%$ \\
\hline 057 & 12 & 3 & 4 & 6.33 & 1134 & 1101 & 1041 & 1092.00 & $0.58 \%$ & $1 \%$ \\
\hline 058 & 1 & 1 & 17 & 6.33 & 1103 & 1122 & 1103 & 1109.33 & $0.57 \%$ & $1 \%$ \\
\hline 059 & 2 & 2 & 4 & 2.67 & 491 & 466 & 461 & 472.67 & $0.56 \%$ & $1 \%$ \\
\hline 060 & 1 & 7 & 11 & 6.33 & 1151 & 1139 & 1140 & 1143.33 & $0.55 \%$ & $1 \%$ \\
\hline
\end{tabular}




\begin{tabular}{|c|c|c|c|c|c|c|c|c|c|c|}
\hline \multirow{2}{*}{$\begin{array}{l}\text { 2School } \\
\text { Code }\end{array}$} & \multicolumn{4}{|c|}{$\begin{array}{c}\text { Number of Students Enrolled in } \\
\text { Virtual Courses } \\
\text { (Unique Student Count) }\end{array}$} & \multicolumn{4}{|c|}{$\begin{array}{l}\text { Total School Enrollment } \\
\text { (Unique Student Count, } \\
\text { Second Month Enrollment) }\end{array}$} & \multirow{2}{*}{$\begin{array}{c}\text { Virtual Course } \\
\text { Enrollment } \\
\text { Divided by Total } \\
\text { School } \\
\text { Enrollment } \\
\text { (Three-Year Ave.) }\end{array}$} & \multirow{2}{*}{$\begin{array}{c}\text { Virtual Course } \\
\text { Enrollment } \\
\text { Divided by Total } \\
\text { School } \\
\text { Enrollment } \\
\text { (Rounded) }\end{array}$} \\
\hline & $\begin{array}{c}2008- \\
2009\end{array}$ & $\begin{array}{c}2009- \\
2010\end{array}$ & $\begin{array}{c}2010- \\
2011\end{array}$ & $\begin{array}{l}\text { Three- } \\
\text { Year } \\
\text { Average }\end{array}$ & $\begin{array}{l}2008- \\
2009\end{array}$ & $\begin{array}{c}2009- \\
2010\end{array}$ & $\begin{array}{c}2010- \\
2011\end{array}$ & $\begin{array}{l}\text { Three- } \\
\text { Year } \\
\text { Average }\end{array}$ & & \\
\hline 061 & 3 & 2 & 8 & 4.33 & 826 & 806 & 811 & 814.33 & $0.53 \%$ & $1 \%$ \\
\hline 062 & 4 & 9 & 6 & 6.33 & 1318 & 1345 & 1336 & 1333.00 & $0.48 \%$ & $0 \%$ \\
\hline 063 & 2 & 6 & 1 & 3.00 & 655 & 658 & 627 & 646.67 & $0.46 \%$ & $0 \%$ \\
\hline 064 & 7 & 6 & 13 & 8.67 & 1903 & 1883 & 1836 & 1874.00 & $0.46 \%$ & $0 \%$ \\
\hline 065 & 1 & 4 & 1 & 2.00 & 437 & 447 & 416 & 433.33 & $0.46 \%$ & $0 \%$ \\
\hline 066 & 1 & 4 & 2 & 2.33 & 522 & 504 & 530 & 518.67 & $0.45 \%$ & $0 \%$ \\
\hline 067 & 1 & 10 & 0 & 3.67 & 878 & 893 & 891 & 887.33 & $0.41 \%$ & $0 \%$ \\
\hline 068 & 2 & 5 & 10 & 5.67 & 1620 & 1589 & 1556 & 1588.33 & $0.36 \%$ & $0 \%$ \\
\hline 069 & 4 & 0 & 0 & 1.33 & 428 & 421 & 409 & 419.33 & $0.32 \%$ & $0 \%$ \\
\hline 070 & 2 & 5 & 1 & 2.67 & 954 & 933 & 869 & 918.67 & $0.29 \%$ & $0 \%$ \\
\hline 071 & 0 & 2 & 2 & 1.33 & 474 & 479 & 432 & 461.67 & $0.29 \%$ & $0 \%$ \\
\hline 072 & 6 & 4 & 0 & 3.33 & 1176 & 1185 & 1216 & 1192.33 & $0.28 \%$ & $0 \%$ \\
\hline 073 & 2 & 0 & 2 & 1.33 & 509 & 474 & 478 & 487.00 & $0.27 \%$ & $0 \%$ \\
\hline 074 & 6 & 0 & 0 & 2.00 & 791 & 751 & 729 & 757.00 & $0.26 \%$ & $0 \%$ \\
\hline 075 & 4 & 1 & 5 & 3.33 & 1327 & 1284 & 1191 & 1267.33 & $0.26 \%$ & $0 \%$ \\
\hline 076 & 1 & 5 & 0 & 2.00 & 765 & 797 & 739 & 767.00 & $0.26 \%$ & $0 \%$ \\
\hline 077 & 3 & 1 & 1 & 1.67 & 677 & 637 & 619 & 644.33 & $0.26 \%$ & $0 \%$ \\
\hline 078 & 4 & 8 & 2 & 4.67 & 1840 & 1848 & 1783 & 1823.67 & $0.26 \%$ & $0 \%$ \\
\hline 079 & 0 & 0 & 6 & 2.00 & 768 & 816 & 809 & 797.67 & $0.25 \%$ & $0 \%$ \\
\hline 080 & 0 & 0 & 3 & 1.00 & 432 & 396 & 382 & 403.33 & $0.25 \%$ & $0 \%$ \\
\hline
\end{tabular}




\begin{tabular}{|c|c|c|c|c|c|c|c|c|c|c|}
\hline \multirow{2}{*}{$\begin{array}{c}\text { School } \\
\text { Code }\end{array}$} & \multicolumn{4}{|c|}{$\begin{array}{c}\text { Number of Students Enrolled in } \\
\text { Virtual Courses } \\
\text { (Unique Student Count) }\end{array}$} & \multicolumn{4}{|c|}{$\begin{array}{l}\text { Total School Enrollment } \\
\text { (Unique Student Count, } \\
\text { Second Month Enrollment) }\end{array}$} & \multirow{2}{*}{$\begin{array}{c}\text { Virtual Course } \\
\text { Enrollment } \\
\text { Divided by Total } \\
\text { School } \\
\text { Enrollment } \\
\text { (Three-Year Ave.) }\end{array}$} & \multirow{2}{*}{$\begin{array}{c}\text { Virtual Course } \\
\text { Enrollment } \\
\text { Divided by Total } \\
\text { School } \\
\text { Enrollment } \\
\text { (Rounded) }\end{array}$} \\
\hline & $\begin{array}{c}2008- \\
2009\end{array}$ & $\begin{array}{c}2009- \\
2010\end{array}$ & $\begin{array}{c}2010- \\
2011\end{array}$ & $\begin{array}{l}\text { Three- } \\
\text { Year } \\
\text { Average }\end{array}$ & $\begin{array}{c}2008- \\
2009\end{array}$ & $\begin{array}{c}2009- \\
2010\end{array}$ & $\begin{array}{c}2010- \\
2011\end{array}$ & $\begin{array}{l}\text { Three- } \\
\text { Year } \\
\text { Average }\end{array}$ & & \\
\hline 081 & 1 & 0 & 0 & 0.33 & 141 & 137 & 138 & 138.67 & $0.24 \%$ & $0 \%$ \\
\hline 082 & 2 & 5 & 3 & 3.33 & 1395 & 1387 & 1381 & 1387.67 & $0.24 \%$ & $0 \%$ \\
\hline 083 & 4 & 1 & 2 & 2.33 & 1084 & 1078 & 1056 & 1072.67 & $0.22 \%$ & $0 \%$ \\
\hline 084 & 3 & 0 & 1 & 1.33 & 623 & 604 & 614 & 613.67 & $0.22 \%$ & $0 \%$ \\
\hline 085 & 4 & 2 & 2 & 2.67 & 1276 & 1195 & 1244 & 1238.33 & $0.22 \%$ & $0 \%$ \\
\hline 086 & 3 & 2 & 0 & 1.67 & 835 & 785 & 755 & 791.67 & $0.21 \%$ & $0 \%$ \\
\hline 087 & 0 & 1 & 5 & 2.00 & 1014 & 1037 & 1036 & 1029.00 & $0.19 \%$ & $0 \%$ \\
\hline 088 & 2 & 1 & 6 & 3.00 & 1591 & 1596 & 1616 & 1601.00 & $0.19 \%$ & $0 \%$ \\
\hline 089 & 2 & 3 & 2 & 2.33 & 1400 & 1327 & 1367 & 1364.67 & $0.17 \%$ & $0 \%$ \\
\hline 090 & 0 & 0 & 2 & 0.67 & 434 & 416 & 430 & 426.67 & $0.16 \%$ & $0 \%$ \\
\hline 091 & 0 & 1 & 1 & 0.67 & 442 & 458 & 439 & 446.33 & $0.15 \%$ & $0 \%$ \\
\hline 092 & 0 & 1 & 0 & 0.33 & 247 & 232 & 234 & 237.67 & $0.14 \%$ & $0 \%$ \\
\hline 093 & 2 & 0 & 0 & 0.67 & 505 & 482 & 460 & 482.33 & $0.14 \%$ & $0 \%$ \\
\hline 094 & 1 & 1 & 5 & 2.33 & 1731 & 1713 & 1685 & 1709.67 & $0.14 \%$ & $0 \%$ \\
\hline 095 & 0 & 3 & 0 & 1.00 & 794 & 786 & 771 & 783.67 & $0.13 \%$ & $0 \%$ \\
\hline 096 & 2 & 3 & 1 & 2.00 & 1654 & 1658 & 1691 & 1667.67 & $0.12 \%$ & $0 \%$ \\
\hline 097 & 1 & 0 & 1 & 0.67 & 571 & 602 & 639 & 604.00 & $0.11 \%$ & $0 \%$ \\
\hline 098 & 0 & 1 & 1 & 0.67 & 651 & 600 & 598 & 616.33 & $0.11 \%$ & $0 \%$ \\
\hline 099 & 2 & 0 & 0 & 0.67 & 631 & 623 & 626 & 626.67 & $0.11 \%$ & $0 \%$ \\
\hline 100 & 0 & 2 & 0 & 0.67 & 664 & 657 & 648 & 656.33 & $0.10 \%$ & $0 \%$ \\
\hline
\end{tabular}




\begin{tabular}{|c|c|c|c|c|c|c|c|c|c|c|}
\hline \multirow{2}{*}{$\begin{array}{l}\text { School } \\
\text { Code }\end{array}$} & \multicolumn{4}{|c|}{$\begin{array}{c}\text { Number of Students Enrolled in } \\
\text { Virtual Courses } \\
\text { (Unique Student Count) }\end{array}$} & \multicolumn{4}{|c|}{$\begin{array}{l}\text { Total School Enrollment } \\
\text { (Unique Student Count, } \\
\text { Second Month Enrollment) }\end{array}$} & \multirow{2}{*}{$\begin{array}{c}\text { Virtual Course } \\
\text { Enrollment } \\
\text { Divided by Total } \\
\text { School } \\
\text { Enrollment } \\
\text { (Three-Year Ave.) }\end{array}$} & \multirow{2}{*}{$\begin{array}{c}\text { Virtual Course } \\
\text { Enrollment } \\
\text { Divided by Total } \\
\text { School } \\
\text { Enrollment } \\
\text { (Rounded) }\end{array}$} \\
\hline & $\begin{array}{l}2008- \\
2009\end{array}$ & $\begin{array}{c}2009- \\
2010\end{array}$ & $\begin{array}{l}2010- \\
2011\end{array}$ & $\begin{array}{l}\text { Three- } \\
\text { Year } \\
\text { Average }\end{array}$ & $\begin{array}{l}2008- \\
2009\end{array}$ & $\begin{array}{c}2009- \\
2010\end{array}$ & $\begin{array}{c}2010- \\
2011\end{array}$ & $\begin{array}{l}\text { Three- } \\
\text { Year } \\
\text { Average }\end{array}$ & & \\
\hline 101 & 0 & 0 & 2 & 0.67 & 706 & 686 & 658 & 683.33 & $0.10 \%$ & $0 \%$ \\
\hline 102 & 0 & 0 & 1 & 0.33 & 347 & 354 & 357 & 352.67 & $0.09 \%$ & $0 \%$ \\
\hline 103 & 0 & 0 & 2 & 0.67 & 722 & 692 & 712 & 708.67 & $0.09 \%$ & $0 \%$ \\
\hline 104 & 1 & 0 & 1 & 0.67 & 888 & 851 & 813 & 850.67 & $0.08 \%$ & $0 \%$ \\
\hline 105 & 0 & 1 & 1 & 0.67 & 1002 & 1052 & 1075 & 1043.00 & $0.06 \%$ & $0 \%$ \\
\hline 106 & 1 & 0 & 0 & 0.33 & 630 & 611 & 633 & 624.67 & $0.05 \%$ & $0 \%$ \\
\hline 107 & 0 & 0 & 0 & 0.00 & 1498 & 1565 & 1557 & 1540.00 & $0.00 \%$ & $0 \%$ \\
\hline 108 & 0 & 0 & 0 & 0.00 & 1017 & 1046 & 1110 & 1057.67 & $0.00 \%$ & $0 \%$ \\
\hline 109 & 0 & 0 & 0 & 0.00 & 1063 & 1069 & 1070 & 1067.33 & $0.00 \%$ & $0 \%$ \\
\hline 110 & 0 & 0 & 0 & 0.00 & 831 & 801 & 826 & 819.33 & $0.00 \%$ & $0 \%$ \\
\hline 111 & 0 & 0 & 0 & 0.00 & 413 & 410 & 392 & 405.00 & $0.00 \%$ & $0 \%$ \\
\hline 112 & 0 & 0 & 0 & 0.00 & 646 & 685 & 692 & 674.33 & $0.00 \%$ & $0 \%$ \\
\hline 113 & 0 & 0 & 0 & 0.00 & 247 & 236 & 227 & 236.67 & $0.00 \%$ & $0 \%$ \\
\hline 114 & 0 & 0 & 0 & 0.00 & 760 & 709 & 687 & 718.67 & $0.00 \%$ & $0 \%$ \\
\hline 115 & 0 & 0 & 0 & 0.00 & 572 & 555 & 532 & 553.00 & $0.00 \%$ & $0 \%$ \\
\hline 116 & 0 & 0 & 0 & 0.00 & 100 & 105 & 96 & 100.33 & $0.00 \%$ & $0 \%$ \\
\hline $\begin{array}{c}\text { STATE } \\
\text { TOTALS } \\
\end{array}$ & 759 & 761 & 828 & 782.67 & 82478 & 81516 & 80613 & 81535.67 & $0.96 \%$ & $1 \%$ \\
\hline
\end{tabular}




\section{Appendix C}

\section{Survey: Factors Affecting Implementation of West Virginia Board of Education Policy 2450, Distance Learning and the West Virginia Virtual School}

The following survey should take less than ten minutes to complete. Please answer the questions taking into consideration your experiences with distance learning courses provided by the West Virginia Department of Education (WVDE) or a WVDE-approved provider.

The following definitions will be used for this survey:

WVBE Policy 2450 is an optional (not a required) policy established with the purpose "to assure consistent high-quality education for the students of West Virginia while utilizing technology-delivered courses" (WVBE, 2012, §2.1). Policy 2450 can be accessed at http://wvde.state.wv.us/policies/p2450.html.

Distance learning is a form of online learning in which instruction and content are delivered primarily via the Internet.

Distance learning courses are technology-delivered courses used for public school credit and made available because of a shortage of certified personnel, a need to provide low-incidence courses, or any other validated student need to access technology-delivered courses.

The distance learning contact is the person at the school who is responsible for distributing information about distance learning courses to students and parents, securing agreements, and contacting the West Virginia Virtual School to enroll students in these courses.

A distance learning course facilitator is a person of record who monitors the academic performance of students enrolled in distance learning courses and is designated to receive reports from the course provider concerning individual student progress.

\section{All responses will be kept confidential.}

Individuals providing email addresses at the end of the survey will be entered into a drawing for $\$ 50$ gasoline cards to be given in appreciation for participating in this study. Don't delay! Two winners will be drawn from those submitting surveys within the first week. 


\section{Perceptions of the Implementation of Policy 2450, Distance Learning and the West Virginia Virtual School}

Directions: Please provide responses regarding your school's implementation of West Virginia Board of Education Policy 2450, Distance Learning and the West Virginia Virtual School.

\begin{tabular}{|c|c|c|c|c|c|c|}
\hline \multicolumn{7}{|c|}{ Category: People } \\
\hline \multicolumn{7}{|c|}{ QUESTION: What effect do the following factors have on the implementation of distance learning in your school (grades 9-12)? } \\
\hline Item & 1 & 2 & 3 & 4 & 5 & \\
\hline $\begin{array}{l}\text { 1. Support of administrators in the local school (e.g., } \\
\text { encouragement to teachers to utilize technology in } \\
\text { instruction, provision of resources) }\end{array}$ & $\begin{array}{l}\text { Significantly } \\
\text { impedes }\end{array}$ & Impedes & $\begin{array}{c}\text { Has no } \\
\text { effect }\end{array}$ & Facilitates & $\begin{array}{l}\text { Significantly } \\
\text { facilitates }\end{array}$ & $\begin{array}{l}\text { Don't } \\
\text { know }\end{array}$ \\
\hline $\begin{array}{l}\text { 2. Principal's perception of traits needed by students to be } \\
\text { successful in distance learning courses }\end{array}$ & $\begin{array}{l}\text { Significantly } \\
\text { impedes }\end{array}$ & Impedes & $\begin{array}{c}\text { Has no } \\
\text { effect }\end{array}$ & Facilitates & $\begin{array}{l}\text { Significantly } \\
\text { facilitates }\end{array}$ & $\begin{array}{l}\text { Don’t } \\
\text { know }\end{array}$ \\
\hline $\begin{array}{l}\text { 3. Principal's willingness to include distance learning } \\
\text { courses in the school curriculum }\end{array}$ & $\begin{array}{l}\text { Significantly } \\
\text { impedes }\end{array}$ & Impedes & $\begin{array}{c}\text { Has no } \\
\text { effect }\end{array}$ & Facilitates & $\begin{array}{l}\text { Significantly } \\
\text { facilitates }\end{array}$ & $\begin{array}{l}\text { Don't } \\
\text { know }\end{array}$ \\
\hline $\begin{array}{l}\text { 4. School faculty's knowledge of teaching methods used in } \\
\text { distance learning }\end{array}$ & $\begin{array}{l}\text { Significantly } \\
\text { impedes }\end{array}$ & Impedes & $\begin{array}{c}\text { Has no } \\
\text { effect }\end{array}$ & Facilitates & $\begin{array}{l}\text { Significantly } \\
\text { facilitates }\end{array}$ & $\begin{array}{l}\text { Don't } \\
\text { know }\end{array}$ \\
\hline $\begin{array}{l}\text { 5. Skills of distance learning course facilitators in the } \\
\text { school }\end{array}$ & $\begin{array}{l}\text { Significantly } \\
\text { impedes }\end{array}$ & Impedes & $\begin{array}{c}\text { Has no } \\
\text { effect }\end{array}$ & Facilitates & $\begin{array}{l}\text { Significantly } \\
\text { facilitates }\end{array}$ & $\begin{array}{l}\text { Don't } \\
\text { know }\end{array}$ \\
\hline $\begin{array}{l}\text { 6. Faculty's willingness to learn about distance learning } \\
\text { courses }\end{array}$ & $\begin{array}{l}\text { Significantly } \\
\text { impedes }\end{array}$ & Impedes & $\begin{array}{c}\text { Has no } \\
\text { effect }\end{array}$ & Facilitates & $\begin{array}{l}\text { Significantly } \\
\text { facilitates }\end{array}$ & $\begin{array}{l}\text { Don’t } \\
\text { know }\end{array}$ \\
\hline $\begin{array}{l}\text { 7. School counselor as a source of information about } \\
\text { distance learning courses }\end{array}$ & $\begin{array}{l}\text { Significantly } \\
\text { impedes }\end{array}$ & Impedes & $\begin{array}{c}\text { Has no } \\
\text { effect }\end{array}$ & Facilitates & $\begin{array}{l}\text { Significantly } \\
\text { facilitates }\end{array}$ & $\begin{array}{l}\text { Don’t } \\
\text { know }\end{array}$ \\
\hline \multicolumn{7}{|l|}{ Comments: } \\
\hline
\end{tabular}




\begin{tabular}{|c|c|c|c|c|c|c|}
\hline \multicolumn{7}{|c|}{ Category: Communication } \\
\hline \multicolumn{7}{|c|}{ QUESTION: What effect do the following factors have on the implementation of distance learning in your school (grades 9-12)? } \\
\hline Item & 1 & 2 & 3 & 4 & 5 & \\
\hline $\begin{array}{l}\text { 8. Communication about distance learning courses among } \\
\text { all school personnel within a school }\end{array}$ & $\begin{array}{l}\text { Significantly } \\
\text { impedes }\end{array}$ & Impedes & $\begin{array}{c}\text { Has no } \\
\text { effect }\end{array}$ & Facilitates & $\begin{array}{l}\text { Significantly } \\
\text { facilitates }\end{array}$ & $\begin{array}{l}\text { Don’t } \\
\text { know }\end{array}$ \\
\hline $\begin{array}{l}\text { 9. Information about distance learning courses made } \\
\text { available to students }\end{array}$ & $\begin{array}{l}\text { Significantly } \\
\text { impedes }\end{array}$ & Impedes & $\begin{array}{c}\text { Has no } \\
\text { effect }\end{array}$ & Facilitates & $\begin{array}{l}\text { Significantly } \\
\text { facilitates }\end{array}$ & $\begin{array}{l}\text { Don't } \\
\text { know }\end{array}$ \\
\hline $\begin{array}{l}\text { 10. Communication about distance learning courses with } \\
\text { external audiences (e.g., parents) }\end{array}$ & $\begin{array}{l}\text { Significantly } \\
\text { impedes }\end{array}$ & Impedes & $\begin{array}{c}\text { Has no } \\
\text { effect }\end{array}$ & Facilitates & $\begin{array}{l}\text { Significantly } \\
\text { facilitates }\end{array}$ & $\begin{array}{l}\text { Don't } \\
\text { know }\end{array}$ \\
\hline $\begin{array}{l}\text { 11. Clarity of WVBE Policy 2450, Distance Learning and } \\
\text { the West Virginia Virtual School }\end{array}$ & $\begin{array}{l}\text { Significantly } \\
\text { impedes }\end{array}$ & Impedes & $\begin{array}{c}\text { Has no } \\
\text { effect }\end{array}$ & Facilitates & $\begin{array}{l}\text { Significantly } \\
\text { facilitates }\end{array}$ & $\begin{array}{l}\text { Don’t } \\
\text { know }\end{array}$ \\
\hline $\begin{array}{l}\text { 12. Guidance from the West Virginia Department of } \\
\text { Education }\end{array}$ & $\begin{array}{l}\text { Significantly } \\
\text { impedes }\end{array}$ & Impedes & $\begin{array}{c}\text { Has no } \\
\text { effect }\end{array}$ & Facilitates & $\begin{array}{l}\text { Significantly } \\
\text { facilitates }\end{array}$ & $\begin{array}{l}\text { Don’t } \\
\text { know }\end{array}$ \\
\hline \multicolumn{7}{|l|}{ Comments: } \\
\hline
\end{tabular}




\begin{tabular}{|c|c|c|c|c|c|c|}
\hline \multicolumn{7}{|c|}{ Category: Resources } \\
\hline \multicolumn{7}{|c|}{ QUESTION: What effect do the following factors have on the implementation of distance learning in your school (grades 9-12)? } \\
\hline Item & 1 & 2 & 3 & 4 & 5 & \\
\hline 13. Cost of distance learning courses & $\begin{array}{l}\text { Significantly } \\
\text { impedes }\end{array}$ & Impedes & $\begin{array}{c}\text { Has no } \\
\text { effect }\end{array}$ & Facilitates & $\begin{array}{l}\text { Significantly } \\
\text { facilitates }\end{array}$ & $\begin{array}{l}\text { Don’t } \\
\text { know }\end{array}$ \\
\hline 14. Student access to technology and instructional support & $\begin{array}{l}\text { Significantly } \\
\text { impedes }\end{array}$ & Impedes & $\begin{array}{c}\text { Has no } \\
\text { effect }\end{array}$ & Facilitates & $\begin{array}{l}\text { Significantly } \\
\text { facilitates }\end{array}$ & $\begin{array}{l}\text { Don’t } \\
\text { know }\end{array}$ \\
\hline $\begin{array}{l}\text { 15. Time available for school personnel to implement } \\
\text { Distance Learning Policy } 2450\end{array}$ & $\begin{array}{l}\text { Significantly } \\
\text { impedes }\end{array}$ & Impedes & $\begin{array}{c}\text { Has no } \\
\text { effect }\end{array}$ & Facilitates & $\begin{array}{l}\text { Significantly } \\
\text { facilitates }\end{array}$ & $\begin{array}{l}\text { Don’t } \\
\text { know }\end{array}$ \\
\hline $\begin{array}{l}\text { 16. Size of the school (i.e., number of students in grades 9- } \\
\text { 12) }\end{array}$ & $\begin{array}{l}\text { Significantly } \\
\text { impedes }\end{array}$ & Impedes & $\begin{array}{c}\text { Has no } \\
\text { effect }\end{array}$ & Facilitates & $\begin{array}{l}\text { Significantly } \\
\text { facilitates }\end{array}$ & $\begin{array}{l}\text { Don’t } \\
\text { know }\end{array}$ \\
\hline $\begin{array}{l}\text { 17. Number of computers available for students in distance } \\
\text { learning courses }\end{array}$ & $\begin{array}{l}\text { Significantly } \\
\text { impedes }\end{array}$ & Impedes & $\begin{array}{r}\text { Has no } \\
\text { effect }\end{array}$ & Facilitates & $\begin{array}{l}\text { Significantly } \\
\text { facilitates }\end{array}$ & $\begin{array}{l}\text { Don’t } \\
\text { know }\end{array}$ \\
\hline $\begin{array}{l}\text { 18. Broadband capacity/access to the Internet at your } \\
\text { school }\end{array}$ & $\begin{array}{l}\text { Significantly } \\
\text { impedes }\end{array}$ & Impedes & $\begin{array}{c}\text { Has no } \\
\text { effect }\end{array}$ & Facilitates & $\begin{array}{l}\text { Significantly } \\
\text { facilitates }\end{array}$ & $\begin{array}{l}\text { Don’t } \\
\text { know }\end{array}$ \\
\hline $\begin{array}{l}\text { 19. Computer network security (protection from computer } \\
\text { viruses and hackers) }\end{array}$ & $\begin{array}{l}\text { Significantly } \\
\text { impedes }\end{array}$ & Impedes & $\begin{array}{r}\text { Has no } \\
\text { effect }\end{array}$ & Facilitates & $\begin{array}{l}\text { Significantly } \\
\text { facilitates }\end{array}$ & $\begin{array}{l}\text { Don’t } \\
\text { know }\end{array}$ \\
\hline $\begin{array}{l}\text { 20. Funding for professional development about distance } \\
\text { learning }\end{array}$ & $\begin{array}{l}\text { Significantly } \\
\text { impedes }\end{array}$ & Impedes & $\begin{array}{c}\text { Has no } \\
\text { effect }\end{array}$ & Facilitates & $\begin{array}{l}\text { Significantly } \\
\text { facilitates }\end{array}$ & $\begin{array}{l}\text { Don’t } \\
\text { know }\end{array}$ \\
\hline $\begin{array}{l}\text { 21. Distance learning course facilitators in your school } \\
\text { having the opportunity to network (i.e., exchange } \\
\text { implementation experiences) with distance learning course } \\
\text { facilitators in other schools. }\end{array}$ & $\begin{array}{l}\text { Significantly } \\
\text { impedes }\end{array}$ & Impedes & $\begin{array}{l}\text { Has no } \\
\text { effect }\end{array}$ & Facilitates & $\begin{array}{l}\text { Significantly } \\
\text { facilitates }\end{array}$ & $\begin{array}{l}\text { Don’t } \\
\text { know }\end{array}$ \\
\hline \multicolumn{7}{|l|}{ Comments: } \\
\hline
\end{tabular}




\begin{tabular}{|c|c|c|c|c|c|c|}
\hline \multicolumn{7}{|c|}{ Category: Structures } \\
\hline \multicolumn{7}{|c|}{ QUESTION: What effect do the following factors have on the implementation of distance learning in your school (grades 9-12)? } \\
\hline Item & 1 & 2 & 3 & 4 & 5 & \\
\hline $\begin{array}{l}\text { 22. Established operating practices in the school (e.g., daily } \\
\text { class schedules, attendance, school calendar, procedures for } \\
\text { recording grades) }\end{array}$ & $\begin{array}{l}\text { Significantly } \\
\text { impedes }\end{array}$ & Impedes & $\begin{array}{l}\text { Has no } \\
\text { effect }\end{array}$ & Facilitates & $\begin{array}{l}\text { Significantly } \\
\text { facilitates }\end{array}$ & $\begin{array}{l}\text { Don’t } \\
\text { know }\end{array}$ \\
\hline $\begin{array}{l}\text { 23. WVBE Policy 2460, Educational Purpose and } \\
\text { Acceptable Use of Electronic Resources, Technologies and } \\
\text { the Internet (pertaining to acceptable use of the Internet) }\end{array}$ & $\begin{array}{l}\text { Significantly } \\
\text { impedes }\end{array}$ & Impedes & $\begin{array}{l}\text { Has no } \\
\text { effect }\end{array}$ & Facilitates & $\begin{array}{l}\text { Significantly } \\
\text { facilitates }\end{array}$ & $\begin{array}{l}\text { Don’t } \\
\text { know }\end{array}$ \\
\hline $\begin{array}{l}\text { 24. Acceptance of credits for distance learning courses by } \\
\text { the county board of education or diploma-granting } \\
\text { authority }\end{array}$ & $\begin{array}{l}\text { Significantly } \\
\text { impedes }\end{array}$ & Impedes & $\begin{array}{l}\text { Has no } \\
\text { effect }\end{array}$ & Facilitates & $\begin{array}{l}\text { Significantly } \\
\text { facilitates }\end{array}$ & $\begin{array}{l}\text { Don’t } \\
\text { know }\end{array}$ \\
\hline $\begin{array}{l}\text { 25. Recognition of distance learning courses by colleges } \\
\text { and universities }\end{array}$ & $\begin{array}{l}\text { Significantly } \\
\text { impedes }\end{array}$ & Impedes & $\begin{array}{l}\text { Has no } \\
\text { effect }\end{array}$ & Facilitates & $\begin{array}{l}\text { Significantly } \\
\text { facilitates }\end{array}$ & $\begin{array}{l}\text { Don’t } \\
\text { know }\end{array}$ \\
\hline $\begin{array}{l}\text { 26. Assessment of student learning in distance learning } \\
\text { courses }\end{array}$ & $\begin{array}{l}\text { Significantly } \\
\text { impedes }\end{array}$ & Impedes & $\begin{array}{c}\text { Has no } \\
\text { effect }\end{array}$ & Facilitates & $\begin{array}{c}\text { Significantly } \\
\text { facilitates }\end{array}$ & $\begin{array}{l}\text { Don’t } \\
\text { know }\end{array}$ \\
\hline $\begin{array}{l}\text { 27. School's ability to maintain academic integrity (control } \\
\text { cheating) in distance learning courses }\end{array}$ & $\begin{array}{l}\text { Significantly } \\
\text { impedes }\end{array}$ & Impedes & $\begin{array}{c}\text { Has no } \\
\text { effect }\end{array}$ & Facilitates & $\begin{array}{l}\text { Significantly } \\
\text { facilitates }\end{array}$ & $\begin{array}{l}\text { Don’t } \\
\text { know }\end{array}$ \\
\hline $\begin{array}{l}\text { 28. Ability for students to enroll in distance learning } \\
\text { courses without experiencing scheduling conflicts }\end{array}$ & $\begin{array}{l}\text { Significantly } \\
\text { impedes }\end{array}$ & Impedes & $\begin{array}{r}\text { Has no } \\
\text { effect }\end{array}$ & Facilitates & $\begin{array}{l}\text { Significantly } \\
\text { facilitates }\end{array}$ & $\begin{array}{l}\text { Don’t } \\
\text { know }\end{array}$ \\
\hline $\begin{array}{l}\text { 29. Support from West Virginia Department of Education } \\
\text { personnel }\end{array}$ & $\begin{array}{l}\text { Significantly } \\
\text { impedes }\end{array}$ & Impedes & $\begin{array}{c}\text { Has no } \\
\text { effect }\end{array}$ & Facilitates & $\begin{array}{l}\text { Significantly } \\
\text { facilitates }\end{array}$ & $\begin{array}{l}\text { Don’t } \\
\text { know }\end{array}$ \\
\hline \multicolumn{7}{|l|}{ Comments: } \\
\hline
\end{tabular}




\begin{tabular}{|c|c|c|c|c|c|c|}
\hline \multicolumn{7}{|c|}{ Category: Culture } \\
\hline \multicolumn{7}{|c|}{ QUESTION: What effect do the following factors have on the implementation of distance learning in your school (grades 9-12)? } \\
\hline Item & 1 & 2 & 3 & 4 & 5 & \\
\hline 30. Faculty’s acceptance of state policy & $\begin{array}{l}\text { Significantly } \\
\text { impedes }\end{array}$ & Impedes & $\begin{array}{c}\text { Has no } \\
\text { effect }\end{array}$ & Facilitates & $\begin{array}{l}\text { Significantly } \\
\text { facilitates }\end{array}$ & $\begin{array}{l}\text { Don't } \\
\text { know }\end{array}$ \\
\hline $\begin{array}{l}\text { 31. Importance of student digital literacy (i.e., abilities to locate, } \\
\text { organize, understand, evaluate, analyze and create information } \\
\text { using technology). }\end{array}$ & $\begin{array}{l}\text { Significantly } \\
\text { impedes }\end{array}$ & Impedes & $\begin{array}{l}\text { Has no } \\
\text { effect }\end{array}$ & Facilitates & $\begin{array}{l}\text { Significantly } \\
\text { facilitates }\end{array}$ & $\begin{array}{l}\text { Don't } \\
\text { know }\end{array}$ \\
\hline \multicolumn{7}{|l|}{$\begin{array}{l}\text { 32. Importance of teacher digital literacy (i.e., abilities to locate, } \\
\text { organize, understand, evaluate, analyze and create information } \\
\text { using technology). }\end{array}$} \\
\hline $\begin{array}{l}\text { 33. Quality of distance learning courses compared to face- } \\
\text { to-face courses }\end{array}$ & $\begin{array}{l}\text { Significantly } \\
\text { impedes }\end{array}$ & Impedes & $\begin{array}{c}\text { Has no } \\
\text { effect }\end{array}$ & Facilitates & $\begin{array}{l}\text { Significantly } \\
\text { facilitates }\end{array}$ & $\begin{array}{l}\text { Don't } \\
\text { know }\end{array}$ \\
\hline 34. Support of distance learning among the faculty & $\begin{array}{l}\text { Significantly } \\
\text { impedes }\end{array}$ & Impedes & $\begin{array}{c}\text { Has no } \\
\text { effect }\end{array}$ & Facilitates & $\begin{array}{l}\text { Significantly } \\
\text { facilitates }\end{array}$ & $\begin{array}{l}\text { Don't } \\
\text { know }\end{array}$ \\
\hline 35. Parents' perception of distance learning & $\begin{array}{l}\text { Significantly } \\
\text { impedes }\end{array}$ & Impedes & $\begin{array}{c}\text { Has no } \\
\text { effect }\end{array}$ & Facilitates & $\begin{array}{c}\text { Significantly } \\
\text { facilitates }\end{array}$ & $\begin{array}{l}\text { Don't } \\
\text { know }\end{array}$ \\
\hline \multicolumn{7}{|l|}{ Comments: } \\
\hline
\end{tabular}

36. What is your position in the school? (Please check one.)
$\square$ Principal
$\square$ Assistant Principal
$\square$ Counselor
$\square$ Librarian
$\square$ Teacher
$\square$ Other - please list 
37. How long have you served in the position identified in Item \#36?

$\square$ Less than 2 years

$\square 2-5$ years

$\square 6-10$ years

$\square 11-15$ years

$\square 15-20$ years

$\square$ More than 20 years (Please indicate length of time:

38. Are you directly involved in distance learning at your school? $\square$ Yes $\quad \square$ No

If "Yes," how are you involved? (Please check all that apply.)

$\square$ I am the school's distance learning contact (person who distributes information to students and parents, secures agreements, and has the authority to enroll students in distance learning courses).

$\square$ I am a distance learning course facilitator (person of record who monitors the academic performance of students enrolled in distance learning courses and am designated to receive reports from the course provider concerning individual student progress).

$\square$ Other - Please explain:

39. What is the total school enrollment in grades 9-12? Less than 450 students 450 to 800 students Over 800 students

Please provide your email address if you wish to be entered into the drawing for $\$ 50$ gasoline cards. All responses will be kept confidential even when email addresses are provided. Email address:

Thank you for participating in this survey. 


\section{Appendix D}

Matrix Displaying the Relationship between the Literature and the Survey Items

\begin{tabular}{|c|c|c|}
\hline \multicolumn{3}{|c|}{ MATRIX: Relationship of Literature to the Policy Implementation Survey Instrument } \\
\hline \multicolumn{3}{|c|}{ 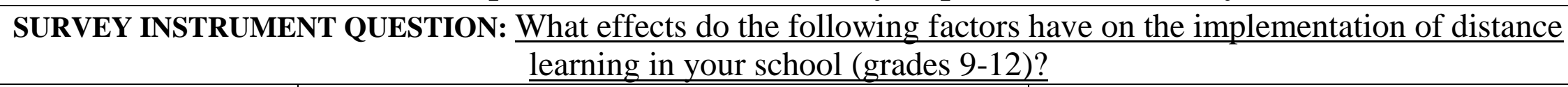 } \\
\hline $\begin{array}{l}\text { PEOPLE: Common } \\
\text { findings }\end{array}$ & $\begin{array}{l}\text { FACILITATING EFFECTS: Fowler (2009), McLaughlin } \\
\text { (1991), and Eisenhart et al. (1988) discuss the effect of will } \\
\text { of individuals to perform tasks }\end{array}$ & $\begin{array}{l}\text { IMPEDING EFFECTS: Kotter (1998) and } \\
\text { Fullan et al. (2004) discuss the effects of } \\
\text { unsupportive leaders; Fowler (2009), Bodilly } \\
\text { (1998), Gross et al. (1971), and Huberman \& } \\
\text { Miles (1984) discuss how individuals who } \\
\text { lack skills can impede implementation. } \\
\text { Myers (2008) found that individual and } \\
\text { organizational will to implement a policy } \\
\text { was a frequent barrier. }\end{array}$ \\
\hline Factor Category & Additional points in literature & Resulting survey item \\
\hline People & $\begin{array}{l}\text { Shepherd's (2001) research identified the level of } \\
\text { administrative support as critical to policy implementation. }\end{array}$ & $\begin{array}{l}\text { 1. Support of administrators in the local } \\
\text { school (e.g., encouragement to teachers to } \\
\text { utilize technology in instruction, provision of } \\
\text { resources) }\end{array}$ \\
\hline
\end{tabular}




\begin{tabular}{|c|c|c|}
\hline Factor Category & Additional points in literature & Resulting survey item \\
\hline People & $\begin{array}{l}\text { Principals serve as instructional leaders in schools and their } \\
\text { approval and support "is essential to the success of virtual } \\
\text { school implementation at the local level" (West Virginia } \\
\text { Department of Education, 2012f, para. 1). Prescott (2004) } \\
\text { found that school principals in Iowa believed that students } \\
\text { must have certain traits to be successful in online courses - } \\
\text { including self-discipline and motivation. }\end{array}$ & $\begin{array}{l}\text { 2. Principal's perception of traits needed by } \\
\text { students to be successful in distance learning } \\
\text { courses }\end{array}$ \\
\hline People & $\begin{array}{l}\text { Fowler (2009), McLaughlin (1991), and Eisenhart et al. } \\
\text { (1988) discuss the effect of will of individuals to perform } \\
\text { tasks }\end{array}$ & $\begin{array}{l}\text { 3. Principal's willingness to include distance } \\
\text { learning courses in the school curriculum }\end{array}$ \\
\hline People & $\begin{array}{l}\text { Bral (2007): } 77.4 \% \text { reported teachers' lack of knowledge } \\
\text { about online teaching and class development was a barrier. }\end{array}$ & $\begin{array}{l}\text { 4. School faculty's knowledge of teaching } \\
\text { methods used in distance learning }\end{array}$ \\
\hline People & $\begin{array}{l}\text { Fowler (2009), Bodilly (1998), Gross et al. (1971), and } \\
\text { Huberman \& Miles (1984) discuss how individuals who } \\
\text { lack skills can impede implementation. }\end{array}$ & $\begin{array}{l}\text { 5. Skills of distance learning course } \\
\text { facilitators in the school }\end{array}$ \\
\hline People & $\begin{array}{l}\text { Shepherd's (2001) research identified teacher attitudes as } \\
\text { critical to policy implementation. }\end{array}$ & $\begin{array}{l}\text { 6. Faculty's willingness to learn about } \\
\text { distance learning courses }\end{array}$ \\
\hline
\end{tabular}




\begin{tabular}{|c|c|c|}
\hline Factor Category & Additional points in literature & Resulting survey item \\
\hline People & $\begin{array}{l}\text { Osumi (2010): In a survey of Hawaii principals and } \\
\text { assistant principals, counselors were identified as the } \\
\text { leading source of course information for students, followed } \\
\text { by marketing materials, friends, and teachers. }\end{array}$ & $\begin{array}{l}\text { 7. School counselor as a source of } \\
\text { information about distance learning courses }\end{array}$ \\
\hline $\begin{array}{l}\text { COMMUNICATION: } \\
\text { Common findings }\end{array}$ & $\begin{array}{l}\text { FACILITATING EFFECTS: Fullan (2001) and } \\
\text { McLaughlin \& Elmore (1982) discuss the need for clear } \\
\text { communication in policy implementation }\end{array}$ & $\begin{array}{l}\text { IMPEDING EFFECTS: Kotter (1998) } \\
\text { discusses the effect of poor communication } \\
\text { and danger of "undercommunicating" }\end{array}$ \\
\hline Communication & $\begin{array}{l}\text { "Our most critical role in developing a consortium for } \\
\text { implementing online learning has more to do with } \\
\text { facilitating communication within districts than actual } \\
\text { computer specifications and course selections" (Brown, } \\
\text { 2011, regarding virtual learning implementation in } 16 \\
\text { Oregon school districts). }\end{array}$ & $\begin{array}{l}\text { 8. Communication about distance learning } \\
\text { courses among all school personnel within a } \\
\text { school }\end{array}$ \\
\hline Communication & $\begin{array}{l}\text { Osumi (2010): In a rating of factors that prevented students } \\
\text { from participating in a dual credit program, } 79.2 \% \text { of } \\
\text { administrators (principals and assistant principals) said } \\
\text { students did not know about the program. }\end{array}$ & $\begin{array}{l}\text { 9. Information about distance learning } \\
\text { courses made available to students }\end{array}$ \\
\hline
\end{tabular}




\begin{tabular}{|c|c|c|}
\hline Factor Category & Additional points in literature & Resulting survey item \\
\hline Communication & $\begin{array}{l}\text { Standard J, Online Teaching Standards, iNACOL: The } \\
\text { online teacher is able to provide ongoing communication } \\
\text { with parents or guardians concerning student learning. } \\
\text { Honig (2006) and Tushman (1977) discussed the value of } \\
\text { communicating policy information to external audiences, } \\
\text { who are defined by Johnson and Chang (2000) as those who } \\
\text { are affected by a policy but have limited participation in the } \\
\text { implementation process. }\end{array}$ & $\begin{array}{l}\text { 10. Communication about distance learning } \\
\text { courses with external audiences (e.g., } \\
\text { parents) }\end{array}$ \\
\hline Communication & $\begin{array}{l}\text { Moser (2005) study found that policy clarity is important to } \\
\text { implementation. }\end{array}$ & $\begin{array}{l}\text { 11. Clarity of WVBE Policy 2450, Distance } \\
\text { Learning and the West Virginia Virtual } \\
\text { School }\end{array}$ \\
\hline Communication & $\begin{array}{l}\text { Moser }(2005) \text { confirmed that the absence of policy guidance } \\
\text { or poor communication of it can lead to inconsistent } \\
\text { implementation }\end{array}$ & $\begin{array}{l}\text { 12. Guidance from the West Virginia } \\
\text { Department of Education }\end{array}$ \\
\hline
\end{tabular}




\begin{tabular}{|c|c|c|}
\hline $\begin{array}{l}\text { RESOURCES: } \\
\text { Common findings }\end{array}$ & $\begin{array}{l}\text { FACILITATING EFFECTS: Fowler (2009) and Berman } \\
\text { \& McLaughlin (1978) discuss how money can affect } \\
\text { implementation as it can be used to obtain other resources }\end{array}$ & $\begin{array}{l}\text { IMPEDING EFFECTS: Fowler (2009) } \\
\text { discussed professional development and the } \\
\text { likely failure of policies when implementers } \\
\text { are not given adequate time. }\end{array}$ \\
\hline Factor Category & Additional points in literature & Resulting survey item \\
\hline Resources & $\begin{array}{l}\text { Costs of virtual courses were mentioned as barriers by } \\
\text { Morse (2010), Setzer and Lewis (2005) and Picciano and } \\
\text { Seaman (2007). }\end{array}$ & 13. Cost of distance learning courses \\
\hline Resources & $\begin{array}{l}\text { "Administrators are responsible for ensuring student access } \\
\text { to technology and instructional support" (West Virginia } \\
\text { Department of Education, 2012f, para. 1). }\end{array}$ & $\begin{array}{l}\text { 14. Student access to technology and } \\
\text { instructional support }\end{array}$ \\
\hline Resources & $\begin{array}{l}\text { Fowler (2009): “...the likely failure of policy when } \\
\text { implementers are not given adequate time." }\end{array}$ & $\begin{array}{l}\text { 15. Time available for school personnel to } \\
\text { implement Distance Learning Policy } 2450\end{array}$ \\
\hline
\end{tabular}




\begin{tabular}{|c|c|c|}
\hline Factor Category & Additional points in literature & Resulting survey item \\
\hline Resources & $\begin{array}{l}\text { Setzer and Lewis (2005) found that the highest percentage } \\
\text { of schools using virtual courses were rural schools with } \\
\text { smaller numbers of students. }\end{array}$ & $\begin{array}{l}\text { 16. Size of the school (i.e., number of } \\
\text { students in grades 9-12) }\end{array}$ \\
\hline Resources & $\begin{array}{l}\text { Morse (2010); Also, Bral (2007): Funding for hardware, } \\
\text { software, and/or equipment was not considered a barrier by } \\
46.8 \% \text { of respondents. }\end{array}$ & $\begin{array}{l}\text { 17. Number of computers available for } \\
\text { students in distance learning courses }\end{array}$ \\
\hline Resources & $\begin{array}{l}\text { Bral (2007): } 79.1 \% \text { of respondents did not see access to the } \\
\text { Internet as a barrier. }\end{array}$ & $\begin{array}{l}\text { 18. Broadband capacity/access to the Internet } \\
\text { at your school }\end{array}$ \\
\hline Resources & $\begin{array}{l}\text { Bral (2007): Online class security issues were not } \\
\text { considered a barrier by } 56.8 \% \text { of respondents. }\end{array}$ & $\begin{array}{l}\text { 19. Computer network security (protection } \\
\text { from computer viruses and hackers) }\end{array}$ \\
\hline Resources & $\begin{array}{l}\text { "The distance learning course facilitator shall receive } \\
\text { inservice training or technology-delivered instructions } \\
\text { pertaining to the course organization, classroom } \\
\text { management, technical aspects, monitoring of student } \\
\text { testing, and securing other student services as needed" } \\
\text { (Policy 2450). Bral (2007): Funding for faculty training } \\
\text { was viewed as somewhat or a significant barrier by } 66.2 \% \\
\text { of respondents. Picciano \& Seaman (2007): Need for } \\
\text { teacher training was one of the major barriers identified }\end{array}$ & $\begin{array}{l}\text { 20. Funding for professional development about } \\
\text { distance learning }\end{array}$ \\
\hline
\end{tabular}




\begin{tabular}{|l|l|l|}
\hline \multicolumn{1}{|c|}{ Factor Category } & \multicolumn{1}{|c|}{ Additional points in literature } & \multicolumn{1}{c|}{ Resulting survey item } \\
\hline Resources & $\begin{array}{l}\text { Fowler (2009) and Shepherd (2001) identified the value of } \\
\text { networking to exchange information and personal } \\
\text { implementation experiences when policy implementers are } \\
\text { located in different settings. }\end{array}$ & $\begin{array}{l}\text { 21. Distance learning facilitators in your } \\
\text { school having the opportunity to network } \\
\text { (i.e., exchange implementation experiences) } \\
\text { with distance learning facilitators in other } \\
\text { schools }\end{array}$ \\
\hline $\begin{array}{l}\text { STRUCTURE: } \\
\text { Common findings }\end{array}$ & $\begin{array}{l}\text { FACILITATING EFFECTS: Hoyt \& Sweetland (2001) } \\
\text { discuss how organizational structures including policies } \\
\text { can promote efficiency and reduce chaos; Boyd \& Crowson } \\
\text { (2002) discuss school system organization and benefits of } \\
\text { coordinated efforts }\end{array}$ & $\begin{array}{l}\text { IMPEDING EFFECTS: Knapp, Bamburg, } \\
\text { convergence of conflicting policies as a } \\
\text { barrier to implementation; Kotter (1996) and } \\
\text { Farkas, Johnson, Duffett, \& Foleno (2001) } \\
\text { describe how structures often become } \\
\text { obstacles to implementation. }\end{array}$ \\
\hline Structure & $\begin{array}{l}\text { Bral (2007): Lack of school policies was not viewed as a } \\
\text { barrier by 56.8\% of respondents. }\end{array}$ & $\begin{array}{l}\text { 22. Established operating practices in the } \\
\text { school (e.g., daily class schedules, } \\
\text { attendance, school calendar, procedures for } \\
\text { recording grades) }\end{array}$ \\
\hline
\end{tabular}




\begin{tabular}{|c|c|c|}
\hline Factor Category & Additional points in literature & Resulting survey item \\
\hline Structure & $\begin{array}{l}\text { Knapp, Bamburg, Ferguson, \& Hill (1998) discuss the } \\
\text { convergence of conflicting policies as a barrier to } \\
\text { implementation. }\end{array}$ & $\begin{array}{l}\text { 23. WVBE Policy 2460, Educational } \\
\text { Purpose and Acceptable Use of Electronic } \\
\text { Resources, Technologies and the Internet } \\
\text { (pertaining to acceptable use of the Internet) }\end{array}$ \\
\hline Structure & $\begin{array}{l}\text { Bral (2007): Greater collaboration between high schools } \\
\text { within and between districts regarding the acceptance of } \\
\text { online credits was cited as needed solution to help } \\
\text { overcome some barriers. }\end{array}$ & $\begin{array}{l}\text { 24. Acceptance of credits for distance } \\
\text { learning courses by the county board of } \\
\text { education or diploma-granting authority }\end{array}$ \\
\hline Structure & $\begin{array}{l}\text { Bral (2007): Greater collaboration between high schools } \\
\text { within and between districts regarding the acceptance of } \\
\text { online credits was cited as needed solution to help } \\
\text { overcome some barriers. }\end{array}$ & $\begin{array}{l}25 \text {. Recognition of distance learning courses } \\
\text { by colleges and universities }\end{array}$ \\
\hline Structure & $\begin{array}{l}\text { Black, Ferdig, and DiPietro (2008) concluded that effective } \\
\text { means for assessing and evaluating distance learning have } \\
\text { not been fully developed. }\end{array}$ & $\begin{array}{l}\text { 26. Assessment of student learning in } \\
\text { distance learning courses }\end{array}$ \\
\hline Structure & $\begin{array}{l}\text { "Those in distance education are faced with a formidable } \\
\text { challenge to ensure the identity of test takers and integrity } \\
\text { of exam results" (Howell, Sorensen, \& Tippets, 2009, para } \\
\text { 1). }\end{array}$ & $\begin{array}{l}\text { 27. School's ability to maintain academic } \\
\text { integrity (control cheating) in distance } \\
\text { learning courses }\end{array}$ \\
\hline Structure & $\begin{array}{l}\text { Over } 60 \% \text { of respondents in Bral's (2007) study determined } \\
\text { that conflicts in student schedules were barriers to the use of } \\
\text { virtual courses in their schools. }\end{array}$ & $\begin{array}{l}\text { 28. Ability for students to enroll in distance } \\
\text { learning courses without experiencing } \\
\text { scheduling conflicts }\end{array}$ \\
\hline
\end{tabular}




\begin{tabular}{|c|c|c|}
\hline Factor Category & Additional points in literature & Resulting survey item \\
\hline Structure & $\begin{array}{l}\text { Barton's (2010) study found that the lack of support from } \\
\text { the district or state contributes to inconsistent policy } \\
\text { implementation. }\end{array}$ & $\begin{array}{l}\text { 29. Support from West Virginia Department } \\
\text { of Education personnel }\end{array}$ \\
\hline $\begin{array}{l}\text { CULTURE: Common } \\
\text { findings }\end{array}$ & $\begin{array}{l}\text { FACILITATING EFFECTS: Jerald (2005) said culture } \\
\text { consists of traditional beliefs, norms, and habits; Fullan } \\
\text { (2007) defined school culture to include the guiding beliefs } \\
\text { and expectations of a school; Penuel et al. (2008) discusses } \\
\text { the value of giving teachers input into policy development; } \\
\text { Moser (2005): The culture of a school and community } \\
\text { affect policy implementation }\end{array}$ & $\begin{array}{l}\text { IMPEDING EFFECTS: Wood (2008) } \\
\text { discussed how new policies may clash with } \\
\text { the existing school culture or deeply } \\
\text { ingrained perceptions of the community; } \\
\text { McCarthy (2001) discusses implementation } \\
\text { resistance within schools }\end{array}$ \\
\hline Culture & $\begin{array}{l}\text { The level of policy acceptance within a school or } \\
\text { community's culture impacts implementation (Wood, 2008) }\end{array}$ & 30. Faculty's acceptance of state policy \\
\hline Culture & $\begin{array}{l}\text { Prensky (2001) labeled today's students as "digital natives" } \\
\text { and their teachers as "digital immigrants." Professional } \\
\text { development sessions to improve teachers' level of digital } \\
\text { literacy have not always produced sustained changes in } \\
\text { instruction. }\end{array}$ & $\begin{array}{l}\text { 31. Importance of student digital literacy (i.e., } \\
\text { abilities to locate, organize, understand, evaluate, } \\
\text { analyze and create information using } \\
\text { technology). } \\
\text { 32. Importance of teacher digital literacy (i.e., } \\
\text { abilities to locate, organize, understand, evaluate, } \\
\text { analyze and create information using } \\
\text { technology). }\end{array}$ \\
\hline
\end{tabular}




\begin{tabular}{|l|l|l|}
\hline \multicolumn{1}{|c|}{ Factor Category } & \multicolumn{1}{|c|}{ Additional points in literature } & \multicolumn{1}{|c|}{ Resulting survey item } \\
\hline Culture & $\begin{array}{l}\text { Many individuals believe virtual courses are less rigorous } \\
\text { than traditionally delivered courses. Concern about course } \\
\text { quality was the leading barrier identified in Picciano and } \\
\text { Seaman's research (2007). Bral (2007): "The most } \\
\text { significant barrier in this category was faculty members' } \\
\text { belief that face-to-face classes are superior to online classes } \\
\text { (79.3\% of respondents identified this as a barrier)" (p. 39). }\end{array}$ & $\begin{array}{l}\text { 33. Quality of distance learning courses } \\
\text { compared to face-to-face courses }\end{array}$ \\
\hline Culture & $\begin{array}{l}\text { New policies have a much greater likelihood of success, if } \\
\text { teachers are given the opportunity to provide input when the } \\
\text { policy is being developed (Penuel et al., 2008). Faculty } \\
\text { resistance to change was identified as a barrier by 57.5\% of } \\
\text { respondents in Bral's (2007) study. }\end{array}$ & $\begin{array}{l}34 . \text { Support of distance learning among the } \\
\text { faculty }\end{array}$ \\
\hline Culture & $\begin{array}{l}\text { Watson (2007) - Common misconceptions of virtual } \\
\text { learning. Also, "In a 2008 Gallup poll (as cited in Barbour } \\
\text { \& Reeves, 2009) only 27\% of people were willing to have } \\
\text { their child take most of their high school courses online at } \\
\text { home without attending a public school." }\end{array}$ & 35. Parents' perception of distance learning \\
\hline
\end{tabular}


Demographic questions:

36. What is your primary position in the school? (Please check all that apply.)

$\square$ Principal $\square$ Assistant Principal $\square$ Counselor $\square$ Librarian $\square$ Teacher $\square$ Other - please list

37. How long have you served in the position identified in Item \#36?

$\square$ Less than 2 years $\square 2-5$ years $\square 6-10$ years $\square \square 11-15$ years

$\square 15-20$ years $\quad \square$ More than 20 years (Please indicate length of time:

38. Are you directly involved in virtual learning at your school? $\quad \square$ Yes $\quad \square$ No

If "Yes," how are you involved? (Please check all that apply.)

$\square$ I am the school's distance learning contact (person who distributes information to students and parents, secures agreements, and has the authority to enroll students in virtual courses).

$\square$ I am a virtual course facilitator (person of record who monitors the academic performance of students enrolled in virtual courses and am designated to receive reports from the course provider concerning individual student progress).

$\square$ Other - Please explain:

39. What is the total school enrollment in grades 9-12? Less than 450 students $\quad 450$ to 800 students Over 800 students

(Item \#39 is included because several of the studies cited report the size of the school in the demographics. These three categories represent nearly the same number of West Virginia high schools based on the data in Appendix B: 38 high schools with less than 450 students, 39 high schools with 450 to 800 students, and 39 schools with over 800 students.) 


\section{Appendix E}

\section{Draft Survey Sent to Panel of Experts for Review}

\section{Survey: Factors Affecting Implementation of West Virginia Board of Education Policy 2450, Distance Learning and the West Virginia Virtual School}

The following survey should take less than ten minutes to complete. Please answer the questions taking into consideration your experiences with virtual courses provided by the West Virginia Department of Education (WVDE) or a WVDE-approved provider.

\section{The following definitions will be used for this survey:}

Distance learning is a type of formal study in which teachers and learners are separated by time or space.

Virtual learning is a form of distance learning in which instruction and content are delivered primarily via the Internet.

Virtual courses are technology-delivered courses used for public school credit and made available because of a shortage of certified personnel, a need to provide low-incidence courses, or any other validated student need to access technology-delivered courses.

The distance learning contact is the person at the school who is responsible for distributing information about virtual courses to students and parents, securing agreements, and contacting the West Virginia Virtual School to enroll students in virtual courses.

A virtual course facilitator is a person of record who monitors the academic performance of students enrolled in virtual courses and is designated to receive reports from the course provider concerning individual student progress.

\section{All responses will be kept confidential.}

Individuals providing email addresses at the end of the survey will be entered into a drawing for $\mathbf{\$ 5 0}$ gasoline cards to be given in appreciation for participating in this study.

Don't delay! Two winners will be drawn from those submitting surveys within the first week. 


\section{Perceptions of the Implementation of Policy 2450, Distance Learning and the West Virginia Virtual School}

Directions: Please provide responses regarding your school's implementation of West Virginia Board of Education Policy 2450, Distance Learning and the West Virginia Virtual School.

\begin{tabular}{|c|c|c|c|c|c|c|}
\hline \multicolumn{7}{|c|}{ Category: People } \\
\hline \multicolumn{7}{|c|}{ QUESTION: What effect do the following factors have on the implementation of virtual learning in your school (grades 9-12)? } \\
\hline Item & 1 & 2 & 3 & 4 & 5 & \\
\hline 1. Administrative support & $\begin{array}{l}\text { Significantly } \\
\text { impedes }\end{array}$ & Impedes & $\begin{array}{c}\text { Has no } \\
\text { effect }\end{array}$ & Facilitates & $\begin{array}{l}\text { Significantly } \\
\text { facilitates }\end{array}$ & $\begin{array}{l}\text { Don’t } \\
\text { know }\end{array}$ \\
\hline $\begin{array}{l}\text { 2. Principal's perception of traits needed by students to be } \\
\text { successful in virtual courses }\end{array}$ & $\begin{array}{l}\text { Significantly } \\
\text { impedes }\end{array}$ & Impedes & $\begin{array}{l}\text { Has no } \\
\text { effect }\end{array}$ & Facilitates & $\begin{array}{l}\text { Significantly } \\
\text { facilitates }\end{array}$ & $\begin{array}{l}\text { Don’t } \\
\text { know }\end{array}$ \\
\hline $\begin{array}{l}\text { 3. Principal's willingness to include virtual courses in the } \\
\text { school curriculum }\end{array}$ & $\begin{array}{l}\text { Significantly } \\
\text { impedes }\end{array}$ & Impedes & $\begin{array}{c}\text { Has no } \\
\text { effect }\end{array}$ & Facilitates & $\begin{array}{l}\text { Significantly } \\
\text { facilitates }\end{array}$ & $\begin{array}{l}\text { Don’t } \\
\text { know }\end{array}$ \\
\hline $\begin{array}{l}\text { 4. Faculty's knowledge of teaching methods used in } \\
\text { distance learning }\end{array}$ & $\begin{array}{l}\text { Significantly } \\
\text { impedes }\end{array}$ & Impedes & $\begin{array}{c}\text { Has no } \\
\text { effect }\end{array}$ & Facilitates & $\begin{array}{l}\text { Significantly } \\
\text { facilitates }\end{array}$ & $\begin{array}{l}\text { Don’t } \\
\text { know }\end{array}$ \\
\hline 5. Skills of virtual course facilitators in the school & $\begin{array}{l}\text { Significantly } \\
\text { impedes }\end{array}$ & Impedes & $\begin{array}{c}\text { Has no } \\
\text { effect }\end{array}$ & Facilitates & $\begin{array}{l}\text { Significantly } \\
\text { facilitates }\end{array}$ & $\begin{array}{l}\text { Don’t } \\
\text { know }\end{array}$ \\
\hline 6. Faculty's willingness to learn about virtual courses & $\begin{array}{l}\text { Significantly } \\
\text { impedes }\end{array}$ & Impedes & $\begin{array}{c}\text { Has no } \\
\text { effect }\end{array}$ & Facilitates & $\begin{array}{l}\text { Significantly } \\
\text { facilitates }\end{array}$ & $\begin{array}{l}\text { Don’t } \\
\text { know }\end{array}$ \\
\hline $\begin{array}{l}\text { 7. School counselor as a source of information about } \\
\text { virtual courses }\end{array}$ & $\begin{array}{l}\text { Significantly } \\
\text { impedes }\end{array}$ & Impedes & $\begin{array}{c}\text { Has no } \\
\text { effect }\end{array}$ & Facilitates & $\begin{array}{l}\text { Significantly } \\
\text { facilitates }\end{array}$ & $\begin{array}{l}\text { Don’t } \\
\text { know }\end{array}$ \\
\hline \multicolumn{7}{|l|}{ Comments: } \\
\hline
\end{tabular}




\begin{tabular}{|c|c|c|c|c|c|c|}
\hline \multicolumn{7}{|c|}{ Category: Communication } \\
\hline \multicolumn{7}{|c|}{ QUESTION: What effect do the following factors have on the implementation of virtual learning in your school (grades 9-12)? } \\
\hline Item & 1 & 2 & 3 & 4 & 5 & \\
\hline $\begin{array}{l}\text { 8. Communication about virtual courses among all school } \\
\text { personnel within a school }\end{array}$ & $\begin{array}{l}\text { Significantly } \\
\text { impedes }\end{array}$ & Impedes & $\begin{array}{c}\text { Has no } \\
\text { effect }\end{array}$ & Facilitates & $\begin{array}{l}\text { Significantly } \\
\text { facilitates }\end{array}$ & $\begin{array}{l}\text { Don't } \\
\text { know }\end{array}$ \\
\hline $\begin{array}{l}\text { 9. Information about virtual courses made available to } \\
\text { students }\end{array}$ & $\begin{array}{l}\text { Significantly } \\
\text { impedes }\end{array}$ & Impedes & $\begin{array}{c}\text { Has no } \\
\text { effect }\end{array}$ & Facilitates & $\begin{array}{l}\text { Significantly } \\
\text { facilitates }\end{array}$ & $\begin{array}{l}\text { Don't } \\
\text { know }\end{array}$ \\
\hline $\begin{array}{l}\text { 10. Communication about virtual courses with external } \\
\text { audiences (e.g., parents) }\end{array}$ & $\begin{array}{l}\text { Significantly } \\
\text { impedes }\end{array}$ & Impedes & $\begin{array}{c}\text { Has no } \\
\text { effect }\end{array}$ & Facilitates & $\begin{array}{l}\text { Significantly } \\
\text { facilitates }\end{array}$ & $\begin{array}{l}\text { Don't } \\
\text { know }\end{array}$ \\
\hline $\begin{array}{l}\text { 11. Clarity of WVBE Policy 2450, Distance Learning and } \\
\text { the West Virginia Virtual School }\end{array}$ & $\begin{array}{l}\text { Significantly } \\
\text { impedes }\end{array}$ & Impedes & $\begin{array}{c}\text { Has no } \\
\text { effect }\end{array}$ & Facilitates & $\begin{array}{l}\text { Significantly } \\
\text { facilitates }\end{array}$ & $\begin{array}{l}\text { Don’t } \\
\text { know }\end{array}$ \\
\hline $\begin{array}{l}\text { 12. Guidance from the West Virginia Department of } \\
\text { Education }\end{array}$ & $\begin{array}{l}\text { Significantly } \\
\text { impedes }\end{array}$ & Impedes & $\begin{array}{l}\text { Has no } \\
\text { effect }\end{array}$ & Facilitates & $\begin{array}{l}\text { Significantly } \\
\text { facilitates }\end{array}$ & $\begin{array}{l}\text { Don't } \\
\text { know }\end{array}$ \\
\hline
\end{tabular}

\section{Comments:}




\begin{tabular}{|c|c|c|c|c|c|c|}
\hline \multicolumn{7}{|c|}{ Category: Resources } \\
\hline \multicolumn{7}{|c|}{ QUESTION: What effect do the following factors have on the implementation of virtual learning in your school (grades 9-12)? } \\
\hline Item & 1 & $\mathbf{2}$ & $\mathbf{3}$ & 4 & 5 & \\
\hline 13. Cost of virtual courses & $\begin{array}{l}\text { Significantly } \\
\text { impedes }\end{array}$ & Impedes & $\begin{array}{c}\text { Has no } \\
\text { effect }\end{array}$ & Facilitates & $\begin{array}{l}\text { Significantly } \\
\text { facilitates }\end{array}$ & $\begin{array}{l}\text { Don’t } \\
\text { know }\end{array}$ \\
\hline 14. Student access to technology and instructional support & $\begin{array}{l}\text { Significantly } \\
\text { impedes }\end{array}$ & Impedes & $\begin{array}{c}\text { Has no } \\
\text { effect }\end{array}$ & Facilitates & $\begin{array}{l}\text { Significantly } \\
\text { facilitates }\end{array}$ & $\begin{array}{l}\text { Don’t } \\
\text { know }\end{array}$ \\
\hline $\begin{array}{l}\text { 15. Time available for school personnel to implement } \\
\text { WVBE Policy 2450, Distance Learning and the West } \\
\text { Virginia Virtual School }\end{array}$ & $\begin{array}{l}\text { Significantly } \\
\text { impedes }\end{array}$ & Impedes & $\begin{array}{l}\text { Has no } \\
\text { effect }\end{array}$ & Facilitates & $\begin{array}{l}\text { Significantly } \\
\text { facilitates }\end{array}$ & $\begin{array}{l}\text { Don’t } \\
\text { know }\end{array}$ \\
\hline $\begin{array}{l}\text { 16. Size of the school (i.e., number of students in grades 9- } \\
\text { 12) }\end{array}$ & $\begin{array}{l}\text { Significantly } \\
\text { impedes }\end{array}$ & Impedes & $\begin{array}{c}\text { Has no } \\
\text { effect }\end{array}$ & Facilitates & $\begin{array}{l}\text { Significantly } \\
\text { facilitates }\end{array}$ & $\begin{array}{l}\text { Don’t } \\
\text { know }\end{array}$ \\
\hline $\begin{array}{l}\text { 17. Number of computers available for students in virtual } \\
\text { courses }\end{array}$ & $\begin{array}{l}\text { Significantly } \\
\text { impedes }\end{array}$ & Impedes & $\begin{array}{c}\text { Has no } \\
\text { effect }\end{array}$ & Facilitates & $\begin{array}{l}\text { Significantly } \\
\text { facilitates }\end{array}$ & $\begin{array}{l}\text { Don’t } \\
\text { know }\end{array}$ \\
\hline $\begin{array}{l}\text { 18. Broadband capacity/access to the Internet at your } \\
\text { school }\end{array}$ & $\begin{array}{l}\text { Significantly } \\
\text { impedes }\end{array}$ & Impedes & $\begin{array}{l}\text { Has no } \\
\text { effect }\end{array}$ & Facilitates & $\begin{array}{l}\text { Significantly } \\
\text { facilitates }\end{array}$ & $\begin{array}{l}\text { Don’t } \\
\text { know }\end{array}$ \\
\hline $\begin{array}{l}\text { 19. Computer network security (protection from computer } \\
\text { viruses and hackers) }\end{array}$ & $\begin{array}{l}\text { Significantly } \\
\text { impedes }\end{array}$ & Impedes & $\begin{array}{c}\text { Has no } \\
\text { effect }\end{array}$ & Facilitates & $\begin{array}{l}\text { Significantly } \\
\text { facilitates }\end{array}$ & $\begin{array}{l}\text { Don’t } \\
\text { know }\end{array}$ \\
\hline 20. Funding for training about virtual learning & $\begin{array}{l}\text { Significantly } \\
\text { impedes }\end{array}$ & Impedes & $\begin{array}{c}\text { Has no } \\
\text { effect }\end{array}$ & Facilitates & $\begin{array}{l}\text { Significantly } \\
\text { facilitates }\end{array}$ & $\begin{array}{l}\text { Don’t } \\
\text { know }\end{array}$ \\
\hline $\begin{array}{l}\text { 21. Distance learning facilitators in your school having the } \\
\text { opportunity to network (i.e., exchange implementation } \\
\text { experiences) with distance learning facilitators in other } \\
\text { schools }\end{array}$ & $\begin{array}{l}\text { Significantly } \\
\text { impedes }\end{array}$ & Impedes & $\begin{array}{l}\text { Has no } \\
\text { effect }\end{array}$ & Facilitates & $\begin{array}{l}\text { Significantly } \\
\text { facilitates }\end{array}$ & $\begin{array}{l}\text { Don’t } \\
\text { know }\end{array}$ \\
\hline \multicolumn{7}{|l|}{ Comments: } \\
\hline
\end{tabular}




\begin{tabular}{|c|c|c|c|c|c|c|}
\hline \multicolumn{7}{|c|}{ Category: Structures } \\
\hline \multicolumn{7}{|c|}{ QUESTION: What effect do the following factors have on the implementation of virtual learning in your school (grades 9-12)? } \\
\hline Item & 1 & 2 & 3 & 4 & 5 & \\
\hline $\begin{array}{l}\text { 22. Established operating practices in the school (e.g., daily } \\
\text { class schedules, procedures for reporting absences, } \\
\text { procedures for recording grades) }\end{array}$ & $\begin{array}{l}\text { Significantly } \\
\text { impedes }\end{array}$ & Impedes & $\begin{array}{l}\text { Has no } \\
\text { effect }\end{array}$ & Facilitates & $\begin{array}{l}\text { Significantly } \\
\text { facilitates }\end{array}$ & $\begin{array}{l}\text { Don't } \\
\text { know }\end{array}$ \\
\hline $\begin{array}{l}\text { 23. WVBE Policy } 2460 \text {, Educational Purpose and } \\
\text { Acceptable Use of Electronic Resources, Technologies and } \\
\text { the Internet (pertaining to acceptable use of the Internet) }\end{array}$ & $\begin{array}{l}\text { Significantly } \\
\text { impedes }\end{array}$ & Impedes & $\begin{array}{l}\text { Has no } \\
\text { effect }\end{array}$ & Facilitates & $\begin{array}{l}\text { Significantly } \\
\text { facilitates }\end{array}$ & $\begin{array}{l}\text { Don’t } \\
\text { know }\end{array}$ \\
\hline 24. Acceptance of credits for virtual courses & $\begin{array}{l}\text { Significantly } \\
\text { impedes }\end{array}$ & Impedes & $\begin{array}{c}\text { Has no } \\
\text { effect }\end{array}$ & Facilitates & $\begin{array}{l}\text { Significantly } \\
\text { facilitates }\end{array}$ & $\begin{array}{l}\text { Don’t } \\
\text { know }\end{array}$ \\
\hline 25. Assessment of student learning in virtual courses & $\begin{array}{l}\text { Significantly } \\
\text { impedes }\end{array}$ & Impedes & $\begin{array}{c}\text { Has no } \\
\text { effect }\end{array}$ & Facilitates & $\begin{array}{l}\text { Significantly } \\
\text { facilitates }\end{array}$ & $\begin{array}{l}\text { Don’t } \\
\text { know }\end{array}$ \\
\hline $\begin{array}{l}\text { 26. School's ability to maintain academic integrity (control } \\
\text { cheating) in virtual courses }\end{array}$ & $\begin{array}{c}\text { Significantly } \\
\text { impedes }\end{array}$ & Impedes & $\begin{array}{c}\text { Has no } \\
\text { effect }\end{array}$ & Facilitates & $\begin{array}{l}\text { Significantly } \\
\text { facilitates }\end{array}$ & $\begin{array}{l}\text { Don’t } \\
\text { know }\end{array}$ \\
\hline $\begin{array}{l}\text { 27. Ability for students to enroll in virtual courses without } \\
\text { experiencing scheduling conflicts }\end{array}$ & $\begin{array}{c}\text { Significantly } \\
\text { impedes }\end{array}$ & Impedes & $\begin{array}{c}\text { Has no } \\
\text { effect }\end{array}$ & Facilitates & $\begin{array}{l}\text { Significantly } \\
\text { facilitates }\end{array}$ & $\begin{array}{l}\text { Don’t } \\
\text { know }\end{array}$ \\
\hline $\begin{array}{l}\text { 28. Support from West Virginia Department of Education } \\
\text { personnel }\end{array}$ & $\begin{array}{l}\text { Significantly } \\
\text { impedes }\end{array}$ & Impedes & $\begin{array}{c}\text { Has no } \\
\text { effect }\end{array}$ & Facilitates & $\begin{array}{l}\text { Significantly } \\
\text { facilitates }\end{array}$ & $\begin{array}{l}\text { Don’t } \\
\text { know }\end{array}$ \\
\hline \multicolumn{7}{|l|}{ Comments: } \\
\hline
\end{tabular}




\begin{tabular}{|c|c|c|c|c|c|c|}
\hline \multicolumn{7}{|c|}{ Category: Culture } \\
\hline \multicolumn{7}{|c|}{ QUESTION: What effect do the following factors have on the implementation of virtual learning in your school (grades 9-12)? } \\
\hline Item & 1 & 2 & 3 & 4 & 5 & \\
\hline 29. Faculty's acceptance of state policy & $\begin{array}{l}\text { Significantly } \\
\text { impedes }\end{array}$ & Impedes & $\begin{array}{c}\text { Has no } \\
\text { effect }\end{array}$ & Facilitates & $\begin{array}{l}\text { Significantly } \\
\text { facilitates }\end{array}$ & $\begin{array}{l}\text { Don’t } \\
\text { know }\end{array}$ \\
\hline 30. Level of digital literacy demonstrated in the school & $\begin{array}{l}\text { Significantly } \\
\text { impedes }\end{array}$ & Impedes & $\begin{array}{l}\text { Has no } \\
\text { effect }\end{array}$ & Facilitates & $\begin{array}{l}\text { Significantly } \\
\text { facilitates }\end{array}$ & $\begin{array}{l}\text { Don't } \\
\text { know }\end{array}$ \\
\hline $\begin{array}{l}\text { 31. Quality of virtual classes compared to face-to-face } \\
\text { classes }\end{array}$ & $\begin{array}{l}\text { Significantly } \\
\text { impedes }\end{array}$ & Impedes & $\begin{array}{l}\text { Has no } \\
\text { effect }\end{array}$ & Facilitates & $\begin{array}{l}\text { Significantly } \\
\text { facilitates }\end{array}$ & $\begin{array}{l}\text { Don’t } \\
\text { know }\end{array}$ \\
\hline 32. Support of virtual learning among the faculty & $\begin{array}{l}\text { Significantly } \\
\text { impedes }\end{array}$ & Impedes & $\begin{array}{l}\text { Has no } \\
\text { effect }\end{array}$ & Facilitates & $\begin{array}{l}\text { Significantly } \\
\text { facilitates }\end{array}$ & $\begin{array}{l}\text { Don’t } \\
\text { know }\end{array}$ \\
\hline 33. Parents' perception of virtual learning & $\begin{array}{l}\text { Significantly } \\
\text { impedes }\end{array}$ & Impedes & $\begin{array}{l}\text { Has no } \\
\text { effect }\end{array}$ & Facilitates & $\begin{array}{l}\text { Significantly } \\
\text { facilitates }\end{array}$ & $\begin{array}{l}\text { Don't } \\
\text { know }\end{array}$ \\
\hline Comments: & & & & & & \\
\hline
\end{tabular}

34. What is your primary position in the school? (Please check all that apply.)
$\square$ Principal
$\square$ Assistant Principal
$\square$ Counselor
$\square$ Librarian
$\square$ Teacher
$\square$ Other - please list 
35. How long have you served in the position identified in Item \#34?

$\square$ Less than 2 years

$\square 2-5$ years

$\square 6-10$ years

$\square 11-15$ years

$\square 15-20$ years

$\square$ More than 20 years (Please indicate length of time:

36. Are you directly involved in virtual learning at your school? $\quad \square$ Yes $\quad \square$ No

If "Yes," how are you involved? (Please check all that apply.)

$\square$ I am the school's distance learning contact (person who distributes information to students and parents, secures agreements, and has the authority to enroll students in virtual courses).

$\square$ I am a virtual course facilitator (person of record who monitors the academic performance of students enrolled in virtual courses and am designated to receive reports from the course provider concerning individual student progress).

$\square$ Other - Please explain:

37. What is the total school enrollment in grades 9-12? Less than 450 students 450 to 800 students Over 800 students

Please provide your email address if you wish to be entered into the drawing for $\$ 50$ gasoline cards. All responses will be kept confidential even when email addresses are provided. Email address:

Thank you for participating in this survey. 


\section{Appendix F}

Directions to Panel of Experts Reviewing the Proposed Survey Instrument

\section{Factors Affecting Implementation of WVBE Policy 2450, Distance Learning and the West Virginia Virtual School}

Directions: Please review the survey invitation letter and survey instrument Factors Affecting Implementation of Distance Learning and the West Virginia Virtual School (attached). The invitation will be distributed via email to the principal, a counselor, and the distance learning contact at 110 West Virginia high schools. Those invited will receive a link to a URL hosting the survey instrument.

As you review the documents, please complete the attached response form following the directions provided at the top of the form. You will be asked to consider the following questions as you review the survey:

- Is each survey item clear and easily understood?

- Is each survey item related to the study's topic and goals?

- Is each survey item important to the research aims?

- $\quad$ Are there survey items you believe should be deleted? If so, which one(s)?

- $\quad$ Are there survey items you believe should be modified? If so, which one(s)?

- $\quad$ Are there additional survey items you would recommend? If so, please describe the item(s) and provide a rationale.

- $\quad$ Are the instructions to respondents clear and easily understood?

- Do respondents have adequate assurance of confidentiality and anonymity?

- Is there an unreasonable cost or burden to the respondent population?

Study Research Questions:

- What are the factors that facilitate the implementation of WVBE Policy 2450, Distance Learning and the West Virginia Virtual School, in high schools according to perceptions of three select groups: (a) principals/assistant principals, (b) counselors, and (c) distance learning contacts and/or virtual course facilitators?

- What are the factors that impede the implementation of WVBE Policy 2450, Distance Learning and the West Virginia Virtual School, in high schools according to perceptions of three select groups: (a) principals/assistant principals, (b) counselors, and (c) distance learning contacts and/or virtual course facilitators?

- Is there a difference in perceptions of factors important to the implementation of WVBE Policy 2450, Distance Learning and the West Virginia Virtual School, in high schools among three select groups: (a) principals/assistant principals, (b) counselors, and (c) distance learning contacts and/or virtual course facilitators?

- Is there a difference in perceptions of factors important to implementation of WVBE Policy 2450, Distance Learning and the West Virginia Virtual School, in schools with 1\% or greater of the high school students enrolled in virtual courses between 2008 and 2011 versus schools with less than $1 \%$ of the high school students enrolled in virtual courses during the same time period?

Please contact Keith Burdette at kburdet4@ mix.wvu.edu or 304-532-0457 if you have any questions. Your input is valuable in improving the survey instrument. Please provide your feedback to kburdet4@mix.wvu.edu no later than DATE.

Thank you for taking the time to review this survey instrument. 


\section{Survey Item Review \\ Factors Affecting Implementation of WVBE Policy 2450, Distance Learning and the West Virginia Virtual School}

Directions: Please enter the words "Yes" or "No" in each space in the first three columns indicating your opinion of the item. In

Column 4, please indicate if the item should be kept, deleted, or modified. Please enter any comments or suggestions in Column 5.

\begin{tabular}{|c|c|c|c|c|c|}
\hline \multicolumn{6}{|c|}{ Category: People } \\
\hline \multicolumn{6}{|c|}{ QUESTION: What effect do the following factors have on the implementation of virtual learning in your school (grades 9-12)? } \\
\hline Item & $\begin{array}{l}\text { Column1: } \\
\text { Clear \& } \\
\text { easily } \\
\text { understood? }\end{array}$ & $\begin{array}{l}\text { Column 2: } \\
\text { Related to } \\
\text { the topic and } \\
\text { goals? }\end{array}$ & $\begin{array}{l}\text { Column 3: } \\
\text { Important to } \\
\text { the research } \\
\text { aims? }\end{array}$ & $\begin{array}{l}\text { Column 4: } \\
\text { Keep, } \\
\text { Delete, or } \\
\text { Modify? }\end{array}$ & $\begin{array}{c}\text { Column 5: } \\
\text { Comments or Suggested } \\
\text { Modifications }\end{array}$ \\
\hline \multicolumn{6}{|l|}{ 1. Administrative support } \\
\hline \multicolumn{6}{|c|}{$\begin{array}{l}\text { 2. Principal's perception of traits } \\
\text { needed by students to be successful } \\
\text { in virtual courses }\end{array}$} \\
\hline \multicolumn{6}{|c|}{$\begin{array}{l}\text { 3. Principal's willingness to include } \\
\text { virtual courses in the school } \\
\text { curriculum }\end{array}$} \\
\hline \multicolumn{6}{|c|}{$\begin{array}{l}\text { 4. Faculty's knowledge of teaching } \\
\text { methods used in distance learning }\end{array}$} \\
\hline $\begin{array}{l}\text { 5. Skills of virtual course } \\
\text { facilitators in the school }\end{array}$ & & & & & \\
\hline
\end{tabular}




\begin{tabular}{|c|c|c|c|c|c|}
\hline Item & $\begin{array}{l}\text { Column1: } \\
\text { Clear \& } \\
\text { easily } \\
\text { understood? }\end{array}$ & $\begin{array}{l}\text { Column 2: } \\
\text { Related to } \\
\text { the topic and } \\
\text { goals? }\end{array}$ & $\begin{array}{l}\text { Column 3: } \\
\text { Important to } \\
\text { the research } \\
\text { aims? }\end{array}$ & $\begin{array}{l}\text { Column 4: } \\
\text { Keep, } \\
\text { Delete, or } \\
\text { Modify? }\end{array}$ & $\begin{array}{l}\text { Column 5: } \\
\text { Comments or Suggested } \\
\text { Modifications }\end{array}$ \\
\hline \multicolumn{6}{|l|}{$\begin{array}{l}\text { 6. Faculty's willingness to learn } \\
\text { about virtual courses }\end{array}$} \\
\hline \multicolumn{6}{|l|}{$\begin{array}{l}\text { 7. School counselor as a source of } \\
\text { information about virtual courses }\end{array}$} \\
\hline \multicolumn{6}{|c|}{ Category: Communication } \\
\hline \multicolumn{6}{|c|}{ QUESTION: What effect do the following factors have on the implementation of virtual learning in your school (grades 9-12)? } \\
\hline $\begin{array}{l}\text { 8. Communication about virtual } \\
\text { courses among all school personnel } \\
\text { within a school }\end{array}$ & & & & & \\
\hline $\begin{array}{l}\text { 9. Information about virtual courses } \\
\text { made available to students }\end{array}$ & & & & & \\
\hline $\begin{array}{l}\text { 10. Communication about virtual } \\
\text { courses with external audiences } \\
\text { (e.g., parents) }\end{array}$ & & & & & \\
\hline $\begin{array}{l}\text { 11. Clarity in State Board Policy } \\
\text { 2450, Distance Learning and the } \\
\text { West Virginia Virtual School }\end{array}$ & & & & & \\
\hline $\begin{array}{l}\text { 12. Written guidance from the West } \\
\text { Virginia Department of Education }\end{array}$ & & & & & \\
\hline
\end{tabular}




\begin{tabular}{|c|c|c|c|c|c|}
\hline \multicolumn{6}{|c|}{ Category: Resources } \\
\hline \multicolumn{6}{|c|}{ QUESTION: What effect do the following factors have on the implementation of virtual learning in your school (grades 9-12)? } \\
\hline$e^{2}$ & $\begin{array}{l}\text { Column1: } \\
\text { Clear \& } \\
\text { easily } \\
\text { understood? }\end{array}$ & $\begin{array}{l}\text { Column 2: } \\
\text { Related to } \\
\text { the topic and } \\
\text { goals? }\end{array}$ & $\begin{array}{l}\text { Column 3: } \\
\text { Important to } \\
\text { the research } \\
\text { aims? }\end{array}$ & $\begin{array}{l}\text { Column 4: } \\
\text { Keep, } \\
\text { Delete, or } \\
\text { Modify? }\end{array}$ & $\begin{array}{c}\text { Column 5: } \\
\text { Comments or Suggested } \\
\text { Modifications }\end{array}$ \\
\hline \multicolumn{6}{|l|}{ 13. Cost of virtual courses } \\
\hline \multicolumn{6}{|l|}{$\begin{array}{l}\text { 14. Student access to technology } \\
\text { and instructional support }\end{array}$} \\
\hline \multicolumn{6}{|l|}{$\begin{array}{l}\text { 15. Time available for school } \\
\text { personnel to implement State Board } \\
\text { Policy } 2450 \text {, Distance Learning and } \\
\text { the West Virginia Virtual School }\end{array}$} \\
\hline \multicolumn{6}{|l|}{$\begin{array}{l}\text { 16. Size of the school (i.e., number } \\
\text { of students in grades 9-12) }\end{array}$} \\
\hline \multicolumn{6}{|l|}{$\begin{array}{l}\text { 17. Number of computers available } \\
\text { for students in virtual courses }\end{array}$} \\
\hline \multicolumn{6}{|l|}{$\begin{array}{l}\text { 18. Broadband capacity/access to } \\
\text { the Internet at your school }\end{array}$} \\
\hline $\begin{array}{l}\text { 19. Computer network security } \\
\text { (protection from computer viruses } \\
\text { and hackers) }\end{array}$ & & & & & \\
\hline
\end{tabular}




\begin{tabular}{|c|c|c|c|c|c|}
\hline Item & $\begin{array}{c}\text { Column1: } \\
\text { Clear \& } \\
\text { easily } \\
\text { understood? }\end{array}$ & $\begin{array}{l}\text { Column 2: } \\
\text { Related to } \\
\text { the topic and } \\
\text { goals? }\end{array}$ & $\begin{array}{l}\text { Column 3: } \\
\text { Important to } \\
\text { the research } \\
\text { aims? }\end{array}$ & $\begin{array}{l}\text { Column 4: } \\
\text { Keep, } \\
\text { Delete, or } \\
\text { Modify? }\end{array}$ & $\begin{array}{c}\text { Column 5: } \\
\text { Comments or Suggested } \\
\text { Modifications }\end{array}$ \\
\hline \multicolumn{6}{|l|}{$\begin{array}{l}20 . \text { Funding for training about } \\
\text { virtual learning }\end{array}$} \\
\hline $\begin{array}{l}\text { 21. Distance learning facilitators in } \\
\text { your school having the opportunity } \\
\text { to network (i.e., exchange } \\
\text { implementation experiences) with } \\
\text { distance learning facilitators in } \\
\text { other schools }\end{array}$ & & & & & \\
\hline \multicolumn{6}{|c|}{ Category: Structure } \\
\hline \multicolumn{6}{|c|}{ QUESTION: What effect do the following factors have on the implementation of virtual learning in your school (grades 9-12)? } \\
\hline $\begin{array}{l}\text { 22. Established operating practices } \\
\text { in the school (e.g., daily class } \\
\text { schedules, procedures for reporting } \\
\text { absences, procedures for recording } \\
\text { grades) }\end{array}$ & & & & & \\
\hline $\begin{array}{l}\text { 23. WVBE Policy } 2460 \text {, } \\
\text { Educational Purpose and } \\
\text { Acceptable Use of Electronic } \\
\text { Resources, Technologies and the } \\
\text { Internet (pertaining to safe and } \\
\text { acceptable use of the Internet) }\end{array}$ & & & & & \\
\hline $\begin{array}{l}\text { 24. Acceptance of credits for virtual } \\
\text { courses }\end{array}$ & & & & & \\
\hline
\end{tabular}




\begin{tabular}{|l|l|l|l|l|l|}
\hline \multicolumn{1}{|c|}{ Item } & $\begin{array}{c}\text { Column1: } \\
\text { Clear \& } \\
\text { easily } \\
\text { understood? }\end{array}$ & $\begin{array}{c}\text { Column 2: } \\
\text { Related to } \\
\text { the topic and } \\
\text { goals? }\end{array}$ & $\begin{array}{c}\text { Column 3: } \\
\text { Important to } \\
\text { the research } \\
\text { aims? }\end{array}$ & $\begin{array}{c}\text { Column 4: } \\
\text { Keep, } \\
\text { Delete, or } \\
\text { Modify? }\end{array}$ & $\begin{array}{c}\text { Column 5: } \\
\text { Comments or Suggested } \\
\text { Modifications }\end{array}$ \\
\hline $\begin{array}{l}\text { 25. Assessment of student learning } \\
\text { in virtual courses }\end{array}$ & & & & & \\
\hline $\begin{array}{l}\text { 26. School's ability to maintain } \\
\text { academic integrity (control } \\
\text { cheating) in virtual courses }\end{array}$ & & & & & \\
\hline $\begin{array}{l}\text { 27. Ability for students to enroll in } \\
\text { virtual courses without } \\
\text { experiencing scheduling conflicts }\end{array}$ & & & & & \\
\hline $\begin{array}{l}\text { 28. Support from the West Virginia } \\
\text { Department of Education }\end{array}$ & & & & & \\
\hline \multicolumn{1}{|c|}{ QUESTION: What effect do the following factors have on the implementation of virtual learning in your school (grades 9-12)? } \\
\hline $\begin{array}{l}\text { 29. Faculty's acceptance of state } \\
\text { policy }\end{array}$ & & & & & \\
\hline $\begin{array}{l}\text { 30. Level of digital literacy } \\
\text { demonstrated in the school }\end{array}$ & & & & & \\
\hline $\begin{array}{l}\text { 31. Faculty members' opinions of } \\
\text { virtual classes compared to face-to- } \\
\text { face classes }\end{array}$ & & & & & \\
\hline $\begin{array}{l}\text { 32. Faculty support of virtual } \\
\text { learning among faculty }\end{array}$ & & & & \\
\hline $\begin{array}{l}\text { 33. Parents' perception of virtual } \\
\text { learning }\end{array}$ & & & & & \\
\hline
\end{tabular}




\begin{tabular}{|c|c|c|c|c|c|}
\hline \multicolumn{6}{|c|}{ Demographic Questions } \\
\hline Item & $\begin{array}{c}\text { Column1: } \\
\text { Clear \& } \\
\text { easily } \\
\text { understood? }\end{array}$ & $\begin{array}{l}\text { Column 2: } \\
\text { Related to } \\
\text { the topic and } \\
\text { goals? }\end{array}$ & $\begin{array}{l}\text { Column 3: } \\
\text { Important to } \\
\text { the research } \\
\text { aims? }\end{array}$ & $\begin{array}{l}\text { Column 4: } \\
\text { Keep, } \\
\text { Delete, or } \\
\text { Modify? }\end{array}$ & $\begin{array}{c}\text { Column 5: } \\
\text { Comments or Suggested } \\
\text { Modifications }\end{array}$ \\
\hline $\begin{array}{l}\text { 34. What is your primary position } \\
\text { in the school? (Please check all that } \\
\text { apply.) } \\
\square \text { Principal } \\
\square \text { Assistant Principal } \\
\square \text { Counselor } \\
\square \text { Librarian } \\
\square \text { Teacher } \\
\square \text { Other - please list }\end{array}$ & & & & & \\
\hline $\begin{array}{l}\text { 35. How long have you served in } \\
\text { the position identified in Item \#34? } \\
\square \text { Less than } 2 \text { years } \\
\square 2-5 \text { years } \\
\square 6-10 \text { years } \\
\square 11-15 \text { years } \\
\square 15-20 \text { years } \\
\square \text { More than } 20 \text { years (Please } \\
\text { indicate length of time: }\end{array}$ & & & & & \\
\hline
\end{tabular}




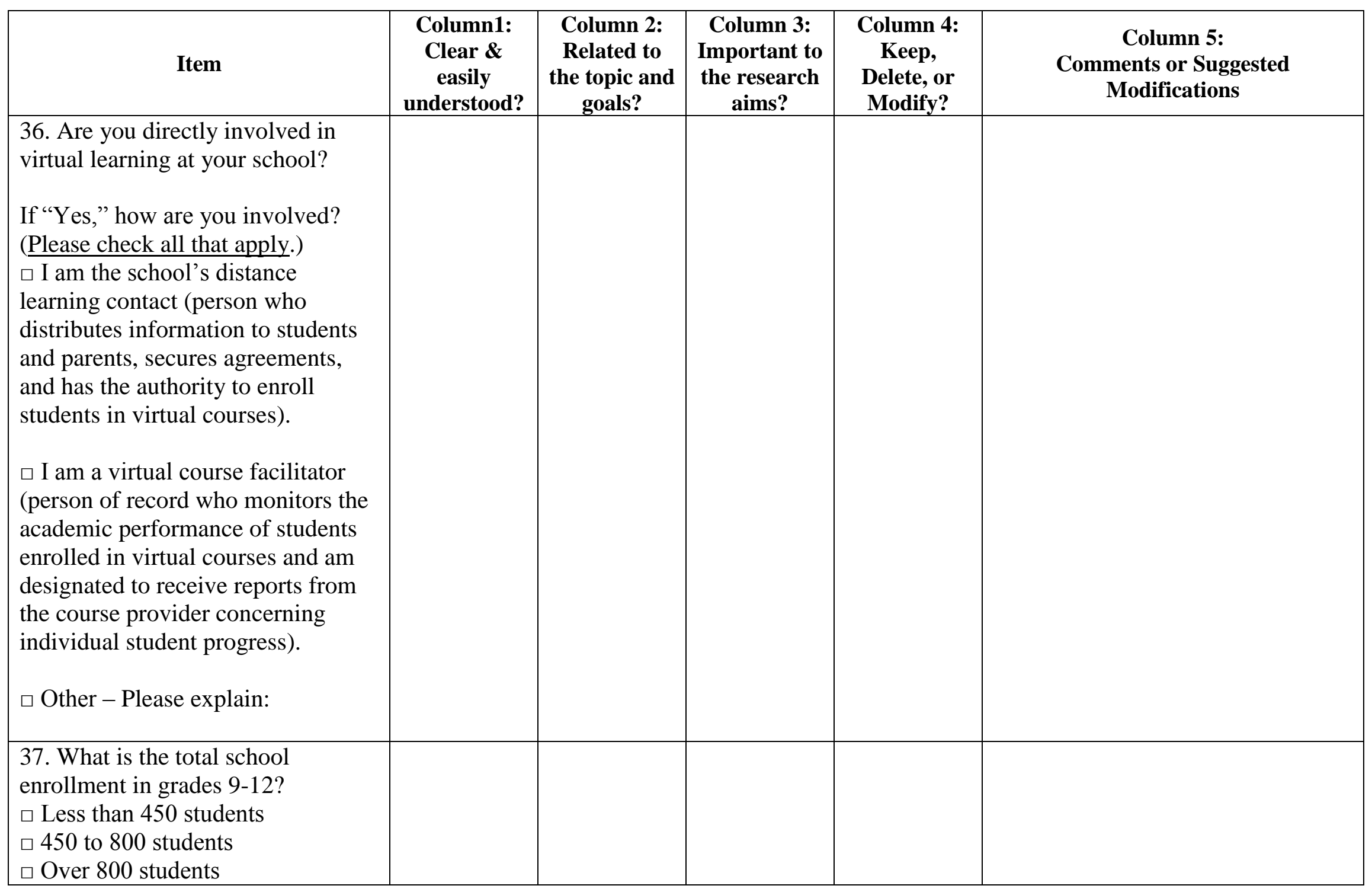




\section{Please respond to the following additional questions:}

1. Are there additional survey items you would recommend? If so, please describe the item(s) and provide a rationale.

2. Are the instructions to respondents clear and easily understood?

3. Do respondents have adequate assurance of confidentiality and anonymity?

4. Is there an unreasonable cost or burden to the respondent population?

5. Other comments:

Thank you for taking the time to review this survey instrument. Your input is greatly appreciated. 


\section{Appendix G}

Superintendent Notification Letter 


\section{WestVirginiaUniversity}

\section{College of Human Resources and Education}

May 1, 2012

Dear Superintendent:

In partial fulfillment of the educational leadership studies doctoral program at West Virginia University, I am required to conduct a research-based study. The purpose of my study is to identify factors that facilitate and impede the implementation of West Virginia Board of Education Policy 2450, Distance Learning and the West Virginia Virtual School in West Virginia high schools according to three select groups: (a) principals/assistant principals, (b) counselors, and (c) distance learning contacts and/or virtual course facilitators. Results of this study will provide perspectives from local personnel about factors that facilitate or impede state policy implementation.

The purpose of this letter is to inform you I will soon be contacting by email the principal, assistant principal(s), counselor(s), and distance learning contact and/or virtual course facilitator(s) at each high school seeking their participation in the study by completing an electronic survey. The survey will take less than 10 minutes of their time. Participation is voluntary and there are no consequences for non-participation.

Respondents may skip any questions they are not comfortable answering or may quit at any point and submit a partially completed questionnaire. Individual survey responses will be kept confidential. Survey results will not indicate the identity of the participants or their respective schools.

Respondents are asked to complete the survey no later than DATE. If you have further questions contact me at kburdet4@mix.wvu.edu or (304) 532-0457. Thank you for your assistance.

Sincerely,

Helen M. Hazi, Ph.D.

Professor and Committee Chairperson
Keith R. Burdette

Doctoral Candidate
Helen.Hazi@mail.wvu.edu Phone: 304-293-1885 Fax: 304-293-2279
Department of Curriculum \& Instruction/Literacy Program of Educational Leadership Studies 608 Allen PO Box 6122

Morgantown, WV 26506-6122 


\section{Appendix H}

Letter of Invitation to Participate in Survey 


\section{WestVirginiaUniversity}

\section{College of Human Resources \\ and Education}

May 1, 2012

Dear Educator:

In partial fulfillment of the educational leadership studies doctoral program at West Virginia University, I am required to conduct a research-based study. The purpose of my study is to identify factors that facilitate and impede the implementation of West Virginia Board of Education Policy 2450, Distance Learning and the West Virginia Virtual School in West Virginia high schools according to three select groups: (a) principals/assistant principals, (b) counselors, and (c) distance learning contacts and/or virtual course facilitators. Results of this study will provide perspectives from local personnel about factors that facilitate or impede state policy implementation.

The purpose of this letter is to seek your participation in the study by completing an electronic survey. The survey will take less than 10 minutes of your time. You must be 18 years of age or older to participate. Your participation is voluntary and there are no consequences for non-participation. You may skip any questions you are not comfortable answering or may quit at any point and submit a partially completed questionnaire. Individual survey responses will be kept confidential. Survey results will not indicate the identity of the participants or your respective schools. West Virginia University's Institutional Review Board acknowledgement of this project is on file.

The online survey can be accessed at the following site: INCLUDE URL.

In appreciation for your involvement, all respondents who provide an email address at the end of the survey will be entered into drawings for three $\$ 50$ gasoline cards. Please don't delay - two of the gas cards will be awarded to those responding by DATE and the third will be awarded on DATE.

I sincerely appreciate your consideration regarding participation in this study. Please complete the survey no later than DATE. If you have further questions contact me at kburdet4@ mix.wvu.edu or (304) 532-0457. Thank you for your assistance.

Sincerely,

Helen M. Hazi, Ph.D.

Professor and Committee Chairperson
Keith Burdette

Doctoral Candidate
Helen.Hazi@mail.wvu.edu Phone: 304-293-1885 Fax: 304-293-2279
Department of Curriculum \& Instruction/Literacy Program of Educational Leadership Studies 608 Allen PO Box 6122

Morgantown, WV 26506-6122 


\section{Appendix I}

Comparison of Early Respondents to Late Respondents on Ratings of Survey Items

\begin{tabular}{|c|c|c|c|c|}
\hline \multirow[b]{2}{*}{$\begin{array}{c}\text { Survey Item } \\
\text { No. }\end{array}$} & \multirow{2}{*}{$\begin{array}{l}\text { Mean Scores } \\
\text { of Early } \\
\text { Respondents }\end{array}$} & \multirow{2}{*}{$\begin{array}{c}\text { Mean Scores of } \\
\text { Late } \\
\text { Respondents }\end{array}$} & \multicolumn{2}{|c|}{ Levene's Test for Equality of Variances } \\
\hline & & & $\mathrm{F}$ & Significance* \\
\hline 1 & 4.33 & 4.34 & .555 & .459 \\
\hline 2 & 4.00 & 4.10 & .520 & .473 \\
\hline 3 & 4.18 & 4.23 & .029 & .866 \\
\hline 4 & 3.42 & 3.50 & .523 & .472 \\
\hline 5 & 3.84 & 3.72 & .388 & .535 \\
\hline 6 & 3.38 & 3.49 & 1.698 & .197 \\
\hline 7 & 4.13 & 4.23 & .000 & .984 \\
\hline 8 & 3.49 & 3.66 & .124 & .725 \\
\hline 9 & 3.89 & 3.84 & .107 & .744 \\
\hline 10 & 3.67 & 3.65 & .007 & .933 \\
\hline 11 & 3.54 & 3.67 & .006 & .937 \\
\hline 12 & 3.68 & 3.97 & 2.132 & .149 \\
\hline 13 & 3.08 & 3.15 & .956 & .332 \\
\hline 14 & 3.59 & 3.64 & 3.871 & .053 \\
\hline 15 & 2.95 & 3.23 & 2.651 & .108 \\
\hline 16 & 3.29 & 3.23 & 2.935 & .091 \\
\hline 17 & 3.61 & 3.53 & 1.301 & .258 \\
\hline 18 & 3.79 & 3.31 & .314 & .577 \\
\hline 19 & 3.79 & 3.48 & 109 & .742 \\
\hline 20 & 3.03 & 3.09 & .287 & .594 \\
\hline 21 & 2.84 & 3.44 & .001 & .978 \\
\hline 22 & 3.57 & 3.76 & 2.375 & .128 \\
\hline 23 & 3.73 & 3.74 & .136 & .713 \\
\hline 24 & 4.14 & 3.89 & 2.043 & .157 \\
\hline 25 & 3.71 & 4.09 & 2.169 & .146 \\
\hline 26 & 3.64 & 3.83 & 2.813 & .098 \\
\hline 27 & 3.51 & 3.76 & 1.555 & .216 \\
\hline 28 & 3.64 & 3.86 & 6.031 & .017 \\
\hline 29 & 3.78 & 4.03 & 2.323 & .132 \\
\hline 30 & 3.63 & 3.54 & .465 & .498 \\
\hline 31 & 3.70 & 3.76 & 2.433 & .123 \\
\hline 32 & 3.73 & 3.83 & 3.818 & .055 \\
\hline 33 & 3.63 & 3.50 & 1.826 & .181 \\
\hline 34 & 3.49 & 3.53 & .187 & .666 \\
\hline 35 & 3.46 & 3.61 & 1.043 & .311 \\
\hline
\end{tabular}

$*_{p}<.05$ 


\section{Appendix J}

Number of Responses, Mean Score, and Standard Deviation of Responses to Survey Items

\begin{tabular}{|c|c|c|c|c|}
\hline $\begin{array}{l}\text { Survey } \\
\text { Item No. }\end{array}$ & Survey Item & $n$ & $M$ & $S D$ \\
\hline 1 & $\begin{array}{l}\text { Support of administrators in local school (e.g., } \\
\text { encouragement to teachers to utilize technology in } \\
\text { instruction, provision of resources) }\end{array}$ & 210 & 4.33 & .904 \\
\hline 2 & $\begin{array}{l}\text { Principal's perception of traits needed by students } \\
\text { to be successful in distance learning courses }\end{array}$ & 208 & 4.18 & .914 \\
\hline 3 & $\begin{array}{l}\text { Principal's willingness to include distance learning } \\
\text { courses in the school curriculum }\end{array}$ & 209 & 4.33 & .904 \\
\hline 4 & $\begin{array}{l}\text { School faculty's knowledge of teaching methods } \\
\text { used in distance learning }\end{array}$ & 201 & 3.51 & 1.107 \\
\hline 5 & $\begin{array}{l}\text { Skills of distance learning course facilitators in the } \\
\text { school }\end{array}$ & 199 & 3.82 & 1.187 \\
\hline 6 & $\begin{array}{l}\text { Faculty's willingness to learn about distance } \\
\text { learning courses }\end{array}$ & 198 & 3.56 & 1.034 \\
\hline 7 & $\begin{array}{l}\text { School counselor as a source of information about } \\
\text { distance learning courses }\end{array}$ & 211 & 4.22 & .992 \\
\hline 8 & $\begin{array}{l}\text { Communication about distance learning courses } \\
\text { among all school personnel within a school }\end{array}$ & 203 & 3.56 & 1.067 \\
\hline 9 & $\begin{array}{l}\text { Information about distance learning courses made } \\
\text { available to students }\end{array}$ & 207 & 3.92 & 1.138 \\
\hline 10 & $\begin{array}{l}\text { Communication about distance learning courses } \\
\text { with external audiences (e.g., parents) }\end{array}$ & 197 & 3.69 & 1.125 \\
\hline 11 & $\begin{array}{l}\text { Clarity of WVBE Policy 2450, Distance Learning } \\
\text { and the West Virginia Virtual School }\end{array}$ & 196 & 3.65 & 1.014 \\
\hline 12 & $\begin{array}{l}\text { Guidance from the West Virginia Department of } \\
\text { Education }\end{array}$ & 200 & 3.89 & 1.093 \\
\hline 13 & Cost of distance learning courses & 193 & 3.23 & 1.255 \\
\hline 14 & $\begin{array}{l}\text { Student access to technology and instructional } \\
\text { support }\end{array}$ & 206 & 3.77 & 1.274 \\
\hline 15 & $\begin{array}{l}\text { Time available for school personnel to implement } \\
\text { Distance Learning Policy } 2450\end{array}$ & 193 & 3.15 & 1.367 \\
\hline 16 & $\begin{array}{l}\text { Size of the school (i.e., number of students in } \\
\text { grades 9-12) }\end{array}$ & 199 & 3.27 & .941 \\
\hline 17 & $\begin{array}{l}\text { Number of computers available for students in } \\
\text { distance learning courses }\end{array}$ & 205 & 3.55 & 1.238 \\
\hline 18 & $\begin{array}{l}\text { Broadband capacity/access to the Internet at your } \\
\text { school }\end{array}$ & 209 & 3.55 & 1.315 \\
\hline 19 & $\begin{array}{l}\text { Computer network security (protection from } \\
\text { computer viruses and hackers) }\end{array}$ & 207 & 3.70 & 1.144 \\
\hline 20 & $\begin{array}{l}\text { Funding for professional development about } \\
\text { distance learning }\end{array}$ & 190 & 3.10 & 1.175 \\
\hline
\end{tabular}




\begin{tabular}{|c|c|c|c|c|}
\hline $\begin{array}{l}\text { Survey } \\
\text { Item No. }\end{array}$ & Survey Item & $n$ & $M$ & $S D$ \\
\hline 21 & $\begin{array}{l}\text { Distance learning course facilitators in your school } \\
\text { having the opportunity to network (i.e., exchange } \\
\text { implementation experiences) with distance }\end{array}$ & & & \\
\hline & learning course facilitators in other schools & 189 & 3.10 & 1.231 \\
\hline 22 & $\begin{array}{l}\text { Established operating procedures in the school } \\
\text { (e.g., daily class schedules, attendance, school } \\
\text { calendar, procedures for recording grades) }\end{array}$ & 197 & 3.66 & 1.020 \\
\hline 23 & $\begin{array}{l}\text { WVBE Policy } 2460 \text {, Educational Purpose and } \\
\text { Acceptable Use of Electronic Resources, } \\
\text { Technologies, and the Internet (pertaining to } \\
\text { acceptable use of the Internet) }\end{array}$ & 193 & 3.70 & .896 \\
\hline 24 & $\begin{array}{l}\text { Acceptance of credits for distance learning courses } \\
\text { by the county board of education or diploma- } \\
\text { granting authority }\end{array}$ & 196 & 4.02 & .961 \\
\hline 25 & $\begin{array}{l}\text { Recognition of distance learning courses by } \\
\text { colleges and universities }\end{array}$ & 164 & 3.85 & 1.054 \\
\hline 26 & $\begin{array}{l}\text { Assessment of student learning in distance } \\
\text { learning courses }\end{array}$ & 189 & 3.70 & 1.046 \\
\hline 27 & $\begin{array}{l}\text { School's ability to maintain academic integrity } \\
\text { (control cheating) in distance learning courses }\end{array}$ & 189 & 3.70 & 1.114 \\
\hline 28 & $\begin{array}{l}\text { Ability for students to enroll in distance learning } \\
\text { courses without experiencing scheduling conflicts }\end{array}$ & 195 & 3.68 & 1.181 \\
\hline 29 & $\begin{array}{l}\text { Support from West Virginia Department of } \\
\text { Education personnel }\end{array}$ & 189 & 3.93 & 1.021 \\
\hline 30 & Faculty's acceptance of state policy & 185 & 3.63 & .919 \\
\hline 31 & $\begin{array}{l}\text { Importance of student digital literacy (i.e., abilities } \\
\text { to locate, organize, understand, evaluate, analyze } \\
\text { and create information using technology) }\end{array}$ & 197 & 3.79 & 1.075 \\
\hline 32 & $\begin{array}{l}\text { Importance of teacher digital literacy (i.e., abilities } \\
\text { to locate, organize, understand, evaluate, analyze } \\
\text { and create information using technology) }\end{array}$ & 195 & 3.81 & 1.055 \\
\hline 33 & $\begin{array}{l}\text { Quality of distance learning classes compared to } \\
\text { face-to-face classes }\end{array}$ & 181 & 3.44 & 1.258 \\
\hline 34 & Support of distance learning among the faculty & 193 & 3.46 & 1.075 \\
\hline 35 & Parents' perception of distance learning & 182 & 3.50 & 1.091 \\
\hline
\end{tabular}




\section{Appendix K}

Survey Items Ranked in Descending Order of Mean Scores (All Respondents)

\begin{tabular}{|c|c|c|c|c|}
\hline $\begin{array}{l}\text { Survey } \\
\text { Item No. }\end{array}$ & Survey Item & $n$ & $M$ & $S D$ \\
\hline 1 & $\begin{array}{l}\text { Support of administrators in local school (e.g., } \\
\text { encouragement to teachers to utilize technology in } \\
\text { instruction, provision of resources) }\end{array}$ & 210 & 4.33 & .904 \\
\hline 3 & $\begin{array}{l}\text { Principal's willingness to include distance learning } \\
\text { courses in the school curriculum }\end{array}$ & 209 & 4.33 & .904 \\
\hline 7 & $\begin{array}{l}\text { School counselor as a source of information about } \\
\text { distance learning courses }\end{array}$ & 211 & 4.22 & .992 \\
\hline 2 & $\begin{array}{l}\text { Principal's perception of traits needed by students } \\
\text { to be successful in distance learning courses }\end{array}$ & 208 & 4.18 & .914 \\
\hline 24 & $\begin{array}{l}\text { Acceptance of credits for distance learning courses } \\
\text { by the county board of education or diploma- } \\
\text { granting authority }\end{array}$ & 196 & 4.02 & .961 \\
\hline 29 & $\begin{array}{l}\text { Support from West Virginia Department of } \\
\text { Education personnel }\end{array}$ & 189 & 3.93 & 1.021 \\
\hline 9 & $\begin{array}{l}\text { Information about distance learning courses made } \\
\text { available to students }\end{array}$ & 207 & 3.92 & 1.138 \\
\hline 12 & $\begin{array}{l}\text { Guidance from the West Virginia Department of } \\
\text { Education }\end{array}$ & 200 & 3.89 & 1.093 \\
\hline 25 & $\begin{array}{l}\text { Recognition of distance learning courses by } \\
\text { colleges and universities }\end{array}$ & 164 & 3.85 & 1.054 \\
\hline 5 & $\begin{array}{l}\text { Skills of distance learning course facilitators in the } \\
\text { school }\end{array}$ & 199 & 3.82 & 1.187 \\
\hline 32 & $\begin{array}{l}\text { Importance of teacher digital literacy (i.e., abilities } \\
\text { to locate, organize, understand, evaluate, analyze } \\
\text { and create information using technology) }\end{array}$ & 195 & 3.81 & 1.055 \\
\hline 31 & $\begin{array}{l}\text { Importance of student digital literacy (i.e., abilities } \\
\text { to locate, organize, understand, evaluate, analyze } \\
\text { and create information using technology) }\end{array}$ & 197 & 3.79 & 1.075 \\
\hline 14 & $\begin{array}{l}\text { Student access to technology and instructional } \\
\text { support }\end{array}$ & 206 & 3.77 & 1.274 \\
\hline 23 & $\begin{array}{l}\text { WVBE Policy 2460, Educational Purpose and } \\
\text { Acceptable Use of Electronic Resources, } \\
\text { Technologies, and the Internet (pertaining to } \\
\text { acceptable use of the Internet) }\end{array}$ & 193 & 3.70 & .896 \\
\hline 27 & $\begin{array}{l}\text { School's ability to maintain academic integrity } \\
\text { (control cheating) in distance learning courses }\end{array}$ & 189 & 3.70 & 1.114 \\
\hline 19 & $\begin{array}{l}\text { Computer network security (protection from } \\
\text { computer viruses and hackers) }\end{array}$ & 207 & 3.70 & 1.144 \\
\hline 26 & $\begin{array}{l}\text { Assessment of student learning in distance } \\
\text { learning courses }\end{array}$ & 189 & 3.70 & 1.046 \\
\hline
\end{tabular}




\begin{tabular}{|c|c|c|c|c|}
\hline $\begin{array}{l}\text { Survey } \\
\text { Item No. }\end{array}$ & Survey Item & $n$ & $M$ & $S D$ \\
\hline 10 & $\begin{array}{l}\text { Communication about distance learning courses } \\
\text { with external audiences (e.g., parents) }\end{array}$ & 197 & 3.69 & 1.125 \\
\hline 28 & $\begin{array}{l}\text { Ability for students to enroll in distance learning } \\
\text { courses without experiencing scheduling conflicts }\end{array}$ & 195 & 3.68 & 1.181 \\
\hline 22 & $\begin{array}{l}\text { Established operating procedures in the school } \\
\text { (e.g., daily class schedules, attendance, school } \\
\text { calendar, procedures for recording grades) }\end{array}$ & 197 & 3.66 & 1.020 \\
\hline 11 & $\begin{array}{l}\text { Clarity of WVBE Policy 2450, Distance Learning } \\
\text { and the West Virginia Virtual School }\end{array}$ & 196 & 3.65 & 1.014 \\
\hline 30 & Faculty's acceptance of state policy & 185 & 3.63 & .919 \\
\hline 8 & $\begin{array}{l}\text { Communication about distance learning courses } \\
\text { among all school personnel within a school }\end{array}$ & 203 & 3.56 & 1.067 \\
\hline 6 & $\begin{array}{l}\text { Faculty's willingness to learn about distance } \\
\text { learning courses }\end{array}$ & 198 & 3.56 & 1.034 \\
\hline 17 & $\begin{array}{l}\text { Number of computers available for students in } \\
\text { distance learning courses }\end{array}$ & 205 & 3.55 & 1.238 \\
\hline 18 & $\begin{array}{l}\text { Broadband capacity/access to the Internet at your } \\
\text { school }\end{array}$ & 209 & 3.55 & 1.315 \\
\hline 4 & $\begin{array}{l}\text { School faculty's knowledge of teaching methods } \\
\text { used in distance learning }\end{array}$ & 201 & 3.51 & 1.107 \\
\hline 35 & Parents' perception of distance learning & 182 & 3.50 & 1.091 \\
\hline 34 & Support of distance learning among the faculty & 193 & 3.46 & 1.075 \\
\hline 33 & $\begin{array}{l}\text { Quality of distance learning classes compared to } \\
\text { face-to-face classes }\end{array}$ & 181 & 3.44 & 1.258 \\
\hline 16 & $\begin{array}{l}\text { Size of the school (i.e., number of students in } \\
\text { grades 9-12) }\end{array}$ & 199 & 3.27 & .941 \\
\hline 13 & Cost of distance learning courses & 193 & 3.23 & 1.255 \\
\hline 15 & $\begin{array}{l}\text { Time available for school personnel to implement } \\
\text { Distance Learning Policy } 2450\end{array}$ & 193 & 3.15 & 1.367 \\
\hline $\begin{array}{l}20 \\
21\end{array}$ & $\begin{array}{l}\text { Funding for professional development about } \\
\text { distance learning } \\
\text { Distance learning course facilitators in your school } \\
\text { having the opportunity to network (i.e., exchange } \\
\text { implementation experiences) with distance } \\
\text { learning course facilitators in other schools }\end{array}$ & 190 & 3.10 & 1.175 \\
\hline
\end{tabular}




\section{Appendix L}

Principals' Ranking of Survey Items in Descending Order of Mean Scores

\begin{tabular}{|c|c|c|c|c|}
\hline $\begin{array}{l}\text { Survey } \\
\text { Item No. }\end{array}$ & Survey Item & $n$ & $M$ & $S D$ \\
\hline 3 & $\begin{array}{l}\text { Principal's willingness to include distance learning } \\
\text { courses in the school curriculum }\end{array}$ & 89 & 4.34 & 0.976 \\
\hline 1 & $\begin{array}{l}\text { Support of administrators in local school (e.g., } \\
\text { encouragement to teachers to utilize technology in } \\
\text { instruction, provision of resources) }\end{array}$ & 87 & 4.33 & 0.948 \\
\hline 2 & $\begin{array}{l}\text { Principal's perception of traits needed by students } \\
\text { to be successful in distance learning courses }\end{array}$ & 89 & 4.13 & 0.882 \\
\hline 7 & $\begin{array}{l}\text { School counselor as a source of information about } \\
\text { distance learning courses }\end{array}$ & 88 & 4.11 & 1.077 \\
\hline 24 & $\begin{array}{l}\text { Acceptance of credits for distance learning courses } \\
\text { by the county board of education or diploma- } \\
\text { granting authority }\end{array}$ & 82 & 3.94 & 0.998 \\
\hline 9 & $\begin{array}{l}\text { Information about distance learning courses made } \\
\text { available to students }\end{array}$ & 88 & 3.93 & 1.133 \\
\hline 32 & $\begin{array}{l}\text { Importance of teacher digital literacy (i.e., abilities } \\
\text { to locate, organize, understand, evaluate, analyze } \\
\text { and create information using technology) }\end{array}$ & 77 & 3.83 & 0.979 \\
\hline 5 & $\begin{array}{l}\text { Skills of distance learning course facilitators in the } \\
\text { school }\end{array}$ & 84 & 3.81 & 1.187 \\
\hline 31 & $\begin{array}{l}\text { Importance of student digital literacy (i.e., abilities } \\
\text { to locate, organize, understand, evaluate, analyze } \\
\text { and create information using technology) }\end{array}$ & 80 & 3.78 & 0.993 \\
\hline 12 & $\begin{array}{l}\text { Guidance from the West Virginia Department of } \\
\text { Education }\end{array}$ & 86 & 3.76 & 1.051 \\
\hline 25 & $\begin{array}{l}\text { Recognition of distance learning courses by } \\
\text { colleges and universities }\end{array}$ & 70 & 3.74 & 1.099 \\
\hline 29 & $\begin{array}{l}\text { Support from West Virginia Department of } \\
\text { Education personnel }\end{array}$ & 78 & 3.69 & 1.023 \\
\hline 10 & $\begin{array}{l}\text { Communication about distance learning courses } \\
\text { with external audiences (e.g., parents) }\end{array}$ & 85 & 3.68 & 1.167 \\
\hline 11 & $\begin{array}{l}\text { Clarity of WVBE Policy 2450, Distance Learning } \\
\text { and the West Virginia Virtual School }\end{array}$ & 85 & 3.64 & 0.937 \\
\hline 27 & $\begin{array}{l}\text { School's ability to maintain academic integrity } \\
\text { (control cheating) in distance learning courses }\end{array}$ & 80 & 3.63 & 1.048 \\
\hline 28 & $\begin{array}{l}\text { Ability for students to enroll in distance learning } \\
\text { courses without experiencing scheduling conflicts }\end{array}$ & 79 & 3.61 & 1.224 \\
\hline 14 & $\begin{array}{l}\text { Student access to technology and instructional } \\
\text { support }\end{array}$ & 85 & 3.59 & 1.284 \\
\hline
\end{tabular}




\begin{tabular}{|c|c|c|c|c|}
\hline $\begin{array}{l}\text { Survey } \\
\text { Item No. }\end{array}$ & Survey Item & $n$ & $M$ & $S D$ \\
\hline 23 & $\begin{array}{l}\text { WVBE Policy 2460, Educational Purpose and } \\
\text { Acceptable Use of Electronic Resources, } \\
\text { Technologies, and the Internet (pertaining to } \\
\text { acceptable use of the Internet) }\end{array}$ & 80 & 3.59 & 0.896 \\
\hline 8 & $\begin{array}{l}\text { Communication about distance learning courses } \\
\text { among all school personnel within a school }\end{array}$ & 86 & 3.58 & 1.090 \\
\hline 30 & Faculty's acceptance of state policy & 77 & 3.58 & 0.908 \\
\hline 22 & $\begin{array}{l}\text { Established operating procedures in the school } \\
\text { (e.g., daily class schedules, attendance, school } \\
\text { calendar, procedures for recording grades) }\end{array}$ & 81 & 3.57 & 1.024 \\
\hline 6 & $\begin{array}{l}\text { Faculty's willingness to learn about distance } \\
\text { learning courses }\end{array}$ & 84 & 3.55 & 1.023 \\
\hline 17 & $\begin{array}{l}\text { Number of computers available for students in } \\
\text { distance learning courses }\end{array}$ & 83 & 3.55 & 1.182 \\
\hline 19 & $\begin{array}{l}\text { Computer network security (protection from } \\
\text { computer viruses and hackers) }\end{array}$ & 87 & 3.55 & 1.149 \\
\hline 26 & $\begin{array}{l}\text { Assessment of student learning in distance learning } \\
\text { courses }\end{array}$ & 79 & 3.54 & 1.084 \\
\hline 4 & $\begin{array}{l}\text { School faculty's knowledge of teaching methods } \\
\text { used in distance learning }\end{array}$ & 87 & 3.51 & 1.077 \\
\hline 18 & $\begin{array}{l}\text { Broadband capacity/access to the Internet at your } \\
\text { school }\end{array}$ & 85 & 3.49 & 1.297 \\
\hline 35 & Parents' perception of distance learning & 73 & 3.48 & 1.069 \\
\hline 34 & Support of distance learning among the faculty & 78 & 3.41 & 1.110 \\
\hline 33 & $\begin{array}{l}\text { Quality of distance learning classes compared to } \\
\text { face-to-face classes }\end{array}$ & 72 & 3.29 & 1.261 \\
\hline 16 & $\begin{array}{l}\text { Size of the school (i.e., number of students in } \\
\text { grades 9-12) }\end{array}$ & 82 & 3.21 & 0.926 \\
\hline 20 & $\begin{array}{l}\text { Funding for professional development about } \\
\text { distance learning }\end{array}$ & 80 & 3.10 & 1.197 \\
\hline 21 & $\begin{array}{l}\text { Distance learning course facilitators in your school } \\
\text { having the opportunity to network (i.e., exchange } \\
\text { implementation experiences) with distance learning } \\
\text { course facilitators in other schools }\end{array}$ & 81 & 3.10 & 1.310 \\
\hline 15 & $\begin{array}{l}\text { Time available for school personnel to implement } \\
\text { Distance Learning Policy } 2450\end{array}$ & 83 & 3.07 & 1.404 \\
\hline 13 & Cost of distance learning courses & 81 & 3.02 & 1.193 \\
\hline
\end{tabular}




\section{Appendix M}

Counselors' Ranking of Survey Items in Descending Order of Mean Scores

\begin{tabular}{|c|c|c|c|c|}
\hline $\begin{array}{l}\text { Survey } \\
\text { Item No. }\end{array}$ & Survey Item & $n$ & $M$ & $S D$ \\
\hline 7 & $\begin{array}{l}\text { School counselor as a source of information about } \\
\text { distance learning courses }\end{array}$ & 80 & 4.40 & 0.821 \\
\hline 1 & $\begin{array}{l}\text { Support of administrators in local school (e.g., } \\
\text { encouragement to teachers to utilize technology in } \\
\text { instruction, provision of resources) }\end{array}$ & 79 & 4.33 & 0.858 \\
\hline 3 & $\begin{array}{l}\text { Principal's willingness to include distance learning } \\
\text { courses in the school curriculum }\end{array}$ & 76 & 4.30 & 0.833 \\
\hline 2 & $\begin{array}{l}\text { Principal's perception of traits needed by students to be } \\
\text { successful in distance learning courses }\end{array}$ & 78 & 4.14 & 0.950 \\
\hline 29 & $\begin{array}{l}\text { Support from West Virginia Department of Education } \\
\text { personnel }\end{array}$ & 72 & 4.03 & 0.964 \\
\hline 24 & $\begin{array}{l}\text { Acceptance of credits for distance learning courses by the } \\
\text { county board of education or diploma-granting authority }\end{array}$ & 71 & 3.97 & 1.014 \\
\hline 9 & $\begin{array}{l}\text { Information about distance learning courses made } \\
\text { available to students }\end{array}$ & 76 & 3.93 & 1.075 \\
\hline 25 & $\begin{array}{l}\text { Recognition of distance learning courses by colleges and } \\
\text { universities }\end{array}$ & 65 & 3.91 & 1.027 \\
\hline 12 & $\begin{array}{l}\text { Guidance from the West Virginia Department of } \\
\text { Education }\end{array}$ & 74 & 3.88 & 1.146 \\
\hline 27 & $\begin{array}{l}\text { School's ability to maintain academic integrity (control } \\
\text { cheating) in distance learning courses }\end{array}$ & 69 & 3.74 & 1.093 \\
\hline 14 & Student access to technology and instructional support & 77 & 3.70 & 1.338 \\
\hline 23 & $\begin{array}{l}\text { WVBE Policy 2460, Educational Purpose and Acceptable } \\
\text { Use of Electronic Resources, Technologies, and the } \\
\text { Internet (pertaining to acceptable use of the Internet) }\end{array}$ & 72 & 3.67 & 0.904 \\
\hline 19 & $\begin{array}{l}\text { Computer network security (protection from computer } \\
\text { viruses and hackers) }\end{array}$ & 76 & 3.66 & 1.217 \\
\hline 26 & $\begin{array}{l}\text { Assessment of student learning in distance learning } \\
\text { courses }\end{array}$ & 68 & 3.65 & 1.004 \\
\hline 10 & $\begin{array}{l}\text { Communication about distance learning courses with } \\
\text { external audiences (e.g., parents) }\end{array}$ & 72 & 3.63 & 1.054 \\
\hline 31 & $\begin{array}{l}\text { Importance of student digital literacy (i.e., abilities to } \\
\text { locate, organize, understand, evaluate, analyze and create } \\
\text { information using technology) }\end{array}$ & 75 & 3.63 & 1.160 \\
\hline
\end{tabular}




\begin{tabular}{|c|c|c|c|c|}
\hline $\begin{array}{l}\text { Survey } \\
\text { Item No. }\end{array}$ & Survey Item & $n$ & $M$ & $S D$ \\
\hline 22 & $\begin{array}{l}\text { Established operating procedures in the school (e.g., daily } \\
\text { class schedules, attendance, school calendar, procedures } \\
\text { for recording grades) }\end{array}$ & 74 & 3.62 & 1.069 \\
\hline 11 & $\begin{array}{l}\text { Clarity of WVBE Policy 2450, Distance Learning and the } \\
\text { West Virginia Virtual School }\end{array}$ & 71 & 3.61 & 1.089 \\
\hline 5 & Skills of distance learning course facilitators in the school & 73 & 3.60 & 1.255 \\
\hline 28 & $\begin{array}{l}\text { Ability for students to enroll in distance learning courses } \\
\text { without experiencing scheduling conflicts }\end{array}$ & 75 & 3.60 & 1.185 \\
\hline 30 & Faculty's acceptance of state policy & 70 & 3.60 & 0.891 \\
\hline 32 & $\begin{array}{l}\text { Importance of teacher digital literacy (i.e., abilities to } \\
\text { locate, organize, understand, evaluate, analyze and create } \\
\text { information using technology) }\end{array}$ & 75 & 3.60 & 1.127 \\
\hline 8 & $\begin{array}{l}\text { Communication about distance learning courses among all } \\
\text { school personnel within a school }\end{array}$ & 75 & 3.53 & 1.044 \\
\hline 6 & $\begin{array}{l}\text { Faculty's willingness to learn about distance learning } \\
\text { courses }\end{array}$ & 73 & 3.47 & 1.055 \\
\hline 34 & Support of distance learning among the faculty & 74 & 3.41 & 1.019 \\
\hline 4 & $\begin{array}{l}\text { School faculty's knowledge of teaching methods used in } \\
\text { distance learning }\end{array}$ & 74 & 3.39 & 1.083 \\
\hline 35 & Parents' perception of distance learning & 72 & 3.39 & 1.069 \\
\hline 33 & $\begin{array}{l}\text { Quality of distance learning classes compared to face-to- } \\
\text { face classes }\end{array}$ & 70 & 3.37 & 1.206 \\
\hline 18 & Broadband capacity/access to the Internet at your school & 79 & 3.33 & 1.393 \\
\hline 13 & Cost of distance learning courses & 73 & 3.30 & 1.330 \\
\hline 17 & $\begin{array}{l}\text { Number of computers available for students in distance } \\
\text { learning courses }\end{array}$ & 77 & 3.30 & 1.319 \\
\hline 16 & Size of the school (i.e., number of students in grades 9-12) & 76 & 3.17 & 0.885 \\
\hline 20 & $\begin{array}{l}\text { Funding for professional development about distance } \\
\text { learning }\end{array}$ & 71 & 3.06 & 1.229 \\
\hline 21 & $\begin{array}{l}\text { Distance learning course facilitators in your school having } \\
\text { the opportunity to network (i.e., exchange implementation } \\
\text { experiences) with distance learning course facilitators in } \\
\text { other schools }\end{array}$ & 69 & 3.03 & 1.248 \\
\hline 15 & $\begin{array}{l}\text { Time available for school personnel to implement } \\
\text { Distance Learning Policy } 2450\end{array}$ & 70 & 2.90 & 1.331 \\
\hline
\end{tabular}




\section{Appendix N}

Distance Learning Contacts/Course Facilitators' Ranking of Survey Items in Descending Order of Mean Scores

\begin{tabular}{|c|c|c|c|c|}
\hline $\begin{array}{l}\text { Survey } \\
\text { Item No. }\end{array}$ & Survey Item & $n$ & $M$ & $S D$ \\
\hline 2 & $\begin{array}{l}\text { Principal's perception of traits needed by students to be } \\
\text { successful in distance learning courses }\end{array}$ & 41 & 4.37 & 0.915 \\
\hline 1 & $\begin{array}{l}\text { Support of administrators in local school (e.g., } \\
\text { encouragement to teachers to utilize technology in } \\
\text { instruction, provision of resources) }\end{array}$ & 44 & 4.34 & 0.914 \\
\hline 3 & $\begin{array}{l}\text { Principal's willingness to include distance learning } \\
\text { courses in the school curriculum }\end{array}$ & 44 & 4.34 & 0.888 \\
\hline 24 & $\begin{array}{l}\text { Acceptance of credits for distance learning courses by the } \\
\text { county board of education or diploma-granting authority }\end{array}$ & 43 & 4.26 & 0.759 \\
\hline 5 & Skills of distance learning course facilitators in the school & 42 & 4.24 & 0.958 \\
\hline 14 & Student access to technology and instructional support & 44 & 4.23 & 1.031 \\
\hline 29 & $\begin{array}{l}\text { Support from West Virginia Department of Education } \\
\text { personnel }\end{array}$ & 39 & 4.23 & 1.038 \\
\hline 12 & $\begin{array}{l}\text { Guidance from the West Virginia Department of } \\
\text { Education }\end{array}$ & 40 & 4.20 & 1.043 \\
\hline 32 & $\begin{array}{l}\text { Importance of teacher digital literacy (i.e., abilities to } \\
\text { locate, organize, understand, evaluate, analyze and create } \\
\text { information using technology) }\end{array}$ & 43 & 4.14 & 0.990 \\
\hline 7 & $\begin{array}{l}\text { School counselor as a source of information about } \\
\text { distance learning courses }\end{array}$ & 43 & 4.12 & 1.074 \\
\hline 31 & $\begin{array}{l}\text { Importance of student digital literacy (i.e., abilities to } \\
\text { locate, organize, understand, evaluate, analyze and create } \\
\text { information using technology) }\end{array}$ & 42 & 4.12 & 1.017 \\
\hline 19 & $\begin{array}{l}\text { Computer network security (protection from computer } \\
\text { viruses and hackers) }\end{array}$ & 44 & 4.07 & 0.925 \\
\hline 26 & $\begin{array}{l}\text { Assessment of student learning in distance learning } \\
\text { courses }\end{array}$ & 42 & 4.07 & 0.973 \\
\hline 18 & Broadband capacity/access to the Internet at your school & 45 & 4.02 & 1.097 \\
\hline 23 & $\begin{array}{l}\text { WVBE Policy 2460, Educational Purpose and Acceptable } \\
\text { Use of Electronic Resources, Technologies, and the } \\
\text { Internet (pertaining to acceptable use of the Internet) }\end{array}$ & 41 & 4.00 & 0.837 \\
\hline
\end{tabular}




\begin{tabular}{|c|c|c|c|c|}
\hline $\begin{array}{l}\text { Survey } \\
\text { Item No. }\end{array}$ & Survey Item & $n$ & $M$ & $S D$ \\
\hline 25 & $\begin{array}{l}\text { Recognition of distance learning courses by colleges and } \\
\text { universities }\end{array}$ & 29 & 3.97 & 1.017 \\
\hline 17 & $\begin{array}{l}\text { Number of computers available for students in distance } \\
\text { learning courses }\end{array}$ & 45 & 3.96 & 1.107 \\
\hline 28 & $\begin{array}{l}\text { Ability for students to enroll in distance learning courses } \\
\text { without experiencing scheduling conflicts }\end{array}$ & 41 & 3.95 & 1.071 \\
\hline 22 & $\begin{array}{l}\text { Established operating procedures in the school (e.g., daily } \\
\text { class schedules, attendance, school calendar, procedures } \\
\text { for recording grades) }\end{array}$ & 42 & 3.93 & 0.894 \\
\hline 9 & $\begin{array}{l}\text { Information about distance learning courses made } \\
\text { available to students }\end{array}$ & 43 & 3.88 & 1.276 \\
\hline 33 & $\begin{array}{l}\text { Quality of distance learning classes compared to face-to- } \\
\text { face classes }\end{array}$ & 39 & 3.85 & 1.288 \\
\hline 10 & $\begin{array}{l}\text { Communication about distance learning courses with } \\
\text { external audiences (e.g., parents) }\end{array}$ & 40 & 3.83 & 1.174 \\
\hline 27 & $\begin{array}{l}\text { School's ability to maintain academic integrity (control } \\
\text { cheating) in distance learning courses }\end{array}$ & 40 & 3.80 & 1.285 \\
\hline 11 & $\begin{array}{l}\text { Clarity of WVBE Policy 2450, Distance Learning and the } \\
\text { West Virginia Virtual School }\end{array}$ & 40 & 3.78 & 1.050 \\
\hline 6 & $\begin{array}{l}\text { Faculty’s willingness to learn about distance learning } \\
\text { courses }\end{array}$ & 41 & 3.76 & 1.019 \\
\hline 30 & Faculty's acceptance of state policy & 38 & 3.76 & 0.998 \\
\hline 35 & Parents' perception of distance learning & 37 & 3.76 & 1.164 \\
\hline 4 & $\begin{array}{l}\text { School faculty's knowledge of teaching methods used in } \\
\text { distance learning }\end{array}$ & 40 & 3.75 & 1.214 \\
\hline 15 & $\begin{array}{l}\text { Time available for school personnel to implement } \\
\text { Distance Learning Policy } 2450\end{array}$ & 40 & 3.75 & 1.193 \\
\hline 34 & Support of distance learning among the faculty & 41 & 3.66 & 1.109 \\
\hline 16 & Size of the school (i.e., number of students in grades 9-12) & 41 & 3.59 & 1.024 \\
\hline 8 & $\begin{array}{l}\text { Communication about distance learning courses among all } \\
\text { school personnel within a school }\end{array}$ & 42 & 3.57 & 1.085 \\
\hline 13 & Cost of distance learning courses & 39 & 3.54 & 1.189 \\
\hline 21 & $\begin{array}{l}\text { Distance learning course facilitators in your school having } \\
\text { the opportunity to network (i.e., exchange implementation } \\
\text { experiences) with distance learning course facilitators in } \\
\text { other schools }\end{array}$ & 39 & 3.23 & 1.038 \\
\hline 20 & $\begin{array}{l}\text { Funding for professional development about distance } \\
\text { learning }\end{array}$ & 39 & 3.18 & 1.048 \\
\hline
\end{tabular}




\section{Appendix O}

Comparison of Mean Scores and Standard Deviations by Respondents' Primary Positions

\begin{tabular}{|c|c|c|c|c|c|c|}
\hline \multirow{2}{*}{$\begin{array}{l}\text { Survey } \\
\text { Item } \\
\text { No. }\end{array}$} & \multicolumn{2}{|c|}{$\begin{array}{c}\text { Principals / Assistant } \\
\text { Principals }\end{array}$} & \multicolumn{2}{|c|}{ Counselors } & \multicolumn{2}{|c|}{$\begin{array}{c}\text { Distance Learning } \\
\text { Contacts and/or Course } \\
\text { Facilitators }\end{array}$} \\
\hline & $M$ & $S D$ & $M$ & $S D$ & $M$ & $S D$ \\
\hline 1 & 4.33 & .948 & 4.33 & .858 & 4.34 & .914 \\
\hline 2 & 4.13 & .882 & 4.14 & .950 & 4.37 & .915 \\
\hline 3 & 4.34 & .976 & 4.30 & .833 & 4.34 & .888 \\
\hline 4 & 3.51 & 1.077 & 3.39 & 1.083 & 3.75 & 1.214 \\
\hline 5 & 3.81 & 1.187 & 3.60 & 1.255 & 4.24 & .958 \\
\hline 6 & 3.55 & 1.023 & 3.47 & 1.055 & 3.76 & 1.019 \\
\hline 7 & 4.11 & 1.077 & 4.40 & .821 & 4.12 & 1.074 \\
\hline 8 & 3.58 & 1.090 & 3.53 & 1.044 & 3.57 & 1.085 \\
\hline 9 & 3.93 & 1.133 & 3.93 & 1.075 & 3.88 & 1.276 \\
\hline 10 & 3.68 & 1.167 & 3.63 & 1.054 & 3.83 & 1.174 \\
\hline 11 & 3.64 & .937 & 3.61 & 1.089 & 3.78 & 1.050 \\
\hline 12 & 3.76 & 1.051 & 3.88 & 1.146 & 4.20 & 1.043 \\
\hline 13 & 3.02 & 1.193 & 3.30 & 1.330 & 3.54 & 1.189 \\
\hline 14 & 3.59 & 1.284 & 3.70 & 1.338 & 4.23 & 1.031 \\
\hline 15 & 3.07 & 1.404 & 2.90 & 1.331 & 3.75 & 1.193 \\
\hline 16 & 3.21 & .926 & 3.17 & .885 & 3.59 & 1.024 \\
\hline 17 & 3.55 & 1.182 & 3.30 & 1.319 & 3.96 & 1.107 \\
\hline
\end{tabular}




\begin{tabular}{|c|c|c|c|c|c|c|}
\hline \multirow{2}{*}{$\begin{array}{l}\text { Survey } \\
\text { Item } \\
\text { No. }\end{array}$} & \multicolumn{2}{|c|}{$\begin{array}{c}\text { Principals / Assistant } \\
\text { Principals }\end{array}$} & \multicolumn{2}{|c|}{ Counselors } & \multicolumn{2}{|c|}{$\begin{array}{c}\text { Distance Learning } \\
\text { Contacts and/or Course } \\
\text { Facilitators }\end{array}$} \\
\hline & $M$ & $S D$ & $M$ & $S D$ & $M$ & $S D$ \\
\hline 18 & 3.49 & 1.297 & 3.33 & 1.393 & 4.02 & 1.097 \\
\hline 19 & 3.55 & 1.149 & 3.66 & 1.217 & 4.07 & .925 \\
\hline 20 & 3.10 & 1.197 & 3.06 & 1.229 & 3.18 & 1.048 \\
\hline 21 & 3.10 & 1.310 & 3.03 & 1.248 & 3.23 & 1.038 \\
\hline 22 & 3.57 & 1.024 & 3.62 & 1.069 & 3.93 & .894 \\
\hline 23 & 3.59 & .896 & 3.67 & .904 & 4.00 & .837 \\
\hline 24 & 3.94 & .998 & 3.97 & 1.014 & 4.26 & .759 \\
\hline 25 & 3.74 & 1.099 & 3.91 & 1.027 & 3.97 & 1.017 \\
\hline 26 & 3.54 & 1.084 & 3.65 & 1.004 & 4.07 & .973 \\
\hline 27 & 3.63 & 1.048 & 3.74 & 1.093 & 3.80 & 1.285 \\
\hline 28 & 3.61 & 1.224 & 3.60 & 1.185 & 3.95 & 1.071 \\
\hline 29 & 3.69 & 1.023 & 4.03 & .964 & 4.23 & 1.038 \\
\hline 30 & 3.58 & .908 & 3.60 & .891 & 3.76 & .998 \\
\hline 31 & 3.78 & .993 & 3.63 & 1.160 & 4.12 & 1.017 \\
\hline 32 & 3.83 & .979 & 3.60 & 1.127 & 4.14 & .990 \\
\hline 33 & 3.29 & 1.261 & 3.37 & 1.206 & 3.85 & 1.288 \\
\hline 34 & 3.41 & 1.110 & 3.41 & 1.019 & 3.66 & 1.109 \\
\hline 35 & 3.48 & 1.069 & 3.39 & 1.069 & 3.76 & 1.164 \\
\hline
\end{tabular}




\section{Appendix P}

Results of One-Way Analysis of Variance (ANOVA)

\begin{tabular}{|c|c|c|c|c|c|c|c|}
\hline $\begin{array}{l}\text { Survey } \\
\text { Item No. }\end{array}$ & Survey Item & Grouping & $\begin{array}{l}\text { Sum of } \\
\text { Squares }\end{array}$ & df & $\begin{array}{c}\text { Mean } \\
\text { Square }\end{array}$ & $\mathrm{F}$ & Sig.* \\
\hline \multirow[t]{3}{*}{1} & \multirow{3}{*}{$\begin{array}{l}\text { Support of administrators in local school } \\
\text { (e.g., encouragement to teachers to utilize } \\
\text { technology in instruction, provision of } \\
\text { resources) }\end{array}$} & Between Groups & .004 & 2 & .002 & .002 & .998 \\
\hline & & Within Groups & 170.663 & 207 & .824 & & \\
\hline & & Total & 170.667 & 209 & & & \\
\hline \multirow[t]{3}{*}{2} & \multirow{3}{*}{$\begin{array}{l}\text { Principal's perception of traits needed by } \\
\text { students to be successful in distance } \\
\text { learning courses }\end{array}$} & Between Groups & 1.715 & 2 & .857 & 1.026 & .360 \\
\hline & & Within Groups & 171.343 & 205 & .836 & & \\
\hline & & Total & 173.058 & 207 & & & \\
\hline \multirow[t]{3}{*}{3} & \multirow{3}{*}{$\begin{array}{l}\text { Principal's willingness to include distance } \\
\text { learning courses in the school curriculum }\end{array}$} & Between Groups & .062 & 2 & .031 & .038 & .963 \\
\hline & & Within Groups & 169.813 & 206 & .824 & & \\
\hline & & Total & 169.876 & 208 & & & \\
\hline \multirow[t]{3}{*}{4} & \multirow{3}{*}{$\begin{array}{l}\text { School faculty's knowledge of teaching } \\
\text { methods used in distance learning }\end{array}$} & Between Groups & 3.337 & 2 & 1.668 & 1.360 & .259 \\
\hline & & Within Groups & 242.882 & 198 & 1.227 & & \\
\hline & & Total & 246.219 & 200 & & & \\
\hline \multirow[t]{3}{*}{5} & \multirow{3}{*}{$\begin{array}{l}\text { Skills of distance learning course } \\
\text { facilitators in the school }\end{array}$} & Between Groups & 10.793 & 2 & 5.397 & 3.946 & .021 \\
\hline & & Within Groups & 268.051 & 196 & 1.368 & & \\
\hline & & Total & 278.844 & 198 & & & \\
\hline
\end{tabular}




\begin{tabular}{|c|c|c|c|c|c|c|c|}
\hline \multirow[t]{3}{*}{6} & \multirow{3}{*}{$\begin{array}{l}\text { Faculty's willingness to learn about } \\
\text { distance learning courses }\end{array}$} & Between Groups & 2.238 & 2 & 1.119 & 1.046 & .353 \\
\hline & & Within Groups & 208.535 & 195 & 1.069 & & \\
\hline & & Total & 210.773 & 197 & & & \\
\hline \multirow[t]{3}{*}{7} & \multirow{3}{*}{$\begin{array}{l}\text { School counselor as a source of } \\
\text { information about distance learning } \\
\text { courses }\end{array}$} & Between Groups & 4.049 & 2 & 2.024 & 2.079 & .128 \\
\hline & & Within Groups & 202.482 & 208 & .973 & & \\
\hline & & Total & 206.531 & 210 & & & \\
\hline \multirow[t]{3}{*}{8} & \multirow{3}{*}{$\begin{array}{l}\text { Communication about distance learning } \\
\text { courses among all school personnel within } \\
\text { a school }\end{array}$} & Between Groups & .098 & 2 & .049 & .042 & .958 \\
\hline & & Within Groups & 229.883 & 200 & 1.149 & & \\
\hline & & Total & 229.980 & 202 & & & \\
\hline \multirow[t]{3}{*}{9} & \multirow{3}{*}{$\begin{array}{l}\text { Information about distance learning } \\
\text { courses made available to students }\end{array}$} & Between Groups & .083 & 2 & .041 & .032 & .969 \\
\hline & & Within Groups & 266.681 & 204 & 1.307 & & \\
\hline & & Total & 266.763 & 206 & & & \\
\hline \multirow[t]{3}{*}{10} & \multirow{3}{*}{$\begin{array}{l}\text { Communication about distance learning } \\
\text { courses with external audiences (e.g., } \\
\text { parents) }\end{array}$} & Between Groups & 1.038 & 2 & .519 & .408 & .666 \\
\hline & & Within Groups & 247.074 & 194 & 1.274 & & \\
\hline & & Total & 248.112 & 196 & & & \\
\hline \multirow[t]{3}{*}{11} & \multirow{3}{*}{$\begin{array}{l}\text { Clarity of WVBE Policy 2450, Distance } \\
\text { Learning and the West Virginia Virtual } \\
\text { School }\end{array}$} & Between Groups & .781 & 2 & .391 & .378 & .686 \\
\hline & & Within Groups & 199.627 & 193 & 1.034 & & \\
\hline & & Total & 200.408 & 195 & & & \\
\hline
\end{tabular}




\begin{tabular}{|c|c|c|c|c|c|c|c|}
\hline $\begin{array}{l}\text { Survey } \\
\text { Item No. }\end{array}$ & Survey Item & Grouping & $\begin{array}{l}\text { Sum of } \\
\text { Squares }\end{array}$ & df & $\begin{array}{c}\text { Mean } \\
\text { Square }\end{array}$ & $\mathrm{F}$ & Sig.* \\
\hline \multirow[t]{3}{*}{12} & \multirow{3}{*}{$\begin{array}{l}\text { Guidance from the West Virginia } \\
\text { Department of Education }\end{array}$} & Between Groups & 5.403 & 2 & 2.701 & 2.292 & .104 \\
\hline & & Within Groups & 232.177 & 197 & 1.179 & & \\
\hline & & Total & 237.580 & 199 & & & \\
\hline \multirow[t]{3}{*}{13} & \multirow[t]{3}{*}{ Cost of distance learning courses } & Between Groups & 7.495 & 2 & 3.747 & 2.414 & .092 \\
\hline & & Within Groups & 295.013 & 190 & 1.553 & & \\
\hline & & Total & 302.508 & 192 & & & \\
\hline \multirow[t]{3}{*}{14} & \multirow{3}{*}{$\begin{array}{l}\text { Student access to technology and } \\
\text { instructional support }\end{array}$} & Between Groups & 12.370 & 2 & 6.185 & 3.918 & .021 \\
\hline & & Within Groups & 320.445 & 203 & 1.579 & & \\
\hline & & Total & 332.816 & 205 & & & \\
\hline \multirow[t]{3}{*}{15} & \multirow{3}{*}{$\begin{array}{l}\text { Time available for school personnel to } \\
\text { implement Distance Learning Policy } 2450\end{array}$} & Between Groups & 19.276 & 2 & 9.638 & 5.396 & .005 \\
\hline & & Within Groups & 339.366 & 190 & 1.786 & & \\
\hline & & Total & 358.642 & 192 & & & \\
\hline \multirow[t]{3}{*}{16} & \multirow[t]{3}{*}{$\begin{array}{l}\text { Size of the school (i.e., number of students } \\
\text { in grades 9-12) }\end{array}$} & Between Groups & 5.144 & 2 & 2.572 & 2.962 & .054 \\
\hline & & Within Groups & 170.203 & 196 & .868 & & \\
\hline & & Total & 175.347 & 198 & & & \\
\hline \multirow[t]{3}{*}{17} & \multirow{3}{*}{$\begin{array}{l}\text { Number of computers available for } \\
\text { students in distance learning courses }\end{array}$} & Between Groups & 12.263 & 2 & 6.131 & 4.121 & .018 \\
\hline & & Within Groups & 300.547 & 202 & 1.488 & & \\
\hline & & Total & 312.810 & 204 & & & \\
\hline
\end{tabular}




\begin{tabular}{|c|c|c|c|c|c|c|c|}
\hline $\begin{array}{l}\text { Survey } \\
\text { Item No. }\end{array}$ & Survey Item & Grouping & $\begin{array}{l}\text { Sum of } \\
\text { Squares }\end{array}$ & df & $\begin{array}{c}\text { Mean } \\
\text { Square }\end{array}$ & $\mathrm{F}$ & Sig.* \\
\hline \multirow[t]{3}{*}{18} & \multirow{3}{*}{$\begin{array}{l}\text { Broadband capacity/access to the Internet } \\
\text { at your school }\end{array}$} & Between Groups & 14.150 & 2 & 7.075 & 4.216 & .016 \\
\hline & & Within Groups & 345.668 & 206 & 1.678 & & \\
\hline & & Total & 359.818 & 208 & & & \\
\hline \multirow[t]{3}{*}{19} & \multirow{3}{*}{$\begin{array}{l}\text { Computer network security (protection } \\
\text { from computer viruses and hackers) }\end{array}$} & Between Groups & 8.012 & 2 & 4.006 & 3.126 & .046 \\
\hline & & Within Groups & 261.418 & 204 & 1.281 & & \\
\hline & & Total & 269.430 & 206 & & & \\
\hline \multirow[t]{3}{*}{20} & \multirow{3}{*}{$\begin{array}{l}\text { Funding for professional development } \\
\text { about distance learning }\end{array}$} & Between Groups & .382 & 2 & .191 & .137 & .872 \\
\hline & & Within Groups & 260.718 & 187 & 1.394 & & \\
\hline & & Total & 261.100 & 189 & & & \\
\hline \multirow[t]{3}{*}{21} & \multirow{3}{*}{$\begin{array}{l}\text { Distance learning course facilitators in } \\
\text { your school having the opportunity to } \\
\text { network (i.e., exchange implementation } \\
\text { experiences) with distance learning course } \\
\text { facilitators in other schools }\end{array}$} & Between Groups & 1.015 & 2 & .507 & .332 & .718 \\
\hline & & Within Groups & 284.075 & 186 & 1.527 & & \\
\hline & & Total & 285.090 & 188 & & & \\
\hline \multirow[t]{3}{*}{22} & \multirow{3}{*}{$\begin{array}{l}\text { Established operating procedures in the } \\
\text { school (e.g., daily class schedules, } \\
\text { attendance, school calendar, procedures for } \\
\text { recording grades) }\end{array}$} & Between Groups & 3.821 & 2 & 1.910 & 1.852 & .160 \\
\hline & & Within Groups & 200.068 & 194 & 1.031 & & \\
\hline & & Total & 203.888 & 196 & & & \\
\hline \multirow[t]{3}{*}{23} & \multirow{3}{*}{$\begin{array}{l}\text { WVBE Policy 2460, Educational Purpose } \\
\text { and Acceptable Use of Electronic } \\
\text { Resources, Technologies, and the Internet } \\
\text { (pertaining to acceptable use of the } \\
\text { Internet) }\end{array}$} & Between Groups & 4.778 & 2 & 2.389 & 3.039 & .050 \\
\hline & & Within Groups & 149.388 & 190 & .786 & & \\
\hline & & Total & 154.166 & 192 & & & \\
\hline
\end{tabular}




\begin{tabular}{|c|c|c|c|c|c|c|c|}
\hline $\begin{array}{l}\text { Survey } \\
\text { Item No. }\end{array}$ & Survey Item & Grouping & $\begin{array}{l}\text { Sum of } \\
\text { Squares }\end{array}$ & $\mathrm{df}$ & $\begin{array}{l}\text { Mean } \\
\text { Square }\end{array}$ & $\mathrm{F}$ & Sig.* \\
\hline \multirow[t]{3}{*}{24} & \multirow{3}{*}{$\begin{array}{l}\text { Acceptance of credits for distance learning } \\
\text { courses by the county board of education } \\
\text { or diploma-granting authority }\end{array}$} & Between Groups & 3.094 & 2 & 1.547 & 1.688 & .188 \\
\hline & & Within Groups & 176.825 & 193 & .916 & & \\
\hline & & Total & 179.918 & 195 & & & \\
\hline \multirow[t]{3}{*}{25} & \multirow{3}{*}{$\begin{array}{l}\text { Recognition of distance learning courses } \\
\text { by colleges and universities }\end{array}$} & Between Groups & 1.406 & 2 & .703 & .630 & .534 \\
\hline & & Within Groups & 179.783 & 161 & 1.117 & & \\
\hline & & Total & 181.189 & 163 & & & \\
\hline \multirow[t]{3}{*}{26} & \multirow{3}{*}{$\begin{array}{l}\text { Assessment of student learning in distance } \\
\text { learning courses }\end{array}$} & Between Groups & 7.899 & 2 & 3.950 & 3.712 & .026 \\
\hline & & Within Groups & 197.910 & 186 & 1.064 & & \\
\hline & & Total & 205.810 & 188 & & & \\
\hline \multirow[t]{3}{*}{27} & \multirow{3}{*}{$\begin{array}{l}\text { School's ability to maintain academic } \\
\text { integrity (control cheating) in distance } \\
\text { learning courses }\end{array}$} & Between Groups & .953 & 2 & .477 & .381 & .684 \\
\hline & & Within Groups & 232.454 & 186 & 1.250 & & \\
\hline & & Total & 233.407 & 188 & & & \\
\hline \multirow[t]{3}{*}{28} & \multirow{3}{*}{$\begin{array}{l}\text { Ability for students to enroll in distance } \\
\text { learning courses without experiencing } \\
\text { scheduling conflicts }\end{array}$} & Between Groups & 3.908 & 2 & 1.954 & 1.407 & .247 \\
\hline & & Within Groups & 266.738 & 192 & 1.389 & & \\
\hline & & Total & 270.646 & 194 & & & \\
\hline \multirow[t]{3}{*}{29} & \multirow{3}{*}{$\begin{array}{l}\text { Support from West Virginia Department of } \\
\text { Education personnel }\end{array}$} & Between Groups & 8.623 & 2 & 4.311 & 4.277 & .015 \\
\hline & & Within Groups & 187.483 & 186 & 1.008 & & \\
\hline & & Total & 196.106 & 188 & & & \\
\hline
\end{tabular}




\begin{tabular}{|c|c|c|c|c|c|c|c|}
\hline $\begin{array}{l}\text { Survey } \\
\text { Item No. }\end{array}$ & Survey Item & Grouping & $\begin{array}{c}\text { Sum of } \\
\text { Squares }\end{array}$ & df & $\begin{array}{c}\text { Mean } \\
\text { Square }\end{array}$ & $\mathrm{F}$ & Sig.* \\
\hline \multirow[t]{3}{*}{30} & \multirow[t]{3}{*}{ Faculty's acceptance of state policy } & Between Groups & .895 & 2 & .448 & .528 & .591 \\
\hline & & Within Groups & 154.370 & 182 & .848 & & \\
\hline & & Total & 155.265 & 184 & & & \\
\hline \multirow[t]{3}{*}{31} & \multirow{3}{*}{$\begin{array}{l}\text { Importance of student digital literacy (i.e., } \\
\text { abilities to locate, organize, understand, } \\
\text { evaluate, analyze and create information } \\
\text { using technology) }\end{array}$} & Between Groups & 6.566 & 2 & 3.283 & 2.896 & .058 \\
\hline & & Within Groups & 219.901 & 194 & 1.134 & & \\
\hline & & Total & 226.467 & 196 & & & \\
\hline \multirow[t]{3}{*}{32} & \multirow{3}{*}{$\begin{array}{l}\text { Importance of teacher digital literacy (i.e., } \\
\text { abilities to locate, organize, understand, } \\
\text { evaluate, analyze and create information } \\
\text { using technology) }\end{array}$} & Between Groups & 8.012 & 2 & 4.006 & 3.698 & .027 \\
\hline & & Within Groups & 207.968 & 192 & 1.083 & & \\
\hline & & Total & 215.979 & 194 & & & \\
\hline \multirow[t]{3}{*}{33} & \multirow{3}{*}{$\begin{array}{l}\text { Quality of distance learning classes } \\
\text { compared to face-to-face classes }\end{array}$} & Between Groups & 8.346 & 2 & 4.173 & 2.688 & .071 \\
\hline & & Within Groups & 276.295 & 178 & 1.552 & & \\
\hline & & Total & 284.641 & 180 & & & \\
\hline \multirow[t]{3}{*}{34} & \multirow{3}{*}{$\begin{array}{l}\text { Support of distance learning among the } \\
\text { faculty }\end{array}$} & Between Groups & 2.029 & 2 & 1.015 & .877 & .418 \\
\hline & & Within Groups & 219.929 & 190 & 1.158 & & \\
\hline & & Total & 221.959 & 192 & & & \\
\hline \multirow[t]{3}{*}{35} & \multirow[t]{3}{*}{ Parents' perception of distance learning } & Between Groups & 3.359 & 2 & 1.679 & 1.417 & .245 \\
\hline & & Within Groups & 212.141 & 179 & 1.185 & & \\
\hline & & Total & 215.500 & 181 & & & \\
\hline
\end{tabular}




\section{Appendix Q}

One-Way Analysis of Variance (ANOVA) Results on Survey Items with Significant Differences among the Means of Principals/Assistant Principals, Counselors, and Distance Learning Contacts and/or Distance Learning Course Facilitators

\begin{tabular}{|c|c|c|c|c|c|c|c|}
\hline $\begin{array}{l}\text { Survey } \\
\text { Item No. }\end{array}$ & Survey Item & Grouping & $\begin{array}{l}\text { Sum of } \\
\text { Squares }\end{array}$ & df & $\begin{array}{l}\text { Mean } \\
\text { Square }\end{array}$ & $\mathrm{F}$ & Sig.* \\
\hline \multirow[t]{3}{*}{5} & $\begin{array}{l}\text { Skills of distance learning course } \\
\text { facilitators in the school }\end{array}$ & Between Groups & 10.793 & 2 & 5.397 & 3.946 & .021 \\
\hline & & Within Groups & 268.051 & 196 & 1.368 & & \\
\hline & & Total & 278.844 & 198 & & & \\
\hline \multirow[t]{3}{*}{14} & $\begin{array}{l}\text { Student access to technology and } \\
\text { instructional support }\end{array}$ & Between Groups & 12.370 & 2 & 6.185 & 3.918 & .021 \\
\hline & & Within Groups & 320.445 & 203 & 1.579 & & \\
\hline & & Total & 332.816 & 205 & & & \\
\hline \multirow[t]{3}{*}{15} & $\begin{array}{l}\text { Time available for school personnel to } \\
\text { implement Distance Learning Policy } 2450\end{array}$ & Between Groups & 19.276 & 2 & 9.638 & 5.396 & .005 \\
\hline & & Within Groups & 339.366 & 190 & 1.786 & & \\
\hline & & Total & 358.642 & 192 & & & \\
\hline \multirow[t]{3}{*}{17} & $\begin{array}{l}\text { Number of computers available for } \\
\text { students in distance learning courses }\end{array}$ & Between Groups & 12.263 & 2 & 6.131 & 4.121 & .018 \\
\hline & & Within Groups & 300.547 & 202 & 1.488 & & \\
\hline & & Total & 312.810 & 204 & & & \\
\hline \multirow[t]{3}{*}{18} & $\begin{array}{l}\text { Broadband capacity/access to the Internet } \\
\text { at your school }\end{array}$ & Between Groups & 14.150 & 2 & 7.075 & 4.216 & .016 \\
\hline & & Within Groups & 345.668 & 206 & 1.678 & & \\
\hline & & Total & 359.818 & 208 & & & \\
\hline
\end{tabular}




\begin{tabular}{|c|c|c|c|c|c|c|c|}
\hline $\begin{array}{l}\text { Survey } \\
\text { Item No. }\end{array}$ & $\begin{array}{c}\text { Survey Item } \\
\end{array}$ & Grouping & $\begin{array}{l}\text { Sum of } \\
\text { Squares }\end{array}$ & df & $\begin{array}{l}\text { Mean } \\
\text { Square }\end{array}$ & $\mathrm{F}$ & Sig.* \\
\hline \multirow[t]{3}{*}{19} & $\begin{array}{l}\text { Computer network security (protection } \\
\text { from computer viruses and hackers) }\end{array}$ & Between Groups & 8.012 & 2 & 4.006 & 3.126 & .046 \\
\hline & & Within Groups & 261.418 & 204 & 1.281 & & \\
\hline & & Total & 269.430 & 206 & & & \\
\hline \multirow[t]{3}{*}{23} & $\begin{array}{l}\text { WVBE Policy 2460, Educational Purpose } \\
\text { and Acceptable Use of Electronic }\end{array}$ & Between Groups & 4.778 & 2 & 2.389 & 3.039 & .050 \\
\hline & $\begin{array}{l}\text { Resources, Technologies, and the Internet } \\
\text { (pertaining to acceptable use of the }\end{array}$ & Within Groups & 149.388 & 190 & .786 & & \\
\hline & Internet) & Total & 154.166 & 192 & & & \\
\hline \multirow[t]{3}{*}{26} & $\begin{array}{l}\text { Assessment of student learning in distance } \\
\text { learning courses }\end{array}$ & Between Groups & 7.899 & 2 & 3.950 & 3.712 & .026 \\
\hline & & Within Groups & 197.910 & 186 & 1.064 & & \\
\hline & & Total & 205.810 & 188 & & & \\
\hline \multirow[t]{3}{*}{29} & $\begin{array}{l}\text { Support from West Virginia Department of } \\
\text { Education personnel }\end{array}$ & Between Groups & 8.623 & 2 & 4.311 & 4.277 & .015 \\
\hline & & Within Groups & 187.483 & 186 & 1.008 & & \\
\hline & & Total & 196.106 & 188 & & & \\
\hline \multirow[t]{3}{*}{32} & $\begin{array}{l}\text { Importance of teacher digital literacy (i.e., } \\
\text { abilities to locate, organize, understand, }\end{array}$ & Between Groups & 8.012 & 2 & 4.006 & 3.698 & .027 \\
\hline & $\begin{array}{l}\text { evaluate, analyze, and create information } \\
\text { using technology) }\end{array}$ & Within Groups & 207.968 & 192 & 1.083 & & \\
\hline & & Total & 215.979 & 194 & & & \\
\hline
\end{tabular}

${ }^{*} p<.05$ 


\section{Appendix R}

Independent Samples t-Test Results

\begin{tabular}{|c|c|c|c|c|c|c|c|c|c|c|}
\hline \multirow{3}{*}{$\begin{array}{l}\text { Survey } \\
\text { Item } \\
\text { No. }\end{array}$} & \multirow{3}{*}{ Condition } & \multicolumn{2}{|c|}{$\begin{array}{c}\text { Levene's Test for } \\
\text { Equality of Variances }\end{array}$} & \multicolumn{7}{|c|}{ t-Test for Equality of Means } \\
\hline & & \multirow[t]{2}{*}{$\mathrm{F}$} & \multirow[t]{2}{*}{ Sig. } & \multirow[t]{2}{*}{$\mathrm{t}$} & \multirow[t]{2}{*}{ df } & \multirow[t]{2}{*}{$\begin{array}{l}\text { Sig. (2- } \\
\text { tailed) }\end{array}$} & \multirow[t]{2}{*}{$\begin{array}{c}\text { Mean } \\
\text { Difference }\end{array}$} & \multirow[t]{2}{*}{$\begin{array}{l}\text { Std. Error } \\
\text { Difference }\end{array}$} & \multicolumn{2}{|c|}{$\begin{array}{l}95 \% \text { Confidence } \\
\text { Interval of the } \\
\text { Difference }\end{array}$} \\
\hline & & & & & & & & & Lower & Upper \\
\hline \multirow[t]{2}{*}{1} & $\begin{array}{l}\text { Equal variances } \\
\text { assumed }\end{array}$ & .341 & .560 & -.102 & 208.000 & .919 & -.013 & .126 & -.261 & .235 \\
\hline & $\begin{array}{l}\text { Equal variances } \\
\text { not assumed }\end{array}$ & & & -.102 & 194.095 & .919 & -.013 & .126 & -.262 & .237 \\
\hline \multirow[t]{2}{*}{2} & $\begin{array}{l}\text { Equal variances } \\
\text { assumed }\end{array}$ & .482 & .488 & .455 & 206.000 & .649 & .058 & .128 & -.194 & .310 \\
\hline & $\begin{array}{l}\text { Equal variances } \\
\text { not assumed }\end{array}$ & & & .457 & 199.888 & .648 & .058 & .127 & -.193 & .309 \\
\hline \multirow[t]{2}{*}{3} & $\begin{array}{l}\text { Equal variances } \\
\text { assumed }\end{array}$ & 1.469 & .227 & 1.422 & 207.000 & .157 & .178 & .125 & -.069 & .425 \\
\hline & $\begin{array}{l}\text { Equal variances } \\
\text { not assumed }\end{array}$ & & & 1.406 & 189.798 & .161 & .178 & .127 & -.072 & .428 \\
\hline \multirow[t]{2}{*}{4} & $\begin{array}{l}\text { Equal variances } \\
\text { assumed }\end{array}$ & .299 & .585 & 1.555 & 199.000 & .122 & .244 & .157 & -.065 & .553 \\
\hline & $\begin{array}{l}\text { Equal variances } \\
\text { not assumed }\end{array}$ & & & 1.546 & 186.108 & .124 & .244 & .158 & -.067 & .555 \\
\hline
\end{tabular}




\begin{tabular}{|c|c|c|c|c|c|c|c|c|c|c|}
\hline \multirow{3}{*}{$\begin{array}{l}\text { Survey } \\
\text { Item } \\
\text { No. }\end{array}$} & \multirow{3}{*}{ Condition } & \multicolumn{2}{|c|}{$\begin{array}{l}\text { Levene's Test for } \\
\text { Equality of Variances }\end{array}$} & \multicolumn{7}{|c|}{$\mathrm{t}$-Test for Equality of Means } \\
\hline & & \multirow[t]{2}{*}{$\mathrm{F}$} & \multirow[t]{2}{*}{ Sig. } & \multirow[t]{2}{*}{$\mathrm{t}$} & \multirow[t]{2}{*}{ df } & \multirow[t]{2}{*}{$\begin{array}{l}\text { Sig. (2- } \\
\text { tailed) }\end{array}$} & \multirow[t]{2}{*}{$\begin{array}{c}\text { Mean } \\
\text { Difference }\end{array}$} & \multirow[t]{2}{*}{$\begin{array}{l}\text { Std. Error } \\
\text { Difference }\end{array}$} & \multicolumn{2}{|c|}{$\begin{array}{l}\text { 95\% Confidence } \\
\text { Interval of the } \\
\text { Difference }\end{array}$} \\
\hline & & & & & & & & & Lower & Upper \\
\hline \multirow[t]{2}{*}{5} & $\begin{array}{l}\text { Equal variances } \\
\text { assumed }\end{array}$ & 1.928 & .167 & 1.192 & 197.000 & .235 & .202 & .170 & -.132 & .537 \\
\hline & $\begin{array}{l}\text { Equal variances } \\
\text { not assumed }\end{array}$ & & & 1.185 & 178.640 & .238 & .202 & .171 & -.135 & .539 \\
\hline \multirow[t]{2}{*}{6} & $\begin{array}{l}\text { Equal variances } \\
\text { assumed }\end{array}$ & .833 & .362 & 1.637 & 196.000 & .103 & .241 & .147 & -.049 & .532 \\
\hline & $\begin{array}{l}\text { Equal variances } \\
\text { not assumed }\end{array}$ & & & 1.629 & 181.352 & .105 & .241 & .148 & -.051 & .534 \\
\hline \multirow[t]{2}{*}{7} & $\begin{array}{l}\text { Equal variances } \\
\text { assumed }\end{array}$ & .200 & .655 & 2.392 & 209.000 & .018 & .325 & .136 & .057 & .593 \\
\hline & $\begin{array}{l}\text { Equal variances } \\
\text { not assumed }\end{array}$ & & & 2.365 & 189.369 & .019 & .325 & .137 & .054 & .596 \\
\hline \multirow[t]{2}{*}{8} & $\begin{array}{l}\text { Equal variances } \\
\text { assumed }\end{array}$ & .580 & .447 & 1.729 & 201.000 & .085 & .260 & .150 & -.036 & .556 \\
\hline & $\begin{array}{l}\text { Equal variances } \\
\text { not assumed }\end{array}$ & & & 1.721 & 185.576 & .087 & .260 & .151 & -.038 & .557 \\
\hline \multirow[t]{2}{*}{9} & $\begin{array}{l}\text { Equal variances } \\
\text { assumed }\end{array}$ & 6.224 & .013 & 1.739 & 205.000 & .084 & .276 & .159 & -.037 & .589 \\
\hline & $\begin{array}{l}\text { Equal variances } \\
\text { not assumed }\end{array}$ & & & 1.711 & 178.752 & .089 & .276 & .161 & -.042 & .594 \\
\hline
\end{tabular}




\begin{tabular}{|c|c|c|c|c|c|c|c|c|c|c|}
\hline \multirow{3}{*}{$\begin{array}{l}\text { Survey } \\
\text { Item } \\
\text { No. }\end{array}$} & \multirow{3}{*}{ Condition } & \multicolumn{2}{|c|}{$\begin{array}{l}\text { Levene's Test for } \\
\text { Equality of Variances }\end{array}$} & \multicolumn{7}{|c|}{ t-Test for Equality of Means } \\
\hline & & \multirow[t]{2}{*}{$\mathrm{F}$} & \multirow[t]{2}{*}{ Sig. } & \multirow[t]{2}{*}{$\mathrm{t}$} & \multirow[t]{2}{*}{ df } & \multirow[t]{2}{*}{$\begin{array}{l}\text { Sig. (2- } \\
\text { tailed) }\end{array}$} & \multirow[t]{2}{*}{$\begin{array}{c}\text { Mean } \\
\text { Difference }\end{array}$} & \multirow[t]{2}{*}{$\begin{array}{l}\text { Std. Error } \\
\text { Difference }\end{array}$} & \multicolumn{2}{|c|}{$\begin{array}{l}\text { 95\% Confidence } \\
\text { Interval of the } \\
\text { Difference }\end{array}$} \\
\hline & & & & & & & & & Lower & Upper \\
\hline \multirow[t]{2}{*}{10} & $\begin{array}{l}\text { Equal variances } \\
\text { assumed }\end{array}$ & 1.145 & .286 & .725 & 195.000 & .469 & .118 & .162 & -.202 & .437 \\
\hline & $\begin{array}{l}\text { Equal variances } \\
\text { not assumed }\end{array}$ & & & .721 & 176.738 & .472 & .118 & .163 & -.204 & .439 \\
\hline \multirow[t]{2}{*}{11} & $\begin{array}{l}\text { Equal variances } \\
\text { assumed }\end{array}$ & 3.490 & .063 & 1.119 & 194.000 & .264 & .164 & .146 & -.125 & .452 \\
\hline & $\begin{array}{l}\text { Equal variances } \\
\text { not assumed }\end{array}$ & & & 1.098 & 164.654 & .274 & .164 & .149 & -.131 & .458 \\
\hline \multirow[t]{2}{*}{12} & $\begin{array}{l}\text { Equal variances } \\
\text { assumed }\end{array}$ & 1.149 & .285 & 1.101 & 198.000 & .272 & .171 & .156 & -.136 & .479 \\
\hline & $\begin{array}{l}\text { Equal variances } \\
\text { not assumed }\end{array}$ & & & 1.094 & 180.456 & .275 & .171 & .157 & -.138 & .481 \\
\hline \multirow[t]{2}{*}{13} & $\begin{array}{l}\text { Equal variances } \\
\text { assumed }\end{array}$ & .871 & .352 & 1.071 & 191.000 & .286 & .194 & .182 & -.164 & .552 \\
\hline & $\begin{array}{l}\text { Equal variances } \\
\text { not assumed }\end{array}$ & & & 1.058 & 173.479 & .292 & .194 & .184 & -.168 & .557 \\
\hline \multirow[t]{2}{*}{14} & $\begin{array}{l}\text { Equal variances } \\
\text { assumed }\end{array}$ & .086 & .770 & .585 & 204.000 & .559 & .104 & .179 & -.248 & .457 \\
\hline & $\begin{array}{l}\text { Equal variances } \\
\text { not assumed }\end{array}$ & & & .584 & 195.847 & .560 & .104 & .179 & -.248 & .457 \\
\hline
\end{tabular}




\begin{tabular}{|c|c|c|c|c|c|c|c|c|c|c|}
\hline \multirow{3}{*}{$\begin{array}{l}\text { Survey } \\
\text { Item } \\
\text { No. }\end{array}$} & \multirow{3}{*}{ Condition } & \multicolumn{2}{|c|}{$\begin{array}{l}\text { Levene's Test for } \\
\text { Equality of Variances }\end{array}$} & \multicolumn{7}{|c|}{ t-Test for Equality of Means } \\
\hline & & \multirow[t]{2}{*}{$\mathrm{F}$} & \multirow[t]{2}{*}{ Sig. } & \multirow[t]{2}{*}{$\mathrm{t}$} & \multirow[t]{2}{*}{ df } & \multirow[t]{2}{*}{$\begin{array}{l}\text { Sig. (2- } \\
\text { tailed) }\end{array}$} & \multirow[t]{2}{*}{$\begin{array}{c}\text { Mean } \\
\text { Difference }\end{array}$} & \multirow[t]{2}{*}{$\begin{array}{l}\text { Std. Error } \\
\text { Difference }\end{array}$} & \multicolumn{2}{|c|}{$\begin{array}{l}\text { 95\% Confidence } \\
\text { Interval of the } \\
\text { Difference }\end{array}$} \\
\hline & & & & & & & & & Lower & Upper \\
\hline \multirow[t]{2}{*}{15} & $\begin{array}{l}\text { Equal variances } \\
\text { assumed }\end{array}$ & 1.352 & .246 & 2.117 & 191.000 & .036 & .416 & .196 & .028 & .803 \\
\hline & $\begin{array}{l}\text { Equal variances } \\
\text { not assumed }\end{array}$ & & & 2.099 & 174.160 & .037 & .416 & .198 & .025 & .807 \\
\hline \multirow[t]{2}{*}{16} & $\begin{array}{l}\text { Equal variances } \\
\text { assumed }\end{array}$ & .000 & .996 & 2.048 & 197.000 & .042 & .272 & .133 & .010 & .534 \\
\hline & $\begin{array}{l}\text { Equal variances } \\
\text { not assumed }\end{array}$ & & & 2.020 & 177.593 & .045 & .272 & .135 & .006 & .538 \\
\hline \multirow[t]{2}{*}{17} & $\begin{array}{l}\text { Equal variances } \\
\text { assumed }\end{array}$ & 1.034 & .310 & .709 & 203.000 & .479 & .124 & .174 & -.220 & .467 \\
\hline & $\begin{array}{l}\text { Equal variances } \\
\text { not assumed }\end{array}$ & & & .717 & 200.622 & .474 & .124 & .172 & -.216 & .463 \\
\hline \multirow[t]{2}{*}{18} & $\begin{array}{l}\text { Equal variances } \\
\text { assumed }\end{array}$ & 3.169 & .077 & -.019 & 207.000 & .985 & -.004 & .183 & -.365 & .358 \\
\hline & $\begin{array}{l}\text { Equal variances } \\
\text { not assumed }\end{array}$ & & & -.019 & 206.291 & .985 & -.004 & .181 & -.361 & .354 \\
\hline \multirow[t]{2}{*}{19} & $\begin{array}{l}\text { Equal variances } \\
\text { assumed }\end{array}$ & .052 & .821 & .872 & 205.000 & .384 & .140 & .160 & -.176 & .455 \\
\hline & $\begin{array}{l}\text { Equal variances } \\
\text { not assumed }\end{array}$ & & & .873 & 197.102 & .384 & .140 & .160 & -.176 & .455 \\
\hline
\end{tabular}




\begin{tabular}{|c|c|c|c|c|c|c|c|c|c|c|}
\hline \multirow{3}{*}{$\begin{array}{l}\text { Survey } \\
\text { Item } \\
\text { No. }\end{array}$} & \multirow{3}{*}{ Condition } & \multicolumn{2}{|c|}{$\begin{array}{l}\text { Levene's Test for } \\
\text { Equality of Variances }\end{array}$} & \multicolumn{7}{|c|}{ t-Test for Equality of Means } \\
\hline & & \multirow[t]{2}{*}{$\mathrm{F}$} & \multirow[t]{2}{*}{ Sig. } & \multirow[t]{2}{*}{$\mathrm{t}$} & \multirow[t]{2}{*}{ df } & \multirow[t]{2}{*}{$\begin{array}{l}\text { Sig. (2- } \\
\text { tailed) }\end{array}$} & \multirow[t]{2}{*}{$\begin{array}{c}\text { Mean } \\
\text { Difference }\end{array}$} & \multirow[t]{2}{*}{$\begin{array}{l}\text { Std. Error } \\
\text { Difference }\end{array}$} & \multicolumn{2}{|c|}{$\begin{array}{l}\text { 95\% Confidence } \\
\text { Interval of the } \\
\text { Difference }\end{array}$} \\
\hline & & & & & & & & & Lower & Upper \\
\hline \multirow[t]{2}{*}{20} & $\begin{array}{l}\text { Equal variances } \\
\text { assumed }\end{array}$ & 4.291 & .040 & .546 & 188.000 & .586 & .094 & .172 & -.245 & .433 \\
\hline & $\begin{array}{l}\text { Equal variances } \\
\text { not assumed }\end{array}$ & & & .537 & 164.895 & .592 & .094 & .175 & -.251 & .439 \\
\hline \multirow[t]{2}{*}{21} & $\begin{array}{l}\text { Equal variances } \\
\text { assumed }\end{array}$ & .251 & .617 & 1.265 & 187.000 & .208 & .227 & .180 & -.127 & .581 \\
\hline & $\begin{array}{l}\text { Equal variances } \\
\text { not assumed }\end{array}$ & & & 1.265 & 181.269 & .207 & .227 & .180 & -.127 & .581 \\
\hline \multirow[t]{2}{*}{22} & $\begin{array}{l}\text { Equal variances } \\
\text { assumed }\end{array}$ & .056 & .813 & .915 & 195.000 & .361 & .134 & .146 & -.155 & .422 \\
\hline & $\begin{array}{l}\text { Equal variances } \\
\text { not assumed }\end{array}$ & & & .921 & 189.991 & .358 & .134 & .145 & -.153 & .421 \\
\hline \multirow[t]{2}{*}{23} & $\begin{array}{l}\text { Equal variances } \\
\text { assumed }\end{array}$ & 6.002 & .015 & 1.344 & 191.000 & .181 & .174 & .129 & -.081 & .429 \\
\hline & $\begin{array}{l}\text { Equal variances } \\
\text { not assumed }\end{array}$ & & & 1.320 & 167.337 & .189 & .174 & .132 & -.086 & .434 \\
\hline \multirow[t]{2}{*}{24} & $\begin{array}{l}\text { Equal variances } \\
\text { assumed }\end{array}$ & .467 & .495 & 1.020 & 194.000 & .309 & .140 & .138 & -.131 & .412 \\
\hline & $\begin{array}{l}\text { Equal variances } \\
\text { not assumed }\end{array}$ & & & 1.012 & 181.728 & .313 & .140 & .139 & -.133 & .414 \\
\hline
\end{tabular}




\begin{tabular}{|c|c|c|c|c|c|c|c|c|c|c|}
\hline \multirow{3}{*}{$\begin{array}{l}\text { Survey } \\
\text { Item } \\
\text { No. }\end{array}$} & \multirow{3}{*}{ Condition } & \multicolumn{2}{|c|}{$\begin{array}{c}\text { Levene's Test for } \\
\text { Equality of Variances }\end{array}$} & \multicolumn{7}{|c|}{ t-Test for Equality of Means } \\
\hline & & \multirow[t]{2}{*}{$\mathrm{F}$} & \multirow[t]{2}{*}{ Sig. } & \multirow[t]{2}{*}{$\mathrm{t}$} & \multirow[t]{2}{*}{ df } & \multirow[t]{2}{*}{$\begin{array}{l}\text { Sig. }(2- \\
\text { tailed) }\end{array}$} & \multirow[t]{2}{*}{$\begin{array}{c}\text { Mean } \\
\text { Difference }\end{array}$} & \multirow[t]{2}{*}{$\begin{array}{l}\text { Std. Error } \\
\text { Difference }\end{array}$} & \multicolumn{2}{|c|}{$\begin{array}{l}\text { 95\% Confidence } \\
\text { Interval of the } \\
\text { Difference }\end{array}$} \\
\hline & & & & & & & & & Lower & Upper \\
\hline \multirow[t]{2}{*}{25} & $\begin{array}{l}\text { Equal variances } \\
\text { assumed }\end{array}$ & 1.942 & .165 & 1.199 & 162.000 & .232 & .199 & .166 & -.128 & .526 \\
\hline & $\begin{array}{l}\text { Equal variances } \\
\text { not assumed }\end{array}$ & & & 1.181 & 142.490 & .240 & .199 & .168 & -.134 & .531 \\
\hline \multirow[t]{2}{*}{26} & $\begin{array}{l}\text { Equal variances } \\
\text { assumed }\end{array}$ & 5.473 & .020 & 2.168 & 187.000 & .031 & .329 & .152 & .030 & .627 \\
\hline & $\begin{array}{l}\text { Equal variances } \\
\text { not assumed }\end{array}$ & & & 2.140 & 168.592 & .034 & .329 & .154 & .025 & .632 \\
\hline \multirow[t]{2}{*}{27} & $\begin{array}{l}\text { Equal variances } \\
\text { assumed }\end{array}$ & 2.244 & .136 & 1.732 & 187.000 & .085 & .281 & .162 & -.039 & .601 \\
\hline & $\begin{array}{l}\text { Equal variances } \\
\text { not assumed }\end{array}$ & & & 1.720 & 173.040 & .087 & .281 & .163 & -.041 & .603 \\
\hline \multirow[t]{2}{*}{28} & $\begin{array}{l}\text { Equal variances } \\
\text { assumed }\end{array}$ & 1.530 & .218 & 2.374 & 193.000 & .019 & .400 & .168 & .068 & .732 \\
\hline & $\begin{array}{l}\text { Equal variances } \\
\text { not assumed }\end{array}$ & & & 2.367 & 180.294 & .019 & .400 & .169 & .066 & .733 \\
\hline \multirow[t]{2}{*}{29} & $\begin{array}{l}\text { Equal variances } \\
\text { assumed }\end{array}$ & 4.621 & .033 & .925 & 187.000 & .356 & .139 & .150 & -.157 & .435 \\
\hline & $\begin{array}{l}\text { Equal variances } \\
\text { not assumed }\end{array}$ & & & .905 & 157.108 & .367 & .139 & .153 & -.164 & .442 \\
\hline
\end{tabular}




\begin{tabular}{|c|c|c|c|c|c|c|c|c|c|c|}
\hline \multirow{3}{*}{$\begin{array}{l}\text { Survey } \\
\text { Item } \\
\text { No. }\end{array}$} & \multirow{3}{*}{ Condition } & \multicolumn{2}{|c|}{$\begin{array}{c}\text { Levene's Test for } \\
\text { Equality of Variances }\end{array}$} & \multicolumn{7}{|c|}{ t-Test for Equality of Means } \\
\hline & & \multirow[t]{2}{*}{$\mathrm{F}$} & \multirow[t]{2}{*}{ Sig. } & \multirow[t]{2}{*}{$\mathrm{t}$} & \multirow[t]{2}{*}{$\mathrm{df}$} & \multirow[t]{2}{*}{$\begin{array}{l}\text { Sig. (2- } \\
\text { tailed) }\end{array}$} & \multirow[t]{2}{*}{$\begin{array}{c}\text { Mean } \\
\text { Difference }\end{array}$} & \multirow[t]{2}{*}{$\begin{array}{l}\text { Std. Error } \\
\text { Difference }\end{array}$} & \multicolumn{2}{|c|}{$\begin{array}{l}\text { 95\% Confidence } \\
\text { Interval of the } \\
\text { Difference }\end{array}$} \\
\hline & & & & & & & & & Lower & Upper \\
\hline \multirow[t]{2}{*}{30} & $\begin{array}{l}\text { Equal variances } \\
\text { assumed }\end{array}$ & .563 & .454 & 2.157 & 183.000 & .032 & .289 & .134 & .025 & .554 \\
\hline & $\begin{array}{l}\text { Equal variances } \\
\text { not assumed }\end{array}$ & & & 2.153 & 176.899 & .033 & .289 & .134 & .024 & .555 \\
\hline \multirow[t]{2}{*}{31} & $\begin{array}{l}\text { Equal variances } \\
\text { assumed }\end{array}$ & .141 & .707 & .490 & 195.000 & .624 & .076 & .154 & -.229 & .380 \\
\hline & $\begin{array}{l}\text { Equal variances } \\
\text { not assumed }\end{array}$ & & & .492 & 187.930 & .624 & .076 & .154 & -.228 & .379 \\
\hline \multirow[t]{2}{*}{32} & $\begin{array}{l}\text { Equal variances } \\
\text { assumed }\end{array}$ & .309 & .579 & .639 & 193.000 & .524 & .097 & .152 & -.203 & .398 \\
\hline & $\begin{array}{l}\text { Equal variances } \\
\text { not assumed }\end{array}$ & & & .638 & 181.842 & .524 & .097 & .153 & -.204 & .398 \\
\hline \multirow[t]{2}{*}{33} & $\begin{array}{l}\text { Equal variances } \\
\text { assumed }\end{array}$ & .488 & .486 & 1.737 & 179.000 & .084 & .326 & .188 & -.044 & .697 \\
\hline & $\begin{array}{l}\text { Equal variances } \\
\text { not assumed }\end{array}$ & & & 1.730 & 163.081 & .086 & .326 & .189 & -.046 & .698 \\
\hline \multirow[t]{2}{*}{34} & $\begin{array}{l}\text { Equal variances } \\
\text { assumed }\end{array}$ & 2.451 & .119 & 2.190 & 191.000 & .030 & .337 & .154 & .034 & .641 \\
\hline & $\begin{array}{l}\text { Equal variances } \\
\text { not assumed }\end{array}$ & & & 2.167 & 174.557 & .032 & .337 & .156 & .030 & .645 \\
\hline \multirow[t]{2}{*}{35} & $\begin{array}{l}\text { Equal variances } \\
\text { assumed }\end{array}$ & 3.208 & .075 & 1.723 & 180.000 & .087 & .280 & .162 & -.041 & .600 \\
\hline & $\begin{array}{l}\text { Equal variances } \\
\text { not assumed }\end{array}$ & & & 1.689 & 153.757 & .093 & .280 & .166 & -.047 & .607 \\
\hline
\end{tabular}




\section{Appendix S}

Comments Provided by Respondents, Grouped by Subject

\section{People}

- "School faculties that are not involved with monitoring students have no knowledge of course methods."

- "I have heard from counselors that they are not recommending distance learning options to students."

- "The principal should support opportunities that allow students to take challenging coursework."

- "Have wanted to create a class during day to allow multiple students to take multiple virtual classes, but has not been implemented by scheduling principal."

- "We have counselors who are very close to retiring and do not put needed effort in to learn new technology."

\section{Communication}

- "We have used Virtual School for students that need credits to graduate. WV Department of Education is very helpful."

- "Again we do not have information regarding these distance programs, so answering is difficult."

- "There needs to be more awareness made about the option of distance learning available to students, because the traditional school setting is difficult for some students due to circumstances such as anxiety, emotional disturbances, bullying, etc. Distance learning can be helpful for credit recovery for students transferring into WV from another school system with a different curriculum. Overall there are many positive uses for distance 
education, but there needs to be a more concerted effort regarding awareness and the pros and cons of distance learning compared to traditional teacher instruction. It's not for everybody."

- "Most students do not know about this program."

- "There doesn't seem to be much communication about distance learning courses, either within the school or the community."

- "Students believe online classes will be easy-they have no idea. Many colleges/ universities will not accept the higher level science classes due to lack of hands-on labs."

- "I am not sure if other schools in the county have distance learning available."

\section{Resources}

- "Reliability of technology affects distance learning more than any other aspect."

- "Does the state still have annual meeting of course facilitators?"

- "I feel very strongly about numbers 15 and 16 . I work as both the contact and the facilitator in addition to my full-time position (which is NOT a distance learning position), yet I receive no compensation in terms of time or pay for my duties. Right now, I am overwhelmed with the number of students I have, and given the lack of time or pay to attend to this job, I am going to have to limit the number of students who can enroll in virtual school courses."

- "Cost of WV Virtual School tuition has been covered for all classes our students have taken."

- "With regard to student access to technology and instructional support, the technology is available whether at the school, in the community at the public library or in the student's home. However, there is a lack of instructional support from trained personnel." 
- "I am the only facilitator for online classes at our school and I am the school counselor."

- "Broadband has improved with BTOP."

- “\#13. I have no data to support this statement but I heard WV virtual school is very expensive. Students in our area will take PA or Ohio courses. Also...I thought these courses were taken at home, not at school."

- "I am not aware of any professional development about distance learning that has been offered. That would be a great idea."

- "Poor questions - lack of would impede and excess would facilitate."

\section{Structure}

- "County Board Policy for the credits is a wise practice; personnel to support the virtual school and monitor student progress critical."

- "It is my understanding that colleges recognize distance learning credits."

- "Many courses only offer .5 credit so students will not take many of the AP courses online."

- "Sharon Gainer has been a great help in the past when getting students to take virtual courses."

- "Sharon Gainer is a wonderful source of support!"

- "Sharon Gainer has been very accommodating and is always available."

- "Again, Sharon Gainer is exceptional!"

- "Sharon Gainer and Gloria Burdette are super with their help!"

- "Sharon Gainer does a wonderful job."

- "Sharon Gainer is exceptionally helpful. I have used her expertise on several occasions and she has always found the answer I need.” 


\section{Culture}

- "Quality of distance learning classes is much different...usually more difficult. Students must be self-motivated and able to be patient while waiting for help from distance learning instructor."

- "Number 35: Parents often push for their students to take online classes because they think the courses will be easy. Then they want me to drop the enrollment when they realize the courses are very time-consuming."

- "Parents do not always understand the distance learning process or virtual courses and what it requires."

\section{Miscellaneous}

- "In order to implement distance online learning students must be motivated, selfdisciplined and monitored. Who pays for this?"

- "We rely on virtual credit recovery classes for our students whose transcripts are a mess when they come to us."

- "We have only taught a few distance learning courses."

- "We do not have any involvement currently in distance learning, so my answers are impedes currently as we do not have the information or skills necessary to implement the program."

- "Not sure how 2012/13 will be handled."

- "This is a very confusing survey. For example, parents' perceptions can either impede or facilitate. It depends on the perception. I am not sure how to answer some of these questions." 